Illinois State University

ISU ReD: Research and eData

Theses and Dissertations

$9-22-2019$

\title{
Beyond The Words: Paratextual And Bibliographic Traces Of The Other Reader In British Literature, 1760-1897
}

Jeffrey Duane Rients

Illinois State University, jrients@gmail.com

Follow this and additional works at: https://ir.library.illinoisstate.edu/etd

Part of the Curriculum and Instruction Commons, Educational Methods Commons, and the English Language and Literature Commons

\section{Recommended Citation}

Rients, Jeffrey Duane, "Beyond The Words: Paratextual And Bibliographic Traces Of The Other Reader In British Literature, 1760-1897" (2019). Theses and Dissertations. 1174.

https://ir.library.illinoisstate.edu/etd/1174

This Dissertation is brought to you for free and open access by ISU ReD: Research and eData. It has been accepted for inclusion in Theses and Dissertations by an authorized administrator of ISU ReD: Research and eData. For more information, please contact ISUReD@ilstu.edu. 
BEYOND THE WORDS: PARATEXTUAL AND BIBLIOGRAPHIC TRACES OF THE

OTHER READER IN BRITISH LITERATURE, 1760-1897

\section{JEFFREY DUANE RIENTS}

292 Pages

Over the course of the late eighteenth and early nineteenth centuries, compounding technological improvements and expanding education result in unprecedented growth of the reading audience in Britain. This expansion creates a new relationship with the author, opening the horizon of the authorial imagination beyond the discourse community from which the author and the text originate. The relational gap between the author and this new audience manifests as the Other Reader, an anxiety formation that the author reacts to and attempts to preempt. This dissertation tracks these reactions via several authorial strategies that address the alienation of the Other Reader, including the use of prefaces, footnotes, margin notes, asterisks, and poioumena. The deployment of such paratextual and bibliographic tools allow the author to manage the fear of the Other Reader while still addressing their text primarily to their own discourse community. KEYWORDS: paratext, asterisk, poioumenon, authorship, audience, eighteenth century, nineteenth century, Britain, Romanticism 
BEYOND THE WORDS: PARATEXTUAL AND BIBLIOGRAPHIC TRACES OF THE OTHER READER IN BRITISH LITERATURE, 1760-1897

JEFFREY DUANE RIENTS

A Dissertation Submitted in Partial Fulfillment of the Requirements for the degree of

DOCTOR OF PHILOSOPHY

Department of English

ILLINOIS STATE UNIVERSITY

2019 
(C) 2019 Jeffrey Duane Rients 


\title{
BEYOND THE WORDS: PARATEXTUAL AND BIBLIOGRAPHIC TRACES OF THE OTHER READER IN BRITISH LITERATURE, 1760-1897
}

\author{
JEFFREY DUANE RIENTS
}

COMMITTEE MEMBERS:

Brian Rejack, Chair

Katherine Ellison

Amy E. Robillard 


\section{ACKNOWLEDGMENTS}

I thank Maureen Brunsdale and Mark Schmitt of Milner Library's Special Collections unit for their research assistance. Julie-Ann McFann bestowed sage advice and read early drafts of chapters 2 and 3. Amy, Elizabeth, Duane, and Cindy Rients provided copious emotional and material support. And special thanks to S. John Ross for the initial inspiration.

J. D. R. 


\section{CONTENTS}

Page

ACKNOWLEDGMENTS

TABLES vii

FIGURES viii

INTRODUCTION: THE GROWING PRESENCE OF THE OTHER READER 1

Italo Calvino and the Reading Other 1

Portrait of the Other as a Print Product 3

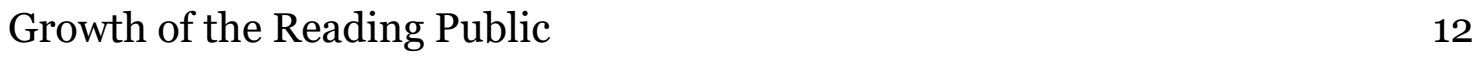

The (Printer's) Devil is in the Details $\quad 19$

$\begin{array}{ll}\text { Gesturing Toward a Phantom } & 25\end{array}$

$\begin{array}{ll}\text { Chapter Details } & 26\end{array}$

CHAPTER I: THE PREFACE PROBLEM: ADDRESSING THE OTHER

READER AT THE OUTER BORDER OF THE TEXT 30

Genette's Theory of the Preface $\quad 31$

$\begin{array}{ll}\text { The Preface and the Other Reader } & 37\end{array}$

The Prehistory of the Preface $\quad 43$

$\begin{array}{ll}\text { The Disavowing Preface } & 48\end{array}$

The Prefaces of the Great Unknown $\quad 51$

$\begin{array}{ll}\text { Conclusion } & 63\end{array}$ 
CHAPTER II: NUMBERED FEET AND OVERBURDENED SHOULDERS:

AUTHORSHIP VIA SELF-ANNOTATION IN SAMUEL TAYLOR COLERIDGE $\begin{array}{ll}\text { AND JAMES MACPHERSON } & 65\end{array}$

The Problem with Paratext $\quad 66$

$\begin{array}{ll}\text { The Parallel Paratext } & 68\end{array}$

$\begin{array}{ll}\text { The Genealogy of the Literary Footnote } & 74\end{array}$

The Macpherson Mystery $\quad 82$

$\begin{array}{ll}\text { The Annotated Rime } & 103\end{array}$

CHAPTER III: THE MIRROR IN THE TEXT: THE DISAVOWAL OF THE

POIOUMENON BY THE WITHDRAWAL OF THE BOOK-WITHIN-A-BOOK 120

$\begin{array}{ll}\text { Defining the Poioumenon } & 121\end{array}$

Poioumena in Nineteenth Century Britain $\quad 130$

$\begin{array}{ll}\text { The Book Within } & 146\end{array}$

$\begin{array}{ll}\text { Conclusion } & 151\end{array}$

CHAPTER IV: THE RAGGED ASTERISK: SAMUEL ROGERS, THE GIAOUR, $\begin{array}{lr}\text { AND THE FOLLY OF THE TORN PAGE } & 158\end{array}$

$\begin{array}{ll}\text { A Ruin of a Poet } & 159\end{array}$

$\begin{array}{ll}\text { Folly and Ruin } & 162\end{array}$

$\begin{array}{ll}\text { History of a Character } & 170\end{array}$

$\begin{array}{ll}\text { The Ragged Line } & 173\end{array}$

CHAPTER V: THE STUDENT AS AUTHOR: NINETEENTH CENTURY

LITERATURE AND A PEDAGOGY OF AUTHORSHIP 191 
The Pedagogy of Authorship in British Literary Studies

$\begin{array}{ll}\text { A Different Approach } & 198\end{array}$

$\begin{array}{ll}\text { What is a Daybook? } & 202\end{array}$

What Gets Written in a Daybook? 203

Why Use Daybooks? $\quad 204$

The History of the Daybook 204

Challenges of the Daybook 206

What are Some of the Ways Daybooks can be Used? 206

How are Daybooks Assessed? $\quad 207$

How Does the Daybook Work in Practice? 209

$\begin{array}{ll}\text { Course Readings and Activities } & 210\end{array}$

The Rime of the Ancient Mariner by Samuel Taylor Coleridge 211

The Giaour by Lord Byron $\quad 211$

Don Juan by Lord Byron $\quad 211$

Dracula by Bram Stoker $\quad 211$

The Daybook and the Learning Management System 215

$\begin{array}{ll}\text { Daybook Submissions } & 216\end{array}$

$\begin{array}{ll}\text { Questionnaires } & 217\end{array}$

$\begin{array}{ll}\text { Case Studies } & 218\end{array}$

$\begin{array}{ll}\text { Case Study 1: Bruno } & 218\end{array}$

$\begin{array}{ll}\text { Daybook \#1 } & 218\end{array}$

$\begin{array}{ll}\text { Daybook \#2 } & 219\end{array}$ 
Questionnaire \#2

Final Daybook

Case Study 2: Bella

Daybook \#1

Daybook \#2

Final Daybook

Case Study 3: Anna

Daybook \#1

Daybook \#2

Final Daybook 225

Case Study 4: Michelle

Daybook \#1

Daybook \#2

Final Daybook 228

Case Study 5: Nina 230

Daybook \#1 230

Daybook \# 2 230

Final Daybook 231

Case Study 6: Joan 231

Daybook \#1 231

Daybook \#2 232

Final Daybook 232 
Conclusion and Discussion

Looking to the Future

CODA 


\section{TABLES}

Table

Page

1. Macpherson Names with Spelling Variants Given in Bold 96

2. Comparison of the Number of Stanzas and Glosses in The Rime of the Ancient Mariner

109

3. Fowler's Poioumena (Kinds of Literature 70, 86, 123-6, 210; A History of English Literature 298, 370)

4. Adherence of four texts to Fowler's Poioumenon conventions

5. Appearance of lines of asterisks in Samuel Rogers' The Voyage of Columbus

176

6. Development of The Giaour

181 


\section{FIGURES}

Figure

Page

1. Job 1.1-11. The holie Bible conteynyng the olde Testament and the newe, 1568

2. Textual Relationships from Orality to Macpherson

101

3. Sibylline Leaves version of Rime, lines 1-4

110

4. Sibylline Leaves version of Rime, lines 79-82

112

5. Sibylline Leaves version of Rime, lines 119-122

6. Sibylline Leaves version of Rime, lines 131-142

7. Sibylline Leaves version of Rime, lines $377-382$

8. Slide with two-part Daybook exercise asking students to reflect on prior work

9. Excerpt from Bruno's Daybook submission \#1

10. Excerpt from Bruno's Daybook submission \#2

11. Excerpt from Bella's Daybook submission \#2

12. Excerpt from Anna's Daybook submission \#2

13. Last page from Anna's final Daybook submission

14. Excerpt from Michelle's final Daybook submission

15. Excerpt from last page of Michelle's final Daybook submission

16. Excerpt from last page of Nina's final Daybook submission

17. Evergreen Daybook questions handout 


\section{INTRODUCTION: THE GROWING PRESENCE OF THE OTHER READER}

What an astonishing thing a book is. It's a flat object made from a tree with flexible parts on which are imprinted lots of funny dark squiggles. But one glance at it and you're inside the mind of another person, maybe somebody dead for thousands of years.

--Carl Sagan, Cosmos

\section{Italo Calvino and the Reading Other}

Although it takes a chapter or two to realize what is happening, Italo Calvino's 1979 postmodernist work If on a winter's night a traveler (Se una notte d'inverno un viaggiatore) unfolds as a novel-length meditation on the tangled relationships between readers, writers, and books. Roughly half of the narrative is written in the second person with the narrator directly addressing a protagonist called either "you" (the original Italian uses the informal second person pronoun, tu) or the Reader (Lettore). The balance of the work consists of excerpts from the books encountered by this Reader. Calvino's Reader is not the general you, not whichever person is holding a copy of If on a winter's night a traveler and whose eyes alight on the page, but rather a specific character within the diegesis of the narrative.

We never learn this character's name or many specifics about them because Calvino wants his actual readers to identify with him as closely as possible. Over the course of the novel we learn that the Reader is a man who works a middle-class desk job in a Western country, that he lives alone, that he is a bit world-weary, that he is heterosexual, and that he is, unsurprisingly, an avid reader. Precious little other biographical or even visual information can be determined about this character; the rest is left as a cipher, blanks for the real reader to project themselves into as we follow the 
Reader along a Tristram Shandy-like quest to finish any of the various books he encounters in his adventures.

Along his travels, the Reader frequently encounters a character named Ludmilla, but who is initially introduced in the Italian original as Lettrice, the feminine form of the masculine Lettore, the Reader. Translator William Weaver renders la Lettrice as "the Other Reader" in the 1981 English edition of the novel. Calvino returns again and again to the theme that this Other Reader is a mystery, partially because she functions as the love interest in the tale, but also because she reads differently. Her choice of authors and subject matter--as well as her goals and modes of reading--differ radically from that of the Reader. La Lettrice approaches the novels in Calvino's tale in a way that parallels Morelli's viewing of the Old Masters: both draw out new, unexpected messages from texts, messages beyond the purview of the originators' intentions.

In chapter eight, Ludmilla discusses her opinions about reading with Silas Flannery, an author of bestsellers who functions as a stand-in for Calvino. Flannery discovers that this Other Reader has no use for him; she is only concerned with "that me made of ink and periods and commas" (quel me stesso d'inchiostro e punti e virgole) (191). The flesh and blood Flannery and his opinions do not matter to her at all. Flannery's response is to make a clumsy pass at her, as if to substitute sexual intimacy for the reassuring illusion of the intimacy of communication between author and reader. Flannery's fumbling advances toward Ludmilla are emblematic of a fundamental anxiety in the era of the written word: the fear of an alien interpretation, an Other Reader. As the development of mechanical means for the speedy reproduction and distribution of text exponentially grows the potential audience for any given publication, 
the spectral presence of this Other Reader haunts the imaginary of the author in a way qualitatively different from the author/reader relations in the preceding world of transmission by hand-copied manuscript only.

\section{Portrait of the Other as a Print Product}

Though Sigmund Freud makes use of the terms der Andere (the other person) and das Andere (otherness), Jacques Lacan's formulation of the Other originated with Georg Wilhelm Friedrich Hegel (Evans 132). In Phenomenology of Spirit (Phänomenologie des Geistes) (1807), Hegel posits the necessity of an other as the requirement of self-consciousness. This other, however, is a phantasmal appendage of the self (sec. 178-180). The incestuous relationship between self and other as defined by Hegel is mirrored in the interaction between the Author and the Reader; in the act of writing, the Reader is constituted, emerging from the imaginary of the writer into actualization within the text. This is the original sin of Authorship, not the mere act of writing, but the act of writing toward an audience.

Lacan expands the Other of Hegel by splitting it into the lower case-o other and the Other (both of which he tends to italicize: autre, Autre):

[T]hat other which is the ego, or more precisely its image. Here there's a radical difference between my non-satisfaction and the supposed satisfaction of the other. There is no image of identity, of reflexivity, but a relation of fundamental alterity.

We must distinguish two others, at least two--an other with a capital $O$, and an other with a small $o$, which is the ego. In the function of speech, we are concerned with the Other. (The Seminar 236) 
In his collected writings, published as Écrits, Lacan further develops his theory of the two others. He defines the other as "the individual that he [the self] sees before him... in the discourse that he holds before him," while the Other is the one "to which his speech must be addressed" (140).

The relationship between the self and the other forms the psychological foundation for the relationship between the Author and the Reader. The Reader is a projection conjured out of the imagination of the Author, the absent target of the Author's communication. However, the imagination of the Author is not without its limits. Because all communication systems are inherently social in nature, the Author's other is bounded by the Author's situation as a member of a discourse community. That is to say, the Author's ability to participate in language is contingent on their participation in larger social systems with their own agendas, communication protocols, genres of writing, and lexicon (Swales 24-6). Our membership in discourse communities shape our worldviews such that, even if we are not intentionally with a specific community, we will inevitably tend to write in modes most intelligible to fellow community members (Bizzell 226-7).

Prior to the print revolution and the quicker dissemination of texts afforded by it, the discourse communities of the monastery and the court dominated manuscript culture. The audience of the text was entirely localized, such that oral performance remained a primary way of publishing (that is, making public) one's work (McLuhan 96, Finnegan 166). Publication by recitation not only ensures an audience consisting primarily of members of the localized discourse community--whether it be the cloister or the court--but it also affords the Author an opportunity to comment on and/or emend 
their text with a real-time reflexivity, responding immediately to questions and comments. Walter J. Ong explores the advantages of this method of "oral conversation" publication in his essay "Literacy and Orality in Our Times," noting that "[i]n conversation, if you omit reasons backing a statement and your hearer wants them, the normal response is to ask you for them, to challenge you. If the connections between the statements you make are not supplied by the concrete situation... your interlocutor can be expected to ask you to specify the connections" (469).

Much work has been done on the interactions between written texts and oral audiences in the medieval period since the contours of the relationship were first traced by pioneers Ong, Marshall McLuhan, and Ruth Finnegan. Further research both in the archive and in the field among contemporary sources (e.g. twentieth and twenty-first century practitioners of traditional oral verseforms) has expanded the range of possible interactions between the written and spoken word. Writing in 2012--at the end of a long career investigating oral literature among the Anglo-Saxons and Ancient Greeks, but also among contemporary Serbian folk poet--scholar John Miles Foley notes that "consensus position" reached within the field suggests that "orality and literacy form a continuum, with considerable room for overlap and cross-fertilization, rather than contrasting, mutually exclusive categories" (Foley and Ramey 79). Some scholars reject the usual assumption that this hybrid space is merely a transitional phenomenon, instead formulating it with a separate identity. Examples include Joyce C. Coleman's use of the term "aurality" to emphasize the privileged role of public, performative reading over the private, solitary, literate mode dominant in later eras, or Ursula Schaefer's similar idea of "vocality," underlining the different roles of the spoken and written word 
in a world where literacy is a luxury (Coleman 26-7, Schaefer 205-6). Foley uses the term "immanent context" to indicate a similar concept, in which the written text is embedded primarily within an oral, performative field (39).

This "immanent context" includes, among other variables, the membership of the Author and their audience in the same discourse community. So long as the Author's text is presented orally and therefore locally, the Author can make some safe assumptions in terms of the accepted truths and values of the audience. So long as the relationship between Author and Reader remains close, the Author may omit more, imply more, and explicate less than an Author writing for a completely unknown audience. This latter scenario describes the relationship between the Author and the Other Reader, which is analogous to the relationship between the self and Lacan's capital-O Other.

The relationship between the Author and the Reader (that is, the intended audience) is a projection built upon the relationship between the individual and society. That relationship is bounded by material, biological limits. According to anthropologist Robin Dunbar, the size of the neocortex limits the number of stable relationships that a primate can maintain ("Neocortex Size" 486). Dunbar examined previously published data on 38 different genera of primates and found a high degree of correlation between average volume of the neocortex and average pack size. Extrapolating based on average neocortex volume for homo sapiens, Dunbar concluded that the "pack size" (that is, the number of stable, ongoing social bonds) for humans to be 147.8 individuals (Grooming 
76-7). ${ }^{1}$ In later work Dunbar identifies evidence that subsistence agriculture villages across a wide variety of cultures from the Neolithic to the present day achieve stability at populations of no more than 150 inhabitants, with some evidence that communities tend to split once they reach about 200 members $(71-2) .^{2}$

The central thesis of Dunbar's 1996 book, Grooming, Gossip, and the Evolution of Human Language is that language itself evolves partially in response to the growing demands of their expanding social networks (78). Other primates maintain their pack bounds by elaborate grooming rituals, but to maintain relations with 150 humans in this way would occupy approximately $40 \%$ of our waking hours. Language, Dunbar argues, provides a less physically demanding means of maintaining relationships.

The work of Dunbar and others suggest a clear horizon on the extent of social relations, determined by at least partially by physical limits on human cognition. Writing, with its inherent ability to reach those at a distance in space or time from the

${ }^{1}$ This figure, usually rounded up to 150 in the literature, has become known as Dunbar's Number. Subsequent research indicates that Dunbar's Number varies somewhat from individual to individual, with an estimated range between 100 and 250 (Hernando et al. 95-6).

${ }^{2}$ Work in the field of social network theory suggests social group numbers on the same order of magnitude as Dunbar but using other methodologies. See, for example, Christopher McCarty, et al., "Comparing Two Methods for Estimating Network Size," which sets the maximum size of a stable social group at 291 individuals (28). 
physical presence of the writer, possesses a near limitless capacity to reach beyond the social circle from which spoken language emerged. With the advent of print it becomes a trivial task to quickly produce in excess of 150 or 300 copies of an instance of language. Therefore, the circulation of copies of a text in excess of that number guarantees that at least some portion of the Author's audience will exist beyond their immediate social relations.

As the chance that the Author knows and has direct social relations with every reader dwindles, so dwindles the possibility that every reader will belong to the same discourse communities as the Author; the large print run is the mechanism by which the Other Reader can come to the attention of the Author. In this dissertation I posit the Other Reader as a construct that haunts a subset of literary writers during the nineteenth century in order to demonstrate that literary production (i.e. inscription as a creative act) is entangled with the regime of print production (the material and economic system surrounding the book as a commodity) in such a way that the expansion of the literary market impacts the literary work. Specifically, the growing anxiety of the Author confronted by the specter of the Other Reader leads the Author to attempt to shape reception of the text, often via extra-textual means. The Other Reader thus leads to the packaging of the text with additional elements, such a prefaces or footnotes, designed to bring errant interpretations under control. Since these tactics bifurcate the field of the reading experience, they necessitate an analysis of the problem of authorial authenticity, particularly of the idea that a great author speaks with a singular, totalizing "voice." 
Note that it is not my contention that the Other Reader is a formation only of the late eighteenth and nineteenth century. From a broader perspective, any change in communication technology in any era brings with it the potential for reaching a larger audience. Inevitably, the author's relationship to that new audience will require renegotiation, leading to an anxiety reaction in some writers. The Other Reader emerges as a recognizable feature whenever this combination of new technology and new audience induces a bifurcation in the text. The text becomes a sort of Janus figure, the right face offering the reader a message and the left face instructing the reader on how to properly decode it. As the new status quo becomes established, this need temporarily recedes, to reappear with later expansion of the literary franchise.

The early publishing history of Lord Byron sheds some light on the phenomenon of the Other Reader entering into the literary process in the nineteenth century. Byron's first publication, Poems on Various Occasions, was printed and circulated privately in 1807 in an edition of only 100 copies (St. Clair 585). The initial printings of Byron's next two publications ran to 500 and 750 copies (586). These figures represent the lower bounds of print runs in nineteenth century commercial publications, suggesting they represent the minimum level for which a printer of the era can hope to turn a profit without venturing too much initial capital on a risky prospect. 3 The situation would

\footnotetext{
${ }^{3}$ A brief survey of Appendix 9 of St. Clair's The Reading Nation in the Romantic Period will show that, throughout the nineteenth century, virtually all first printings of new writers range from 500 to 1,000 copies. Nineteenth century publisher Edward Moxon's policy was to print 500 copies of the first work of new authors, or 2,000 copies for the
} 
change following the 1812 publication of Childe Harold's Pilgrimage, the work that established him as a popular sensation. By 1814 his star has so ascended that one of his follow-up works, a "Turkish tale" called The Corsair, merited a total print run of 25,000 copies with the first 10,000 copies sold out on its first dale for sale (King, St. Clair 587).

The commodification of the book under the capitalist regime of nineteenth century book production combined with the limitations set by the size of our primate brains inevitably leads to a situation in which the audience of a book stretches beyond the Author's immediate social horizon. Certainly, in all times and places following the invention of writing the possibility existed that any particular writing might finds its way to someone other than the intended addressee but print runs in excess of Dunbar's Number turns this possibility into absolute fact. Of the 10,000 freshly-printed copies of The Corsair purchased on February 1st, 1814, we cannot be certain how many ended up in the hands of those who considered themselves friends of Lord Byron. But we can safely estimate that Lord Byron counted at most only a scant one or two percent of them among his friends. Some portion of the rest undoubtedly belonged to one or more discourse communities that also included Lord Byron in their ranks (the discourse community of British nobility, for example, or the discourse community of political radicals), but it is inevitable that someone with a vastly different life experience--

first edition of new work by a known author (Erickson 37). Modern publishing house practice does not seem to differ much, as my own first two books had print runs of 500 and 2,000 copies, with the latter number including over 300 copies still sitting unsold in the publisher's warehouse. 
different education, different values, a different class position, a different gender role, etc.--would end up reading a copy of The Corsair.

The disconnect between Author and Reader becomes even more fraught in the Byron case when one takes account of the proliferation of Byronic hoaxers. The short story The Vampyre, rewritten and completed by John Polidori but based upon Byron's unfinished work, was initially published under Byron's name ("John William Polidori (7 September 1795-27 August 1821)" 249). Goethe praised it as Byron's best work (255). Consider also the case of John Clare, who wrote his own versions/expansions of Don Juan and Child [sic] Harold, adopting the authorial identity of Lord Byron in the process (Authorial Identity and the Critical Act 71). Clare wrote his own 37-stanza Don Juan inspired by the copy of the Continuation of Don Juan, Cantos XVII and XVIII received as a gift from London printer C. F. Pitman (Robinson and Summerfield 24). Alongside Clare's work appeared numerous other Don Juans, such as William Hone's Canto the Third, Gerald Noel Byron's The New Don Juan, Isaac Star Clason's Don Juan Cantos XVII-XVIII, William Cowley's Don Juan Reclaimed, or His Peregrination Continued, George William MacArthur Reynolds's A Sequel to Don Juan, and eventually Henry Morford's The Rest of Don Juan Inscribed to the Shade of Byron. The proliferation of these continuations and alternatives to Don Juan results in a proliferation of possible Byrons formed in the minds of the readers, especially given that several of these texts were initially published with their actual authorship concealed in an attempt to fool the market. Likewise, when Cantos both real and spurious circulate among readers unknown, Byron's ability to perceive a unitary Reader is further compromised, and the Other Reader emerges. 


\section{Growth of the Reading Public}

This situation (a reader vastly different than the writer) has existed in potentiality since the dawn of writing, but the above factors ensure it as fact, especially given the changing nature of the reading audience over the course of the nineteenth century. As Lee Erickson notes in The Economy of Literary Form: English Literature and the Industrialization of Publishing, 180o-1850:

In a county of eleven million people lacking many of our modern forms of instruction or entertainment, a book in great demand sold ten to twenty thousand copies in 1810 . Almost all books were read and bought by the wealthy, even though book clubs and circulating libraries in the late eighteenth and early nineteenth centuries were bringing books to the middle classes--that is, the rest of the upper 10 percent of the population. By way of contrast, in 1850, after the technological revolution in printing and with the general rise in the standard of living, a very popular book would sell several hundred thousand copies. (24)

Numbers for actual readers are hard to estimate. How many copies sat on shelves unread? How many volumes were passed to other readers? How often were individual copies read by more than one individual? As Leah Price notes in How to Do Things with Books in Victorian Britain, most evidence for reading practices in the nineteenth century stem from two sources: 1) those practices documented in the literature of the period, and 2) interactions with books that can be "read" from the traces left behind on individual copies of books (smudges, tears, marginalia, etc.) (23). The latter requires an exhaustive effort to gather data useful on a large scale, while the former inevitably 
suffers from selection bias, filtering out the experiences of those who were unwilling or unable to record their experiences in writing. Although the documents of the era will never provide us with a comprehensive picture of reading practices (such incompleteness is an inevitable property of any archive), some trends can still be teased out of the written record.

Reading aloud for family or friends was a common practice throughout the Romantic period, resulting in some works being heard much more than they were read (St. Clair 188). William St. Clair estimates that the roughly fourfold increase in book production over the last quarter of the eighteenth century led to a fifty-fold increase in "acts of reading" (118). Assuming a linear relationship between increases of production and increases in reading, this means than the increase in production of two orders of magnitude from 1810 to 1850 would lead to an increase of reading of $12,500 \%$.

Such an increase would not seem mathematically possible, if one accepts Erickson's argument that some substantial portion of the top $10 \%$ economically advantaged of the British public were readers in 1810, though some portion of the expansion of readership could reflect the opening of new markets. Adrian Johns, in Piracy: The Intellectual Property Wars from Gutenberg to Gates, outlines the growth of the export business from Scotland, to both America and Europe, starting in the second half the eighteenth century and continuing through the nineteenth (119). Ireland's export trade increased eightfold in the first 40 years of the nineteenth century, driven primarily by the craze for Sir Walter Scott's Waverley novels (295-6).4

\footnotetext{
${ }^{4}$ For more on the Waverly novels, see Chapter I.
} 
Nineteenth-century American reprinting of English works also picked up steam, literally, with the adoption of technological innovations such as steam-powered papermaking and later, continuous (roll-based) papermaking machines (295).

But the fact remains that print runs grew over the course of the century to accommodate expanded readerships, including new audiences among the lower classes. The growth of the reading public is illustrated by what St. Clair calls "tranching down," a sales strategy in which a publisher offers a fairly short print run, often in a larger, deluxe format (such as quarto sized, with higher quality paper) followed by a larger, substantially cheaper print run in octavo for a wider, more general audience, followed eventually by a third, duodecimo-sized print run of much cheaper quality for the lowest class of reader $(32-3 ; 198)$.

Johns notes that many (though certainly not all) of the volumes of English literature brought forth by Scottish, Irish, and North American publishers were unauthorized, illicit editions, or to put it more succinctly, pirated copies (182-4). From the point of view of the reader, the legal status of the copy in hand has no real bearing on the reading experience, a fact acknowledged by Johns (12). However, this isn't to dismiss Johns' overall project of tracing the complex relationship between commerce and creativity as mediated via the historical development of legal frameworks for intellectual property (15). The existence of piracy can only contribute to the growing anxiety that an Author may have lost touch with their audience. For one thing, piracy increases the likeliness that smaller, cheaper editions of successful works make their way down the social ladder, a piratical version of St. Clair's "tranching" (Johns 48). For another, the pirate interrupts the communication circuit between Author and 
publisher5; no Author can be certain what changes a pirate may make to their text. The mere existence of the pirate invokes the possibility that some fraction of the Author's audience is reading a text that differs, perhaps substantially, from the manuscript submitted to their legitimate publisher. Beyond the possibility of errors arising from lax production quality, a pirated edition could be abridged, epitomized, bound with other texts, or translated, all without input from the author (46).

The expansion of the reading audience creates an environment where the social relations between Author and Reader are alienated. Eric Eisner traces the effect of this alienation upon the Reader's perception of the Author in his work Nineteenth-Century Poetry and Literary Celebrity:

The literary culture... is in fact marked by the competition between two models of authorial personality. The charismatic author is often seen as an object of wonder: a special, unique being whose power over readers is viewed with awe and sometimes suspicion. Such a perception of authorship builds on the cultural resonance of Romantic concepts of genius, individuality and original creativity; it takes up the legacy of postRevolutionary charisma embodied in epochal figures like Napoleon, and reflects the frisson attached to literary celebrity following the sensational success of figures like Radcliffe, Scott, Moore and Byron. This emphasis on

\footnotetext{
${ }^{5}$ Here I am referring to the communication circuit as originally formulated by Robert Darnton in his essay “What is the History of Books?", appearing in his essay collection The Kiss of Lamourette: Reflections in Cultural History.
} 
the singular, transcendent personality of the author increasing overlaps, however, with a perception of authorial identity as the impermanent product of a set of impersonal market structures--what Harriet Martineau called, in an 1839 essay in the London and Westminster Review, a "system" of "literary lionism." In this system, authors are subjected to an oxymoronic form of public anonymity... the system of lionism marks them out as a professionalized class and puts them permanently on display... (10)

This oscillation between the Author's existence as "an object of wonder" and "an oxymoronic form of public anonymity" (that is, a personal name that attaches to one or more texts rather than a human body) is the result of the mediation of social relations betwixt Reader and Author through the commodification of the book. The Other Reader is the expression of the same effect from the other end of the equation. The growth of the market exacerbates the anxiety that Ong attributes to the shift from oral to written culture: "To move from the entirely natural oral world6 into this artificial world of writing is bewildering and terrifying. How do I deal with persons who are not present to me and who never will be?” (469).

For some authors, the anxiety caused by the Other Reader--the projection of the physical absence of an audience composed of innumerable unknown people--manifests

${ }^{6}$ I disagree with Ong's assessment that oral communication is "entirely natural." Despite its prehistoric pedigree and ease-of-use (even small children can employ it) spoken language is just as artificial in nature as any other communication system. 
as an attempt to manage the reading experience from outside the traditional bounds of the text. Those boundaries consist of accepting three fundamental assumptions that underpin our everyday conception of the text.

The first of these assumptions is that the text is unitary, an object for which we can clearly define a beginning and an ending. We flip through a novel and see a stream of text flowing from page one until the final page of the final chapter. This allows us to readily identify the text of that novel, to locate it in space, and to differentiate it from all other texts.

The second assumption is that a text presents itself in a linear fashion. That is not to say that, narratively, the action of a text must proceed from the first event to the last without flashbacks or anticipations. Rather, I refer to the assumption that we will engage the text by reading from start to finish. We imagine reading as beginning the text with the first word of the first sentence of the first paragraph of the first page of the first chapter and making our way to the straight through to the final word of the final sentence of the final paragraph of the final chapter.

The third assumption is that texts are composed of words built from alphabetical characters, supplemented with a handful of punctuation marks, the latter primarily used to signal the end of a sentence or an internal pause. We also imagine the words as semantic units, isolated from their physical instantiation, rather than as configuration of dark ink held in the medium of a page. Little consideration is given to the situation of the words on the page, in relation to other graphic elements, or in relation to other words in other sentences. 
The Other Reader can emerge whenever the author is alienated from some portion of the audience. This alienation can happen at the level of the individual author, or it can become a major component of the zeitgeist of a literary period when a critical mass of authors struggle with their understanding of their own audiences. For purposes of this study, I chose the year 1760 as the point of departure. That year saw the publication of James Macpherson's Fragments of Ancient Poetry Collected in the Highlands of Scotland, and translated from the Galic or Erse language, explored further in Chapter II. This was followed later in the decade by Thomas Chatterton's Rowley poems and Horace Walpole's Castle of Otranto, further detailed below.

As will be discussed, all three of these works initially appeared to the public as hoaxes, i.e. they were published under false pretenses (Ruthven 7). The authors opted to distance themselves from their work by inventing an earlier provenance that they presented to the public as real. Macpherson's Fragments was introduced to the world as the result of field research revealing a heretofore unknown 3rd century Scottish poet named Ossian (Thomson 2). Chatterton insisted he was merely the discoverer of manuscripts written by a fifteenth century monk called Rowley (Ingram 41-2). Walpole similarly insisted that his tale is a contemporary translation of a medieval Italian manuscript (Walpole iii). Although literary hoaxes can be found in all periods, I read the appearance of these three near-simultaneous spuriosities as indicative of a sea-change, the harbinger of a new period of renegotiation of author-reader relations. Such high profile literary hoaxes demand a new formulation of what it means to be an author and the author's responsibilities to the audience 


\section{The (Printer's) Devil is in the Details}

In 1880 Giovanni Morelli turned the world of painting on its ear with the publication of his German-language treatise Die Werke Italienischer Meister (literally, "The Work of the Italian Masters," but titled Italian Painters; Critical Studies of Their Works when eventually translated into English). In Die Werke, Morelli argues that the work of the Old Masters could be distinguished--a Raphael from a Correggio, or a true Raphael from a forgery--by close attention to hitherto unremarkable details, such as the idiosyncratic shapes of fingers or earlobes:

The right understanding of the outward form in a work of art, to which I attach especial importance, is not accorded to everyone. This outward form in the representation of the human figure is by no means accidental, as many contend, but is determined by inward conditions... The typical, or fundamental, form (Grundform) of hand and ear in the works of all independent masters, and afford valuable evidence for identifying them...

Morelli was the first to call attention to these tiny details in painting, previous authenticators relying primarily on either holistic intuitions about the theme, action, or spirit of a painting (e.g. "Only Botticelli could have produced a work this marvelous.") or well-known features of the masters (such as Perugino always depicting central figures with eyes raised to heaven). Following a period of pushback from traditionalists7, the

\footnotetext{
${ }^{7}$ A similar consternation has enveloped the world of literary attribution studies, with the rise of stylometrics, or "non-traditional authorship attribution," the attempt to employ
} 
"Morelli technique" became the standard for the authentication of paintings (Ginzburg 81-2).

Following William Harmon and Hugh Holman's definition of a text as "anything isolated for attention", Morelli's accomplishment amounts to a new form of reading (549). He read the same texts as his predecessors but attended to different details and therefore reached different conclusions. Moreover, there is nothing to suggest that any of the Italian masters ever painted ears or hands with any agenda other than the depiction of the human form; Morelli was locating meaning in places in the text where the creators had intended none. In literary terms, he finds a reading that exceeds the intentions of the author.

Morelli is not alone in this respect. One way in which readers demonstrate their ability to find meaning in unexpected locations is by the detection of deception. One subset of such deceptions in the literary hoax, what we might consider as an Other Writer. Such a persona is often adopted as a strategy for keeping the reader at arm's length or for addressing an otherwise inaccessible discourse community. Consider the case of Thomas Chatterton and his Rowley poems. In southwest England in the year 1768 a major bridge was replaced in the city of Bristol. The Bristol Journal coverage of the event ignited a local sensation when it published an unsigned letter quoting a medieval account of the opening of the fifteenth-century bridge the new edifice replaced.

computer-assisted, quantitative techniques to problems of authorship. See Joseph Rudman's “The State of Non-Traditional Authorship Attribution Studies--2012: Some Problems and Solutions," for an entry point into the debate. 
Inquiries led to a teenager named Thomas Chatterton, who initially refused to discuss his source for the ancient text (Gregory xxi-xxii, Ingram 62-63). Eventually he revealed that the original text had been found in an unused upper room of an old church. Young Chatterton secured two patrons, a gentleman named George Catcott and a surgeon named William Barrett, who provided encouragement as well as social and financial incentives to locate more ancient manuscripts (Gregory xxix-xx, Ingram 75). More discoveries followed, the majority of which were the poetical works of a late medieval cleric named Rowley (Ingram 41-2).

Chatterton was immediately suspected of a ruse. Horace Walpole was taken in, but only for a time, while Thomas Gray immediately declared the Rowley material to be a forgery (Gregory xxxix). At a dinner party in early 1771 Oliver Goldsmith was chided by Samuel Johnson for suggesting that the Rowley poems may be authentic historical relics (Cook 109-110).

Although the Rowley material had found few adherents in letters sent to London in April of 1769, Chatterton travelled to the city to seek his fame and fortune as a writer. A letter back home to his mother details how he was soon earning approximately eight guineas a month writing magazine articles and various incidental pieces (Gregory lvii). Later Chatterton biographer John H. Ingram dismisses this claim of Chatterton, as it appears designed to alleviate the worries of his mother. Chatterton's lodgings, wherein he shared a bedroom with plasterer's son, point toward a lower standard of living than suggested by the proclaimed income (Ingram 115-6).

Chatterton's Rowley corpus remained mostly unpublished until seven years after his death, when the authenticity question was intentionally stoked by bookseller Thomas 
Tyrwhitt with his coyly titled Poems, supposed [emphasis mine] to have been written at Bristol, by Thomas Rowley, and others, in the fifteenth century; the greatest part now first published from the most authentic copies, with an engraved specimen of one of the mss. To which are added, a preface, an introductory account of the several pieces, and a glossary (Lolla 151). Although the matter of the authorship of the Rowley material was largely settled, Tyrwhitt's preface argued insincerely for a fair hearing for both sides of the controversy (Cook 109):

It may be expected perhaps, that the Editor should give an opinion upon this important question; but he rather chooses, for many reasons, to leave it to the determination of the unprejudiced and intelligent reader... Whether the Poems be really antient or modern; the compositions of Rowley, or the forgeries of Chatterton; they must always be considered a most singular literary curiousity. (Tyrwhitt xii)

Tyrwhitt's volume contained almost 300 pages of Rowleyan poetry. During his brief literary career Chatterton produced only four manuscript pages in support of his claims, and those leaves contained no more than 124 lines of verse in total (Gregory cxxiv). Despite the dearth of evidence on the side of authenticity, the public attention was sufficiently captured by Tyrwhitt's ruse to merit the issue of a second edition of Poems, supposed to have been written at Bristol, by Thomas Rowley in 1777 and four more before the end of the century. The field proved lucrative enough that a rival text appeared, the Miscellanies in prose and verse; by Thomas Chatterton, the supposed author of the poems published under the names of Rowley, Canning, \&c. Additional materials followed, in the form of minor supplements and a pamphlet of the shorter poem "The 
Romavnte of a Knyghte”.

So successful was Tyrwhitt's campaign of doubt that the question of authenticity of the Rowley material remained open for nearly a century. Only with the publication of philologist Walter Skeat's "Essay on the Rowley Poems", included in an 1872 edition of Chatterton's Poetical Works, could the matter be considered settled (Groom 5). Skeat's scathing assessment left little room for doubt: not only were all the Rowley works modern rather than medieval, but in Skeat's opinion anyone with a schoolboy's education should have been to reach the same conclusion (Lolla 153, Williams 61).

Despite this dire proclamation, Horace Walpole briefly believed that one of Chatterton's minor works, "The Ryse of Peynceteynge, yn Englande," was the missing piece in his own project of writing a history of the visual arts in Britain (Haywood 150). Walpole would later denounce Chatterton as "a complete genius and a complete rogue" whose "ingenuity in counterfeiting styles" might better be applied to the forging of "promissory notes" (Meyerstein 277, 282). Chatterton shot back in a poem intended for but never sent to Walpole:

Thou, who in luxury nurst, behold'st with scorn

The boy, who friendless, fatherless, forlorn,

Asks thy high favor--thou mayst call me cheat,

Say, didst thou ne'er practise such Deceit?

Who wrote Otranto ? but I will not chide ;

Scorn I'll repay with scorn, and pride with pride. ("To Horace Walpole” 38)

Although many later editions of Walpole's Otranto bear the title The Castle of Otranto, A Gothic Story, the full title of the original 1764 edition reads The Castle of 
Otranto, a story. Translated by William Marshal, Gent. from the original Italian of Onuphrio Muralto, Canon of the Church of St. Nicholas of Otranto. Here Walpole plays the role of both translator William Marshall and original author Onuphrio, claiming that the tale presented is recovered from an antique past rather than the creation of the present (Walpole iii).

Chatterton and the Rowley corpus differ from Walpole in two major regards. The first is their differing social positions. As a fatherless Bristol boy of no means, Chatterton lacked the social and political clout of the son of a Prime Minister (Lewis 20). Walpole's wealth also afforded him the usage of his own printing press, allowing him to bypass the editorial oversight of the publishing establishment. The second great difference between the two was Walpole's ability to read the reading public, as it were. Walpole was in the position to both understand and respond to the dreadful precarity of Otranto's initial anonymous success. A second edition quickly appeared-- shorn of reference to lost manuscripts and translators-- subtitled simply A Gothic Story. The new preface laid bare the sins of the previous trickery with a brief apology (Sabor 59, 62). Thus, Walpole's fate becomes that of a canonical author, inaugurating the new genre of the gothic novel ${ }^{8}$, while Chatterton languishes in the company of literary criminals. In effect, Chatterton's doom

\footnotetext{
${ }^{8}$ Similarly, Aphra Behn, though not as well-connected as Horace Walpole, was already an established playwright by the time she published the novel Oroonoko, which makes certain hoax-like claims to truth. But she had the social capital to position the work as a literary act, especially since she wrote in a period where the boundaries of the novel and the relationship between fiction and non-fiction therein were less stable.
} 
is his inability to foresee the impact his work will have on an audience outside the Bristol locals. His inability to imagine the Other Reader leads him astray. Walpole is saved by his ability to respond to the Other Reader who might be angered by his literary tricks.

\section{Gesturing Toward a Phantom}

The differing results of Chatterton and Walpole's efforts to address the Other Reader demonstrate an important point: the phantasmal nature of the Other Reader provokes a variety of responses, none of which can ever completely succeed. The Author's anticipatory response to the Other Reader is always incommensurate to the task, as that response is always finite and timebound, while the potentialities of the Other Reader can only grow in variety.

The bulk of this dissertation examines a series of strategies employed by lateeighteenth- and nineteenth-century authors for circumventing the boundaries of the three assumptions of unity, linearity, and alphabetical primacy mentioned above. Each strategy affords the Author an opportunity for addressing the Other Reader. Since the Other Reader remains an unknown, the impossibility of contact a prerequisite of their existence, these opportunities are always impossible attempts to turn the unidirectional communication of writing into a polyvocal exchange.

To put it another way, our understanding of the relationship between the origin and audience of the text is always mediated. Part of this mediation remains material in nature, consisting of the entire process in the drafting, editing, typesetting, binding, selling, distributing, etc., of the physical object (the book) that serves as the conduit of communication of the text. But entangled in this material remediation is a process that occurs at the level of the social. It is in this latter domain that the senders and receivers 
of the textual signal become encoded as the (singular) Author and the (singular) Reader, until the changes in print technology mentioned above make visible the possibility of the Other Reader lurking beyond the boundaries of the discourse community. It is the overall project of this work to illuminate some the writerly moves that are employed in order for the Author to come to terms with the bifurcation of the Reader into the seemingly-known Reader and the enigmatic Other Reader. The model of the Author/Reader/Other Reader triad is offered as but one possible framework, suitable for interpreting texts at a specific moment in the development of the material history of literature. Doubtless other configurations suitable to other material conditions can be found, should, as I hope, this method prove useful.

\section{Chapter Details}

In Chapter I, "The Preface Problem: Addressing the Other Reader at the Outer Border of the Text," I examine the strategy of the authorial paratext, those threshold texts identified by Gérard Genette in a treatise of the same name. In particular, I focus on the paratext of the preface. I argue that the preface provides a venue for pre-empting criticism and instructing the Other Reader how the forthcoming text is to be read. Beginning with the preface of Robert Burton's The Anatomy of Melancholy (1621) as an early example of the author struggling with the reader, I outline Genette's theory of the paratext as developed in his work Paratexts: Thresholds of Interpretation. This is followed by a discussion of the relationship of the preface to the Other Reader and a brief look at the prehistory of the preface. Using the framework thus established, I investigate prefaces of three authors, Horace Walpole, Sir Walter Scott, and Charles 
Dickens. I demonstrate that all three authors use the preface as a site for managing the expectations of the Other Reader prior to encountering the text.

Extending the examination of paratext in chapter II, "Numbered Feet and Overburdened Shoulders: Authorship via Self-annotation in Samuel Taylor Coleridge And James Macpherson," I examine the pre-emptive nature of most paratexts prior to examining an alternate category of paratext that runs parallel to the main text. The use of parallel paratexts, particularly footnotes and margin notes, are examined as an authorial tactic for providing a running commentary on the text. I argue that the Author attempts to solve the problem of the absence of the Other Reader by becoming more present in the vicinity of the main text. To this end, I provide a history of the footnote, followed by an examination of two texts that existence in tension with authorial annotation, James Macpherson's Fragments of Ancient Poetry, collected in the Highlands of Scotland, and translated from the Gaelic or Erse language and Samuel Taylor Coleridge's poem The Rime of the Ancient Mariner.

In chapter III, "The Mirror in the Text: The Disavowal of the Poioumenon by the Withdrawal of the Book-within-a-book," I explore the presence of the spectre of the Other Reader in the poioumenon, or "work-in-progress novel." The chapter begins with a review of critic Alastair Fowler's analysis of the poioumenon. Four nineteenth-century texts are examined using Fowler's framework: Sir Walter Scott's Lay of the Last Minstrel, James Hogg's The Private Memoirs and Confessions of a Justified Sinner, Thomas Carlyle's Sartor Resartus, and Bram Stoker's Dracula. I argue that the poioumenon represents a state of maximum saturation of paratext, in which commentary about the text and the text itself are united. In crafting a narrative that 
includes its own creation, the poioumenon seeks to incorporate the Author's response to the Other Reader into the text written for the Reader. However, the poioumenon cannot solve the conundrum of the Other Reader, and the book-within-a-book emerges as a sign testifying to the poioumenon's incompleteness.

Chapter IV, "The Ragged Asterisk: Samuel Rogers, The Giaour, and The Folly of The Torn Page," examines a particular use of asterisks in one of Lord Byron's “Turkish Tales," The Giaour, and its spiritual predecessor, Samuel Roger's fragmentary poem The Voyage of Columbus. Both texts make use of lines of asterisks to indicate the presence of intentional aporia, interruptions in the text. I begin by introducing Rogers, an obscure figure today who once loomed large in London literary circles. Then I provide an overview of the architectural folly, those eighteenth and nineteenth century edifices of conspicuous consumption. After providing a history of the asterisk as a mark of erasure, I argue that Rogers and Byron utilize lines of asterisks in a manner parallel to the artificial aging of architectural follies.

Finally, Chapter V, “The Student as Author: Nineteenth-Century Literature and a Pedagogy of Authorship," examines the Other Reader in the literature classroom. The Other Reader is used as a metaphor for understanding two sets of relations. The first set is that between the text and the student, who are almost always outside the discourse community of the text's composition. The second is between the student's writing and the instruction. In the former case, the anxiety of the Other Reader is addressed by reformulating the student as co-author of their learning. In the latter case, the instructor, as the primary audience for written classroom assessments, is identified with the Reader. The Other Reader is the future self of the student, to whom the student 
writes using a journaling technique called the daybook. By tasking students with ongoing journaling and then requiring them later to review and comment on their own work, a metacognitive feedback loop is built into their learning. I provide an overview of the use of the student daybook in an interdisciplinary literature course, as well as six case studies of student writing. I end the chapter with an analysis of the successes and setbacks of the course and plans for future improvements.

Overall, the goal of this project is to demonstrate that the relationship between the Author and the Reader does not always operate along a single channel on a single valence. Under this rarely-interrogated model, the author's relationship to the reader is mediated by the text. The existence of the Other Reader complicates this simple, linear arrangement, creating a new, multi-dimensional situation where authors attempt to account for the Morellis and Lettrices (or, more properly, Lettrici) of the world. The addition of the Other Reader alters the calculus by which the author must operate. 
CHAPTER I: THE PREFACE PROBLEM: ADDRESSING THE OTHER READER AT THE OUTER BORDER OF THE TEXT

Persons attempting to find a motive in this narrative will be prosecuted; persons attempting to find a moral in it will be banished; persons attempting to find a plot in it will be shot.

--Mark Twain, Preface to Adventures of Huckleberry Finn

Near the end of "Democritus Junior to the Reader," the preface to The Anatomy of Melancholy (1621), author Robert Burton declares "To conclude, this being granted, that all the world is melancholy, or mad, dotes, and every member of it, I have ended my task, and sufficiently illustrated that which I took upon me to demonstrate at first. At this present I have no more to say" (120). In fact, Burton continues for nearly two thousand more words before ending his preface. Almost halfway through the remaining span of the preface he declares "I owe them nothing (reader), I look for no favour at that hands, I am independent. I fear not” (122). Burton then spends most of the remaining thousand words offering reasons why his readers should be gentle in their judgement of the work they are about to read and its author.

As with anyone who takes up the labyrinthine wit of Burton, we find ourselves trapped in wry paradoxes. Why is Democritus Junior (Burton's pen-name) concluding before the text proper has begun? If his task is ended here, why should we continue reading? If Burton/Democritus Junior owes us nothing, why did he take it upon himself to write a preface of over 46,000 words (110 pages in the New York Review Books edition) directly addressed “to the Reader?" Burton is clearly playing with us in the preface, but what is the nature of the game? How is it played? 
In this chapter, I argue for the preface as a primary site of the constitution of the relationship between the author and the Other Reader. The preface is entangled with a constellation of material affordances, economic pressures, and cultural practices that tend to give it this shape, but the foremost of these factors is the emergence of the wider audience and the author's awareness of that audience, i.e. the Other Reader. A new relationship between the author and the Other Reader emerges in the second half of the eighteenth century, marked by the shifting prefaces of Horace Walpole's The Castle of Otranto. The preface as a locus for addressing the threat of the Other Reader reaches full form in the prefaces of the Waverly novels of Sir Walter Scott, which trace Scott's evolving relationship with his readership.

Prior to delving into these texts, I will begin with an examination of the analysis of prefaces in the seminal work on paratexts, Gérard Genette's Paratexts: Thresholds of Interpretation. Building on his theory, I will contextualize and historize the preface as a response to the Other Reader, a usage born of technological development, the growth of the reading public, and the development in the Romantic period of a new approach to remediation. I argue that the second half of the eighteenth and the first half of the nineteenth centuries constitute a specific moment in the development of the preface as a means of dealing with the uncertainty of the Other Reader. I will then examine the prefaces of Walpole and Scott within the light of this framework, demonstrating how each author wrangles with the problem posed by the Other Reader.

\section{Genette's Theory of the Preface}

In Paratexts: Thresholds of Interpretation, Gérard Genette defines preface as class of paratext including "every type of introductory (preludial or postludial) text, 
authorial or allographic, consisting of a discourse produced on the subject of the text that follows or precedes it" (161). Following Genette's general definition of paratext as "a verbal or other production... that surrounds or extends [a literary work] in order to present it”, the existence of a preface necessarily implies a primary or main text (a "literary work," in Genette's formulation) that the paratext accompanies (1-2).

Genette considers five elements that are crucial to the analysis of the paratext: form, place, time, sender, and addressee. The most common form of the preface is a "discourse in prose" whose discursive features contrast with the narrative, dramatic, or poetic mode of the main text (171). E.g. it is uncommon to find a preface to the script of a play that is itself written in the form of a script. Rather, some sort of change in style or register accompanies the movement from preface to main text or main text to postface, perhaps something as simple as the change from third person to first person narration or vice versa. An example of the latter can be found in Thomas Hardy's 1895 preface to his 1874 novel Far from the Madding Crowd. Only four paragraphs long (740 words total), nine different first-person sentences can be found, while in the main text of the novel all 1,561 uses of the word $I$ are found in direct quotes (i.e. dialogue), with the narration related in the third person.

By the place of the text, Genette refers to the location of the preface vis-à-vis the main text within the layout of the book, noting that "[t]he choice between the two locations, preludial or postludial, is obviously not neutral" (172). Genette takes up the ramifications of placing this paratext before or after the text in a chapter on the functions of the original preface, but for now it is important to note that for a text to be 
considered a preface, it must be attached to the main text--physically within the same book--either before or after it.

Genette considers it axiomatic that prefaces are written after the creation of the main text (174). A preface written prior to the composition of the text it accompanies is no preface at all, or at least it falls so far outside the normal functions of a preface as to constitute some sort of special case. Thus, for Genette's categorization scheme, the time of a preface constitutes not a spectrum of infinite extension, but rather a ray with a terminus at one end and continuous expansion away from it. The terminus in this case represents a preface published simultaneously with the first printed edition of the main text, which Genette classifies as an original preface.

In addition to the original preface, Genette notes the existence of the two other types of preface, which translator Jane E. Lewin renders as later and delayed. The former category refers to prefaces appearing in editions subsequent to the first, the author taking the opportunity of the initial success of the work to offer a (relatively) timely comment. The typical subjects of the later preface are the success of the book and its reception. Dickens's preface to the third edition of Oliver Twist, explored at length below, is an example of a later preface (Giuliano and Collins 548).

The delayed preface, on the other hand, is less about the success of the moment and more concerned with the future trajectory of the main text. Citing Austrian philosopher Robert Musil, Genette refers to the delayed preface as "pre-posthumous" in character, i.e. the author, perhaps considering their own impending mortality, writes a new preface in hopes of securing their legacy (175). In the foreword of his prose 
collection Nachlass zu Lebzeiten (the English is titled Posthumous Papers of a Living Author), Musil writes

There are poetic estates that also happen to be great gifts; but as a rule, literary legacies bear a suspicious resemblance to everything-must-go store clearance sales and cheap bargains. The popularity that such work nonetheless enjoys may indeed derive from the fact that the reading public has a forgivable weakness for a poet ${ }^{9}$ who for the last time lays claim to their attention. However the case may be, and whatever questions may arise as to whether such a legacy may be truly worthwhile or merely of some worth, might lead one to suppose--I at any rate have decided to forestall publication of my own last literary effects before the time comes when I will no longer have a say in the matter. And the most dependable way to make sure of this is to publish it myself while still alive, whether this makes sense to everyone or not. (ix)

As is often the case with humor, Musil makes plain the anxieties in the situation; the delayed preface serves as the author's last message from beyond an imagined grave.

The fourth of Genette's five dimensions of preface analysis is the sender of the preface, by which he means the putative or nominal author. Genette maps out the variety of senders in a two-dimensional array. Along one axis is the role of the sender, either authorial, allographic, or actorial. The authorial preface is written by the author

9 "Poet" here is a rendering of the German dichter, which includes literary writers in prose. 
of the main text. The actorial preface is written by a person who appears in the main text, such as the subject of a biography writing a forward for their biographer (Recall that Genette considers any sort of preludial text under the broad category preface). The allographic sender is any third party, neither the listed author of the work nor someone appearing in the text (178-9).

Genette calls the other axis of the array of possible senders the regime. This he divides into three categories as well, the authentic, the fictive, and the apocryphal. The authors of authentic prefaces correspond with the claims made to their identity, i.e. the inscriber of the preface is correctly credited. Fictive prefaces are ascribed to imaginary persons, while apocryphal prefaces are misattributed to a real person.

To give a few examples here, Dickens' preface for the third edition of Oliver Twist is an example of an authorial, authentic sender. It purports to be written by the author and no question of its authenticity has ever been raised. An instance of an authorial, apocryphal preface would be the original preface to the first edition of Mary Shelley's Frankenstein; or, the Modern Prometheus. This unsigned text is clearly meant to be taken as the work of the author, with the first-person assumption of that role in lines such as "I shall not be supposed as according the remotest degree of serious faith to such an imagination; yet, in assuming it as the basis of a work of fancy, I have not considered myself as merely weaving a series of supernatural terrors." Yet this preface was written by Shelley's husband Percy Bysshe Shelley and not by the author herself (Hunter 5 n. 1). Under Genette's system, this would make the Frankenstein preface apocryphal in its regime. The imaginary figure purportedly responsible for the introductory "Editor's Narrative" at the beginning of James Hogg's The Private Memoirs and Confessions of a 
Justified Sinner constitutes an allographic, fictive sender. It is allographic because it is presented as the writing of someone besides the author and fictive because the editor is not a real person, but a mask worn by the author. ${ }^{10}$

The final category distinguishing prefaces is the addressee or addressees of the preface. The default mode here, according to Genette, is that the imagined audience of the preface is the potential reader of the text. The preface postulates that its reader is poised for an imminent reading of the text (or in the case of a postface has just concluded a reading) without which its preparatory or retrospective comments would be largely meaningless and, naturally, useless (194).

What Genette does not account for is the presence of multiple categories of actual readers, those within the discourse community of the writer (i.e. the author's intended reader) and those outside it (the Other Reader). Although the de facto addressee of any book is the individual human scanning a particular copy with their eyes, the author must imagine that reader based from the author's vantage point of participation in a specific discourse community. The later preface of Oliver Twist clearly contemplates the Other Reader's response to the previous editions, responding in part to alternate readings of Nancy's vocation, while Scott's Magnum Opus edition anticipates the Other Reader yet to come, born long after Scott's demise.

${ }^{10}$ Genette's taxonomy of prefaces does not account for unsigned (i.e. anonymous) prefaces, nor does it distinguish joint prefaces written by multiple parties, such as the influential "Advertisement" at the beginning of the first edition of Lyrical Ballads. 
Instead of an imagined dialogue between author and present reader, later and delayed prefaces tend to suggest the existence of a three-way relationship featuring the author, the present reader, and one or more past readers. In effect, the author is simultaneously writing back to past readers while directly addressing the present reader. This can manifest as the author taking a victory lap, underlining the fact that past readers loved the work so much that it affords the author the opportunity to write a preface directed to new readers. But it can also take the form of the author educating the new reader because some prior readers did a bad job (from the author's point of view) interpreting the original text. That is, an encounter with the Other Reader induces the author to take steps to try to control the reception of their text.

\section{The Preface and the Other Reader}

However, it is not necessary for either the intended reader or the Other Reader to be actual human beings for them to influence the author. Wolfgang Iser discusses two types of virtual reader in The Act of Reading:

Almost diametrically opposite the contemporary reader [Elsewhere Iser also refers to this person as a "real reader."] stands the oft quoted ideal reader. It is difficult to pinpoint precisely where he is drawn from, though there is a good deal to be said for the claim he tends to emerge from the brain of the philologist or critic himself. Although the critic's judgement may well have been honed and defined by the many texts he has dealt with, he remains nothing more than a cultured reader--if only because an ideal reader is a structural impossibility as far as literary communication is concerned. (28) 
Iser rejects the ideal reader as a mystification of criticism, but the existence of the preface reveals the author capable of the same act of invention. The ideal reader of the author is an ego-driven fantasy, a mirror to reflect the author's own thoughts and opinions on the text. As such, the ideal reader exists entirely within the discourse community of the author. The ideal reader is a phantom designed to cross the chasm from the reader the author wants to the real human beings who pick up the book, but the variety of possible readers will always exceed the imagination of the author. The real audience is diverse and unruly, thanks to their individual experiences, their unpredictable reading practices, and their tendency to find meanings in the text that the author did not consciously place there. The polyvocal, amorphous reality of the audience beyond the boundaries of the discourse community haunts the author as the Other Reader.

The gulf between the author's ideal audience and the realities of all possible audience opens two rhetorical options for the preface-writing author. The first is to ignore the actual audience completely and focus on the ideal reader, allowing the author to withdraw from the world entirely and live in a fantasy world where all their readers think exactly as they do. The temptation to go down this path is particularly strong with the original preface, as the number and type of readers of the main text prior to publication is limited to those persons with whom the author is willing to share their manuscript. This narrows the range of readers to friends, associates, and editors who will no doubt be fellow-travelers in a variety of ways, possibly including race, gender, national origin, political affiliation, religious sentiment, etc. 
Once loosed into both the marketplace of ideas and the literal market as a published work, the range of potential readerly dispositions grows to encompass multitudes. In later and delayed prefaces, a second rhetorical option becomes available, where the ideal reader serves as a tool for gaining leverage over real readers, or worse, as a rod with which to chastise them. The author, presumably aware of some portion of the variety of responses to the appearance of their work, somehow reacts to these unruly readers by an explicit or implicit comparison to the ideal reader.

Another important voice speaking to the nature and function of the preface is Jacques Derrida, who, perhaps unsurprisingly, wryly treats on the subject in the pages of a preface. Dissemination collects three essays by the French theorist, "Plato's Pharmacy," "The Double Session" and the essay from which the work takes its name, "Dissemination." Prior to these three pieces, Derrida offers a new preface (that is, a later one, in Genette's terminology) written specifically to introduce the collection, the topic of which is the function of the preface that he is writing. Derrida's concern is the preface as an act of presentation, that is, the preface has no function outside its relationship with the text it introduces (3). As is typical of Derrida, the preface to Dissemination offers this definition in the middle of the act of resisting its implications. He tells us that presenting the text is what his preface would do, if prefaces functioned as imagined by Genette, as a means of controlling reception. ${ }^{11}$ Derrida acknowledges that the intent of the preface is to narrow the range of meanings available to the reader, but argues that

\footnotetext{
${ }^{11}$ As presented here, my argument inverts the timeline of the discussion. Genette writes partially in response to Derrida, not vice versa (Genette 196).
} 
what in fact is happening is that the preface adds to the creation of meaning in the main text:

Prefaces, along with forewords, introductions, preludes, preliminaries, preambles, prologues, and prolegomena, have always been written, it seems, in the view of their own self-effacement. Upon reaching the end of the pre- (which presents and precedes, or rather forestalls, the presentative production, and, in order to put before the reader's eyes what is not yet visible, is obliged to speak, predict, and predicate), the route which has been covered must cancel itself out. But this subtraction leaves a mark of erasure, a remainder which is added to the subsequent text and which cannot be completely summed up within it. [Italics original.] (9) Forestalling the presentative production--as Derrida puts it--highlights the inherent contradiction of the preface (or, at least, of the preludial preface, to use Genette's taxonomy). The preface is, in effect, a sort of time machine. From the point of view of the author, the order of events surrounding the preface typically follows these lines:

1. The main text is composed.

2. The original preface is composed, if one is written.

3. The main text or the original preface + main text is published.

4. The Other Reader reacts to the main text in ways not anticipated by the author.

5. The work is successful enough to call for a new edition.

6. A new edition is issued with the addition of a later preface, attempting to account for the Other Reader.

7. Possibly repeat steps 4 through 6 one or more times. 
8. Years later, the work is successful enough to warrant inclusion in some sort of collection or to be issued in a special edition.

9. Author, often near the end of their life, desires to secure legacy, writes a delayed preface.

The reader, however, experiences these texts in any of a variety of orders. After all, there's nothing to prevent a reader from skipping front matter. I sometimes open a novel in the middle and start reading from there, looping back around to the front of the work only if I find it particularly good. ${ }^{12}$ Accounting for just those well-behaved readers who always start with the preface(s) and read front-to-back, the number of possible reader experiences increases with each new preface. If there is no original preface, then early adopters, second hand purchasers of early editions, and purchasers of later nofrills cheap editions will encounter the main text sans preface. Some readers of later and delayed prefaces will be re-readers, who first encountered the main text without a preface or with the original one.

We are, of course, free to read in any order desired, skipping words, moving up and down the page, flipping pages backwards, etc. We can even read the letter order of individuals words in some non-standard way, reading "dog" as "god" or "odg," for example. However, when reading without conscious attention to the act, the normal tendency is the left-to-right, top-to-bottom method described above, at least for readers of English. This default mode of reading can be disrupted at any time, either by reader

\footnotetext{
${ }^{12}$ For additional methods of reading a text see Daniel Pennac's The Rights of the Reader and Ron Padgett's Creative Reading: What It Is, How to Do It, and Why.
} 
choice or some error, such as two pages sticking together when attempting to turn to the next page.

Given the linear nature of the default mode of reading, any bit of text appearing toward the front of the book is privileged. More people are likely to at least glance at the front matter and beginning of a book. And it must be remembered that not every reader makes it all the way through a text. I still haven't finished Joyce's Ulysses after five or so attempts. (I find Finnegan's Wake much more appealing.) But despite never finishing it and never quite liking it, the opening image of Black Mulligan shaving has left a distinct impression on my memory.

This phenomenon partially explains why first lines tend to be more famous than last lines, whether we're talking about Edward Bulwer-Lytton's much-lampooned "It was a dark and stormy night..." or Dickens's "It was the best of times, it was the worst of times, it was the age of wisdom, it was the age of foolishness..." or Austen's "It is a truth universally acknowledged, that a single man in possession of a good fortune, must be in want of a wife." We recall such famous lines because they are the first encountered in the main text and because they therefore offer the reader a sort of proposal, almost a thesis statement on the rest of the novel. We can tell from one sentence (or at least we think we can tell) that Austen is going to be domestic and witty, Dickens' is inviting us to explore the inherent contradictions of the human condition, and Bulwer-Lytton is serving up overwrought sensationalism.

These are the conclusions we can draw from reading that opening sentence. In a way, the preludial preface usurps this function. With opening lines, we begin the interaction of art and perception, i.e. we begin to make meaning with/from the author's 
words. The preface preemptively interrupts this interaction, as if we are in an art museum and an artist statement is displayed in front of every painting and sculpture. Or if before the screening of a film, the projectionist first ran a review of the movie you are about to watch.

Genette argues that the primordial scene of the preface--what we might call its default mode--is a discourse in prose that is preludial to the text, original to the first edition, with an authentic authorial sender, and the audience consisting of those about to read (who or at least considering reading) the text for the first time. Why this arrangement is the norm for prefaces--as opposed to the other various arrangements-hinges partially on the economic factor. All prefaces implicitly or explicitly argue for the value of the text that follows. That is, they have an advertising function, as they afford an opportunity to speak directly to someone holding the text but still considering whether to read or possibly purchase the text. This situation provides the justification for guiding the reader of the preface through a tour of the text and the author's reflections upon it, i.e. it gives the writer an opportunity to remediate the text without revising it.

\section{The Prehistory of the Preface}

A genre antecedent to the preludial preface is the lengthy titles and subtitles of the seventeenth and eighteenth centuries. Their function of introducing or previewing the material of the book, much like the overture of an opera or the prologue of a play, can be seen in some titles, such as Samuel Richardson's novel commonly referred to as Pamela or Pamela, or Virtue Rewarded. The original title page of 1740 gave the title as Pamela: Or, Virtue Rewarded In a Series of Familiar Letters From a Beautiful Young Damsel, to Her Parents. Now First Published In order to cultivate the Principles of 
Virtue and Religion in the Minds of the Youth of Both Sexes. This title introduces both the epistolary form of the novel and offers a justification for its existence.

Referring to the development of the title page as a space of self-promotion for early printers, Elizabeth Eisenstein notes:

Indeed, their use of title pages entailed a significant reversal of scribal procedures; they put themselves first. Scribal colophons had come last. They also extended their new promotional techniques to the authors and artists whose work they published, thus contributing to the celebration of lay culture-heroes and to their achievement of personal celebrity and eponymous fame. (59)

In effect, the shift from the auctor of St. Bonaventura, who "writes both his own work and others' but with his own work in principal place adding others' for purposes of confirmation," to the author of the print era is precipitated by the commercial development of the paratext of the title page (qtd. in Eisenstein 122).

The move from auctor to author to preface-writing author consists of an ongoing effort to influence the reader of the text. The defining characteristic of the auctor is the presentation of original ideas within the context of the ideas of other writers. Those others are past authors, whose work is martialed as supporting evidence for the claims of the auctor. This model places the author and reader on nearly the same status level, reflecting the social reality of the medieval world of letters, where the Venn diagram showing the relationship between inscribers of manuscripts and readers of the same would almost completely overlap (Ong 469, Gutenberg Galaxy 96-7). To offer original ideas without the backing of the great authorities would move the writer out of the 
network that binds the medieval scholastics to each other and to their classical and early Christian roots.

The early print author defines a new set of relations, between the title of the work, the printer, the author, and any artists involved. The earlier network of scholarly correspondents is replaced with a new commercial network consisting of fellow contributors to the production of a commodity. As a member of a workshop, the early modern author is tasked with producing one component in a product, the raw text, just as the artist produces the visuals, and the printer supplies paper and ink.

In a way, the preface-writer reconstitutes the earlier form of the auctor, but in a macrocosmic state, almost parodic of the medieval form. In the preface, the writer sets up a network relationship with their own earlier writing. The main text becomes the others' work appearing "for purposes of confirmation." By introducing (presenting) the main text, it becomes the work of Author ${ }_{2}$ confirming the claims made by Author ${ }_{1}$. The combined figure Author ${ }_{1+2}$ is then the new face of the author, a binary formation in which the preface-writer appoints themselves as primary interpreter of their own main text.

That the original preface is a component of the default mode of the preface is a matter of economics. Every additional page costs more in terms of paper, ink, and labor. Thus, not all books are produced with the luxury of the preface. And a minority of books are successful enough to warrant the additional risk of new editions, consequently resulting in fewer later and delayed prefaces.

The economic and cultural conditions of the nineteenth century enabled a flourishing of later and delayed prefaces. The improvements in technology--such as the 
Stanhope iron press, the power train of George Clymer, and Richard Cope's counterweighted 'Albion' press--allowed for faster production of cheaper copies (Howard 114-5). Furthermore, changes in commercial practices created new opportunities for the writing of prefaces. William St. Clair details the process that he calls "tranching down," by which publishers marketed multiple editions to multiple audiences: a cheap edition for the lower classes, a standard edition for middle class households, and deluxe editions for the wealthiest of book buyers (32-3). These versions were rarely all released simultaneously, creating more opportunities for later prefaces. Similarly, the conversion of triple decker novels (a single novel released as three separate volumes) to all-in-one books also afforded new opportunities for the later preface. The transition of a novel from serialization in a periodical to book form also made later prefaces possible, as was the case of the 1841 Oliver Twist.

Perhaps the most important technological development contributing to the urgency of the preface in the Romantic period is growing use of stereotypy. A method whereby a casting is taken of the printing plate after the compositor lays out the type, stereotyping allows for the readied plate for each sheet of print to be easily reused (Robinson 108). The plate can be used immediately, freeing up the letters of type for another project, but it can also be put to other uses. The stereotype plate allows for the book to be stored so that it can be reprinted at a later date without the labor of recomposition (Bhaskar 126). They also allow the cheap export of a text between printing houses in distant places, saving the cost of shipping complete books (McGill 679).

Both uses of the stereotype result in a huge increase of potential readers--reprints allowing new readers to be reached later in time, shipping to distant venues allowing 
new readers more distant in space--which in turn leads to the Other Reader looming as a larger presence in the mind of the author. Combine this with all the technological innovations described above--all of which tend toward more, cheaper copies in distribution--enables a wider audience along an economic axis as well.

Another factor contributing to the rise in prominence of the preface in the nineteenth century includes the growth of literacy among the lower classes. Over the course of human history reading had expanded from the prerogative of elite clerical/scribal classes to a tool of daily commercial activity to an everyday activity even for much of the proletariat. Although the actual numbers of readers in any period is difficult to quantify, some proxies can be used to understand the general trajectory of readership in the period.

The steady growth in print runs for popular works, as documented by William St. Clair is one such proxy. Take Samuel Rogers's first poetic success, The Pleasures of Memory, as an example: in 1792, a print run of only 250 copies was deemed sufficient (St. Clair 632). Thanks to its success among upper-class female readers at the end of the eighteenth century, three more small print runs followed (Clayden 213). New printings followed nearly every year from 1801 to 1816 , with these later print runs averaging over 1,000 copies each. Roger's poetry was sufficiently popular two decades later to warrant a final edition of 1,500 copies. By 1850 , popular works could sell hundreds of thousands of copies (Erickson 24).

Other evidence points toward an overall expansion of the book market. For example, nearly 5,000 new works of poetry were published in Britain from 1789 to 1824 (Langan and McLane 240). The number of provincial booksellers had been growing 
steadily since the middle of the eighteenth century, reaching a total of approximately 1,000 individual vendors in over 300 towns by 1790 (Finkelstein and McCleery 77). Similarly, the number of printing houses in England grew from the twenty-four authorized by the Printing Act of 1662, to sixty-five printers at the beginning of the eighteenth century, to hundreds of English presses by 1800 (McDowell 234). Although none of these constitutes proof of a growing readership, all this commercial activity suggests a significantly growing consumer base.

Thus, the period centered around 1800 was a time of massive change in the methods and technologies used to produce text as well as expansion of the audiences they could reach. These changes in the medium environment--the tools used, the protocols employed, the people involved--happened concurrently with the Romantics' project of reconsidering the mediated nature of text itself (Langan and McLane 242; Maas 433-4). Under these specific developments of these material circumstances, the protocols of the preface become a site to remediate the text for the Other Reader. In the next section, I will examine how the preface becomes used as a buffer between the author and the Other Reader, disposing of the threat posed by the unknowable Other by increasing the metaphorical distance between them and the writer of the text.

\section{The Disavowing Preface}

An alternative method of dealing with the Other Reader is through an act of disavowal. The preface provides an opportunity for authors to distance themselves from their text, of which Horace Walpole's The Castle of Otranto provides a striking example. Although many later editions bear the title The Castle of Otranto, A Gothic Story, the full title of the original 1764 edition reads The Castle of Otranto, a story. Translated by 
William Marshal, Gent. from the original Italian of Onuphrio Muralto, Canon of the Church of St. Nicholas of Otranto. Here Walpole plays the role of both translator William Marshall and original author Onuphrio. In Genette's terms, this preface is preludial and original, but with an author pretending to be an allographic, fictive sender.

In the original preface Walpole gives a false provenance for the text:

The following work was found in the library of an ancient Catholic family in the North of England. It was printed at Naples, in the black letter, in the year 1529. How much sooner it was written does not appear. The principal incidents are such as were believed in the darkest ages of Christianity; but the language and conduct have nothing that favours of barbarism. (Walpole iii)

Note the claim to antiquity that seems plausible enough but remains unverifiable, combined with the concealed self-congratulation on the "language and conduct". The latter serves as sort of winking gesture to those within Walpole's immediate circle, who are already aware of its true authorship.

Two key characteristics distinguish Walpole from most authors. First, as the son of prime minister Robert Walpole, he was an insider with large amounts of capital (both financial and social) in the milieu of literary London (Lewis 20). Walpole's second advantage was the ability to intuit the tenor of the reading public and react accordingly. Once the first edition of Otranto achieved some success, Walpole recognized either the opportunity for glory or danger in pseudonymity. The second edition--published less than four months later--bore both his name and the now-familiar subtitle, A Gothic Story, in lieu of any mention of Marshal or Onuphrio on the title page. Additionally, a new preface 
for the second edition contained a brief mea culpa for previously hoodwinking the public (Sabor 59, 62). By this deft maneuver Walpole avoided the perils of being labeled a hoax and successfully repositioned The Castle of Otranto as a literary work:

The favorable manner in which this little piece has been received by the public, calls upon the author to explain the grounds on which he composed it. But before he opens those motives, it is fit that he should ask pardon of his readers for having offered his work to them under the borrowed personage of a translator. As diffidence of his own abilities, and the novelty of the attempt, were his sole inducements to assume that disguise, he flatters himself shall appear excusable. (xiii)

This preface offers a second disavowal of the text, this time in terms of a proper modesty for his own abilities, especially considering the experimental nature of the work. The narrow window, less than a third of a year, between the first and second editions, shows an author responding to the Other Reader's embrace of his text with a speed and agility available to few authors.

By owning his own printing press, Walpole was able to exercise total control over the physical details of The Castle of Otranto. This control extended to choices of book size, paper used, and typography employed as well as the inclusion of the preface of the first edition that tells the story of the false "found document" nature of the text. He also controlled the preface of the subsequent edition wherein he apologizes for the deception and claims credit for his work. By means external to the text itself, Walpole was able to obscure, then reveal himself as the author of his novel. Although an extreme case, The 
Castle of Otranto reveals the entanglement of authorship and authenticity with the paratextual and bibliographic elements that accompany the text in the age of print.

Possession of his own means of production allowed Walpole a golden opportunity to manage the authorial anxiety created by the phantom of the Other Reader. He was able to publish anonymously, with the cover story of the found manuscript, as a way of shielding himself from the Other Reader's opprobrium, should the "novelty of the attempt" fail to find approval with the public. But he was also positioned to just as quickly exploit the initial success of the book to take full credit for the work in the second and subsequent editions, easing the way by apologizing to the same public for his deception.

\section{The Prefaces of the Great Unknown}

Thanks in part to the economic factors that privilege successful novels as sites for prefaces, the most intriguing example of preface-writing in nineteenth-century British letters are the novels of Sir Walter Scott. In the first half of the nineteenth century Scott was simultaneously the best-selling poet in Britain and the best-selling novelist, but much of his reading public did not know that fact. His reputation as a poet, based upon works such as The Lay of the Last Minstrel and The Lady of the Lake, was second to none and rivalled only by the less morally acceptable poetry of Lord Byron. But at the beginning of the nineteenth century the novel as a genre still carried with it a scent of the illicit, a suggestion of impropriety that a wholesome member of the upper class like Scott could not so easily dismiss, so he opted to publish his initial novels anonymously. This anonymous author became known as "The Author of Waverly" or "The Great Unknown." So successful was this veiled authorial identity that it was taken up by 
pirates, used to sell a forgery commissioned by a German bookseller (Russett 102, 111). Later, Scott chose to populate his prefaces with an array of characters existing only within the world of the preface. Using Genette's terminology, the bulk of Scott's prefaces are a dazzling hybrid of anonymous, authorial, authentic and allographic (i.e. 3rd party) fictive senders. For example, Scott's 1820 novels The Monastery and The Abbot novels both begin with a fictitious epistle to or from “Captain Clutterbuck, Late of His Majesty's -- -- Infantry" that serve to introduce and authenticate the text presented by the Author of Waverley (Furner 269, Prothero 473 n1)).

The Waverly Novels comprise a series of book-length historical fiction written by Sir Walter Scott, beginning with Waverly, or, Tis Sixty Years Since, first published in 1814. One or more additional novels were published every year from 1815 through 1831 , with the exceptions of 1827 and 1830 . In total, twenty six novels appeared during this sixteen year period, including four subseries, the Tales of My Landlord (comprising seven novels: The Black Dwarf (1816), The Tale of Old Mortality (1816), The Heart of Midlothian (1818), The Bride of Lammermoor (1819), A Legend of Montrose (1819), Count Robert of Paris (1831), and Castle Dangerous (1831)), Tales from Benedictine Sources (The Monastery (1820), The Abbot (1820)), Tales of the Crusades (The Betrothed and The Talisman, both 1825), and the Chronicles of Canongate (The Fair Maid of Perth (1828)).

Scott was the most popular and successful author of the Romantic period, and his popularity continued well past his death in 1832 (St. Clair 632). Between its first appearance in 1814 and 1821, Waverly went through eight editions. Each print run amounted to 1,000 to 2,000 copies, as was typical of the era. (For example, the initial 
1818 print run of Austen's Northanger Abbey ran to 1,750 copies. In 1822 the first book edition of De Quincey's Confessions of an English Opium Eater was only 1,000 copies, despite its prior success in the pages of the London Magazine $(580,596)$.$) The total$ number of editions listed by St. Clair excludes numerous pirated versions produced in the United States, France, and elsewhere, many of which made their way back to the British marketplace. Prior to 1836 a total of 40,000 authorized copies of Waverly, or, Tis Sixty Years Since had been printed (636). Following the smash success of Waverly, it was not uncommon for Scott's novels to appear in initial print runs of 10,000 copies (637-9). By 1834 twenty different collected editions of Waverly novels had been issued, ranging in size from six to 48 volumes, each with print runs ranging from 1,000 to 7,000 copies (641-2).

Following the insolvency of Scott's original publisher, Constable and Company, the rights to print Scott's work were acquired by former Constable partner Roger Cadell (Johnson 1102-3). Cadell would go on to print more than 8 million Scott volumes prior to 1865 , including over a million copies of the Waverly Novels designed to be sold exclusively on trains and at train stations (St. Clair 643). Scott's work was so far reaching that it not only established the historical novel as a distinct genre, it influenced the way history itself is imagined in the English reading world (Harvey Wood 93-4; Duncan 96-104). As the best-selling author of the period, Scott casts a long shadow. His relationship to the formation of authorship and how he constructs that relationship in his numerous prefaces are of preeminent interest.

Sixteen out of twenty-six of the Waverly novels were published with original prefaces to their first editions. All received new prefaces with the publication of the 
Magnum Opus edition. Additionally, Scott penned a General Preface for the Magnus Opus reprints. Of the original prefaces, I will touch upon six examples that are especially relevant to the question of the formation of authorship in the nineteenth century. I will begin with the unusual proto-prefaces of Waverly and then turn to the preface of Quentin Durward. These two works provide different vantage points on Scott's evolving relationship with his writing, his publishers, the commercial realities of the book trade, and his literary public, i.e. his vision of the Other Reader.

The original publication of Waverly, or, Tis Sixty Years saw the novel appear with both two prefaces and none. This paradox exists as a result of two preface-like chapters found at the beginning and end of the novel. Functionally, both chapters operate as prefaces in that, per Genette, they present the work to the reader. However, they differ formally from many prefaces in that they are incorporated in the body of the work. That is to say, they are not marked as texts separate from the main texts. The page numbering is consistent through the text; as front matter, prefaces are typically numbered with lower case roman numerals as part of the front matter. The front preface is titled "Introductory," an atypical term for a preface but one which effectively signals its prefatory function. However, it is also labeled at the top of the first page as chapter I (3). Similarly, the postface is chapter XLIII, curiously titled "A Postscript, which should have been a Preface" (364). The chapter titles use the same italic typography used for the chapter titles throughout the novel.

Returning to Genette's five elements of prefaces--form, place, time, sender, and addressee--we find both the first and last chapter to be original prefaces sent by an authentic albeit anonymous author addressed to readers and taking the form of the 
narrator turning away from the narrative to discuss narration itself. The difference between the two is, of course, place; the Introductory is preludial, while the Postscript is postludial.

Both prefaces express the same kind of anxiety that the original preface of the Castle of Otranto was designed to conceal; the reception of the text is clearly foremost on Scott's mind. The Introductory begins "The title of this work has not been chosen without the grave and solid deliberation which matters of importance demand from the prudent” (3). He then devotes a considerable amount of space to an explanation of both the title of the book, Waverly, and its subtitle, Tis Sixty Years Since. For the title--and thus the surname of his protagonist--Scott speculates that he could have selected a "chivalrous" name like Howard, Mordaunt, Mortimer, or Stanley or "the softer and more sentimental sounds" of names such as Belmour, Belville, Belfield, or Belgrave (4). He alights upon Waverly as the name for his hero as "an uncontaminated name, bearing with its sound little of good or evil." Thus, Scott has selected the name Waverly as a sort of cypher, unlikely to prejudice the reader regarding the content of the novel.

Scott's discussion of the subtitle focuses on the genre assignment of the novel, and, by proxy, his fear of being pigeonholed at the dawn of his career as a novelist. He speculates that Waverley, a Tale of other Days and Waverley, a Romance from the German would have led readers to believe that his work was a Gothic novel in the mode established by Horace Walpole, while subtitling the work a Sentimental Tale would have suggested a novel with a female protagonist (5-6). Finally, Scott rejects the idea of calling his novel A Tale of the Times by asking "wouldst thou not, gentle reader, have demanded from me a dashing sketch of the fashionable world, a few anecdotes of private 
scandal thinly veiled, and if lusciously painted, so much the better?” (6-7).

An extended concern with fashion rounds out the Introductory chapter, with Scott connecting the attire of the characters appearing in novels to the genre, following lines similar to his discussion of subtitles:

Thus the coat-of-mail of our ancestors, and the triple-furred pelisse of our modern beaux, may, though for very different reasons, be equally fit for the array of a fictitious character; but who, meaning the costume of his hero to be impressive, would willingly attire him in the court dress of George the Second's reign, with its no collar, large sleeves, and low pocket-holes? The same may be urged, with equal truth, of the Gothic hall, which, with its darkened and tinted windows, its elevated and gloomy roof, and massive oaken table garnished with boar's-head and rosemary, pheasants and peacocks, cranes and cygnets, has an excellent effect in fictitious description. (8-9)

Scott tries on a variety of titles and subtitles, followed by dressing and undressing his hero. The underlying metaphor of this preface to the first novel of Sir Walter Scott is that of the author as a naked human, vulnerable before his readers. The nearly meaningless title, Waverly, is a fig leaf wavering in the wind. The subtitle Tis Sixty Years Since invokes a safe, comforting old blanket thrown over Scott to avoid any lewd suggestion of Gothic intent.

Also in this preface, Scott attempts to disavow his own novel. Although not to the totalizing extent practiced by Walpole when he invented a fictitious history of his text in the 1st edition of Otranto, Scott suggests that rather than the story being of his own 
invention, it is drawn "from the great book of Nature, the same through a thousand editions, whether of black-letter, or wire-wove and hot-pressed, that I have venturously essayed to read a chapter to the public" (11). The term book of Nature refers to a philosophical concept--originating with the Platonists but first formalized as a mode of religious inquiry by Church Father Origen in the 3rd century AD--in which the phenomena in the natural world can be interpreted symbolically as possessing moral implications for humans (Harrison 13). Thus, nature can be "read" as a book capable of imparting wisdom, in this case Scott suggests that the book of Nature contains a "chapter" on the resolution of Anglo-Scottish relations following the Jacobite uprising of 1745 .

The term wire-wove refers to the "wove" method of papermaking invented by James Whatman (1702-1759) in or near 1750. A weave of fine wire mesh provided for smoother pages than the traditional methods used in the West in previous centuries (Bidwell lxxiv). Whatman worked closely with printer John Baskerville (1706-1775), whose most lasting legacy may be the typeface he developed which still bears his name. Baskerville developed the "hot press" technique, in which heat and pressure are applied after the page is printed, to make his pages slicker and shinier than those of the competition (Meggs 122).

What are we to make of this introduction of specific book technologies into this metaphor of the book of Nature? All three technologies--typography, papermaking, and page-finishing--directly impact the aesthetic appeal of the printed page no matter what text is made manifest upon it. Scott is imagining a book of Nature (of which his novel is only a chapter) that utilizes an of older technology (blackletter typeface) with more 
recent but still dated technologies (wire-wove paper, hot press finished pages). In short, when Scott writes "book of Nature" he means a printed book, as opposed to a medieval manuscript or clay tablets or any other media. Furthermore, it is a printed book that looks aesthetically pleasing, taking advantage of technologies available in Scott's own youth. Just as the adventures of Edward Waverly reflect neither modern or medieval Scotland, but a past gone but sixty years, so is Scott's book of Nature assembled out of his own sense of nostalgia for books of bygone eras. ${ }^{13}$

Turning to "A Postscript, which should have been a Preface," we find a similar level of anxiety at the intersection of text, paratext, and reader. The title of the chapter does not state a sincere regret over its appearance at the end of the chapter due to some rush or error in production, as can be seen from the simple fact that this chapter with its unusual title remains at the end of all subsequent editions of Waverly. As such, the title exists to express Scott's ambiguous feelings over the placement of paratext in relation to the main text and, by extension, the role of paratext in mediating the relationship between reader and text and, ultimately, between the author and the Other Reader.

The choice of the word should here as modal auxiliary verb to express the subjunctive mood is interesting. The title is not "A Postscript, which could have been a

\footnotetext{
${ }^{13}$ Among these texts bygone texts are Macpherson's Fragments of Ancient Poetry, an eighteenth-century text purporting to be written by the spurious third-century bard Ossian. Scott's fondness for the works of Ossian served as an impetus for his own Scottish national project (Lockhart 436-7, Ruthven 105). For more on Macpherson, see chapter II.
} 
Preface," indicating a recognition of untapped potential. Nor is it "which would have been a Preface," suggesting the intervention of some circumstance preventing its appearance at the front of the book. Could and would are also modal auxiliary verbs for express the subjunctive mood, suggesting ability and intention respectively. Instead, Scott uses should, which indicates that the postscript ought to have been a preface, but it isn't (Gramley 139; van Gelderen 107-8). The earlier function of should as the past tense of shall suggests an obligation ("shall, v."). If the postscript was in some way obligated to be a preface, who is that obligation to and why was it broken? The answer to the first query can only be the Other Reader, the only other entity in Scott's field of vision as he writes the text. He offers an explanation why in the second paragraph of the chapter: This should have been a prefatory chapter, but for two reasons: First, that most novel readers, as my own conscience reminds me, are apt to be guilty of the sin of omission respecting that same matter of prefaces; Secondly, that it is a general custom with that class of students to begin with the last chapter of a work; so that, after all, these remarks, being introduced last in order, have still the best chance to be read in their proper place. (364-5)

In addition to the professed reasons of fearing that the bulk of novel readers skip clearly marked prefaces and that such readers often begin by reading the final chapter of the book, there is of course a third reason: Scott is trying to have his cake and eat it, too. He wants to write both preludial and postludial prefaces to serve as a buffer between himself and the Other Reader, guaranteeing himself both the first and the last word on the text. Furthermore, his fear of an unorthodox reader skipping to the end is so great 
that he designs his postface as if it were a preface. ${ }^{14}$

Scott goes on to make a confession of his reluctance surrounding making the novel available to the public:

I feel no confidence, however, in the manner in which I have executed my purpose. Indeed, so little was I satisfied with my production, that I laid it aside in an unfinished state, [and only found it again by mere accident among other waste papers in an old cabinet, the drawers of which I was rummaging in order to accommodate a friend with some fishing-tackle,] after it had been mislaid for several years. (369)

Genette identifies this sort of hesitation as a basic formulaic response found in a wide variety of original authorial prefaces (207-9). Note that the passage in brackets was added to the preface after the first printing. Given the fact that it appears as an added detail after the initial formula of the hesitant author, I read it as an apocryphal addition; this narrative detail of the "mislaid manuscript" looks too much like a contrivance in same vein as the found manuscript of the original preface of Walpole's Otranto.

The point of this rhetorical maneuver is to distance the writer-as-artist from the mechanisms of commercial book production and distribution. Professions of reluctance

\footnotetext{
${ }^{14}$ Also of note here is Scott's usage of the term "class of students" as a metaphor for novel readers. He is anxious that wayward schoolboys will skip the preface and go right to the last chapter to see how the novel turns out. Instead, Scott has a lecture waiting for them, like some cruel schoolmaster who shows up to class late and keeps his students after the bell to make up for it.
} 
to enter the world of publishing allows Scott to retain the posture of a man of immaterial genius immune to the material vicissitudes of the crude, commercial world of hot press, wire-woven paper, but both prefaces also carry with them an underlying current of a desire to distance the authorial self from the Other Reader.

This distancing effect comes under crisis in the preface to Scott's 1823 novel Quentin Durward. Appropriately, Quentin Durward was Scott's first novel set primarily outside of Britain, following the adventures of a fifteenth century Scottish archer in the service of King Louis XI of France. In the original preface, which is often omitted in later editions, ${ }^{15}$ Scott relates his own trip abroad during which he makes the acquaintance of a French nobleman whose household has nearly been ruined by the events of the Napoleonic wars.

According to the narrative that unfolds in the preface, Scott faces his own sort of ruination. Having suffered a downturn in his personal finances, he travels incognito through post-Napoleonic France in order to save money, mentioning that, if nothing else, he will save on the "cart-loads of coals" needed to heat his chilly Scottish manor house (iii-iv). While in France, he encounters the Marquis de Hautlieu, a nearly bankrupt French nobleman who invites Scott to dine at his nearby chateau (x-xv). Much of the work of laying out the meal falls upon the Marquis's ancient servant La Jeunesse:

"You will he entertained with my poor La Jeunesse," he said, $u$ who, by the way, is ten years older than I am-(the marquis is above sixty)-. he

\footnotetext{
${ }^{15}$ A random sampling of twenty of the over two hundred editions of Quentin Durward available via the Internet Archive showed 40\% of them lacking the original preface.
} 
reminds me of the player in the Roman Comique, who acted a whole play in his own proper person-he insists on being maitre d'hotel, maître de cuisine, valet-de-chambre, a whole suite of attendants in his own poor individuality. He sometimes reminds me of a character in the Bridle of Lammermore, which you must have read, as it is the work of one of your gens de lettres, qu'on appelle, je crois, le Chevalier Scott."

"I presume you mean Sir Walter ?"

"Yes-the same-the same," said the marquis; (xxi)

The narrator of this tale goes on to correct the Marquis. The Bride of Lammermoor--not Bridle--is part of Scott's Waverley subseries the Tales of My Landlord. Here Scott is confronted by his own worst fear: a reader so unruly that he can't even read the title of a novel without getting it wrong. The word choice is particularly apt: the Marquis has seized the reins of the text from the author. Note also the parallel here between the comical figure La Jeunesse, the servant who insists on playing multiple roles simultaneously, and Scott himself, who is directing all the various characters in the preface, i.e. he insists on playing numerous additional roles in a space typically imagined as that of the singular author directly addressing the reader. This is in addition to the parallel established in the overall narrative between the financially embarrassed Scott and the nearly ruined Marquis.

In the nine years and fifteen novels between Waverly and Quentin Durward, Scott's engagement with the Other Reader has changed, as can be seen by the differences in his prefaces. In his first novel, he applies a preface at either end of the text to insulate himself from the Other Reader, wearing the preface like chainmail armor as 
protection from unanticipated reactions to his tale of sixty years ago. By the time of Quentin Durward, Scott's relationship with the reading public had evolved, but the Other Reader still causes unease. Instead of erecting the preface as a barrier between the Other Reader and the text, Scott fictionalizes the Other Reader in the same way he fictionalizes himself. Both are drawn into a virtual world set apart from the main text, where Scott can meet the Other Reader as an equal, as a fellow aristocrat beset with hard times. Even though Scott feels less naked and vulnerable in the face of the Other Reader, he can only deal with the threat of the Other Reader's unruly readings by imagining him as a foreigner of equal dignity. But in this virtual space, Scott can confront the amorphous desires of the Other Reader and gain thereby, as within the virtual world of the preface it is the ancestral library of the Marquis de Hautlieu that provides the historical material from which the plot of Quentin Durward is derived (lxiilxiii). Thus, although still alien and unruly, Scott's vision of the Other Reader has matured to the point where the Other Reader is recognized as an equal partner in the endeavor of literature.

\section{Conclusion}

On the surface, Walpole, and Scott each deploy their prefaces to seemingly different ends. Walpole uses his original and later prefaces to first protect himself from public scrutiny, then to take credit for the success of his gothic experiment. Scott's prefaces in Waverly holds the public at a distance while simultaneously documenting how vulnerable he feels in the face of his readers. In the preface to Quentin Durward, Scott continues to document that vulnerability, but negotiates a new relationship with an imaginary stand-in for his readers. 
Genette argues that the primary function of the preface is educative, to "ensure that the text is read properly" (197). Genette's investigation of the preface doesn't ask why some authors take great pains to provide this form of paratextual education, while others do not. The economic and sociological feedback loop of faster, cheaper book production and a growing reading public, each responding to the other, combined with the growing recognition of the remediated nature of reality reaching maturation in the Romantic period provides a fertile ground for the proliferation of the Other Reader as a phantom haunting the author. In the prefaces of Walpole, Scott, and others we see the author's attempt to exorcise this haunting, to hold it at bay from the text. In subsequent chapters I examine how the authorial response to this haunting takes up residence within the text itself. 
CHAPTER II: NUMBERED FEET AND OVERBURDENED SHOULDERS:

AUTHORSHIP VIA SELF-ANNOTATION IN SAMUEL TAYLOR

COLERIDGE AND JAMES MACPHERSON

$[\mathrm{H}]$ uman life is but a series of footnotes to a vast obscure unfinished masterpiece. --Vladimir Nabokov, Pale Fire

In this chapter I argue that paratext can be employed for literary effect, to intervene in the text as if from an outsider position. I begin with an overview of the inescapable problem the paratext poses to any reader, that of pre-empting an unbiased reading the text it accompanies. Following that, I identify a subset of paratexts, the parallel paratexts, and describe their unique properties regarding the management of readers. Then follows the history of the literary footnote, a form of parallel paratext that emerges in the age of print. As will be demonstrated, use of parallel paratext as a literary device originates at the end of the seventeenth century. But the form achieves new vigor at end of the eighteenth and beginning of the nineteenth century, with the development of a bivocal approach to annotation, wherein the parallel paratext is written in a separate authorial voice.

To this end, I examine the function of parallel paratexts in the work of eighteenth-century literary hoaxer James Macpherson and Samuel Taylor Coleridge's The Rime of the Ancient Mariner. My primary concerns here are the effect of the location of annotation relative to the main text and the effect achieved by simulated intrusion from a later author. Macpherson employs the footnote and Coleridge the shoulder note to offer commentary on their own primary texts, both taking advantage of the authorial distance afforded by the paratext. 


\section{The Problem with Paratext}

A wide variety of paratexts either precede or follow the main text. I pull a book from a nearby shelf--in this case Danielle Steel's novel 1992 novel Mixed Blessings--and set it down upon the table. I immediately encounter not the text, but rather a series of paratexts. We begin with the cover design, upon which the author's name displayed prominently, occupying the top third of the field. Or rather it is the truncated, more marketable version of her legal name Danielle Fernandes Dominique Schuelein-Steel (Kort 311). The large, stylish gold letters on ivory (perhaps once snowy white) background suggests a certain opulence. The abstract gold and silver oval in the center of the page suggests a large wave about to crash, somehow invoking both Hokusai's The Great Wave off Kanagawa and the logo on a bottle of Ocean Spray cranberry juice. I open the book and find the first half of the book jacket blurb on the left and the bookplate of the public library in which I sit. Before I can reach the start of the novel's narrative (labeled as page 1), I must encounter--either reading or at least flipping past-the half title page, showing just the title Mixed Blessings in the same decorative font used on the cover, followed by a unassuming advertisement in the form of a list of 29 other titles labeled “Also by Danielle Steel.” Next comes the title page proper, followed by the standard publication information. Then we arrive at a ten-line dedication that is signed, following a practice originating in Germany in the eighteenth century, with the simple lower-case initials "d.s." (Luckombe 390-1). After that comes "beloved miracle," a free verse poem of 52 lines. It snakes down two and half pages with many unnecessary indentations, consisting of lines of mostly two words and never more than five. To my eye it looks like how someone would describe what a poem looks like from across a 
room. Them the title appears one more time, still in the stylish font of the original cover. Finally, I reach chapter one.

Flipping to the back of the book, there's no afterword or epilogue. The only things resembling back matter are the rest of the book jacket blurb and the pocket containing the card for borrowing the book. The stamps on the card and the slip pasted onto the pocket document continuous borrowing of this copy from December 1992 to October 1995. The local popularity of Mixed Blessings trails off after that, but as recently as September 2013 someone has borrowed this book. The back cover features the UPC symbol and a large headshot of Ms. Steel, looking wistfully into the camera. She's wearing a crisp white blouse with the collar popped and quite possibly the largest diamond earrings I have ever seen. Her hair is short, pulled back taut and her make-up is, of course, perfect. The photo has a slight haziness to it, suggesting the use of a filter like those reserved in Hollywood for leading ladies who have the temerity to begin to show signs of aging. The overall effect is that of a beautiful woman in her forties presented by some agent of the publisher as if she were still in her thirties in order to enhance her marketability.

The comparatively meager paratexts orbiting the main text of Mixed Blessings reveal little about the plot of the novel (save for the cover blurb, which I eyed rather than read), but nonetheless I have been primed with certain ideas about what to expect starting one page 1 . The huge amount of front cover space devoted to her name, plus the diamond-studded glamor shot on the back suggests a celebrity-author of the bestseller variety, especially when combined with the list of twenty-nine prior works. As an economic force, she's in the league of a Stephen King or a John Grisham. The other 
vector is the poem. Earnest but of a quality that any undergraduate with a composition notebook and a Bic could produce, I can't help but detect of hint of desperation, an urgent desire to be taken seriously as a wordsmith. My conclusion is that Danielle Steel writes novels of light entertainment that are long on thrills and short on literary merit.

\section{The Parallel Paratext}

All the paratexts mentioned above--cover, title page, dedication, advertisement, etc.-- are what might be called convergent paratexts. They gesture toward an imminent but not yet present main text. The reader flipping a few pages or turning even a single page can find themselves leaving the paratext behind and entering the main text. The maxim "You can't judge a book by its cover" warns us against the inherently prejudicial nature of convergent paratexts. ${ }^{16}$ After all, publishers decorate the covers of their wares precisely because they want us to judge it favorably enough to warrant a purchase.

The parallel paratext differs from the convergent in the former's immediate copresence with the text. In the case of the parallel paratext and the main text, both are juxtaposed at the individual page level. In Paratexts, Genette focuses primarily on convergent paratexts, with parallel paratexts discussed in just under fifty pages of his

\footnotetext{
${ }^{16}$ The earliest known form of this adage comes from clergyman Edward Corbet's 1642 sermon in which he argues "If the liquor be cordiall, what matter if the vessell be earthen? If the Tabernacle be all gold within, what though the covering be of badgers skin? A Scholler will not judge a book by the bulke and out-side, but by the contents. A Souldier will not chuse a sword by the luster of the hilt, but by the goodnesse of the blade" (22-23).
} 
$400+$ page treatise. His first example of a parallel paratext is the intertitle, or internal title, of which the chapter title is the most common example (294). Of course, a chapter title is but a momentary intervention in the flow of the text, relating to the chapter that follows in the same way that the title page relates to the book as a whole.

A more intrusive version of both paratexts is the running header, which constantly reminds you of the chapter and/or book title (316-7). The singular intervention of the title becomes a constant drumbeat, a running commentary reminding the reader that each part of the main text needs to be read in light of the title, the signifier for the whole work. Running headers that display subsection titles, such as chapter titles, provide the same reminder at a smaller scale while also aiding in navigation in the text.

Just as a running header typically sits in the margin of the page, other entities can poach that white space forbidden to the main text. Genette lumps the bulk of these invaders under the simple rubric notes, which he then analyzes using the same taxonomy he applies to prefaces, as discussed in chapter I (322). Under this general heading of notes, four key categories, based upon method and location, can be distinguished along an axis perpendicular to Genette's scheme. Based upon medium of presentation and location on the page, notes can be categorized broadly as glosses, marginalia, footnotes, and endnotes.

As defined here, glosses are handwritten notes found in any margin. Marginalia are printed notes typically appearing in the vertical spaces of the page, usually the outer margin. Marginalia is often thematically connected to some portion of the main text located horizontally on the same page (320). Footnotes are printed notes found at the 
bottom of the page, which often use an indexing symbols, referred to as an indicator in British publishing terminology or a callout in American printing houses (321 n. 6). ${ }^{17} \mathrm{An}$ early form of the indicator is the bracketed or parenthetical letter (e.g. (a), [J]), while a later convention called for the use of an asterisk $\left(^{*}\right)$ for the first footnote on a page, followed by an obelisk, or dagger $(\dagger)$, then a double dagger $(\ddagger)$, a section sign (§), a parallel (||), and finally, a pilcrow, or paragraph symbol (ף) (Zerby 19; Burkle-Young and Maley 9-10). Endnotes use indicators/callouts to direct the reader to notes at the end of the text or a subunit of it, as in the case of chapter endnotes. ${ }^{18}$

${ }^{17}$ In manuscript studies, the equivalent term is signe-de-renvoi ("sign of return") (Neudorf and Liu). In online discourse the hyperlink and hashtag provide similar functionality.

${ }^{18}$ The distinction I draw here is for the purpose of intelligibility. Additional equivalent terms used prior to the 20th century include "scholia" and "postilla" (Sherman 20). (The term footnote is itself relatively recent, not extant in the record until 1841 (BurkleYoung and Maley 9 n. 6).) The normal scholarly practice of using the term marginalia to refer to both written and printed comments in the margins elides over their radically different methods of production. Also note that some glosses and marginalia make use of indicators/callouts, though owing to their ability to align horizontally with the relevant portion of the main text, such devices are only needed in cases where the amount of paratext begins to overwhelm the margins. Nor does this chapter investigate the use of non-textual graphical elements in parallel paratexts, such as the pointing hand, or manicule ( $\varpi^{\prime}$. For a treatment of the importance of the handwritten manicule 
The shift from the medieval practice of utilizing handwritten glosses in any/all spaces on the page to printed marginalia to the footnote and then to the endnote follows the contours of changes in the method of book production. Just as the historical move from oral literacy to writing to print to digital media as the dominant form of communications technology still leaves open vast spaces for the preceding modes, so do the earlier forms of parallel paratext remain operant in later ages. The overall action is one of an opening up of new modes of discourse, not the supplanting of one technology by another. To give just two examples, the written gloss remains in use from the age of print through to today (much to the dismay of librarians everywhere) and printed marginalia remain in use, such as the summaries and tips that often appear in modern textbooks, offset from the main text. ${ }^{19}$

During the era of the medieval codex, the annotator used the same technology as the original inscriber of the main text in order to gloss it, handwriting. Indeed, one option available to the preprint copyist denied to most readers of later ages was the ability to invisibly incorporate their comments directly into the text, if they so desired. In this manner a work could grow agglutinatively, swelling like a textual Knossos or

in early modern texts, see William H. Sherman's Used Books: Marking Readers in Renaissance England. For the printed manicule, see William W. E. Slights, Managing Readers: Printed Marginalia in Early Renaissance Books. ${ }^{19}$ Modern print Bibles employ a variety of schema for cross-referencing and commentary. A perfectly ordinary edition sitting on my shelf employs a layout nearly identical to the 16th century Geneva Bible. 
Winchester House. This agglutinative practice demonstrates the complication of normal authorial attribution as multiple voices speak on the same page.

An example of this agglutinative practice is the Sphaera Mundi of Johannes de Sacrobosco ${ }^{20}$, the second most popular book (after the Bible) in the first two centuries of print (Eisenstein 510). A brief introduction to the field of astronomy from the thirteenth century, many pre-Gutenberg copies of the Sphaera Mundi include copious commentary by later hands in the form of appendices and marginal glosses (Thorndike 21-41). Although Sacrobosco cites Ptolemy's Almagest as his major source, as well as ninth century Arab scholar Alfraganus (Ahmad ibn Muhammad ibn Kathir al-Farghani), what is not necessarily obvious to readers of the Sphaera is the extent to which the main body of the Sphaera incorporates earlier commentaries on the Almagest. Historian Lynn Thorndike identifies the presence of notes to the Almagest from at least three sources, the Roman scholar Macrobius writing in the fifth century, tenth century monastic mathematician Helpericus of Auxerre, and Sacrobosco's near-contemporary, the scholastic William of Conches (Thorndike 19; Borst 48; Kedwards 125). The incorporation of these comments into the main body of the text is unmarked (that is,

${ }^{20}$ The author's name is sometimes given as Ioannis de Sacro Bosco, simply Sacrobosco, as well as variants including John of Halifax and John of Holywood, those his associations with those English locations has been disputed (Thorndike 2). His text is sometimes referred to as the De sphaera mundi, Tractatus de sphaera, Textus de sphaera, De sphaera, or just Sphaera. Prior to the regulating influence afforded by the easy reproducibility of print, names of authors and works easily mutate and proliferate. 
uncited); no signal is given that they belong to anyone but Sacrobosco or his two named sources, Ptolemy and Alfraganus.

If Sacrobosco wrote his text in the modern era, his failure to cite his three sources could lead us to indict him for the vile crime of plagiarism, that bane of honest academic discourse. However, Sacrobosco operated within a medieval framework of authorship that differed from later models of authorship. St. Bonaventure's fourfold model of authorship is often cited by medievalists in this regard:

One person writes material composed by other people, adding and changing nothing; and this person is said to be merely the scribe [scriptor]. Another one writes material composed by others, joining them together but adding nothing of his own; and this person is said to be the compiler [compilator]. Another writes both materials composed by others and his own, but the materials composed by others are the most important materials, while his own are added for the purpose of clarifying them; and this person is said to be the commentator [commentator], not the author. Another one who writes both his own materials and those composed by others, but his own are the most important materials and the materials of others are included in order to confirm his own; and this person must be called the author [auctor]. (Wogan-Browne et al. 3)

Note that Bonaventure's scheme lacks an author who writes in a mode of complete originality. The implication here is that an author's work is never in isolation, but always comes into existence in relation to a preexisting corpus. The work may be imagined as a new node in a network formation; a key function of the author is to connect their work 
with pre-existing nodes--that is, with the work of earlier authors (Bartal 149, Galloway and Thacker 13). In order to better illuminate the networking function of the footnote and its relationship to the author's anxiety of the Other Reader, I will now briefly outline the historical development of the footnote.

\section{The Genealogy of the Literary Footnote}

Poet and journalist Chuck Zerby traces the inauguration of the footnote in English literature to a technical issue in the production of The holie Bible conteynyng the olde Testament and the newe, known also as the Bishops' Bible (19-21). First published in 1568, this English translation of Scripture served as the Church of England's response to the publication of the Geneva Bible by English Puritans (Pattison 79-81). As with the earlier Calvinist translation, the margins of the pages of the Bishops' Bible are festooned with copious notes. Many of these marginal notes take the form of cross-references to other verses, while others clarify or interpret difficult passages.

The technical issue arises from the layout for the first page of the book of Job (see figure 1). As with each page introducing a new book, below the running header is the title "The booke of Iob." preceded by a fleuron, or aldus leaf (s૯). Below the title is an italic label, "The firft Chapter.", followed by a three-line argument with each of the four sentences of the argument marked with indicator/callout for the relevant verse in the main text. This is followed by an illustration of a stricken Job conversing with his friends, which occupies approximately one third of the real estate of the page area within the margins.

Additional page space is occupied by the large initial "I" that begins the first verse. It occupies a space vertically equivalent to seven lines of text and half of one 
column horizontally. ${ }^{21}$ Not including the large initial that begins the main text of the chapter, the first eleven verses of the Book of Job are crammed into a space equivalent to only slightly more than $30 \%$ of the entire page. ${ }^{22}$

However, despite only eleven verses appearing in a small subsection of the page, no less than fourteen marginal notes refer to this same text. This creates a page design/layout conundrum. Twelve of the fourteen notes for Job 1:1-11 are in the right and left margins, with only note (a) and part of note (b) pushing up into the margin adjacent to the illustration of Job and his interlocutors. Almost by default, perhaps even in an act of desperation, notes (f) and (g) are squeezed into the bottom of the page, laid out as an independent block separate from the notes in the right and left margin. This block, Zerby argues, is the inauguration of the footnote, the typographical equivalent of the fossil that captures the exact moment when primitive primates evolved into modern humanity (18-21).

${ }^{21}$ The main text of the Bishops' Bible is laid out in a 2-column format.

${ }^{22}$ This percentage was obtained by using a screengrab tool to capture an image of the relevant from Princeton Theological Seminary's copy of the first edition of the Bishops' Bible, a scan of which is available via archive.org. 


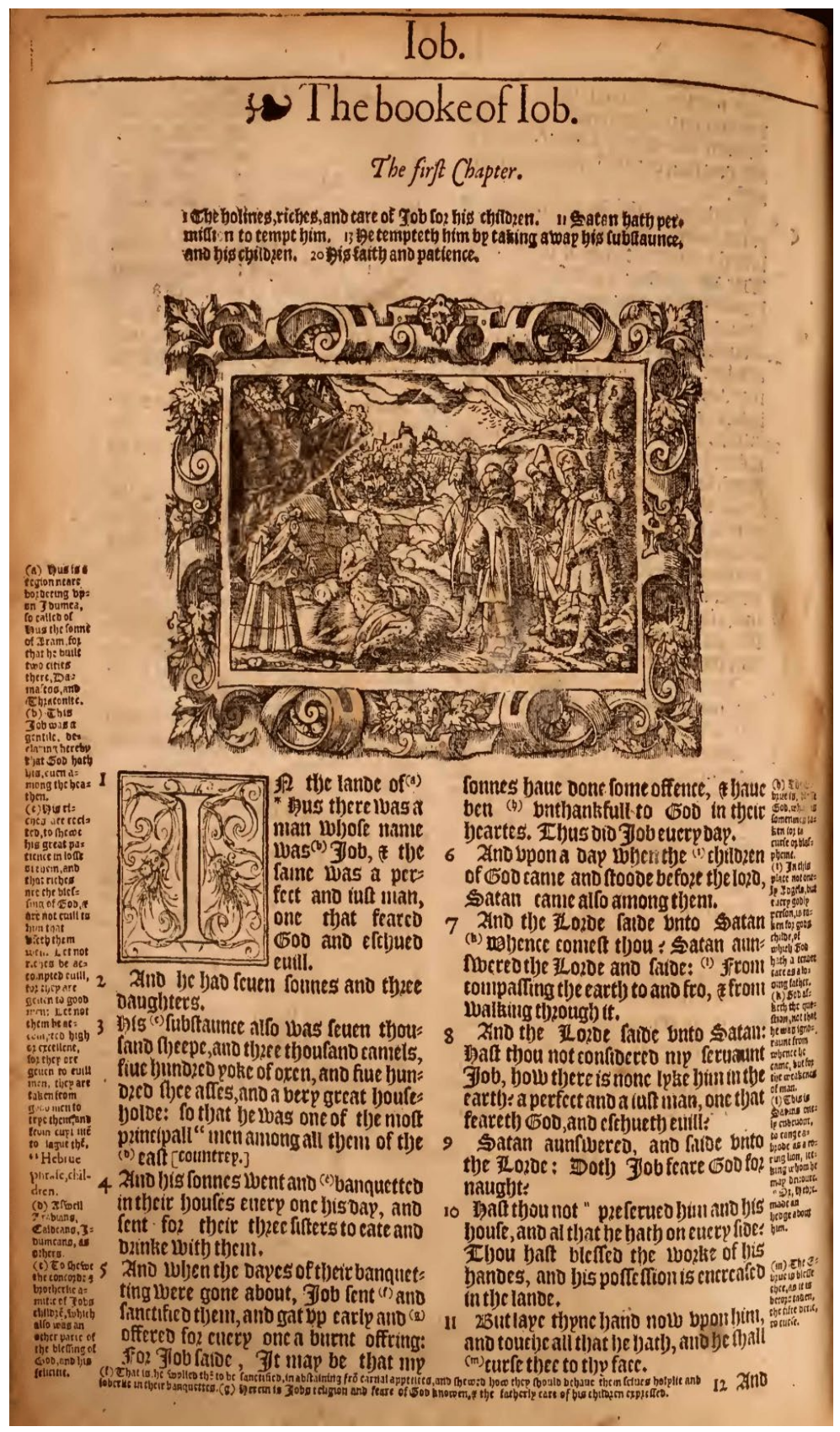

Figure 1. Job 1.1-11. The holie Bible conteynyng the olde Testament and the newe, $15^{6} 8^{23}$

${ }^{23}$ Public domain image from Theological Commons, Princeton Theological Seminary, http://commons.ptsem.edu/id/holiebibleconteyoolond. 
This transition is not instantaneous, however. As late as 1684, printer and lexicographer Joseph Moxon, in his influential treatise Mechanick Exercises; Or The Doctrine of Handy-works Applied to the Art of Printing, treats footnotes as a minor subset of marginal notes (236; Burkle-Young and Maley 7). The short shrift given by Moxon to footnotes reflects the fact that marginal notes pose a greater technical challenge to the compositor, the member of the printer's staff responsible for selecting and aligning the letters of each individual line of type. Since type is laid out by the line, i.e. horizontally, the aligning type in the foot of the page does not require special equipment or techniques, as there is no main text to account for on the same line (32-4).

1684 is also the year of the first documented use of footnotes for literary purposes, according to Zerby. He points to Aphra Behn as the innovator in the use of footnotes by an author to create a bi-vocal textual performance (50-2). Her collection Poems upon Several Occasions with A Voyage to the Island of Love includes the poem "A Letter to a Brother of the Pen in Tribulation," a short poem consisting of 48 lines of rhymed couplets laid out over the bottom of page 80 and all of pages 81 and 82 . The text playfully mocks a fellow writer--identified only as "Damon"--for claiming to retire from society for a time in order to focus on his writings, when he actually was seeking treatment for a venereal disease contracted from a sex worker (Gardiner 291-2). The printed footnotes provide a context that would have been available to Behn's literary circle but not to a general audience. More than that, though, these footnotes are themselves part of the text and not mere appurtenances to it. Every detail revealed by Behn in the footnotes, Zerby argues, could have been included in the body of the poem. And if Behn wanted certain details to remain private, she would not have revealed them 
in the footnotes. By explicating her own work to reveal the sordid details of "Damon's" sexual adventure, she turns the main text into a set up for a punchline revealed in the footnotes (52).

This fruitful tension set up by a single author placing text and paratext in conversation with each other reaches a crescendo in Pierre Bayle's five-volume Dictionnaire Historique et Critique, the first two volumes appearing in 1696. The Dictionnaire was the smash hit of eighteenth-century philosophy, appearing in the catalogs of more libraries of the period than the works of John Locke, Isaac Newton, Jean-Jacques Rousseau, Voltaire, or even Plato (Lennon 7; Jerome 42). Bayle’s original plan was to produce a monograph on the history of errors, focusing on the mistakes made in reference books (Grafton 192-3). Prevailed upon by friends that such a project was not a feasible commercial product, Bayle instead wrote a history of human thought in which the errors of previous authorities were thoroughly documented in copious annotations (Zerby 63-4). Bayle scholar Thomas Lennon describes the resulting "cluttered mess" of interconnected textual objects as the first hypertext (7). ${ }^{24}$ As scholar of the development of Western Culture Joseph Jerome puts it, "On paper, the Dictionary is a cluttered mess of columns of different sizes and fonts, reading the work is a sure way to acquire a headache, but the way in which articles and their footnotes link up together to create an entire work of philosophic thought... is remarkable" (47).

${ }^{24}$ I am partial to Robert Burton's Anatomy of Melancholy, which precedes Bayle's dictionary by three quarters of a century, as an earlier example of book-as-hypertext, but cf. medieval Rabbinic commentary for even earlier examples. 
Bayle's Dictionnaire is literally more paratext than text. Opening one of the original volumes at random, in this case part 2 of volume 2, we find the beginning of Bayle's essay on Sappho on page 1006. But only 2 lines on the supreme Greek poetess, not even two whole sentences, appear on this page. Most of the page is dedicated to middle portion of footnote (C) for the previous entry on Thomas Sanchez, whose own entry occupies 14 lines of the Dictionnaire (1004-5). The three footnotes to Sanchez's entry occupy the bulk of pages 1004, 1005, 1006, and 1007, amounting to 418 lines. Although not every entry in the Dictionnaire exhibits so stark a ration of main text to annotations as 14 lines to 418 , flipping through any volume leaves the peruser with the distinct impression of a vast subterranean structure supporting a relatively meager superstructure.

The footnotes are themselves sometimes annotated. Zerby reports that these marginal notes also sometimes lead the reader into loops, a marginal note can direct the reader to some other footnote, or even another primary entry in the dictionary (73). Text and paratext become imbricated in a labyrinthine world where the author subverts the main texts via an excess of annotation in order to fulfill his original intention while still producing a commercially viable commodity for the book industry.

Bayle's methods became the dominant model for eighteenth century scholarship (Grafton 197). Bayle's approach to the use of footnotes and marginalia (which is best viewed as a culmination and magnification of prior practices, rather than an innovation) becomes the standard by which such practices are measured for more than a century. The humorous notes of Swift's A Tale of the Tub and Pope's Dunciad lampoon the pedants writing in Bayles' style, but lacking the latter's deftness and wit. The apotheosis 
of this response is Gottlieb Wilhelm Rabener's 1743 satire Hinkmars von Repkow Noten ohne Text (Hinkmar von Repkow's Notes without Text), which purports to be the scholarly annotations to a work that has not been written. Fictive author von Repkow argues in the preface that since scholarly rigor is nowadays solely measured by number and length of annotations, surely the existence of the main text is irrelevant (Dworkin 66). Grafton translates a key passage of Repkow's (i.e. Rabener's) argument:

People, of whom one would swear, that Nature had made them fit for any calling other than that of scholar; people who, without thinking themselves, explicate the thoughts of the ancients and other famous men; such people make themselves great and fearful, and with what? With notes. (120)

Richard Bentley's 1732 edition of Paradise Lost marks a high (or perhaps, low) point of the trifling schoolboy exactitude targeted by Swift, Pope ${ }^{25}$, and Rabener; his footnotes often directly contradict the well-attested final version produced by Milton in a hamhanded attempt to recast the iconoclastic puritan poet as a totally orthodox Enlightenment-era Man of Reason. In effect, Bentley deploys the footnotes as a weapon

${ }^{25}$ Bentley is one of Pope's targets; in the fourth book of the final version of the Dunciad (1743), Bentley appears as the "mighty scholiast, whose unwearied pains/Made Horace dull, and humbled Milton's strains." (IV:211-2). Zerby notes that the ratio of lines of verse to lines of footnotes in the first edition of the Dunciad Variorum comes out to nearly 1:20, arguing that one of the targets of Pope's poetic scorn is the practice of scholarly footnotes itself, rather than simply abusers of the practice $(50,57)$. 
in his attempt to colonize the verse of the blind bard of Bread Street and remake the poet in his own image.

The most infamous of his proposed rewrites comes at the end of Milton's work. In response to the final lines "Then hand in hand with wand'ring fteps and flow,/Through Eden took their folitary way.", Bentley's editorial asterisk leads to his proposed emendation "THEN hand in hand with SOCIAL steps their way/Through Eden took, WITH HEAVENLY COMFORT CHEER'D.” (399). Unwilling to let Milton's masterpiece end on a thoughtful, melancholy note, Bentley anticipates the modern studio executive who re-cuts a somber film to ensure a happy ending.

Apart from the pedants and their parodists, Bayle's most successful disciple in the English-speaking world is Edward Gibbon, author of the six-volume The History of the Decline and Fall of the Roman Empire. Published incrementally from 1776 to 1789, Gibbon's Decline and Fall was a successful business venture for publishers for three quarters of a century. The first volume went through three editions prior to the appearance of the second and third volumes in 1781 . William St. Clair, in The Reading Nation in the Romantic Period, documents print runs totaling at least 43,500 copies by 1853 (589-9).

Gibbon's usage of footnotes cements "a reputation for both impudence and erudition," the latter for his copious citations, the former for his commentary (Grafton 226). Like Bayle, Gibbon regularly changes register when shifting from main text to footnote and back. In the main text he chillingly describes the bloodbaths of emperors while making seemingly unrelated quips in the footnotes, or generously cities prior historians in one place while in a footnote turning a withering gaze of utter contempt 
upon the follies of those selfsame predecessors (Zerby 81-3, Grafton 182). Anglo-French historian Hilaire Belloc independently arrives at the same conclusion as Grafton, that Gibbon's use of the footnote in the Decline and Fall was a turning point for the device, rhetorically, noting that Gibbon would often use the footnotes to create two competing narratives in his history (43-4). In Belloc's analysis, the main text contains an official version that would be most politically acceptable and least susceptible to censure or censor. The footnotes, meanwhile, often directly contradict the assertions of the main text. Bayle and Gibbon demonstrated to wide audiences a range of possibilities inherent in that particular form of annotation.

Zerby ultimately claims that the use of annotation as a specifically poetic technique was murdered in the cradle by Pope's self-parody of the form, that no poet dare employ such devices following Pope's virtuoso skewering of the footnote and its adherents (57). However, examples of poetic annotation can be found in James Macpherson's collection Fragments of Ancient Poetry, collected in the Highlands of Scotland, and translated from the Gaelic or Erse language and Samuel Taylor Coleridge's poem The Rime of the Ancient Mariner. Although each of these appearances of the poetic annotation differs in specific manifestation, they each demonstrate the poet's engagement with the Other Reader.

\section{The Macpherson Mystery}

James Macpherson's literary achievements are overlooked today, his work relegated to the dustbin of history as a literary hoax. Yet his Fragments of Ancient Poetry enter the world at a specific moment in history, where they serve as a linkage between the empiricism of the Augustan age and the Romantic urge to reimagine the 
past. Politically, Macpherson provides a vision of a heroic Celtic past the equal to Homer or the Icelandic sagas at a time when the Scottish cultural engines are gaining steam in Edinburgh (Sher 151).

The year 1760 heralded a new age for epic poetry, for in Scotland the works of an ancient highland Homer had been unearthed. The name of this lost poet was Ossian, and the first smatterings of his genius were published by their discoverer and translator James Macpherson as Fragments of Ancient Poetry Collected in the Highlands of Scotland, and translated from the Galic or Erse language (deGategno 1). The preface in Fragments of Ancient Poetry, written by but not attributed to Edinburgh University professor of rhetoric and belles letters Hugh Blair (Ruthven 7), makes a claim of authenticity in its opening line. It asserts that "[t]he public may depend on the following fragments as genuine remains of ancient Scottish poetry", explaining that the following prose translates into English certain ancient manuscripts "which the translator has seen". According to this preface, the provenance of these manuscripts was an unnamed monk transcribing songs sung by a third century bard, Ossian (Fragments iii-iv, Thomson 2).

Fragments of Ancient Poetry was an instant success. The original Edinburghpublished edition of the Fragments sold out quickly enough that a second edition appeared before the year was over. The popularity of the work spread far enough to necessitate an additional edition out of Dublin in that same year. In England the Fragments were excerpted in popular magazines, rewritten from the translator's prose into English verse, imitated and parodied (Saunders 82-3). Within a few years translations of the English version appeared in Bohemian, Danish, Dutch, French, German, Greek, Hungarian, Italian, Polish, Russian, Spanish and Swedish (Smart 11, 
Ruthven 13). Follow up works appeared, including two full-length Ossian epics unearthed and translated by Macpherson, the six-book Fingal of Ossian, published in 1762, and the following year's Temora, an Ancient Epic Poem, in Eight Books. A two-volume Works of Ossian, collecting translations of all known Ossian poems soon appeared.

Over forty English editions of Macpherson's translations appeared before the turn of the nineteenth century. The fragment Oithóna, a tale of star-crossed lovers, was adapted for operatic performance by the Royal Theater in 1768 (deGategno 74-5). Early famous admirers of Macpherson's translation included David Hume, Thomas Gray, William Blake, William Hazlitt and Napoleon (deGategno 27, Gaskill 140, Saunders 22). Napoleon preferred Ossian to Homer (Heyward 281), while Hazlitt considered the blind ancient his equal, alongside Dante and the Bible (Smart 18). Walt Whitman later compares Ossian favorably to the Bible as well (Ruthven 11).

Public challenges to the authenticity of Macpherson's discoveries began in 1762, with the publication of Ferdinando Warner's Remarks on the history of Fingal, and other poems of Ossian: translated by Mr. Macpherson, a pamphlet challenging the chronology of historical events described by Ossian (Smart 131). Warner's primary argument concerned the Scandinavian invasion of Ireland that served as the backdrop of many of Fragments, which pre-dated by centuries all such invasions mentioned in available historical records (Warner 5, Smart 132). These Remarks were followed by an article in the French Journal des Sçavans written by a "M. de C." that noted inexplicable correlations between passages in the fragment "Carthon" and Satan's address to the sun in book 4 of Paradise Lost (Smart 133, deGategno 60). Adding to the objections of Warner and M. de C., Irish scholar Charles O'Connor devoted an appendix in his Dissertations on 
the History of Ireland listing several geographical errors in Ossian's works, such as locating well-known cities in counties far from their actual location (Smart 134).

Just a few years after the initial publication of Fragments of Ancient Poetry public opinion was split between a minority view that dismissed Ossian as a hoax and a wider audience that continued to enjoy the works regardless of any public questioning of its authenticity (Ruthven 13). As these questions increased Macpherson vacillated from indignant silence to occasional offers to prove of his claims to public attacks on Irish historians questioning his chronology (Saunders 191). Reversing his earlier belief in the authenticity of the Fragments, David Hume personally interviewed Macpherson about the matter. Macpherson flew into a rage and then left Britain to serve as the secretary to the Governor of Florida for two years (deGategno 101-2). After Macpherson's death in 1796 the Highland Society of Scotland empaneled a committee to investigate the matter (Smart 163-4). They took seven years to compile their 155-page report, which was supported with 22 appendices containing 200 pages of supporting evidence. While the committee refused to openly declare Macpherson a fraud, they noted that they were unable to identify a single verified text that matched in title or content the works of Ossian (deGategno 110-1).

Examined outside the context of the crisis of authenticity precipitated by the claims in its preface, the Fragments consist of a series of fifteen prose poems, averaging 485 words in length. Fragment XIII--in which the hero Cuchulaid hears his ally Moran's report on the coming of giant warrior Garve--is the shortest at 300 words, while the 
longest; Fragment VII--in which Oscian ${ }^{26}$ relates the circumstances leading to the death of his son Oscur--measures 746 words in total $(59-61,31-6) .{ }^{27}$

Nine of the Fragments (II, III, V, and VI through XI) are monologues relating a single tragic incident in the ongoing doomed romances and internecine wars of ancient Celts. Five Fragments (I, IV, and XII through XIV) feature a dialogue between two characters. Three of these feature an exchange between star-crossed lovers: the lady Vinvela promising to honor the memory of her lover Shilric should he fall in the wars of Fingal, father of Oscian; the warrior Connal asking his lover Crimora to raise a tomb for him should he be slain the next day fighting the mighty Dargo and his invading army; Duchomar and Morna slay each other when the maiden Morna admits to her suitor Duchommar that her heart belongs to another, Cadmor, whom Duchammar has just slain in battle (9-12,19-22, 62-6). The other two dialogues consist of Moran's report to Cuchulaid described above and the aged bard Alpin reciting to the hero Ryno the tragedy of the mighty Morar, who fought bravely but was the last of his line (56-58).

${ }^{26}$ Although spelled Ossian in Macpherson's later works and the resulting scholarship, the original spelling of the character's name as it first appeared was $O \int c i a n$. ${ }^{27}$ These numbers are based upon the .txt file derived from the optical character recognition (ocr) scan of the National Library of Scotland's first edition copy of the Fragments, as found on the Internet Archive, archive.org. Owing to the imprecision of the ocr scan, the numbers given above are only approximations. The remainder of the analysis in this chapter is based upon the more accurate facsimile scan of the same volume also available in the Internet Archive. 
The fifteenth and final installment of the Fragments involves three speakers. The hero Lamderg seeks his beloved Gealchoffa at their appointed rendezvous but does not find her (67). Lambderg's ally Firchios suggests they consult the druid Allad, who reveals that Gealchoffa has been carried off by the warrior Ullin, who awaits to duel over her (689). Just as Lamderg rushes to confront Ullin, the Fragment, and the text as a whole, ends abruptly with an elongated hyphen (70). From Vinvela's initial declaration of love at the beginning of the first Fragment to Lamberg's hastening to fight Ullin at the end, three main themes emerge from Macpherson's work: the fragility of young love, the glories of battle, and the passing of greatness in the world, in the form of the death of heroes and their bloodlines.

As originally presented to the public, the Fragments were nearly an authorless text, a remnant from a preliterate orality. The myth offered in the preface, that "a Culdee or Monk is presented as desirous to take down in writing from the mouth of Oscian" no more explains the origins of the text than a mythical Homer accounting for the composition of the Iliad and the Odyssey (iv). Both are stories told after the fact, retroactively imposing a mode of authorship that was not extant at the time of composition.

However, I do not propose examining the Fragments under its original context-when a large portion of the reading public accepted the claims of its ancient heritage as fact--nor do I intend to analyze Macpherson's work within the regime of the literary hoax. The latter tends to devolve into a dialectic consisting of an opposition between "criminal" texts and the legitimate literature that is constituted by their exclusion. Or, as K. K. Ruthven expresses it in his treatment Faking Literature, "the relationship between literarity and spuriosity is framed as a binary opposition, in which literature is valorized 
as the authentic Self and literary forgery disparaged as its bogus Other" (3). ${ }^{28}$ Instead, I will approach Fragments of Ancient Poetry Collected in the Highlands of Scotland, and translated from the Galic or Erse language as an "event" occurring within the regime of probabilistic materiality, as defined by media scholar Johanna Drucker:

Probabilistic materiality conceives of a text as an event, rather than an entity. The event is

the entire system of reader, aesthetic object and interpretation - but in that set of relations, the 'text' is constituted anew each time.

Like weather produced in a system around a landmass, the shape of the Reading

${ }^{28}$ Ruthven's thesis is that literature itself is constituted by its own spuriosity. For more on the relationship between the literary hoax and the rise of literary criticism see also Anthony Grafton's Forgers and Critics: Creativity and Duplicity in Western Scholarship. Additional key works in this area include John Whitehead's This Solemn Mockery: The Art of Literary Forgery, Ian Haywood's The Making of History: A Study of the Literary Forgeries of James Macpherson and Thomas Chatterton in Relation to Eighteenth-Century Ideas of History and Fiction, Margaret Russett's Fictions and Fakes: Forging Romantic Authenticity, 176o-1845, Susan Stewart's Crimes of Writing: Problems in the Containment of Representation, the anthology Cultures of Forgery: Making Nations, Making Selves (edited by Judith Ryan and Alfred Thomas), and Jonathon Keats, Forged: Why Fakes Are the Great Art of Our Age. 
has a codependent relation to the structure from

Which

it arises. Probability is not free play. It

is constrained play, with outcomes calculable in accord with the complexity of the system and range of variable factors, and their combinatoric and transformative relations over

$$
\text { time. }(8)^{29}
$$

If we accept Drucker's premise that text is "an event... constituted anew each time" that a reader encounters writing, then to attend to that constitution, the event-ness of the text requires a certain mode of reading. The scientific analog of this mode is the Copernican principle. Proposed in the middle of the twentieth century by Anglo-Austrian cosmologist Hermann Bondi, the Copernican principle holds that there is no privileged vantage point for observation of the physical universe (Peacock 66). Just as Copernicus proposed in 1543 that the Earth was not the center of the system of planets, the Copernican principle de-centers the Solar System, the Milky Way galaxy, and all other points in the universe (Kuhn 1). Under Bondi's extension of Copernicus' great insight, there is no objectively better or worse place (that is, context) to observe and interpret the physical universe, just relatively better or worse vantage points for the observation of specific phenomena.

${ }^{29}$ I have attempted here to faithfully replicate the layout of the passage as it appears in the original. Drucker works as both a media scholar and a visual artist and makes her arguments for probabilistic materiality in part via the way the words are presented upon the page. 
Similarly, in an event-based reading of text, neither those who accepted Macpherson's initial claims, those who were skeptical from the first, or later analyses focusing on the controversy of the hoax are privileged positions. Each observational framework is valuable only to the extent that it yields useful and interesting results. Any other point in the readerly universe could produce just as rich a reading or an even richer one.

Note that this is not the same as asserting that all points yield equivalent results. Just as the center of the Sun is a bad location for studying the phases of the Moon, some reading approaches inevitably produce a better range of useable results. Drucker indicates that probabilistic materiality is "constrained play" not "free play." In short, a large (infinite?) number of readings become available when text is approached as event, but some readings are still clearly better than others. For Macpherson's Fragments, I read from the following position:

- I generally dismiss as irrelevant the truth value of the claims made in the preface as to origins of the Fragments. They are not translations of ancient Celtic verse, but English prose poems pretending to be such. The preface exists within the diegesis of the text, not without it. (Macpherson's prefaces come from an allographic, fictive sender, to use the schema outlined in chapter I (Genette 181).)

- Although I agree with skeptics such as the Highland Society committee, I refuse to participate in the binary discourse that enshrines Macpherson's work as a crime against legitimate literature, as mentioned above.

- Rather, I approach the hoax origins of the text as a component of its 90 
composition history that does not necessarily impinge upon the event of reading it today. I argue that we can be aware of hoax origins of the Fragments but remain aloof from that history in the moment of reader/writing interaction.

This dismissal of the common modes of reading Macpherson is a calculated move designed to bring new details to light, in much the same way that astronomical instruments are placed in orbit to afford views of the stars from beyond the Earth's atmosphere. From this new position, the view that emerges is one in which the Fragments appear as a tripartite assemblage, a single text consisting of the preface, the 15 prose poems, and the eight footnotes to the prose poems. These three components work together to establish the verisimilitude of a fictional world inhabited by Oscian et al. in much the same way that J. R. R. Tolkien's Lord of the Rings trilogy is supported by the map of Middle Earth typically included in the front matter of the text and his genealogical, linguistic, and historical appendices found after the main text of the narration has concluded.

The first footnote appears near the end of Fragment VII. Oscur, son of Oscian, finds himself caught in a love triangle with his best friend Dermid and the unnamed daughter of their mutual enemy Dargo. Both men love the daughter of Dargo, but she prefers Oscur. In anguish, Dermid invites his friend to slay him, an offer that Oscur rejects. Dermid laments, declaring:

Who then is worthy to slay me, O Oscur son of Oscian? Let not my life pass away unknown. Let none but Oscur slay me. Send me with honour to the grave, and let my death be renowned. (33) 
Rather than slay his friend outright, Oscur counters Dermid's proposal by offering to duel him instead. The two friends fight "by the brook of the mountain; by the streams of Branno" (34). Dermid loses the encounter and dies, sending Oscur into a deep grief. He tricks the daughter of Dargo, a renowned archer, into slaying him with her bow. The line "Her arrow flew and " ends with an asterisk, which serves as the indicator for a footnote immediately below the line:

* Nothing was held by the ancient Highlanders more essential to their glory, than to die by the hand of some person worthy or renowned. This was the occasion of Oscur's contriving to be slain by his mistress, now that he was weary of life. In those early times suicide was utterly unknown among that people, and no traces are found of it in the old poetry. Whence the translator suspects the account that follows of the daughter of Dargo killing herself, to be the interpolation of some later Bard. (35)

This footnote makes four specific moves. First, it explains the motivation of first Dermid and then Oscur to die at the hands of someone famous. However, the explanations offered before and after the footnote make that clarification unnecessary. In addition to Dermid's lines above insisting on the propriety of Oscur killing him, Oscur echoes the same sentiment when speaking to the daughter of Dargo. His breast already pierced by her arrow, Oscur ask rhetorically, "[W]ho but the daughter of Dargo was worthy to slay me?” (36).

Second, the footnote anticipates the action of the next page, spoiling the death of the daughter of Dargo. This move places the reader in a position where they are receiving new narrative information from the footnote first. Reader confidence in this paratext aids 
in creating an environment where the claims of authenticity made in the preface are subtly bolstered.

Third, it introduces an internal contradiction into the overall work--the tripartite assemblage of preface/fragments/footnotes--by claiming that "the old poetry" contains no evidence of suicide in ancient Scotland, yet later in this Fragment the distraught daughter of Dargo stabs herself and dies (36). If, as claimed, Oscian is the ancient Homer of the Highlands, then the daughter of Dargo's suicide must be accepted as strong evidence of the practice of self-murder among the ancient Celts of the region; the footnote casts doubts on the veracity of the main text. However, this contradiction can also be read as serving the cause of the hoax, an argument I will take up in the explication of the second Fragments footnote, below.

Finally, by calling attention to the writer of the footnote as the text's ostensible translator, the footnote reminds us that, within the scope of the overall diegesis of the hoax, this text is a translation. Again, the claims of the preface are strengthened by their reappearance at nearly the midpoint of the work. Thus, although it takes on the appearance of a scholarly comment, Macpherson's first footnote is actually an authorial aside re-inviting the reader to participate in the world of his Highland hoax.

The next footnote in the sequence appears in Fragment IX, the tale of tragic love between the hero Ronnan the Bold and his beloved, Rivine. Ronnan must travel to Norway on a mission for his king (42). The footnote here indicates that this king is "[s]upposed to be Fergus II. This fragment is reckoned not altogether so ancient as most of the rest." Typically listed as the fortieth king of Scotland in the traditional reckoning, Fergus II is one of 67 legendary kings preceding Alpin, the ninth century ruler with the 
strongest claim to the title of first historical king of much of what is now called Scotland (Buchanan 10; "The Kings and Queens of Scotland.").

The footnote does not include an explanation as to why the unnamed king in the text should be interpreted as the second king Fergus; no evidence in support of this thesis is offered. Nor does the annotator explain how such a surmise affects the dating of this Fragment vis-a-vis the others. The casual reader is left with little choice but to take at face value that the translator and editor are offering the best available information in the footnotes. $3^{\circ} \mathrm{A}$ more skeptical reader is left with further questions regarding the dating of the Fragments. Who, if anyone, was king of Scotland during the period in which the overall narrative is set? Is there any importance to Ronnan's voyage to Norway, save as a narrative pretext to separate him from his beloved? Does this Norwegian adventure appear in the historical record? And most important, how does the annotator know what they know, i.e. what are the sources backing the claims made in this footnote?

The balance of the footnotes (six in total) appear in the last three Fragments. The asterisk used as the indicator/callout for the fourth footnote appears after the number of the untitled thirteenth Fragment, i.e. "XIII *" (59). The note itself reads "* This is the opening of the epic poem mentioned in the preface. The two following fragments are part of some episodes of the same work." Again, a contradiction emerges, as the preface states "Though the poems now published appear as detached pieces in this collection, there is ground to believe that most of them were originally episodes of a greater work which

\footnotetext{
${ }^{30}$ An even less inquisitive reader and/or one purely interested in the narrative will skip the footnote entirely, of course.
} 
related to the wars of Fingal" (v). The last three Fragments only constitute $20 \%$ of the total, not "most" of the prose poems published.

Similarly, the last four footnotes raise as many questions as they answer. The fifth footnote, also in Fragment XIII, supplies a detail missing from the text, that "the tree of the rustling leaf" by which the hero Cuchulaid sits is an "aspen or poplar tree" (59). Again, the footnote conflicts with a claim made in the preface, which states "The translation is extremely literal. Even the arrangement of the words in the original has been imitated;" (vi-vii). If that were true, how does the annotator identify the tree type if the only information available is that the tree in question possesses noisy leaves? And why can't the annotator distinguish between aspen and poplar? Paradoxically, the footnote is both too specific and not specific enough.

The fifth, sixth, and seventh footnotes in the Fragments are all of a type, each giving the "signification" of one or more proper nouns. In the first instance Moran, son of Fithil, declares of the enemy chief "Garve, well art thou named," which is accompanied with a footnote explaining that "Garve signifies a man of great size" (60). The following two footnotes provide explications for the names of eleven people and one place-name $(62,67)$. These names, their meanings, and where they are found appear in Table 1 . As with the other explanatory footnotes, no source is given for this information. Nor is explained why such explanations are available only for names appearing in the last two Fragments and not for the numerous names in the prior thirteen.

Additionally, the orthography of the annotated names is unstable. As shown in Table 1, the names are spelled one way in the main text and another way in the footnotes. In the case of Tuathal Teachimar/Tuathal-Teachvar the two variants are mere fractions 
of an inch apart on the same page, the former appearing in the last line of the body of page 67, while the latter appears in the second line of the footnote on the same page. Again, no explanation for these variations is available, nor is there an explanation as to why both variations of Muirne/Morna appear in the footnote.

Yet another mystery is the fact that only some of the names in the last two Fragments are glossed. In Fragment XIV, the names Branuin, Fingal, and Cadmor pass without comment, as do Carbre and Ullin in the fifteenth Fragment $(63-4,69)$. The last character introduced in the Fragments, "Allad *, the grey-haired son of the rock" is given a footnote explaining "Allad is plainly a Druid consulted on this occasion" (68). A reader ignoring the diversion of the footnote callout/indicator can reach the same conclusion upon encountering the very next sentence: "He liveth in the circle of stones;". The footnote itself admits its own redundancy with the use of the adverb "plainly."

Table 1

Macpherson Names with Spelling Variants Given in Bold

\begin{tabular}{|l|l|l|l|}
\hline Name in footnote & Name in text & Given Meaning & Footnote Page \\
\hline Garve & Garve & "man of great size” & 60 \\
\hline Dubchomar & Duchommar & $\begin{array}{l}\text { "a black, well- } \\
\text { shaped man" }\end{array}$ & 62 \\
\hline
\end{tabular}

(Table Continues) 
Table 1, continued

\begin{tabular}{|c|c|c|c|}
\hline Name in footnote & Name in text & Given Meaning & Footnote Page \\
\hline $\begin{array}{l}\text { Muirne or } \\
\text { Morna }\end{array}$ & Morna & $\begin{array}{l}\text { "a woman beloved } \\
\text { by all" }\end{array}$ & 62 \\
\hline Cormac-cairbre & Cormac-Carbre & $\begin{array}{l}\text { "an unequalled and } \\
\text { rough warrior" }\end{array}$ & 62 \\
\hline Cromleach & Cromleach & "a crooked hill" & 62 \\
\hline Mugruch & Mugruch & $\begin{array}{l}\text { "a surly, gloomy } \\
\text { man" }\end{array}$ & 62 \\
\hline Tarman & Tarman & "thunder" & 62 \\
\hline Tarman & Tarman & "thunder" & 62 \\
\hline Moinie & Moinie & $\begin{array}{l}\text { "soft in temper and } \\
\text { person" }\end{array}$ & 62 \\
\hline Gealchossack & Gealchossa & "white-legged" & 67 \\
\hline $\begin{array}{l}\text { Tuathal } \\
\text { Teachimar }\end{array}$ & $\begin{array}{l}\text { Tuathal- } \\
\text { Teachvar }\end{array}$ & $\begin{array}{l}\text { "surly, but } \\
\text { fortunate man" }\end{array}$ & 67 \\
\hline
\end{tabular}

(Table Continues) 
Table 1, continued

\begin{tabular}{|l|l|l|l|}
\hline Name in footnote & Name in text & Given Meaning & Footnote Page \\
\hline Lambhdearg & Lamderg & "bloody-hand" & 67 \\
\hline Ulfadha & Ulfadha & "long beard" & 67 \\
\hline Firchios & Firchios & "conqueror of men" & 67 \\
\hline
\end{tabular}

Reaching the end of the Fragments, a careful reader is left with the following questions that are only raised thanks to reading the footnotes:

- Why do the footnotes provide information that can be readily gleaned from the text, such as the desire of ancient heroes to die by exalted hands, or Allad's status as a druid?

- Why do the footnotes reveal information before it appears in the text, i.e. the death of Dargo's daughter?

- Why do the footnotes contradict the explicit claims of the preface (number of Fragments that are part of the Wars of Fingal sequence) or the main text (the rejection of the death of Dargo's daughter as evidence of suicide)?

- Why is the ninth Fragment dated to the reign of Fergus II, but no effort is made to date any other individual Fragments?

- If the Fragments are "extremely literal" word-for-word translations (as claimed in the preface), how does the annotator conclude that "the tree of the rustling leaf" must be either an aspen or poplar? 
- Again, given the preface's commitment to literal translation, how do the variant names come to appear in the footnotes of the last three Fragments?

- Why are some of the names in the last two Fragments explicated and not others? The dismissive answer to these conundrums is that James Macpherson was an ineffective hoaxer, that he cannot keep the details of his own deception consistent when composing his footnotes. But to accept that explanation would also dismiss the sophistication of Macpherson's original audience in the face of the wild initial success of the Ossian hoax. The briefest of surveys of human folly from the ancient past to the present day reveals that we as a species readily succumb to all manner of frauds and deceptions. Rather than conclude that late-eighteenth- and early-nineteenth-century readers of Macpherson were particularly gullible--an argument that would undoubtedly prove wildly hypocritical in this era of Fake News--I instead argue that the ambiguities introduced by the work contribute to the overall aesthetic effect of a partially-revealed mystery.

Macpherson uses the footnote to dramatically shift the role of the author in his text. Authorship--in the naive Foucauldian sense as the individualized originator of a discourse, outside and preceding the text--is rejected in the preface, in which Macpherson (writing anonymously) invites the readers to interpret the main text as "remnants" of an ancient pre-Christian tradition (Foucault 115; Macpherson 2-3). We thereby enter "a time when those texts which we now call 'literary' (stories, folk tales, epics, and tragedies) were accepted, circulated, and valorized without any question about the identity of their author. Their anonymity was ignored because their real or supposed age was a sufficient guarantee of their authenticity" (Foucault 125). 
But footnotes do not exist in this era of orality from which epics and folk tales originate. The footnote is a product of the age of print, which presupposes a threefold model of authorial time: the author predates the text which exists prior to its encounter with a reader. This is depicted in figure 2, scenario 2 with the author as the circular black dot from which the text (black line) originates, interacting with the surrounding discourse community (arrowhead). The older oral model outlined by Foucault is twofold: the text comes into existence in an ancient, authorless time and later is taken up by a discourse community of readers who accept it as authentic (scenario 1).

The virtual reality constructed by Macpherson requires both these formations, merging into a fivefold arrangement depicted in figure 2, scenario 5. First, the original compositions that decay into the Fragments emerge from ancient, authorless time. Later, ancient Scots accept the work as authentic, attaching a mythical author to them after the fact. Then, the modern editor/translator takes up the task of collecting, curating, and translating the Fragments, to which the annotations are attached. The translated text plus paratexts then enter the world, where they become available to both the reader in Macpherson's discourse community and the Other Reader. 

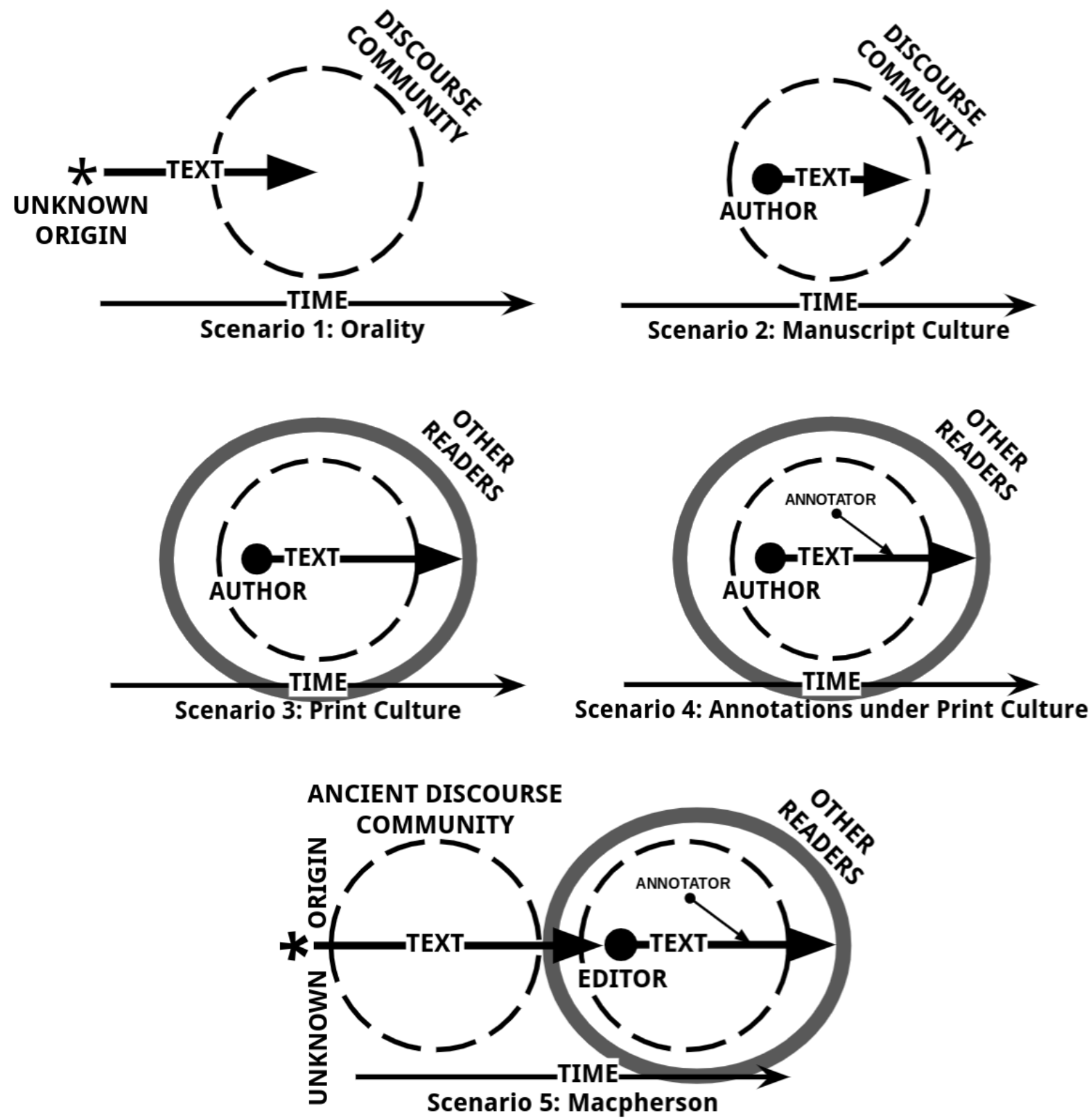

Figure 2. Textual Relationships from Orality to Macpherson

Thanks to the practice of laying out the main text and the footnote with the space in between serving as one of the markers indicating the difference between the two (the other being the change in the size of the text), the authorial footnote makes physically manifest the discontinuities inherent in text itself. As Foucault notes "the author 
remains at the contours of texts--separating one from the other, defining their form, and characterizing their mode of existence... it [the author's name] is situated in the breach, among the discontinuities, which gives rise to new groups of discourse and their singular mode of existence" (123).

With each footnoted page, the whitespace that normally sits calmly at the bottom rises up like a waveform passing through the book. The footnotes well up from below this flowing whitespace, revealed like sunken treasures glittering on the bottom of the sea. This oceanic manifestation parallels the irruptions of the unconscious into consciousness, welling up from the occluded depths of the mind. However, the unconscious never becomes conscious thought, but is endlessly deferred. The unconscious cannot be written or printed, merely represented. What appears at the bottom of the page is not the unmediated unconscious of the author, but rather another mediation, just as a literary text is always a mediation of the author's unconscious thoughts, first mediated through consciousness, then through the act of writing, then through the process of entry into the world of print. The literary footnote is the trace of the conscious mind coming to terms with the other, both in terms of the reader who is not I, but also the mysterious reader who is the I that is not conscious. The footnote wrestles with the ontological instability of the unified self, testifying to the analogy of the breach between author and text and the breach inherent in the self.

The difference between text and paratext here is one of an additional remove, as the annotator ruminates over the existing text. The Other Reader that induces the anxiety to write paratext is no longer exterior to the author. In the breach between writing and annotation, the author becomes reader as well. The very act of annotation 
requires a standing aloof from the text, forcing the writer to identify with the Other Reader. When used as a literary device, the footnote inevitably takes the form of that alienation. New anxieties and priorities well up from the unconscious. In Macpherson's case these take the form of a nervous need to restate the obvious and a sudden concern with details that did not bother him when writing the text: dates, orthography, etymology. Like a jittery bronze age despot consulting the entrails of animals for details revealing the stability of their reign, Macpherson seeks reassurance of the stability of his literary project in minutiae. But just as desperate, paranoid efforts to oust court conspirators inevitably creates the environment where intrigue runs riot, so do Macpherson's efforts tip his hand slightly.

\section{The Annotated Rime}

Samuel Taylor Coleridge's The Rime of the Ancient Mariner demonstrates the literary development of the same anxieties after the initial act of authorship. That is not to say that Coleridge acted upon realizing that he was being misunderstood; rather, he recognized the ability of the parallel paratext to influence the Other Reader and deployed annotation for literary effect. Such a recognition becomes possible as part of the larger Romantic project of remediating modernity's relationship with the medieval.

The Rime of the Ancient Mariner is Coleridge's most famous work, his status as a great poet resting on the continued interest in it, "Kubla Khan," and Christabel (Newlyn 7; "The Later Poetry" 91). The Rime originally appeared as the first poem in Lyrical Ballads, the anonymous poetry collection produced in collaboration with William Wordsworth that would prove to be a watershed moment in the early history of British Romanticism (Halmi, et al. 54; Gamer and Porter 15, 17). The original seed of the Rime 
was Coleridge's friend John Cruikshank, who reported dreaming of a "skeleton ship" (Halmi, et al. 55).

The first version was composed in the months of late 1797 and early 1798, though Coleridge continued to revise the work for the rest of his career (Worthen 22; Halmi, et al. 56). At least 18 versions (ten in manuscript form, eight published) can be documented over the course of the poet's life, but no more than eight of them can be said to possess more than "minor distinctive differences" (Poetical Works 506-9; Stillinger 60). The first four published versions of the Rime appear in the 1798, 1800, 1802, and 1805 editions of Lyrical Ballads, respectively. The last three versions published in Coleridge's lifetime appear in the first three editions collecting his Poetical Works (in 1828, 1829, and 1834). It is to the published version between Lyrical Ballads and Poetical Works, the version of The Rime of the Ancient Mariner as it appears in Coleridge's 1817 collection Sibylline Leaves, that I now turn.

The Sibylline Leaves version of Rime records a key moment in Coleridge's ongoing project of tinkering with the poem, for he introduces, among other alterations, two key changes. The first is the dropping of the brief argument summarizing the action of the poem from the beginning of the work in favor of a Latin epigraph from seventeenth-century Protestant theologian and natural philosopher Thomas Burnet's work Archaeologiae Philosophicae (Poetical Works 509-10; Gardner 36-7). The second is the addition of 58 marginal glosses to the main body of the text. A fifty-ninth gloss subsequently appeared in the 1828 Poetical Works and subsequent editions (Halmi, et 
al. $73 ;$ n. 5$) \cdot 3^{31}$

Zerby's theory that Pope's use of the footnote inhibited the form's development may in part explain Coleridge's decision to utilize the margin note (57). Pope loomed large in Coleridge's mindscape of verse. In his 9 October 1797 letter to friend and benefactor Thomas Poole, he reminisces about his brother Francis reading Pope's translation of Homer to him when young Coleridge was confined to his bed due to a bout of putrid fever (typhus) in 1778. Coleridge discussed Pope repeatedly in his correspondence with fellow Lake Poet Robert Southey, counting Pope among the "great single names" of English poetry, alongside Chaucer, Spenser, Shakespeare, Milton, Dryden, and Taylor ${ }^{22}$ (10 Nov. 1799; July 1803). In his longform meditation on poetry, Biographia Literaria; or Biographical Sketches of My Literary Life and Opinions, Coleridge divides the history of poetry into two halves, before and after "Mr. Pope and his followers" (13).

However, a more likely explanation for Coleridge's use of notes in the outside margin as opposed to the foot can be found in the overall nostalgic agenda of the poem, as clearly outlined near the end of the original preface (labeled 'Advertisement') of Lyrical Ballads: “The Rime of the Ancyent Marinere was professedly written in imitation of the style [emphasis original], as well as of the spirit of the elder poets; but

${ }^{31}$ The additional gloss is "No twilight within the courts of the Sun." It appears adjacent to the thirteenth stanza of Part III, immediately after Life-in-Death wins the dice game. ${ }^{32}$ Literary history has not been kind to Coleridge's naming of poet William Taylor--a fellow enthusiast of German romanticism--as one of the greats of English poetry. 
with few exceptions, the Author believes that the language adopted in it has been equally intelligible for these three last centuries." Three centuries prior to the 1798 appearance of Lyrical Ballads takes us back to the year 1498, in the era of the incunabula, those early print texts that most resemble the late medieval manuscripts that they immediately preceded (Harmon and Holman 289).

The word "preceded" is not used here to imply a simple linear succession of communication technology. Although oral communication preceded the written word which preceded print, each step in this development was an expansion of the number of available communication channels rather than one form replacing another. Obviously, we still use oral, written, and print communication in this new era of digital communication technology. The different affordances of each new development alter our relationship to all of them, e.g. bards and oral messengers become less necessary in a literate society, while print shifts the provenance of writing more toward letters, journals, business communications, etc. Each new technological development brings with it a period where the new communication form is treated like an extension of the previous one. McLuhan noted in Understanding Media that "the 'content' of a medium is always another medium" (8). This maxim applies just as much to the genre boundaries of the new medium as to the content it contains, at least initially. As the new medium is explored and exercised, its new possibilities and boundaries allow for different expressions outside the limits of the predecessor media. 33

${ }^{33}$ For example, until director Jerry Fairbanks demonstrated the dramatic possibilities of the multiple-camera set-up in 1950, early television programs tended to be shot with a 
With Rime, Coleridge invokes an older genre order, which is immediately communicated to the reader via antiquated orthography in the title; initially, rhyme, ancient, and mariner appear in variant spellings, as do many other words in the body of the work, including minstralsy, emerauld, withouten, gossameres, fheere, clombe, and countrée (Stafford 146). Most of these spellings are reverted to modern standards in the revisions for the 1800 edition of Lyrical Ballads, but rime remains in the title as a signal of Coleridge's archaizing project (Poetical Works 506). Additionally, as mentioned, the original version of Rime began with a brief prose argument, a prose summary paratext (a predecessor to the preface) that flourished as a form during the Renaissance (Preminger and Brogan 98). Notably, no other work in the 1798 Lyrical Ballads begins with an argument. ${ }^{34}$ Finally, the verse form itself is based upon the traditional English

single camera, mimicking unconsciously the single vantage point of an audience member attending a stage show (“Flight to the West?”). Similarly, early superhero comic books tended to follow the panel structure of the newspaper comics that preceded them until comic artist Ben Thompson's innovation (in Marvel Mystery Comics \#11, September, 1940) of the two-page splash, depicting a single moment of action in a tableau filling the entirety of a single opening of the book (Cronin 3). The two-page splash was physically impossible in a standard three to five panel newspaper comic, and hence unthinkable for artists trained in that medium.

${ }^{34}$ Wordsworth's The Complaint of a Forsaken Indian Woman begins with a prose passage in brackets, but it does not take the form of an argument. Rather, it introduces 
ballad form, a form that had experienced a small resurgence in the wake of Thomas Percy's 1765 collection Reliques of Ancient English Poetry (Gardner 38; Stafford 123).

Coleridge's decision to employ medieval-style marginal comments rather than footnotes also stems from his own writing (that is to say, manuscript) practice. In the monograph Romantic Readers: The Evidence of Marginalia, H.J. Jackson describes Coleridge as "the most notorious of all writers of marginalia in English; he is sometimes described as incomparable in this genre" (173). Princeton University Press's marginalia portion of Coleridge's Collected Works runs to six volumes ranging from 750 to more than 1,200 pages each. As George Walley notes in the introduction to the first volume, "There is no body of marginalia--in English, or perhaps in any other language-comparable with Coleridge's in range and variety and in the sensitiveness, scope, and depth of his reaction to what he was reading" (lvii). Thus, Coleridge's choice of the outer margins for his commentary aligns both his natural inclinations as a writer with the late medieval/early Renaissance Gothicism of the Rime.

The result of this alignment is a series of 58 individual prose glosses, ranging in length from three to 48 words. Table 2 summarizes the number of glosses in each of the seven parts of the Rime, as compared to the number of stanzas in the same section. The glosses are sufficiently numerous that no two-page spread of the poem is without at least one gloss. In fact, only the beginning of the poem on page three (page two is the Latin epigraph quoting Thomas Burnet) and the opening containing pages 26 and 27

action that happens before the narrative of the poem commences. The argument as a genre reports on what the reader is about to encounter (Harmon and Holman 44). 
have just a single gloss visible. The other seventeen openings comprising the balance of the Rime all display between two and five glosses each. Once a reader begins the Rime, with the first gloss attached to the first line of the poem, the glosses become inescapable for the remainder of the work. Even if they are not read, they dot the landscape of the page.

Table 2

Comparison of the Number of Stanzas and Glosses in The Rime of the Ancient Mariner

\begin{tabular}{|c|c|c|c|}
\hline Part & Stanzas & Glosses & $\begin{array}{c}\text { Glosses as a of } \\
\text { the stanzas }\end{array}$ \\
\hline I & 20 & 9 & $45 \%$ \\
\hline II & 14 & 7 & $50 \%$ \\
\hline III & 18 & 12 & $67 \%$ \\
\hline IV & 15 & 10 & $67 \%$ \\
\hline V & 26 & 6 & $24 \%$ \\
\hline VI & 25 & 6 & $32 \%$ \\
\hline VII & 25 & 8 & $41 \%$ \\
\hline total & 143 & 58 & \\
\hline
\end{tabular}


The glosses appear in a smaller-sized typeface than the poetic text and are aligned horizontally so that the start of a new gloss is directly across from a line from the poem. Thus, each gloss can be read as intervening in a specific moment in the text, not between lines, but as a simultaneous event. The first gloss appears as shown in figure 3 .

IT is an ancient Mariner,

And he stoppeth one of three.

"By thy long grey beard and glittering eye,

"Now wherefore stopp'st thou me?
An ancient

Mariner

meeteth three

Gallants bid-

den to a wed-

ding-feast, and detaineth

one.

Figure 3. Sibylline Leaves version of Rime, lines 1-435

It must be noted that this arrangement means that there is no ideal way to read the glosses. Because of this parallel placement, to read the gloss before the indicated line of verse is too soon, to read it afterwards is too late. Following the elementary school procedure of reading left to right until the line is exhausted would result in nonsense: "It is an ancient Mariner, An ancient/Mariner/And he stoppeth one of three. meeteth three."

${ }^{35}$ All images and description of Sibylline Leaves are from Cornell University Library's 1817 copy, as scanned and uploaded to the Internet Archive. The Cornell University Library Archive's About page (https://archive.org/details/cornell?tab=about) notes that "no known copyright restrictions in the United States on the use of the texts." 
Every encounter with a new gloss requires the reader to decide the relationship between it, the verse, and the kind of reading experience they wish to have. Is it worth interrupting the smooth flow of $\mathrm{ABCB}$ and $\mathrm{ABAB}$ rhymes employed in the verse--which begins to feel like riding the crest and troughs of the waves with the Mariner's ship--in order to bring aboard more prose commentary? Do we need to stop the forward momentum of the vessel just to find out a stanza in advance that the three are heading to a wedding feast? If we do, we discover that the next stanza reveals the existence of the feast; the gloss has, in fact, proven an unnecessary and redundant side trek.

At least it is unnecessary if the reader aligns closely with Coleridge's mental image of his readers, who will be able to successfully interpret the second stanza:

“The Bridgegroom's doors are open'd wide,

“And I am next of kin ;

" The guests are met, the feast is set :

“May'st hear the merry din.” (5-8)

The gloss to the first stanza makes explicit the implications of the second stanza. The Other Reader being serviced--at least by the initial glosses--is one who cannot extract the plot of the Rime from its dense, archaic, poetic language. The result is that the prose of the glosses is clear but uninspiring reportage. If, as Robert Frost says, poetry is "that which is lost out of both prose and verse in translation," Coleridge's initial glosses translate the plot of the Rime into dull prose, throwing the poetry overboard (Brown 200).

However, Coleridge shifts from mere reportage of events to adding to the descriptions provided in the verse, starting with the final stanza of the first part, as 
depicted in figure 4. Describing the Mariner's act of shooting the Albatross as "inhospitable" and the bird itself as "pious" introduces moral judgements not explicit in the verse. The stanzas sans gloss ends the first part of the poem with a stark and inexplicable mystery, like the unaccountably strange behavior of someone in a dream, the killing of the albatross simply happens. The act is pure urge, pure id. The gloss intrudes on the scene as if the wagging finger of the superego attempting to fit it into the framework of conventional morality.

\section{"God save thee, ancient Mariner! The ancient \\ From the fiends, that plague thee thus! - $\quad \begin{aligned} & \text { Mariner } \\ & \text { inhospitably }\end{aligned}$ Why look'st thou so?"-With my cross- killeth the bow pious bird of good omen. \\ I shot the Albatross!}

Figure 4. Sibylline Leaves version of Rime, lines 79-82

This same moralizing conventionalization, this denuding of the enigmatic, dreamlike qualities of the poem continues in Part the Second, at one of the most famous scenes in the work, see figure 5. The calmness of the seas first introduced in line 107 (“Down dropt the breeze, the sails dropt down,") initially appears to be a natural phenomenon of the kind any sea traveler in the age of sail might encounter. The lack of wind and subsequent depletion of fresh water supplies only takes on a moral dimension with this gloss's invocation of vengeance as the cause. 
And the

Albatross

begins to be

avenged.

\section{Water, water, every where, \\ And all the boards did shrink; \\ Water water, every where, \\ Nor any drop to drink.}

Figure 5. Sibylline Leaves version of Rime, lines 119-122

On page 11 of Sibylline Leaves (the conclusion of Part the Second), the glosses irrupt into the space normally occupied by the verse, a veritable tsunami of paratext threatens to overwhelm the poem, as seen in figure 6. In terms of number of words appearing on the page, the glosses almost achieve parity with the verse. The three stanzas contain 77 words total, while the two glosses add up to 75 words. Visually, the rationalizing, conventionalizing, moralizing glosses appear to be literally containing the nightmare world of the Mariner. 
And some in dreams assured were

Of the spirit that plagued us so:

Nine fathom deep he had followed us

From the land of mist and snow.
A spirit had followed them; one of the invisible inluabitants of this planet, ncither departed souls

And every tongue, through utter drought, Was wither'd at the root;

We could not speak, no more than if We lad been choak'd with soot. nor angels ; concerning whon the learned Jew, Joseplus, and the Ilatonic Constantinopolitan, Michael Psellus,

may be consulted. They are very numcrous, and there is no climate or element without one-or more.

Ah! well a-day! what evil looks

Had I from old and young!

Instead of the cross, the Albatross

About my neck was hung.
'The shipmates, in their sore distress, would fain throw the whole guilt on the ancient

Mariner: in sign whereof they hang the dead sea-bird round his neck.

Figure 6. Sibylline Leaves version of Rime, lines 131-142 
Additionally, the gloss objectively confirms the presence of a spirit; within the diegesis of the verse, the spirit is only a possibility hinted at in the dreams of some of the Mariner's shipmates. Although to a 21st century reader it may seem like an oddity for the rational voice of gloss to confirm the ship was haunted, Coleridge is, in fact, confirming the annotator's existence as a separate fictional entity.

Flavius Josephus was a Jewish aristocrat, priest, politician, and historian who lived circa $37 \mathrm{CE}$ to circa $100 \mathrm{CE}$. His most famous work is the Antiquities of the Jews, a history of the Jewish people from Creation to the events just prior to the destruction of the temple in Jerusalem in 70 CE. The Antiquities of the Jews famously contains passages that seem to independently confirm the historical existence of Jesus of Nazareth, but the consensus of modern scholars is that these sections are later additions ("Josephus"). Michael Psellus lived nearly a millennium after Josephus (c.1018-c.1081 CE). In his day he was the foremost scholar of the Byzantine Empire; his writings include histories, commentaries on Aristotle and Plato, scientific treatises, as well as funeral orations and satirical poetry. Emperor Constantine IX awarded him the title hypatos tōn philosophōn ("highest of philosophers") (Browning).

The naming of these ancient authorities establishes that the author of the marginalia occupies a chronological position in the distant past, when both figures could be reasonably cited in matter relating to the haunting of the world by spirits. Like the footnotes in Fragments of Ancient Poetry, collected in the Highlands of Scotland, the glosses establish a complex fictitious compositional history to the poem. In this case it takes the form of 1) Mariner experiences events he narrates in the poem, 2) Mariner narrates these events, 3) an unknown hand records his tale in manuscript form, putting 
into the form of a traditional ballad, 4) a later, more informed but more conventionally moral hand glosses the work, and 5) this glossed version is brought to light as the printed poem.

And like the medieval glosses they simulate, Coleridge's glosses act as explanatory asides aimed at keeping the Other Reader from straying too far in their interpretation of the work. This function becomes most readily apparent in Part the Fifth, when the spirit mentioned above ceases to propel the ship northward and haunt the Mariner. The verse simply reports that the sails cease their movement and the ship comes to stop, while the gloss explains the issue (see figure 7). The writer of the glosses-already established as an expert on the world of spirits as reported by Josephus and Michael Psellus--offers us a reading of the line "the spirit slid" that reaches far beyond the simple ceasing of movement of the vessel. Instead, the gloss draws the reader into an ordered universe where the spirit of the south pole reaches the limit of its jurisdiction at the equator ("the line") and, despite not being of the order of angels (as described in the gloss mentioning Josephus and Michael Psellus), must nonetheless answer to the dictates of the angels. However, although the spirit must relinquish the Mariner, he still has a claim on him for the unjust slaying of the Albatross. 


\section{Under the keel nine fathom deep,}

From the land of mist and snow,

The spirit slid: and it was he

That made the ship to go.

The sails at noon left off their tune,

And the ship stood still also.

The lonesome spirit from the south-pole carries on the ship as far as the line, in obedience to the angelic troop, but still requireth: vengeance.

Figure 7. Sibylline Leaves version of Rime, lines 377-382

In short, despite all the wonders and horrors encountered by the Mariner-including the emerald green icebergs $(53-4)$, the rotting sea $(123,240)$, the slimy creatures crawling on the surface of the sea $\left(125^{-6}, 238\right)$, the water burning like witchfire (129-30), the skeleton-shop of Death and Life-in-Death (177-193), the souls departing his fellow crew-members (216-223) only to be replaced with angelic fire, bringing them to a semblance of life (313-334)--the writer of the glosses insists that these events occur in a world that is comprehensible even if it is not comprehended. Furthermore, this world is just, even if that justice eludes the world of man. There is a moral structure to the universe and a hierarchy in which humans, spirits, angels, and albatrosses all have a place. Without the glosses to inform us of these facts, the Rime is more easily read as a nightmare of irrationality, possibly existing only in the deranged mind of the Mariner.

The glosses testify to a reality external to the work. Romanticist and philosopher Timothy Morton argues that the Rime's annotations explore his ethic of 
"supplementarity," where authentic creation supplies needs, as opposed to creating new wants to be serviced (176). The annotations attempt to explain the text but are written from a point of view alien to the author: i.e. the annotator is the Other Reader. The result is a text that can be more easily navigated by further Other Readers, because it has been package for them. As Morton puts, The Rime of the Ancient Mariner is an 'antiquated' text, always already, prepared for the literary tradition that it itself helps to instigate Coleridge's poem is an exquisite instance of the antiquating phenomenon. This quality of antiquing ironically bestows what is most universal about The Ancient Mariner... It comes ready-made as a timelessly valuable antique. (122-3)

Macpherson's Fragments are similarly "ready-made" antiques, but a key difference between the two works lies outside the text but still within the circle of the discourse community: Macpherson tried to pass off his manufactured patinas as real aging, while Coleridge never denied the artifice in his antiqued works. Following Coleridge's logic of supplementarity, Macpherson attempted to create new wants instead of satisfying authentic needs.

Both Macpherson's Fragments of Ancient Poetry, collected in the Highlands of Scotland and Coleridge's 1817 version of The Rime of the Ancient Mariner position their annotations as a form of ready-made, at-hand expert testimony. They are designed to allow the Other Reader to enter the world of the work while remaining within interpretive bounds afforded by aid. Like following a tour guide in a museum, the result is always a better informed but safer aesthetic experience as you travel from exhibit to exhibit with the official interpretation always accompanying you. It might be possible to 
develop an independent reading in the presence of the parallel paratexts of the marginal gloss and the footnote, but their convenient presence on the same page as the main text combined with their direct connection to specific portions of the text makes them far easier to consult in a moment of hesitation or confusion than paratexts located elsewhere. 


\section{CHAPTER III: THE MIRROR IN THE TEXT: THE DISAVOWAL OF THE}

POIOUMENON BY THE WITHDRAWAL OF THE

\section{BOOK-WITHIN-A-BOOK}

"I know there are readers in the world, as well as many other good people in it, who are no readers at all, - who find themselves ill at ease, unless they are let into the whole secret from first to last, of every thing which concerns you."

--Laurence Sterne, The Life and Opinions of Tristram Shandy, Gentleman

In Act III, scene ii of Hamlet, the melancholy Dane arranges the performance of a play, whose action is designed to mimic the circumstances of the murder of Hamlet's father. This play-within-a-play, which Hamlet calls The Mouse-trap, begins with a dumbshow pantomiming the theatrical action about to unfold before the King and his court $(2105 ; 1990-2002) .{ }^{6}$ Starting sixteen pages into the thirty-one First Folio pages occupied by Hamlet, the action of The Mouse-trap sits at the physical heart of the play, "to hold as 'twer/the Mirrour vp" to the narrative surrounding it (1869-70). The microcosm of The Mouse-trap explicates the macrocosm of Hamlet.

In a series of writings spanning 1982 to 1990, Scottish literary critic Alastair Fowler elucidates what he calls the poioumenon, or work-in-progress novel. A hypothetical poioumenal version of Hamlet would see the writing and/or staging of The Mouse-Trap commingled with the entirety of the play, expanding the act of producing the "inner" play to encompass the action of the "outer" one. In this chapter I formally

${ }^{36}$ Line number references to Hamlet are taken from the University of Victoria's online transcription of the First Folio version of the play. 
define the term poioumenon followed by a series of examples of the concept's usage in literary criticism from its origination to the present. Following this overview, I then demonstrate the poioumenal nature of four nineteenth-century texts: Sir Walter Scott's The Lay of the Last Minstrel, James Hogg's The Private Memoirs and Confessions of a Justified Sinner, Thomas Carlyle's Sartor Resartus, and Bram Stoker's Dracula. Each of these texts also possesses a text-within-a-text, like the The Mouse-trap except that the interiority of it is unavailable to the reader. For these four works, it is as if Hamlet's instructions to the players before the show is immediately followed by Claudius' reaction to performance, which the audience does not see. Scott, Hogg, Carlyle, and Stoker introduce a semiotic vacuum into their text, a narrative hole into which meaning vanishes. These present-yet-absent texts-within-texts are simulacra without origins beyond their own ontological boundaries.

Ultimately, I argue that the poioumenon can be considered a form of maximal paratext designed to finally overcome the problem of the Other Reader. However, the issue of the Other Reader can never be fully solved within the regime of the print-bookas-commodity and the vacated text-within-a-text, hereafter referred to as the withdrawn text, marks the inability of the poioumenon to account for the Other Reader. The withdrawn text is the unaccountable excess in the system of the poioumenon.

\section{Defining the Poioumenon}

The word poioumenon (Greek for "product") was first proposed as the name of a category of literature by Fowler in his 1982 study of literary genres, Kinds of Literature: In the poioumenon or work-in-progress novel, at least one narrator or character is engaged in writing, whether a novel (At Swim-Two-Birds), 
biography (Sartor Resartus), autobiography (Tristram Shandy), notebook or other considerable work (The Golden Notebook). There are likely to be inset texts, or prominent accounts of books and papers... And there may also be an additional, symbolic work-in-progress (Toby's fortifications; coining in Les Faux Monnayeurs)... The inset works of art remind us that what we are reading is itself a work of fiction, and provide occasions for treating a principal theme of the genre: the relation of art to life. (123) Fowler would revisit and expand his formulation of the poioumenon, first in his $1987 \mathrm{~A}$ History of English Literature: Forms and Kinds from the Middle Ages to the Present and his 1989 essay "The Future of Genre Theory: Functions and Constructional Type.” He also touches upon the concept in the entry on "Genre" in the 1990 edition of The Encyclopedia of Literature and Criticism (151-163). Table 3 lists every work of literature identified by Fowler as a poioumenon. Fowler identifies ten additional features of the genre, beyond a character writing the text:

- "discontinuous action" (Kinds of Literature 70)

- "rhetorical bravura" (72)

- functions as a counter-genre or anti-genre to some other genre (177)

- "farrago-like character" (190)

- preoccupation with its own fictive state (253)

- following the protagonist's thought process rather than action (A History of English Literature 195)

- "the author is fictionalised" (195) 
- an overall concern with writing, expressed as a "multiplication of references to writing” (“The Future of Genre Theory" 297)

- depiction of "multitudinous loose papers" and other writing materials (297;

$$
\text { “Genre" 160) }
$$

- "inset texts or works of art" (160)

Following Wittgenstein's theory of "family resemblance" (Familienähnlichkeit), Fowler acknowledges that genres are not fixed entities with hard borders. Rather, genres are mutable, continually renewed repertoires of characteristic features (external structure, rhetoric, topics and the like). Such repertoires are not a means of classification so much as a resource of signs in a language or coding system that allows economical yet intelligible communication. Change of the repertoires is continual, for new works signify precisely by their modulating of specific previous states of the genre. Hence their own addition to it modifies the existing state... (157-8)

Thus, not all the ten genre features need be present in any one poioumenon, rather some constellation of these items will manifest with any given instantiation of the genre. Furthermore, Fowler's approach to genre is explicitly diachronic; genre borders change over time as new texts push the genre in new directions. In keeping with this approach, Fowler proposes three additional provisional features of the genre, which he sees as first emerging with Sartor Resartus: a "speculative provisionality," the "author's struggle with coherence," and a "diminished expectation of strong closure" ("The Future of Genre Theory" 297). 
Table 3

Fowler's Poioumena (Kinds of Literature 70, 86, 123-6, 210; A History of English

Literature 298, 370)

\begin{tabular}{|l|l|l|}
\hline Work & Published & Author \\
\hline Tristram Shandy & $1759-1767$ & Laurence Sterne \\
\hline Sartor Resartus & 1836 & Thomas Carlyle \\
\hline Vanity Fair & $1847-8$ & William Makepeace Thackeray \\
\hline The House of Seven Gables & 1851 & Nathaniel Hawthorne \\
\hline The Egoist & 1879 & George Meredith \\
\hline Les Faux-monnayeurs (The & 1925 & André Gide \\
Counterfeiters) & 1927 & Virginia Woolf \\
\hline To the Lighthouse & 1928 & Aldous Huxley \\
\hline Point Counter Point & 1939 & Flann O'Brien (Brian O’Nolan) \\
\hline At Swim-Two-Birds & $1951-1960$ & Samuel Beckett \\
\hline Molloy/Malone Dies/The & & \\
\hline
\end{tabular}

(Table Continues) 
Table 3, Continued

\begin{tabular}{|l|l|l|}
\hline Work & Published & Author \\
\hline Balthazar, Mountolive, Clea) & $1957-1960$ & Lawrence Durrell \\
\hline The Golden Notebook & 1962 & Doris Lessing \\
\hline Pale Fire & 1962 & Vladimir Nabokov \\
\hline V. & 1963 & Thomas Pynchon \\
\hline Snow White37 & 1967 & Donald Barthelme \\
\hline G & 1972 & John Berger \\
\hline B & 1972 & Eva Figes \\
\hline H & 1973 & Philippe Sollers \\
\hline The Story of the Weasel & 1976 & Carolyn Slaughter \\
\hline Doctor Copernicus & 1976 & John Banville \\
\hline Falstaff & Robert Nye \\
\hline
\end{tabular}

(Table Continues)

${ }^{37}$ Fowler refers to Donald Barthelme's novel Snow White as a "mock poioumenon" (Kinds of Literature 126). 
Table 3, Continued

\begin{tabular}{|l|l|l|}
\hline Work & Published & Author \\
\hline Caves of Alienation & 1977 & Stuart Evans \\
\hline The Mutual Friend & 1978 & Frederick Busch \\
\hline Midnight's Children & 1981 & Salman Rushdie \\
\hline Mantissa & 1982 & John Fowles \\
\hline The Paper Men & 1983 & William Golding \\
\hline
\end{tabular}

Since the initial description of the genre by Fowler, the poioumenon concept has been taken up by several critics. Translator and critic Tom Toremans argues in his article "Sartor Resartus and the Rhetoric of Translation" that the question of the overall coherence of Carlyle's novel and its status as a poioumenon has "haunted critical analyses of the work through the twentieth century" (61). Creative writing researcher Daniel Southward finds investigation of poioumenon as a genre particularly apposite for investigating the divide between creation and critique, finding it "useful to examine novels which point to their own construction and which flaunt their influences, academic or otherwise, and overtly dramatize this divide" (277). Indian scholars Ramen Sharma and Preety Chaudhary's 2011 survey of "Common Themes and Techniques of Postmodern Literature of Shakespeare" includes a section on the poioumenon (195-6). They add Gilbert Sorrentino's 1979 novel Mulligan Stew to Fowler's list of poioumenon 
(196). Pearl McHaney finds the concept of the poioumenon of use to her analysis of Kathryn Stockett's 2009 novel The Help, arguing that its poioumenon-like features contribute to the overall postmodern effect achieved by Stockett (88).

In Stefan Löchle’s essay “The Impostor as Trickster as Innovator: A Re-Reading of Carlos Castaneda's Don Juan-Cycle" (appearing in the 2014 critical anthology Fake Identity?: The Impostor Narrative in North American Culture) the poioumenon-which Löchle describes as "fiction that copes with the process of creation"--is connected to Joyce Carol Oates' critique of the "Structural Analysis" portion of Castenada's first work, The Teachings of Don Juan: A Yaqui Way of Knowledge (91). Löchle argues for a reconsideration of Castaneda's work, previously derided as a New Age hoax, as a literary project with poioumenon-like properties. ${ }^{8}$ Instead of reading The Teachings of Don Juan as a non-fictional but deceptive record of anthropological research into the spiritual practices of the Yaqui people, Löchle proposes interpreting the text as a literary work designed to critique the Western scientific viewpoint that operate within the conceit of an anthropological dissertation (81).

The use of the poioumenon concept has also grown beyond Fowler's original designation as a genre of novel. Anna Beth Rowe argues that David Lehman's short poem "The Breeders' Cup" represents a poioumenon in verse form (9-10, 23-4). Canadian literary and cultural critic Sheldon Fischer examines performative storytelling in Canadian fiction, examining the poioumenon-like way early Canadian writers attempt

${ }^{38}$ Löchle's call for a literary re-reading of Castaneda's Don Juan cycle parallels my own attempt to rehabilitate James Macpherson's Ossian materials in chapter II. 
to speak their homeland into existence (90-1, 94-5). Artist and art critic Martin Westwood even finds a use for the poioumenon in photography criticism. Westwood analyzes the collage-like photographs of Aby Warburg, who attempts to depict "photographic circulation," focusing on the process of photography rather than reverence for the final image (120). 39

${ }^{39}$ Additionally, the term receives an entry in the second edition (2016) of Fran Mason's Historical Dictionary of Postmodernist Literature and Theater (362-3). In addition to giving "poioumenon" its own entry, Mason identifies poioumenon in two other entries in the Dictionary: French writer Laurent Binet's 2009 novel $H H h H$ (an abbreviation for the German phrase "Himmlers Hirn heißt Heydrich" or "Himmlers brain is called Heydrich”) and Hungarian novelist László Krasznahirkai’s 1999 work Háború és háború (War \& War) (76-7, 254-5).

"Poioumenon" also serves as the title of a short story by writer Jon Steiner, appearing in the 2011 Australian fiction anthology Escape. The story consists largely of the narrator relating his struggle to write postmodernist fiction that doesn't sound like David Foster Wallace (48-52). It was later adapted for the Australian radio program Radiotonic in May 2015 and appeared in his 2018 collection The Last Wilkie's and Other Stories ("Poioumenon”).

Finally, Ron Reikki's 2014 review of Joe Amato's novella Big Man with a Shovel list the poioumenon as the foremost of Amato's postmodern techniques (“American Book Review" 26). 
Not all who encounter Fowler's poioumenon take it up with the same verve. Susan Wolfson, writing only three years after Kinds of Literature, critiques it as a category of literature in their essay "Keats's 'Isabella' and the 'Digressions' of 'Romance.” Wolfson offers a counterpoint to Fowler's formulation, arguing that Fowler merely "classifies digression under the 'subgenre'... in such a subgenre, of course, digression is not so much a generic component as it is a permissible form of discontinuity" (248). Wolfson's essay focuses on digression, explaining the choice to highlight that feature as the lynchpin of the poioumenon. And although Fowler names Tristram Shandy, the epitome of the literary digression, as his inaugural example of the poioumenon (in Kinds of Literature he refers to Sterne's novel as the poioumenon's "paradigmatic form" (177)), digression itself is not the exclusive identifying attribute of the genre. That is to say, digression alone is neither a necessary nor sufficient condition for a text to be classified as a poioumenon. Furthermore, digression is only one mode of "discontinuous action" (70). Narration with digression implies the existence of a main narrative thread, from which the flow of the text turns. Another possibility would be for multiple narrative threads to be developed each on an equal footing with the others, with the text switching from one thread to another, favoring none of them. Under this structure, none of the switches in narrative focus would qualify as a digression, as a digression always presupposes a primary diegesis. 40

${ }^{40}$ For example of this mode of discontinuous action, see Karen Tei Yamashita's postmodern, postcolonial novel Tropic of Orange. 
While Fowler and later users of the poioumenon concept do not connect it to the paratext, I argue that, despite the genre features of the poioumenon existing within the main body of a text, it can be read as a paratextual formation. The function of the paratext is to shape reader reception of the text. Chapters I and II demonstrate the ways in which various paratexts can be used by authors to form an interface between their text and the Other Reader. The poioumenon, by making the act of writing manifest in the product of writing, embeds this same interface within the text. Whereas the traditional paratext is a second order text commenting on a first order text, the poioumenon is a first order text commenting on itself. The poioumenon serves, in effect, as its own paratext. It is paratext at its maximum saturation of the text, where the boundary between text and paratext is erased, as will be outlined with respect to four nineteenth century examples of the poioumenon: Sir Walter Scott's poem The Lay of the Last Minstrel, James Hogg's The Private Memoirs and Confessions of a Justified Sinner, Thomas Carlyle's Sartor Resartus, and Bram Stoker's Dracula.

\section{Poioumena in Nineteenth-Century Britain}

Edinburgh-born Sir Walter Scott (1771-1832) achieved success in life as a lawyer, scholar, and literary critic (McGhee 254). He is remembered today as the most popular British poet of the beginning of the nineteenth century and, thanks to the Waverly series, the world's most popular novelist of the same era (Langan 49). William St. Clair documents over 13 million Scott-penned volumes printed and sold in the nineteenth century (633-43).

Scott's first major publication was the 1802 two-volume Minstrelsy of the Scottish Border, an anthology of traditional verse collected and edited by Scott (633). 
Inspired by the antiquarian efforts of Thomas Percy's Reliques of Ancient English Poetry (1796) and James Macpherson's Ossian cycle (see chapter II). The success of the collection prompted Scott to try his hand at a "border ballad" of his own. Originally intended to appear in the third volume of Minstrelsy's second edition, in which notable poets of Scott's era wrote in imitation of the traditional ballads, The Lay of the Last Minstrel instead appeared as a separate publication in 1805 (Richardson 243; St. Clair 633).

Set in the sixteenth century, the Lay tells of the romance between Lady Margaret of the Scott Clan and Lord Cranstoun of the Ker Clan. Margaret's mother Lady Janet disapproves of the match, her own husband having fallen in battle with the Kers. To thwart their impending nuptials, Lady Janet dispatches Sir William Deloraine to Melrose Abbey, to retrieve the grimoire of the dead wizard Michael Scott. Lord Cranstoun encounters Deloraine and wounds him before he can return to Lady Janet. Cranstoun's mysterious goblin page steals the book and uses a spell from it to lure Lady Janet's young son into the woods. The boy is captured by the English, who lay siege to Lady Janet's castle. She offers to resolve the dispute by having Deloraine fight as her champion. Since Deloraine is wounded, Cranstoun has the goblin use the spell to make him appear as Deloraine. Cranstoun-as-Deloraine wins the combat, saving the child and relieving the siege. A grateful Lady Janet agrees to the marriage between Margaret and Cranstoun. At the wedding feast the wizard Michael Scott's ghost appears to magically vanish the goblin page. The wedding guests then all make a pilgrimage to Melrose Abbey in honor of the memory of Michael Scott.

Although The Lay of the Last Minstrel is not a novel and does not portray the 
creation of a new work of art, it does possess several poioumenon-like properties. There is a work in progress over the course of the poem, in the form of the framing narrative set in the century following that of the main action of the narrative; the eponymous Last Minstrel in Scotland, now “infirm and old," sings the bulk of the ballad for Anne, Duchess of Buccleuch and Monmouth, whose husband is presumed to descend from Scott clan in his lay (Introduction.2, Introduction 37n)41. Thus, while the Last Minstrel's work does not comprise an act of textual composition, it does constitute on ongoing performance of text. After the Introduction establishes the Minstrel in the court of the Duchess, each of the six cantos of the poem brings us back to that scene with a short coda of 14 to 29 lines in which the Minstrel pauses his tale. The regular return to the scene of the performance not only insures a discontinuity in the action, it also calls attention to its fictionality and to the Minstrel himself as a fictionalized stand-in for Scott as poet.

Furthermore, the Lay serves as a countergenre to the traditional border ballad, in that it was designed explicitly as modern, print, authorial response to the ancient, oral, anonymous works Scott collected in Minstrelsy of the Scottish Border (Duncan 242). In fact, it was originally sketched out as one of the modern responses to the Minstrelsy to appear in the third volume to the second edition (Eller 44).

Although there is no concern with writing or multiplication of references to

\footnotetext{
${ }^{41}$ All references to and quotes from The Lay of the Last Minstrel appearing in this chapter are derived from the scan of Oxford University's copy of the first edition, available from the Internet Archive.
} 
writing, there is a concern with and multiplication of the performance of oral verse. In the final canto three ballads are sung during the wedding feast (VI.xi-xx, xxii-xxiii). Note that for each of these songs, the Last Minstrel sings as the attributed singer within the diegesis of his own lay; the framing narrative contains the lay, which contains these smaller songs. Additionally, the main action of the poem (prior to the final coda) ends with a "Hymn for the Dead," sung by all the penitents at Melrose Abbey; the number of voices singing in the poem proliferates to include every character still alive at the end of the Lay (VI.xxxi).

To summarize, if we accept that the Lay is a work-(of performance)-in-progress, it fulfills six of the genre criteria for a poioumenon: the Lay serves as a countergenre to the traditional ballad. The codas interrupting the Minstrel's narrative provides for discontinuous action. These codas regularly call attention to the work's own fictionality as well as fictionalizing the author. The four songs at the end demonstrate a multiplication of writing and these works plus the wizard's spell book are also all examples of inset texts.

A summary of the relationship to Fowler's genre criteria of the Lay and the other three texts considered here can be found in Table 4. A cell marked with an "x" indicates a close adherence to the individual criterion, while a tilde (“ $\sim)$ indicates a partial adherence. As can be seen, none of these texts possess all the characteristics of the genre, though Sartor Resartus comes close. However, keeping in mind Wittgenstein's "family resemblance" model; a genre is not an exhaustive checklist but a description of possible border conditions that create a gestalt formation. 
Table 4

Adherence of four texts to Fowler's Poioumenon conventions

\begin{tabular}{|c|c|c|c|c|}
\hline & $\begin{array}{c}\text { Lay of the } \\
\text { Last Minstrel }\end{array}$ & $\begin{array}{c}\text { Justified } \\
\text { Sinner }\end{array}$ & $\begin{array}{c}\text { Sartor } \\
\text { Resartus }\end{array}$ & Dracula \\
\hline $\begin{array}{l}\text { Work in } \\
\text { progress }\end{array}$ & $x$ & $\sim$ & $\mathrm{x}$ & $\mathrm{x}$ \\
\hline $\begin{array}{l}\text { Discontinuous } \\
\text { action }\end{array}$ & $\mathrm{x}$ & $\mathrm{x}$ & $\mathrm{x}$ & $\mathrm{x}$ \\
\hline $\begin{array}{l}\text { Rhetorical } \\
\text { bravura }\end{array}$ & & & $\mathrm{x}$ & \\
\hline $\begin{array}{l}\text { Counter-genre } \\
\text { or anti-genre }\end{array}$ & $\mathrm{x}$ & $\mathrm{x}$ & $\mathrm{x}$ & $\mathrm{x}$ \\
\hline Farrago-like & & $\mathrm{x}$ & $\mathrm{x}$ & $\mathrm{x}$ \\
\hline $\begin{array}{l}\text { Preoccupied } \\
\text { with its own } \\
\text { fictive state }\end{array}$ & $\mathrm{x}$ & & $\mathrm{x}$ & $\mathrm{x}$ \\
\hline
\end{tabular}


Table 4, Continued

\begin{tabular}{|c|c|c|c|c|}
\hline & $\begin{array}{c}\text { Lay of the } \\
\text { Last Minstrel }\end{array}$ & $\begin{array}{c}\text { Justified } \\
\text { Sinner }\end{array}$ & $\begin{array}{c}\text { Sartor } \\
\text { Resartus }\end{array}$ & Dracula \\
\hline $\begin{array}{l}\text { Focus on } \\
\text { thought rather } \\
\text { than action }\end{array}$ & & $x$ & $x$ & \\
\hline $\begin{array}{l}\text { Author } \\
\text { fictionalized }\end{array}$ & $\mathrm{x}$ & $\mathrm{x}$ & $\mathrm{x}$ & $\mathrm{x}$ \\
\hline $\begin{array}{l}\text { Concern with } \\
\text { writing or the } \\
\text { multiplication } \\
\text { of writing }\end{array}$ & $\mathrm{x}$ & $\sim$ & $\sim$ & $\mathrm{x}$ \\
\hline $\begin{array}{l}\text { Loose papers } \\
\text { and other } \\
\text { writing } \\
\text { materials }\end{array}$ & & $\mathrm{x}$ & $\mathrm{x}$ & $x$ \\
\hline $\begin{array}{l}\text { Inset texts or } \\
\text { other works of } \\
\text { art }\end{array}$ & $\mathrm{x}$ & $\mathrm{x}$ & $\mathrm{x}$ & $\mathrm{x}$ \\
\hline
\end{tabular}


After Sir Walter Scott, the second most famous Scottish literary figure of the early nineteenth century was James Hogg (1770-1835) (Hughes 154). The son of a tenant farmer, Hogg spent twenty-five years working as a laborer and a shepherd before moving to Edinburgh to pursue a career in letters (N. Smith 178). One of Hogg's earliest publications was the hoax poem "Auld Maitland," which appeared in the first edition of Scott's Minstrelsy of the Scottish Border under the pretense of an ancient origin (Ruthven 105). Although known in his own day primarily for his poetry, Hogg's is remembered today primarily for his novel, The Private Memoirs and Confessions of a Justified Sinner. Originally published anonymously in 1824, Justified Sinner languished in obscurity until rediscovered by Nobel Prize-winning author André Gide ${ }^{42}$ and reissued in 1947 (Hughes 154).

Like Scott's Lay, Hogg's book unveils a romanticized Scottish past. Set in seventeenth century Scotland, the plot of Justified Sinner centers on the thoughts and activities of Robert Wringhim, a fanatical young Calvinist who considers himself among the Elect, those souls pre-ordained by God to enter Heaven no matter how much they sin while on Earth. Wringhim is led into a dark world of treachery and murder by his strange companion Gil Martin, who seems to possess the ability to alter his shape to resemble other people. Much of the interest of the novel resides in the ontological status of Gil Martin: is he a supernatural entity, a fiend tempting Wringhim to damnation? Or is he a psychological phenomenon, a symptom of Wringhim's twisted morality that

\footnotetext{
${ }^{42}$ The same André Gide whose novel Les Faux-monnayeurs (The Counterfeiters) appears in Table 3 .
} 
allows him to displace the guilt he would otherwise feel for his many crimes? The novel provides no easy answers to these questions.

The Private Memoirs and Confessions of a Justified Sinner differs from many poioumenon in that it is less explicitly concerned with its own fictive nature and the act of writing itself does not begin until page 339 of a 390 page novel, hence the word memoirs in the title. 4344 However, Private Memoirs also demonstrates most of the genre characteristics of the poioumenon. Wringhim's fanatical thought process and its tragic consequences are the primary driver of the plot. The action is discontinuous in

${ }^{43}$ The page numbers given here and all subsequent references to the Private Memoirs are based upon the Google Books scan of the copy of the original 1824 edition housed in the Bibliotheca Regia Monacensis, known today as the Bayerische Staatsbibliothek (Bavarian State Library).

${ }^{44}$ Because of the narrative's past tense relation to the bulk of its composition, the Private Memoirs could be fruitfully analyzed under the genre of the "self-begetting novel," a genre proposed by Steven G. Kellman in a treatise of the same name. Kellman casts a wider net than Fowler, considering any work that is "reflexive" vis-a-vis its own literary production (9). His list of examples of the self-begetting novel include several of Fowler's poioumena (the Beckett trilogy, Durrell's Alexandrian Quartet, Gide, Huxley, Lessing, Nabokov, O'Brien/O’Nolan, Sterne) but also encompasses Borges' Ficciones, Don Quixote, three works by Joyce (A Portrait of the Artist as a Young Man, Ulysses, and Finnegans Wake), Proust's A la recherche du temps perdu, Whitman's Leaves of Grass, as well as Wordsworth's The Prelude (144-5). 
two different ways. First, the narrative is divided into discrete sections, that pile up, farrago-like, upon one another. The "Editor's Narrative" begins the work by relating the local tradition concerning the tragedy of Wringhim from a nameless, omniscient, first person perspective (1-142). This is followed by the section labeled "Private Memoirs and Confessions of a Sinner," (an "unjustified" variant of the novel's title), relating the same events from Wringhim's point of view (145-340). After this is an addendum to Wringhim's memoir, taking the form of dated journal entries, in which he relates the circumstances surrounding the writing and printing of the preceding section (340-368). Finally, we return of the Editor, who excerpts a letter from Blackwood's Magazine regarding this ancient tale and then travels to Scotland to attempt to verify it, discovering a copy of the prior two sections (368-390)

Additionally, the action within the second section of the novel becomes discontinuous as Wringhim begins to suffer from blackouts, during which time numerous crimes and perfidies are committed by either Gil Martin disguised as Wringhim and/or Wringhim himself (267).

The Private Memoir works as an antigenre to the genre of the confession. Northrop Frye observes, in his Anatomy of Criticism, that the key genre feature of a confession is the protagonist describing their life as part of a process of resolving some interior flaw or issue (308). Hogg's novel spurns the closure expected of a confession, as Wringhim never achieves the wisdom that allows him to make sense of the grotesqueries of his existence.

The author of the novel is trebly fictionalized. First, Wringhim is responsible for the bulk of the novel (the second and third sections mentioned above). The Editor- 
character is responsible for most of the remainder. Furthermore, Hogg himself makes an appearance, in the form of his Blackwood's Magazine persona, the Ettrick Shepherd. Hogg moved to Edinburgh in 1810 to pursue his writing career full time, yet in the novel he is still a shepherd in 1823, selling sheep in the market at Thirlestane-green when he meets the Editor (Hughes 156; Hogg 378).

Several inset texts appear in the novel (and indeed, Wringhim's memoir is a sort of inset text, given that it is enclosed with the Editor's Narrative). Examples include the deed to the farm acquired by Wringhim (or his double) during one of his blackouts, Wringhim's servant Penpunt's tale of the crow-footed cleric that disturbed the community of Auchtermuchty, and the aforementioned Blackwood's article (274-5; $303-10 ; 368-76)$.

Loose papers appear in the text in the form of Wringhim's original manuscript and all but one printed copy of his "Private Memoirs and Confessions of a Sinner," which are consigned to the flames when the printer discovers their blasphemous content $(340-1)$.

Although not concerned with writing on an ongoing basis in the manner of Tristram Shandy or--as we shall see--Dracula, the Private Memoir does repeatedly call attention to itself as an artifact both of writing and of book production. This concern begins before the main text of the work, with "Fac Simile" printed opposite the title page. This page, purportedly Wringhim's handwritten journal entry for 8 September 1712 , is included in the book by the Editor as a testament to the veracity of the story (366-7; 388). The opening section of the work could be left untitled or referred to with a more neutral-seeming term like Preface or Introduction. Instead, it is labeled the 
Editor's Narrative, which in two words economically calls attention to the presence of an Editor intervening in the text and the narrative nature of that text. Lawyer Linkum's attention to the signatures on the false farm deed parallel the Editor's attempt to verify the text with the Fac Simile:

See, madam, here are ten signatures of privy councillors of that year, and here are other ten of the present year, with His Grace the Duke of Queensberry at the head. All right. See here it is, sir-all right-done your work. So you see, madam, this gentleman is the true and sole heritor of all the land that your father possesses, with all the rents thereof for the last twenty years, and upwards. Fine job for my employers ! Sorry on your account, madam-can't help it. (276)

Wringhim's own concern with writing begins after his life as Lord of Dalcastle disintegrates and he finds himself in Edinburgh, a major hub of both English letters and the business of printing following the 1707 Acts of Union (Sher 151). Falling in with a laborer at the Queen's printing house, Wringhim decides to commit his adventures to paper and campaign for them to be printed (Hogg 339). The work even ends by calling attention to its own existence as materialized text; the last page ends with the final sentence, followed by a blank line, followed by the word "FINIS." centered on the line, followed by another blank line, followed by a short horizontal line reaching from the left margin to the center of the page, followed by the brief notice--in smaller type-“PRINTED BY JAMES CLARKE \& CO./EDINBURGH 1824." The reader cannot finish the novel without being reminded of its ontological status as an object of print production. 
The ontological status, or lack thereof, of a print object is central to the conceit of Sartor Resartus, by Thomas Carlyle (1795-1881). Carlyle was born the son of a stonemason in the remote Scottish farming village of Ecclefachan, far from the cities of Scotland but on a route connecting the major Scottish universities to the English industrial north (Campbell 48). The author of numerous essays, histories, lectures, and satires, Sartor was Carlyle's only original work of fiction. Sartor Resartus (Latin for "the tailor re-tailored" or "the tailor patched") first appeared via serial installments in the pages of Fraser's Magazine for Town and Country from November 1833 to August 1834. Initial response to the work was almost entirely negative, including some Fraser's readers canceling their subscriptions over the work (Engar 39). Thanks to Carlyle's friendship with Ralph Waldo Emerson, the first book version of Sartor Resartus appeared in Boston in 1836, followed by a London edition of 1838 (Riedler 38).

The central conceit of Sartor Resartus is that the text consists of the labors of an unnamed Editor (presumably Carlyle himself) in attempting to review a fictional German philosophical treatise, Die Kleider, ihr Werden und Wirken (Clothes, their Origin and Influence) written by an equally fictional academic named Diogenes Teufelsdröckh (literally, “god-born devil's-dung”) (Tarr 244 n6.15).45 The work is divided into three books. In the first book, the Editor struggles to make sense of the book and its author, in order to summarize and comment on it for the reader's benefit. The Editor then receives a parcel containing a great deal of unorganized biographical

${ }^{45}$ All quotes and references to Sartor Resartus are taken from the Internet Archive scan of the second American edition copy (1837) found in the Library of Congress. 
material concerning the life of Teufelsdröckh. The Editor spends the second book attempting to decipher this baffling material in order to draw a coherent picture of the author and his strange philosophy of clothes. The third book returns to the task of reviewing Teufelsdröckh's text, culminating in the Editor finally grasping the author's all-embracing philosophy of "Natural Supernaturalism."

Mentioned more times than any other work save Tristram Shandy, Sartor Resartus serves as one of Fowler's exemplars of the poioumenon genre (Kinds of Literature 123-6; A History of English Literature 369-70; "The Future of Genre Theory" 297). Sartor manifests all ten genre characteristics for a work-in-progress novel. It possesses rhetorical bravura in its dazzling ability to strategically reveal startling new details from the text of Die Kleider, ihr Werden und Wirken and Teufelsdröckh's biography in order for the Editor to comment upon them; the novel is a constant tease of discontinuous action, zigzagging toward the slow reveal of a transcendental ecstasy. It serves an anti-genre to both the book review and the biography, as Carlyle somehow leaves us with both too much information and too little for either of those genres to be completed. It is a farrago made of chapter excerpts, biographical tidbits, and editorial commentary all piling up, one upon another, with no obvious structure compelling the text other than the Editor's insistence that the puzzle of the Teufelsdröckh and his book must be solved. More than once the editor considers the possibility that the whole project is fiction, such as when he decides to omit the credibility-straining accounts of Teufelsdröckh’s encounters with “illustrious Persons, as Sultan Mahmoud, the Emperor Napoleon, and others" (bk. II ch. VI). The thought processes of both the Editor and Teufelsdröckh are fore fronted as the central drivers of action above any bodily 
movement or encounters between characters. The author is fictionalized, as the line between Carlyle and the unnamed Editor is blurred. Loose papers abound, as the Editor spends Book II sifting through the six bags of biographical documents that he receives in the mail from Teufelsdröckh's friend Herr Herausgeber (bk. I ch. IX). Nearly every chapter features inset text, either one or more quotes from Die Kleider, ihr Werden und Wirken or excerpts from the biographical bags. Perhaps the biggest difference between Tristram Shandy and Sartor Resartus is that the former is concerned with the proliferation of writing, while Sartor is an account of being overwhelmed by reading.

Three of the four great poioumenon of the nineteenth century originate in Scotland, while the fourth was written by an Irishman. ${ }^{46}$ Abraham "Bram" Stoker (18471912) was born in Clontarf near Dublin, Ireland. He spent eight years of his childhood bedridden from a mysterious illness that may have been psychosomatic in nature (Moss 230). Stoker came into his own in Trinity College, becoming a prize-winning athlete and admirer of Walt Whitman's Leaves of Grass. Graduating with honors, he spent a short time in a civil service post secured for him by his career bureaucrat father (Farson and

${ }^{46}$ The fact that none of these works originate from the mainstream London literary scene suggests that perhaps the poioumenon form is a kind of outsider art, as perhaps could be expected from a genre that purports to show the sausage being made. Insiders in the literary world (that is to say, authors writing from a position of privilege) stand to gain more from a position that venerates the author as a "natural" talent. Documenting too much of the machinery of writing undermines the cult of the author that allows establishment writers to trade on their name recognition. 
Dematteis 248). He spent most of his professional life in show business, writing play reviews, managing the Lyceum Theatre in London, and arranging tours in England and abroad for actor Henry Irving (Murray 284). Dracula is his fifth novel of the twelve he completed and was first published by Archibald Constance and Company in May 1897 (Moss 283-4).

The central conceit of the presentation of Dracula is that of a multimedia collage. Each passage in the text is designated as coming from a journal, a letter, a newspaper clipping, a diary, or the transcription of a phonograph diary. The story that unfolds relates the tale of the titular vampire's efforts to relocate his lair from his native Transylvania to London and the efforts by the humans caught up in this scheme to thwart him.

Dracula fulfills eight of Fowler's ten additional criteria for a poioumenon. The action is both discontinuous and farrago-like, as the narrative is literally assembled from a proliferation of disparate documents not wholly unlike the scraps in the biographical bags of Sartor Resartus. The whole text is arguably a set of inset texts, but especially the clippings from periodicals, such as the Dailygraph newspaper report of the wreck of the Demeter (itself inset with entries from the captain's logbook), the Pall Mall Gazette's account of the wolf missing from the Zoölogical Gardens, and the Westminster Gazette's report of the mysterious Bloofer Lady (ch. VII; XI; XIII). The author is completely obscured by a variety of fictionalized sub-authors, of which Mina Harker (née Murray) arises as the preeminent figure. The victory over Dracula hinges on her decision in chapter XVII to collate all the previous documentation of the vampire's activities and type a copy of the same (Mina Harker's Journal, 29 September; Dr. 
Seward's Diary, 30 September.). Not only does this act assemble the narrative thus far, allowing the vampire hunters access to the entirety of the fiction as it has unfolded up until that moment, but it also preserves this precious information (and thus the novel itself) when Dracula consigns the loose papers of the original manuscript documents to burn in a fireplace (ch. XXI).

Dracula's status as a counter-genre rests on its multimodal nature, which destabilizes the genres of the memoir narrative (Harker's journal) and the epistolary novel (Mina and Lucy's correspondence). The conceits of the journal and the exchange of letters each provide a rhetorical framework, a structure upon which an author may neatly lay out their plot. By switching from one form, then to the other, then exploding into a bewildering array of other textual artifacts, Dracula takes up the moment-tomoment tactical advantage of these predecessor genres while removing the reassurances of a conventional resolution to either form.

Dracula's preoccupation with its own fictive state manifests as an insistence that it is not fiction. This insistence is established in the opening passage, which appears in the front matter of the novel, though its exact location varies from edition to edition. In the original British edition, this passage appears opposite the first page of chapter I. 47 This unlabeled anonymous preface that lures the reader into the world of the novel:

${ }^{47}$ Thank you to Lisa Schoblasky, Special Collections Services Librarian of the Newberry Library for her assistance in verifying the placement of the opening note in the original 1897 London edition of Dracula. All other quotes and references to Dracula in this chapter come from Project Gutenberg's transcription of the original 1897 edition. 
HOW these papers have been placed in sequence will be made manifest in the reading of them. All needless matters have been eliminated, so that a history almost at variance with the possibility of latter-day belief may stand forth as simple fact. There is throughout no statement of past things wherein memory may err, for all the records chosen are exactly contemporary, given from the standpoints and within the range of knowledge of those who made them.

The novel's insistence as to its own verity returns in Jonathan Harker's postfatorial onepage "Note," where he reminds us of the existence of the Mina-typed transcript attesting to the reality of their adventure. He then quotes a defiant (that is, defensive) Van Helsing, "We want no proofs; we ask none to believe us!"

\section{The Book Within}

In addition to various features endemic to the genre of the poioumenon as described by Fowler, The Lay of the Last Minstrel, The Private Memoirs and Confessions of a Justified Sinner, Sartor Resartus, and Dracula all share a further commonality. They each contain a book as a narrative element, but the text of that book remains unquoted, unrevealed, or otherwise withdrawn. These withdrawn texts are the key markers of the ultimate failure of the poioumenon as a response to the Other Reader, in that each withdrawn text gestures toward an absent communication, a legibility that remains forever unavailable. Their appearance is an aberration, a signal of the failure of the poioumenon to represent a universe beyond the text.

In The Lay of the Last Minstrel, the withdrawn text is the book of spells belonging to the wizard Michael Scott. It begins the tale withdrawn from the world of 
the living, entombed with the wizard's body in Melrose Abbey (II.xiv-xv). When Sir William of Deloraine obtains the book, it resists access to its content, physically, with "iron clasped, and with iron bound" (II.xviii). When the goblin page acquires the book after Deloraine is wounded, the book actively opposes its efforts to obtain the information therein:

The iron band, the iron clasp, Resisted long the elfin grasp ; For when the first he had undone, It closed as he the next begun.

Those iron clasps, that iron band, Would not yield to unchristened hand.

Till he smeared the cover o'er With the Borderer's curdled gore ;

A moment then the volume spread.

And one short spell therein he read. (III.ix)

Note here that the interiority of the book only becomes available to the goblin page after he smears it with blood; access to its inner secrets only becomes possible when contact is made via the inner medium of biological life. But the reader is never directly presented with the text of the "one short spell," much like a subatomic particle whose presence cannot be observed but only inferred. Instead, its effects upon the plot are all we are allowed to see.

Similar to Michael Scott's grimoire, we can see this effect of withdrawal as two texts disappear from The Private Memoirs and Confessions of a Justified Sinner. The 
first is the manuscript for Wringhim's confession narrative, mentioned above. The reader is denied access to the original manuscript. Of course, this is true for every published text in a regime of print reproduction, but Hogg calls attention to that fact in a way that invites us to consider the layers of mediation between us and the act of authorship.

Earlier in Wringhim's confession we encounter another withdrawn text, upon the first conversation with the possibly-hallucinatory shapeshifter Gil Martin:

I came up to him and addressed him, but he was so intent on his book that, though I spoke, he lifted not his eyes. I looked on the book also, and still it seemed a Bible, having columns, chapters, and verses ; but it was in a language of which I was wholly ignorant, and all intersected with red lines and verses. A sensation resembling a stroke of electricity came over me, on first casting my eyes on that mysterious book, and I stood motionless. He looked up, smiled, closed his book, and put it in his bosom. " You seem strangely affected, dear sir, by looking at my book," said he mildly.

" In the name of God, what book is that?" said I.. " Is it a Bible?"

" It is my Bible, sir," said he... (187)

Note that this enigmatic Bible is withdrawn from the purview of the text by the act of putting it in his bosom, as if to attempt to bodily internalize the text. This is the same method Deloraine uses to secretly transport Michael Scott's book of spells in The Lay of the Last Minstrel (II.xxiv).

However, Gilmartin's Bible is even more withdrawn than Scott's grimoire, as the 148 
former never impacts the plot of the Private Memoirs. Wringhim has sufficient opportunity to glance at Gil Martin's book to see that it is organized like a Bible, even if the language is unfamiliar. However, the text is also "intersected with red lines and verses," which would have been unfamiliar to an early eighteenth-century Protestant. Following the era of incunabula, rubricated (that is, red-decorated) text was largely replaced by the use of italics in printed Bibles up until the introduction of the modern red-letter editions at the end of the nineteenth century (M. Smith 34; Eng). Gil-Martin's book is both familiar and unfamiliar, an oddity that enters into the world of the unheimlich ('uncanny') as described by Freud in his essay of the same name (120).

The central conceit of Sartor Resartus is that it is an attempt to review Die Kleider, ihr Werden und Wirken. To this end, we are given numerous excerpts from Teufelsdröckh's magnum opus. However, two things must be kept in mind here. First, the excerpts are completely at the discretion of the Editor character and the total excerpts do not add up to the entirety of Teufelsdröckh's text. Second, the original text is in German, so every excerpt we read is “translated” from an original that doesn’t exist. Each excerpt is a simulacrum, a copy without an original. The bags of biographical information are a similar case; the Editor mediates what the reader can access, both in terms of selection and translation.

The third withdrawn text in Sartor Resartus is the forthcoming sequel to Die Kleider, ihr Werden und Wirken, which Teufelsdröckh titles "Palingenesie der menschlichen Gesellschaft (Newbirth of Society)" (Bk. III ch. IX). He claims that the deeper mysteries of his philosophy of clothes will be revealed in that book, "treating practically of the Wear, Destruction, and Retexture of Spiritual Tissues, or Garments, 
forms, properly speaking, the Transcendental or ultimate Portion of this my work on Clothes, and is already in a state of forwardness" (Bk. III ch. II). Near the end of the work the Editor speculates that perhaps one day this work will come to light (Bk. III ch. XII).

In a story that hinges on the management of the proliferation, two texts withdraw from the protagonists in Dracula. The first is Jonathan Harker's journal, constituting the first four chapters of the novel, the only copy of which he desires to keep from the world and Mina secures: "I took the book from under his pillow, and wrapped it up in white paper, and tied it with a little bit of pale blue ribbon which was round my neck, and sealed it over the knot with sealing-wax, and for my seal I used my wedding ring” (Ch. IX). The journal, containing valuable firsthand information regarding Dracula, remains withdrawn until Mina reads it at the beginning of chapter XIV. Additionally, Van Helsing's telegram to Seward dated 17 September is withdrawn from the action of the story, as Van Helsing fails to address the telegram effectively; he directs it to "Seward, Carfax" not realizing that in addition to the estate of Carfax (the intended designation of the message) there is also a better-known village by that name in Sussex (Ch. XI). The result of the withdrawal of this text from circulation is the death of Lucy at Dracula's hands and her subsequent curse of undeath.

The primary withdrawn text of Dracula is the text of the novel itself. As mentioned above, Dracula throws the originals of the various journals and manuscripts into a fire in an attempt to thwart his opponents' efforts to organize against him (Ch. XXI). Mina's typewritten copies are all that remains as evidence of the existence of the original documents, as Harker mentions in the final note: 
I took the papers from the safe where they have been ever since our return so long ago. We were struck with the fact, that in all the mass of material of which the record is composed, there is hardly one authentic document; nothing but a mass of type-writing, except the later note-books of Mina and Seward and myself, and Van Helsing's memorandum. We could hardly ask any one, even did we wish to, to accept these as proofs of so wild a story.

Thus Dracula, a novel built up out of contemporary first-person accounts and newspaper clippings, ends by calling attention to the break in the line of transmission from those now-lost originals to the printed copy in the reader's hands.

\section{Conclusion}

Through the act of drawing the author and the writing process into the narrative, the poioumenon attempts to surmount the fundamental disconnect of writing in the age of print: instead of the direct communication of the author to the physically present audience (as in the era dominated by oral literature), the author writes for an unknown number of absent, anonymized readers. The additional layers of mediation increase the possibility of miscommunication with each additional step in the chain of transmission; what begins as a thought in the author's head must pass into manuscript form, that manuscript must be edited into a text that serves as a print commodity, where it is taken up and decoded into the readers' thoughts, which may or may not have any correspondence with the author's originating thoughts. The spectre of the Other Reader, 
who will misinterpret the author's intent ${ }^{48}$, looms so large that some authors take the drastic action of placing themselves and the writing process directly into the text. The fantasy at play here is that somehow the gulf between signifier and signified can be bridged by the appearance of an authorial proxy, in the form of an authorial character and/or the fictionalization of writing itself. The presence of this proxy attempting to mitigate the threat of the Other Reader is what Fowler identifies as the poioumenon. By laying open the machinery of literary composition itself to scrutiny, the author invites the reader to gaze directly on the literary work in its moment of origination. We are no longer readers; the poioumenon invites us to be co-participants in the composition, to grasp the same pen as the author and watch the words emerge for the first time.

However, the poioumenon will never solve the problem it is designed to address. Instead of clarifying authorial intent or level the relationship between author and reader, the presence of the poioumenal proxy serves only to create additional layers of remediation. In Deleuzian terms, the author and their writing process are drawn into the virtuality of the narrative. Previously outside that virtual space, the author could serve as the imagined ground of the text, what Foucault calls the "contour" of the text (123). Drawing the author within the contours of the very thing those contours outline

${ }^{48}$ This is not to say that authorial intent is the sole determiner of meaning in a text. What matters here is that at the moment of inscription the will of the author seems to be the sole driver of the act of writing. Although the conscious thoughts of the author cannot account for the entirety of meaning, the act of creation includes a certain "asifness" that, though subject to challenge and complication, cannot be completely denied. 
destabilizes the boundary between the text and the rest of the universe. The distinction between writing the noun and writing the verb collapses. Like a biological cell bereft of its outer membrane, there is no longer a way to distinguish between what is interior to the text and exterior to it. The division between individual and environment vanishes, leaving only pure circulation. The reader is left, not holding the authorial pen, but rather a pig in a poke. The poioumenon is an attempt to overexplain, overjustify, and therefore overdetermine the text. It is text seeking to write itself into existence, a moment of pure proliferation without origin. Like a king declaring a new law or a priest declaring a couple man and wife, it is performative act, achieving its end in its own language. Barthes' dead author rises from the grave as a fictionalized "explanation of a work" [emphasis original], no longer exterior to it (143).

The withdrawn text form of the book-within-the-book appears in the pages of poioumenon as a stopgap solution to this category crisis. It effectively inverts the normal relation between inner text and outer universe, creating a world where inside the text is an inaccessible mystery. That hidden universe can take many forms, whether it be the inaccessible magics of the wizard Michael Scott's spellbook, the enigmatic theologies of the red-lined Bible of Gil Martin, the eternally forthcoming follow-up to Teufelsdröckh's philosophical magnum opus, or the original real-time documents attesting to the threat of Dracula. These texts are only present as absences, in a place where the reader cannot follow.

In the effort to escape the instability of the poioumenon, the use of the withdrawn text creates an ouroboric effect; the author is pulled within the gravitational field of the text to plead directly to the Other Reader, but the withdrawn text re-opens the very 
unintelligibilities the poioumenon was meant to avoid. Addressing the threat of the Other Reader via the complete saturation of text with paratext creates an event horizon in which meaning itself vanishes. The Other Reader will never be able to misinterpret Gil Martin's Bible or Michael Scott's grimoire, because no one has access to those texts. They are the necessary suture in the text, testifying to the incompleteness of any literary system to completely account for itself.

Furthermore, the book-within-a-book remediates the fear of the unknown at the heart of the Other Reader formation, revealing the specific technological, economic, and cultural sources of that anxiety. The spellbook in The Lay of the Last Minstrel, a text of great but inaccessible magical power, shows Scott attempting to navigate authorship as an identity category. One the one hand, we find a wizard bearing the author's name possesses strange powers which he can transmit via a book. One the other, that wizard and his book appears in a poem designed to mimic the oral, prelapsarian past. As Foucault notes, "there was a time when those texts we know call 'literary' (stories, folk tales, epics, and tragedies) were accepted, circulated, and valorized without any question about the identity of their author" ("What is an Author" 125). Scott acknowledges this pre-authorial era by never providing a name for either the fictional author of the lay sung by the last minstrel, nor of the minstrel himself. They function not as the individual origin point of a print text, but as the anonymous corporate voice of a preliterate culture. Sir Walter sits at the boundary of these two modes, his Minstrelsy of the Scottish Border preserving the old order (and thereby remediating it to print) just prior to entering the new regime of print as the "Great Unknown," the foremost novelist of the age, whose name is anonymity itself (see chapter I). The Lay fabulizes this moment of 
transition, depicting the older, bardic order passing away while anticipating the anguish of becoming a name attached to a book rather than a body, a strange existence where any old goblin, or Other Reader, can do what they please with your words. No amount of poioumenal activity can resolve this anxiety, which is signaled by the withdrawal of the spellbook from the purview of the reader.

Gil Martin's Bible suggests a similar breakdown of the poioumenon, an indicator of its ability to depict the totality of the authorial intent in the face of the Other Reader. In this case, what is at stake is biblical authority itself, as Wringhim's status as a “justified" sinner rests upon his Calvinist interpretation of Scripture. But this justification can never be complete in a universe that contains an alternative, yet unavailable Scripture. Gil Martin's mysterious book serves as a metaphor for the inability to locate the original meaning of holy writ from a position approximately 1,600 years, 3,000 miles, and numerous layers of remediation from their origin. Wringhim stands in for all us, his faith-driven excesses warn us that we are all Other Readers of the Bible.

Sartor Resartus features a pair of books-within-a-book, both of which are withdrawn from the text. The first is Die Kleider, ihr Werden und Wirken (Clothes, their Origin and Influence), the book that Sartor Resartus ostensibly reviews. The other is Professor Teufelsdröckh's forthcoming follow-up volume, On the Palingenesia, or Newbirth of Society (Carlyle Bk. III ch. III). The function of a review is to account for a text, to provide a summary--that is, a paraphrase--of use to a particular audience. Sartor itself is thus an account Die Kleider, but unlike a typical review, the reader cannot use it to decide whether or not to pursue the object it reviews. This alienation is further 
compounded by the fictional and hypothetical status of On the Palingenesia, which is even more phantasmal than Die Kleider. Teufelsdröckh claims that the Palingenesia is the culmination and explanation of his prior work, which leaves the reader with a paraphrase of an incomplete text and no ability to ever check that paraphrase for accuracy or completeness. The answers to the questions raised by Carlyle's review can only be answered in a book that doesn't exist, unless they are found in a book that exists even less. The effect achieved is a double insulation: Sartor cannot possibly account for a text that cannot account completely for itself! Carlyle has built a world where the Other Reader cannot gain a foothold with an idiosyncratic interpretation of the text, because the text itself is nothing but an interpretation.

The manuscript pages of Dracula hurled into the fire by the eponymous vampire account for twenty of twenty-seven chapters of the novel. Nearly the entire action of the novel prior to the harrowing of Dracula out of London, the chase back to Transylvania and the monster's destruction has been reduced to "nothing but a mass of typewriting" ("Note"). The written manuscript, the signet attesting to the authorial origin in the regime of print, has disappeared, leaving only a mechanical simulacrum. The typed version serves as an intermediary between the original and the print edition in the reader's hand. This intermediation disrupts the structural relationship between manuscript and print that was operational from Gutenberg to the advent of the individual typewriter, whereby the author's fair copy served as an analogue to the signified, while the print edition was analogous to the signifier. Although the original manuscript may not have been available in actuality for a reader to check their print copy against, such a relationship existed virtually. Dracula's vandalism disrupts the 156 
virtual space in which the print edition analogizes the handwritten original, resulting in a situation where the original documents are unavailable to the Other Reader for scrutinization. Van Helsing declares in the final Note, "We want no proofs, we ask none to believe us" in direct contradiction of the truth claim made in the opening paratext. Those readers willing to accept the story as given have everything they need to enjoy the text, those Other Readers who wish to investigate further are left with a vacuity.

As poioumena, all four of these texts seek to hermetically seal the text by including its own composition within its diegetic action. However, this walling off from the world inevitably comes with the threads of its own undoing, as a text cannot be both isolated from the world inside its own bubble and still go forth as a published text. The withdrawn book-within-a-book establishes a limit to that containment, a space where neither the author nor the Other Reader can probe further. Like the flaw in a Persian rug, the withdrawn book-within-a-book completes a poioumenon by acknowledging its own incompleteness. 
CHAPTER IV: THE RAGGED ASTERISK: SAMUEL ROGERS, THE GIAOUR, AND THE FOLLY OF THE TORN PAGE

Printer's ink and paper, canvas and oils can be lavished, their cost is small restraint; but the hewn stones, the scaffolds, and the vast array of masons make architectural follies too prodigal for repetition.

--Rhys Carpenter, The Esthetic Basis of Greek Art of the Fifth and Fourth Centuries B.C.

This chapter focuses on two texts, Lord Byron's The Giaour and Samuel Rogers' The Voyage of Columbus. Both poems take the form of collections of fragments that present themselves as the work of multiple authors. Furthermore, both poems make use of a specific non-alphabetic typographic move, employing multiple instances of lines of asterisks that interrupt the flow of the verse. Since Rogers is an obscure figure rarely mentioned in modern scholarship (apart from his connection to The Giaour) I will begin with a brief outline of his career. Additionally, I will offer a brief history of the asterisk from its origins in ancient Mesopotamia to its usages in eighteenth- and nineteenthcentury printing practices. My argument is that the line of asterisks used in both The Giaour and The Voyage of Columbus build upon the long history of the asterisk as an indicator of erasure. Each line of asterisks marks a moment of simulated disruption of the act of narrative, an intentional ruining of the flow of the narrative. I will draw a parallel here with the architectural follies of the eighteenth and nineteenth century, particularly those follies that are designed as ruins. Ultimately, I conclude that, just as the folly invokes an earlier era of historical construction, the asterisks employed by Byron and Rogers realign their relationship with readers, shifting them from those relations inherent to the age of print to an earlier oral/manuscript mode. 
The authors of the texts examined in the previous two chapters attempt to address the Other Reader by the addition of apparatus to guide/control their reading. Rather than an additive approach designed to ease the way for the imagined Other Reader, Rogers and Byron take a more oppositional, reactionary stance. Instead of attempting to make the text more accessible via the addition of satellite texts, Rogers and Byron offer effaced texts that alienate. The line of asterisks employed by the two poets takes the material form of a supplement to the text, but that supplement is itself an absence.

\section{A Ruin of a Poet}

Byron critic Alice Levine's introduction to The Giaour indicates that Roger's 1812 work The Voyage of Columbus, serves as "model and inspiration for the fragmented narrative form" of Byron's poem (122). Rogers is rarely mentioned today outside of this context, but at one time he was a well-known figure in British letters. For example, see the 1936 volume British Authors of the Nineteenth Century: Complete in One Volume with 1000 Biographies and 350 Portraits, edited by a Stanley J. Kunitz. The entry for Samuel Rogers amounts to three columns of text, a page and a half, out of this hefty 677page work. By way of comparison, Edward Bulwer-Lytton has about the same size entry, while Byron gets 3 and half pages and Keats not quite 3 .

In his journal entry for 24 November 1813 Byron counts Rogers the second greatest poet living, surpassed only by Sir Walter Scott, who sits atop the apex of a poetical pyramid devised by Byron, which includes Thomas (a.k.a. Anacreon) Moore and Thomas Campbell just below Rogers with Robert Southey, Wordsworth, and Coleridge below them (Moore 227). In his discussion of the hierarchy of British poets 
Byron mentions that he considers Rogers to be "the last of the best school" rather than the best of the last. Byron also notes that this ranking is not based upon his own preferences, but rather what he believes to be the popular opinion of the day, though his does dedicate The Giaour to him (Levine 123). William St. Clair documents over 45,000 copies of Rogers-penned poetry sold prior to 1847 (632).

When Byron penned his dedication to Rogers the bad boy of Romanticism was 25 years old while Rogers was forty. By that time Rogers had been living well in London for more than 20 years, with an income of $£ 5,000$ per year from the family banking business. According to the Bank of England inflation calculator, that would amount to over $£ 340,000$ per annum in 2018 pounds, a figure approaching approximately half a million US dollars or more, depending on the exchange rate ("Inflation Calculator"). The two-volume Bookman Illustrated History of English Literature, an unabashedly opinionated and decidedly teleological work published in 1906, refers to Rogers as "that anomaly in nature, a rich poet, a Parnassian banker, a Liberal in spirit, and a Tory in form" (383). He was offered the Poet Laureateship on the death of Wordsworth but declined (St. Clair 632).

British Authors, the Bookman Illustrated History, and the Cambridge History entries all agree that Roger's largest contribution to literary history was breakfast. His regular morning fetes served as the hub in a large literary circle that included Byron, Wordsworth and Richard Sheridan. He was also a patron of the arts, including a collection that sold for $£ 50$, 00o following his death in 1855 . 
In 1818 Byron writes a humorous poem about Rogers, though it isn't published until it appears in the pages of Fraser's Magazine in January 1833. The work is short, 76 lines divided into two sections, labeled "Question" and “Answer.” It is perhaps not completely irrelevant to note that the first section (“Question”) describes Rogers's physical appearance as that of a shriveled, mummified corpse, i.e. as a human ruin:

Nose and chin would shame a knocker ;

Wrinkles that would puzzle Cocker;

Mouth that marks the envious scorner,

With a scorpion in each corner

Curling up his tail to sting you,

In the place that most may wring you ;

Eyes of lead-like hue and gummy ;

Carcass pick'd out from some mummy ;

Bowels (but they were forgotten,

Save the Liver, and that's rotten) ;

Skin all sallow, flesh all sodden,--

Form the devil would frighten God in.

Is't a corpse stuck up for show,

Galvanized at times to go ?

With the Scripture in connexion,

New proof of the resurrection?

Vampire, ghost, or goul, what is it?

I would walk ten miles to miss it. (1l. 1-18) 
Despite his own literary achievements and connections to numerous other artists, Rogers has faded in obscurity. Today, when he is mentioned, it is almost always in connection with Byron and The Giaour. He is a more-than-half-forgotten relic of an earlier age of pre-Romantic sentimental verse. His only existence is as a crumbling ruin decorating an odd corner of the vast literary estate of Lord Byron, a folly in the shape of a man. In the next section I will outline the history of the architectural folly and its relationship to Byron's literary project.

\section{Folly and Ruin}

At the conclusion of "Marge vs. the Monorail," a fourth season episode of the animated situation comedy The Simpsons, the camera pulls out during the monologue, revealing the dubious public works built by the people of Springfield. Julie Kavner (voice actor for the role of Marge Simpson) provides the concluding narration:

And that was the only folly the people of Springfield embarked upon. Except the popsicle stick skyscraper. And the fifty-foot magnifying glass. And that escalator to nowhere.

(“Marge vs. the Monorail.”)

As the last line is spoken, three citizens of Springfield ride the escalator into the sky, promptly falling off when they reach its zenith.

Marge Simpson's characterization of the Springfield Monorail and the other nonsensical public works as follies taps into the double meaning of the term. Derived from the Old French folie, the original meaning of the word in English is "The quality or state of being foolish or deficient in understanding; want of good sense, weakness or derangement of mind; also, unwise conduct" ("folly, n.1."). This use of folly is attested to 162 
in the record as early as 1225. Approximately four centuries later the term would also come to mean "A popular name for any costly structure considered to have shown folly in the builder."

The Old French folie also carried with it the connotation of "delight;" a folly is a pleasant foolishness. We can see the entanglement of the unwise and the delightful in the first known edifice to bear the term in its name. Hubert's Folly was the name given to the partially completed castle built by Hubert de Burgh. He had named it because of the delight the new abode would bring him, but was accounted presciently foolish when, in 1228, a new obligation under a treaty with the Welsh required that the erstwhile fortification be pulled down to its foundation stones (de Wendover 350-1).

In one sense the term folly is a catch-all, given the wide variety of sizes, designs, functions, and materials from which they are made. But in another sense, they all share a set of common features. Perhaps the most important feature of a folly is the sense of excess. This aura of excess is not solely expressed in terms of the funds lavished upon, for example, constructing a garden hothouse to look like a gigantic stone fruit, as in the case of the Dunmore Pineapple in Stirlingshire, Scotland (Buxbaum 50). The folly, by its very existence, exceeds the bounds of time and space. There is the case of the Dunmore Pineapple, another space invoked in both its physical resemblance to a fruit grown in another clime and its function of enabling tropical vegetation to be grown in the inhospitable Scottish clime. Another time is also invoked by the creation of warm summer climes even in the midst of winter.

The builders of the false ruin type of folly (see below) anticipate Jean Baudrillard's concept of the hyperreal, a "model of a real without origin or reality" (1). 163 
Umberto Eco further traces the borders of the concept in his essay collection Travels in Hyperreality, noting that the "imagination demands the real thing and, to attain it, must fabricate the absolute fake; where the boundaries between game and illusion are blurred" (8). A classic example of the hyperreal would be Cinderella's Castle at the Magic Kingdom of Walt Disney World. Cinderella's Castle isn't a medieval fortification, but rather a restaurant, gift shop, and never-used apartment constructed to resemble a monarchal domicile from the late Middle Ages. Yet every day thousands of tourists treat it with a special reverence that exceeds the utilitarian functions of the edifice. Alone, a false ruin or a semi-castle is merely an oddity. What makes it a folly is its participation in a wider array of architectural, economic, and spatial relations. They implicate times and places that are neither present nor current.

Although follies run a mad gamut of architectural styles from Greco-Roman to faux Egyptian to Gothic, the folly at Benington Lordship in Hertfordshire possesses some elements typical of many such structures. A Norman castle with a dry moat was built on the site in 1138, but was razed on order of Henry II in 1177, leaving only the moat and a few crumbling walls. It was rebuilt prior to 1192 but pulled down a second time by King John in 1212 ("Benington Castle"). The current red brick manor house was built at the end of the seventeenth century. In 1826 a new owner hired architect Thomas Smith and builder James Pulham to add a new Norman "ruin" to the structure (“Benington Castle, TL 297-236 Hertfordshire”). James Pulham’s son--also named James--described the project in Picturesque Ferneries and Rock Garden Scenery, an 1877 pamphlet advertising the family firm: 
There is a fine example of various parts of a Norman castle, forming a courtyard to a gentleman's house at Benington, including an apartment for smoking room, corridor, large dining hall; gateway, with high towers on each side; a staircase, with enclosing buttressed walls, etc, all built of flint, with artificial stone dressings, mouldings, windows etc, executed by us in 1835-36-37 and 1838, as a ruin, supposed to be real... (qtd in Hitching 21) Unlike many follies, the finished gatehouse at Benington Lordship is an integral part of the manor house, built as an extension of the primary structure of the estate. What makes it typical of an English folly are the following:

- Invoking a past time period - Here the architecture is neo-Norman. Examples of neo-Roman and neo-Classical follies are also common.

- Anachronistic or absent function - Follies tend to either lack a purpose (apart from aesthetics) or else their utility is incommensurate with their obsolete design. The gatehouse at Benington does not serve to guard the entryway to a castle, as a proper Norman gatehouse would. Rather it serves, among other things, as a smoking room, a category of chamber unknown to the Norman conquerors.

- Materials are selected to contrast with those of the primary structure on the estate. - In this case the Norman folly is made of cut stone to distinguish it from the red brick of the manor house it enhances. In her survey of the follies of the Britain, Barbara Jones refers to the gatehouse as "tacked on" to the seventeenth century manor (343).

- Artificial ruin - Note the younger Pulham's phrase "as a ruin, supposed to be real." The gatehouse at Benington is not just an extension of the manor house 
done in a retro style; rather, it is conceived of as an exercise of constructing a past that never existed. This is accomplished by building a new structure with the appearance of wear and tear. Interior decorators today refer to this as the "distressed look," which is accomplished by such means as painting a piece of wooden furniture, sanding part of the dried paint away, then finally applying stain over the paint to give the appearance of aging to both wood and paint (Fazio, Hiller). The elder Pulham made his name as a folly builder thanks to his development of "Pulhamite," a form of artificially weathered stone (Follies, Grottoes \& Garden Buildings 272-3).

Folly historians Gwyn Headley and Wim Meulenkamp describe the prototypical folly as "a big, Gothick, ostentatious, over-ambitious and useless structure, preferably with a wildly improbable local legend attached" (Follies: A National Trust Guide xxi). The overall effect of these four traits is to grant the folly the ability to gesture toward an unreal past by signaling the present's break from that past. The very discontinuities of the folly--in terms of style, function, form, and state of disrepair--create a connection to an artificial past.

Writing in the introduction of Preposterous Erections, a survey of tower follies, Peter Ashley notes that the absurdity of a folly is a state imposed by someone other than the owner, architect, or builder of such edifices:

But the word [folly] is the label most often attached to them, and at least everyone knows what's being talked about. But the word has a tendency to suggest foolish or absurd actions, that these highly visible towers are somehow just fanciful whimsy... but it would be wrong to think of all their 
builders as profligate and unthinking megalomaniacs. However... folly building does indeed rise up into our consciousness with varying degrees of both idiosyncrasy and incongruity, and all are imbued with a certain intrigue and mystique. (7)

In her monograph Follies: Fabulous, Fanciful, and Frivolous Buildings, architectural historian Gwyn Headley argues that "Follies are misunderstood buildings. In almost every case, the buildings... were erected by men (and a couple of women) who believed that what they were erecting was logical and necessary" (6). Headley concurs with Ashley that the term folly usually only becomes attached to a building after it is built, upon the judgment of the general public. That is to say, these edifices fully manifest as follies only in the presence of an audience outside the immediate circle of the builder and the owner. From the perspective of the owner, the folly is an expression of individual aesthetics: "the folly builder, then, indulges a natural urge to express eccentricity with all the resources of wealth and imagination he can muster." (Follies: A National Trust Guide xxi) They are follies-as-in-foolishness only viewed from the outside, from a position of the architectural equivalent of the Other Reader.

That is to say, the folly is legible as a text, at least from within the discourse community of the moneyed class capable of financing these edifices. The parallel to the Author here is the individual who commissioned the construction of the folly, while the imagined Reader are the members of high society who, it is hoped, will appreciate the aesthetic play of the architectural conspicuous consumption (Veblen 69). But outside the boundaries of that community, the farcical nature of the folly as an ultimate gesture of upper-class excess becomes visible. 
Critic Shahidha K. Bari explicates the poetic function of the (non-folly) ruin in Romantic verse, arguing that "The ruin is, itself, always anamorphic. The surviving remainder of a lost past that continues as a reminder in the present, the ruin is, at once, something and nothing" (144). This vector of the Romantic project can be traced back to Horace Walpole's Castle of Otranto, inaugurating the new genre of Gothic literature (Praz 15). The Romantics inherit two key concerns from the earliest Gothic novels: the experience of overwhelming emotion and a fascination with ruins. Both these factors can be seen in Wordsworth's Tintern Abbey or the narrator overcome at the "ruined fort" of "The Female Vagrant" (1. 192). From Coleridge we see the sympathetic agonies encountered in the anguish of the sonnet "On a Ruined House in a Romantic Country," and the horrific ghost ship encountered in The Rime of the Ancient Mariner is a floating ruin, a haunted Gothic castle upon the waves.

A survey of Byron's poetic output shows that he mentions ruins in no less than fifteen of his works. Among these are the poem that secured his literary superstardom, Childe Harold's Pilgrimage, and two works about his family home, Newstead Abbey. The latter was in a state of ruin, as described by Francis Hodgson after visiting Byron there in 1811: "[A] straggling, gloomy, depressive, partially inhabited place the Abbey was. Those rooms, however, which had been fitted up for residence were so comfortably appointed, glowing with crimson hangings, and cheerful with capacious fires, that one soon lost the melancholy feeling of being domiciled in the wing of an extensive ruin." (219).

Mention of ruins can be found in several of Byron's correspondence. In the 26 April 1809 letter to John Hanson discussing his faltering finances, he insists on clinging 
to Newstead Abbey, despite its dilapidated state, preferring to suffer financial ruin rather than part with the physical one: "I can meet ruin, but I will never sell Newstead; the Abbey and I shall stand or fall together, and, were my head as grey and defenceless as the Arch of the Priory, I would abide by this resolution." Several times during his tour of the continent he reports back to his mother that he has visited a ruin. The 12 November 1809 letter to his mother mentions seeing "the ruins of Nicopolis, built by Augustus in honour of his victory," while his March 19th, 1810 letter to her indicates that he travelled a day out of his way from Smyrna to visit the ruins of Ephesus. A subsequent letter to his mother, dated April 1oth of that year, suggests that he made a return trip to the ruins. In his 5 May 1810 letter to Francis Hodgson, Byron suggests he may be ready to return home to England, claiming to have already seen "all the most celebrated ruins of Greece and Ionia" and his 28 June 1810 letter to his mother reports "I have seen the ruins of Athens, of Ephesus, and Delphi." His 29 November 1813 letter to publisher John Murray refers to The Giaour as "a string of passages" and refers to the writing of fragments as "a species of composition" like a "ruin in a view."

In short, Byron conceptualizes The Giaour as a folly made of words rather than Pulham's artificial stone. Each fragment functions as artificially weathered "remains", tastefully arranged to suggest a whole that never existed, just as with a folly placed at an aesthetically advantageous point on an estate. Within this crumbling edifice of words, the lines of asterisks mark the artificially weathered surfaces, places of intentional illegibility that attested to a false veracity. The next section provides and overview of the origin and development of the asterisk as the preeminent symbol for the indication of an absence, a marker of the distance between the text as presented and the text the author 
desires to present.

\section{History of a Character}

A symbol consisting of lines radiating from a central point has been a component of the collective symbology of humanity for at least 26,000 years. As part of her efforts to construct the first comprehensive database of non-animal symbols in Ice Age cave art, paleoanthropologist Genevieve von Petzinger located five examples of the asterisk among Upper Paleolithic humanity. Two are located in caves in the Dordogne river valley of France, not far from the famous Lascaux cave complex. The other two are found in caves in northern Spain (200-2). The fifth is incised on a deer tooth that forms part of an elaborate necklace worn by the so-called La Dame de St. Germain-la Rivière, the corpse of a richly-adorned paleolithic woman uncovered by French archaeologists in the 1930 (192-2). Like the 31 other geometric signs documented in von Petzinger's survey of fifty-two sites of European cave art, the meaning ascribed to these asterisks by their creators remains a mystery that may never be solved (265-6).

The Sumerians used an asterisk glyph called dingir as a silent symbol to indicate the name of a deity, in much the same way the ancient Egyptians put the name of pharaohs in cartouches to provide a visual mark of authority and power. Sumerianists translate the dingir glyph, “稆, made by using the stylus to form four lines crossing at a single point, as the word "a god," possibly originally referring to a singular god named An, the sun/sky father (Edzard 172; Houston 98). The Akkadian and Hittites later adapted the symbol to their own language, as they did with much of the Sumerian script and vocabulary. Similar developments can be seen in the adaptation of the Phoenician alphabet (itself perhaps influenced by the Sumerian cuneiform) by the Greeks and the 
later co-option of Greek culture by the Romans and Greco-Roman culture by the Germanic barbarians. It is perhaps through this series of transmissions that the rune ior, “*," appears in the Anglo-Saxon Rune Poem (R. Page 85). Thus, the asterisk or a mark like it has been in use by humanity longer than many of the alphabetical symbols it now punctuates.

Asterisk-like marks have been used in the same way we use check marks on lists, with examples going back at least 3,000 years (Humez and Humez 30). The asterisk enters in usage as a paratextual bibliographic indicator nearly two millennia ago. The earliest form of the term asterisk (derived from the Ancient Greek root for "star") appears in the work of 2nd-century BC scholars Aristophanes of Byzantium and Aristarchus of Samothrace. In their work compiling the known sources of Homer in a single edition, their practice was to mark duplicate lines in manuscripts with a symbol resembling an $\mathrm{X}$ with a dot in each angle: $※$, which they called the asteriskos (Grafton et al. 83). Later, the Church Father Origin used the same symbol to indicate missing lines in his translation of the Hebrew scriptures (Parkes 14; Schironi 447). In late antiquity, Isidore of Seville formalized this function, stating in his Etymologiarum sive Originum that the asterisk "is put in place of something that has been omitted so as to call attention to the omission" (Houston 99).

At the dawn of the age of print, the asterisk reached its modern form. It continued in use for the marking of omissions, but also became used as a marker directing the reader to additional information in the side or bottom margins (Parkes 57). Historian Anthony Grafton notes that Jonathan Swift wielded the asterisk as a weapon in his ongoing belletristic war against the scholar Richard Bentley, showing "that he 
knew the minutiae of philological technique when he left gaps in his own text, filling them with asterisks and describing them, in the margins, as 'hiatus in MS'" (The Footnote 113). In the era of the typewriter, the primary usage of the asterisk was "to signify omission of something that can be found elsewhere (as in the footnote) or gathered intuitively (as in a $\mathrm{f}^{* * *}$-letter word)" (Lundmark 120). Historical linguists use the asterisk to mark hypothetical, typically reconstructed utterances that are unattested, i.e. not within the record (Finegan 41). In the field of computer science, the asterisk functions as a wildcard character, holding a place to indicate that any possible character could be indicated, while statisticians use it to indicate probability (Lundmark 119). Or to put it another way, the asterisk stands for "anything and nothing in particular" (Humez and Humez 71).

As can be seen by this brief survey, since at least Origen in the second century of the common era the asterisk has been a symbol of withdrawal. An asterisk indicates an absence, a lack, a displacement, whether that lack is a god who is named but physically absent, or an obscene word that has been withheld from the delicate sensibilities of the reading public, or the proposed retraction of a line of verse for an editorial reconstruction. If there is an asterisk, the text is not here, but elsewhere, whether that missing text is displaced in the margins, lost in the past, or otherwise left to the reader to supply (Dworkin 79). Even in the case of the Sumerian dingir, the symbol either indicated a god in general, i.e. the name of an entity that never manifests in physical reality, or the sun/sky god An, visible but forever out of reach. In this way, the asterisk is the typographical parallel to Pulhamite or the other marks of antiquity worn by follies. Both the asterisk and the false ruin of the folly gesture toward something beyond their 
constituent bodies, both indicate a signifying lack awaiting a reader to complete.

\section{The Ragged Line}

The same strange coupling of real discontinuity and artificial continuity that marks an architectural folly manifests on the pages of both The Giaour and the Voyage of Columbus by entire lines of asterisks. These formations appear to be a variant of the “dinkus" or "dingus," a smaller, tighter formation typically made of three asterisks centered on the page, like so:

The dinkus is often used to indicate the passage of time, i.e. a break in the narrative (Lundmark 120).49

As presented in the The Poetical Works of Samuel Rogers (published 1852, just three years before Rogers' death), The Voyage of Columbus begins with a glorious whirlpool of paratextual elements to draw the reader deep under the waves. We begin with a title page with a quote by Dante, followed by an illustration of a cherub holding a stern mask under which Shakespeare is misquoted: "I have seen the day,/That I have worn a visor, and could tell/A tale-", a misremembering of Romeo and Juliet, Act 1, Scene 5 (62). Following the preface is a short poem entitled "Inscribed on the Original Manuscript" in which the document itself addresses the reader:

Unclasp me, Stranger; and unfold,

${ }^{49}$ A titillating example of dinkus usage can be found in Leopold von Sacher-Masoch's 1870 novella Venus in Furs. The flow of the text is interrupted by three asterisks at each point where a reader of a certain frame of mind would expect to find a lurid sex scene. 
With trembling care, my leaves of gold,

Rich in Gothic portraiture-

If yet, alas, a leaf endure. (1. 1-4).

This same poem claims that the work is the fragmentary remains of ancient work translated from the original Castilian (1. 7).

After these initial claims follows the "Preface to the Second Edition" in which the author again insists that the poem is an ancient text recovered from the Iberian Peninsula, even arguing that the faults in the plotline must be accepted given the antiquity of the source. Next comes the Argument and finally we get to the text of the poem, divided into 12 very short cantos, consisting of a page or two of verse each. Following the main body of the text are four more pages of fragments introduced in the following manner: "On the two last leaves, and written in another hand, are some stanzas in the romance or ballad measure of the Spaniards. The subject is an adventure soon related" (109). Four pages of "Additional Notes" follows, which refer to the "translator" of the poem as if a real person, much like the first edition of the Castle of Otranto (see Chapter I).

The lines of asterisks serve to implicate the reader in an imaginary past where these verse narratives existed in an intact form. But this original exists only as a Platonic ideal if it exists at all. There's no evidence to suggest that Rogers ever intended the Voyage of Columbus to be a more intact work. Rather, the work was designed as a series of vignettes, anticipating the filmic technique of the montage. Evidence that Columbus is a complete work can be found in the paratexts introducing the cantos. The Preface warns in the first paragraph that the poem is "sudden in its transitions" (63). Following 
the preface is a 50 -line verse prologue, which takes the form of a message from the fictitious original manuscript inscribed on itself. The last four lines of this message warn of the material condition and contrafactual state of its own contents:

My leaves forsake me, one by one ;

The book-worm thro' and thro' has gone

Oh haste--unclasp me, and unfold ;

The tale within was never told! (1. 47-50)

The theoretical damage rendered to the text by the voracious bookworm appears in the text as deliberate interruptions of the narrative, indicated by one or two lines of asterisks. A typical example of this technique appears early in the first canto. The poem opens with the narrator introducing Columbus by praising him and his divine mission to bring the gospel to the New World, but then abruptly shifts:

Him could not I exalt--by Heaven designed

To lift the veil that covered half mankind !

Yet, ere I die, I would fulfil my vow ;

Praise cannot wound his generous spirit now.

'Twas night. The Moon, o'er the wide wave, disclosed

Her awful face ; and Nature's self reposed ;

When, slowly rising in the azure sky, 
Three white sails shone--but to no mortal eye,

Entering a boundless sea. (I.15-24a) 50

The two lines of asterisks signal a hard break from the narrator's opening paean to Columbus. Suddenly, we find ourselves in the Atlantic at night, among the Niña, Pinta, and Santa María. Of the twelve cantos of the Voyage, seven of them have at least one line of asterisks intentionally interrupting the normal narrative flow of the text. Table 5 summarizes the appearance of lines of asterisks in the twelve cantos of the main text of The Voyage of Columbus, as well as the hybrid verse/prose epilogue.

Table 5

Appearance of lines of asterisks in Samuel Rogers' The Voyage of Columbus

\begin{tabular}{|c|l|}
\hline Canto & Lines of asterisks \\
\hline I & Double line \\
\hline II & Single line at beginning of canto \\
\hline III & Two double lines--one of which ends the canto--and a single line \\
\hline IV & Begins with a single line, another single line appears 7 lines later \\
\hline
\end{tabular}

(Table Continues)

${ }^{50}$ Unless otherwise indicated, all quotations from the Voyage of Columbus are taken from the 1856 edition of Rogers' Poetical Works, which does not include line numbers in the text. I count each line of asterisks as one additional line, although they can represent longer imaginary lacunae. 
Table 5, Continued

\begin{tabular}{|c|l|}
\hline Canto & Lines of asterisks \\
\hline V & Begins with a single line, ends with a double \\
\hline VI & Two double lines, one of which ends the canto \\
\hline VII & NONE \\
\hline VIII & NONE \\
\hline IX & NONE \\
\hline X & Single line at beginning of canto \\
\hline XI & NONE \\
\hline XI & NONE \\
\hline XII & No lines of asterisks, but an anomalous line of dashes \\
\hline Epilogue & Two single lines, one double line \\
\hline
\end{tabular}

Each of these lines indicates a shorter or longer break in the narrative, where the scene, the characters present, the person speaking, and/or the mood of the sequence abruptly changes. The only exception to the abrupt shifts attached to these lacunae is the aberrant use of dashes in the final canto, titled "A Vision," in which the Almighty Himself warns Columbus: 
"Not then to leave Thee! to their vengeance cast, Thy heart their aliment, their aliment, their dire repast !

To other eyes shall Mexico unfold (XII.29-32)

Not only is a different character used here, the dash instead of the asterisk, but three other differences can be noted. The first is the number of characters used per line. All instances of asterisks involve six characters per line, while line XII.31 uses no less than thirty dashes. Second, the line is spaced exactly the same as the surrounding lines of text, while the lines of asterisks are always padded by a blank line before and after they appear. The third difference can be found in earlier editions of the poem which adhere to the earlier punctuation convention of using inverted commas (i.e. quotation marks) at the beginning of every line of a lengthy speech. In 1827 Poems by Samuel Rogers: A New Edition, for instance, all four lines quoted above are preceded by quotation marks, not just the first line of the Almighty's pronouncement.

These differences suggest a different function for this line of dashes. It marks an omission, just as the lines of asterisks do, but only a single line. In contrast the lines of asterisks mark the omission of an indeterminate number, with a single line indicating a relatively short lacuna--but more than a single line--and a pair of lines of asterisks indicating a relatively long lacuna. The numbering of the cantos is the only thing that establishes an upper limit for the size of the gap suggested by a pair of asterisks; since there are twelve cantos clearly marked in sequence, no single gap in the narrative can be as large as a canto in size. If the double line of asterisks indicated a greater absence, the 
numbering of the cantos would skip, going from, for example, Canto V to Canto VII. ${ }^{51}$

Byron adopts this schema for The Giaour but does not employ subsection markers like the cantos in The Voyage of Columbus. Byron himself describes the result as a "snake of a poem," but without clear internal markings we cannot determine how long the snake is supposed to be (Marchand 100). "Much of the poem's interest," writes Byron critic Alice Levine, "lies in the shifting symbolic relations" between the title character, his beloved Leila and the antagonist, the Emir Hassan (121). Although subtitled "A Fragment of A Turkish Tale," 52 the fragmentary nature of the poem is

${ }^{51}$ Another method for signaling this incompleteness-by-design relies entirely on section labels, e.g. Henry MacKenzie's tactic of beginning the main text of his novel The Man of Feeling with the heading "Chapter XI."

${ }^{52}$ While Childe Harold's Pilgrimage was Byron's first literary success, Philip W. Martin argues that it is his Turkish Tales, verse narratives composed between 1813 and 1816, that cement the popularity of the Byronic hero and its author (Byron: A Poet Before His Time 30). Martin makes his case primarily on the grounds that the Turkish Tales, which he identifies particularly as The Giaour, The Siege of Corinth, The Bride of Abydos, and Parisina $(45-6,49,53)$, are published during the apex of popularity for English narrative verse. Childe Harold predates this peak (and arguably precipitating it, given the sensational public response to it), while Byron's greatest work, Don Juan, rests on the downward slope. This popularity correlates to a dramatic rise then drop of paper prices; large works became out of reach of some households, leaving smaller texts, such 
multiple, not singular, consisting of a bewildering variety of fragments told from a series of shifting and conflicting viewpoints, ranging from the Giaour and Hassan to the more obscure figures of a storyteller in a coffeehouse and a Turkish fisherman and presided over by a poetic voice who intrudes upon the narrative (The Giaour 388-438, 916-870). Each of these five voices form nodes in a network, allowing the whole of The Giaour to emerge as a shattered text somehow greater than the sum of its fragmentary parts.

Levine notes that, in just over 1300 hundred lines the narrative of The Giaour shifts perspective 13 times (121). We begin with the poet, then shift to the storyteller followed by the fisherman, only to return to the storyteller. A dialogue follows between Hassan and a boatman (who may be the fisherman), only to return to the original the poet before joining the storyteller again. Only after all this do we hear from the Giaour himself, after which a Turk speaks. We then return to the fisherman for a second or third time, followed by the storyteller a third time. Finally, we here from the monk, then the poet who started the piece, ending with more from the Giaour. The narrative push and pull starts calls to mind Tristram Shandy graphing the progress of his autobiography (bk. VI, ch. 40).53

as poetry collections or singular works such as The Giaour the best choice for budgetconscious media consumer of the day (Boehm 469). ${ }^{53}$ Constellations of asterisks appear throughout Tristram Shandy. Book V, chapter 1 includes a section labeled "The Fragment" that begins with a line of asterisks, anticipating Rogers use of asterisks in Cantos II, IV, V, and X. 
However, The Giaour was not always 1300 lines long. The original published version was only 685 lines in length, with Byron expanding the poem over the next six editions of the work. Table 6 summarizes the length of the The Giaour over a selection of seven early editions of the poem, all published in 1813 and 1814.54

Table 6

Development of The Giaour

\begin{tabular}{|l|l|l|l|}
\hline Edition & Date & Length & Asterisk-lines \\
\hline First & 1813 & 685 lines & 29.5 \\
\hline Third & 1813 & 850 lines & 29.5 \\
\hline Fifth & 1813 & 1215 lines & 29.5 \\
\hline Seventh & 1813 & 1334 lines & 29.5 \\
\hline Eighth & 1813 & 1334 lines & 29.5 \\
\hline Tenth & 1814 & 1334 lines & 29.5 \\
\hline Eleventh & 1814 & 1334 lines & 29.5 \\
\hline
\end{tabular}

${ }^{54}$ The sampling listed on Table 6, consisting of all electronically scanned editions available via Google Books and the Internet Archive, represent seven of the fourteen editions published in the first two years of the life of The Giaour. All told, these fourteen editions sold 12,500 copies of the work (St. Clair 586). 
It is important to note that, despite growing to nearly twice its original size, The Giaour is not an incomplete poem fobbed off on the public as a fragment of what was intended to be a larger work. Rather, the fragmentary nature of the work was an intentional effect. This can be readily seen from the fact that as the poem grows, the number of breaks indicated by lines of asterisks remains unchanged; Byron expands the individual incidents that constitute the poem while leaving the ligatures that should connect them unwritten.

However, Byron does not claim these gaps are the result of holes in the original manuscript. Rather, he posits them as interruptions in oral transmission. Romanticist Marjorie Levinson explains:

[W]here Rogers employs the fiction of a found, and of course, greatly defaced manuscript to explain textual ruptures, Byron declares in the Preface to "The Giaour" that he heard a complete story, and that the parts missing from the poem are alive in and (theoretically) recoverable from the balladeer's repertoire and Byron's own mind. The structural imperfection is not, then, represented as a circumstantial necessity but rather as the result of Byron's bad--which is to say, selective--memory. In short, "The Giaour"s fragmented form fails to confer any of the advantages secured by Roger's use of a similar technique. (116)

Levinson does not further elaborate on how an incomplete memory stored in the imperfect medium of the human brain differs substantially from an incomplete memory stored in the imperfect medium of an aged manuscript. The putative complete original of The Giaour perhaps looks more readily recoverable, in that Byron need only further 
search his recollection and/or return to his oral source. Meanwhile, the appearance of another manuscript copy could allow for a complete recovery of the missing passages from The Voyage of Columbus.

All three retrieval mechanisms are, of course, impossible under the circumstances of these works' composition. These ruinations in the text, the lines of asterisks, gesture toward times and places not to be found within the text or anywhere else. They break the narrative while simultaneously connecting the text to an imaginary world where the rest of the poem resides. In other texts, a line of asterisks signals an editorial intervention that is an act of erasure. A presence in the manuscript has been turned into an absence on the printed page, but the asterisks remain as traces of what once was. The line of asterisks in Voyage of Columbus and The Giaour do not function in this way. Rather, they simulate the trace left by the loss of something. They are empty symbols, signifiers without a signified. They gesture toward nothing, denying the reader the uninterrupted continuation of the narrative. However, like the five successive "nevers" uttered by Lear just prior to his death, these denials are not without meaning (King Lear, Act 5, Scene 3). These asterisked breaks in the narrative are the typographical discontinuities in the narrative, which diegetically are caused by discontinuities in the non-existent original manuscript/ballad.

Whereas Rogers uses the line of asterisks to mark tatters in the manuscript in order to abbreviate his narrative and focus on the highlights, Byron deftly employs the asterisk technique to play with his audience. Byron's first use of lines of asterisks appears only six lines into The Giaour. We begin at the cliffside tomb of $5^{\text {th }}$ century Athenian populist Themistocles (The Works of Lord Byron 85 n. 55): 
No breath of air to break the wave

That rolls below the Athenian's grave,

That tomb which, gleaming o'er the cliff,

First greets the homeward-veering skiff

High o'er the land he saved in vain;

When shall such Hero live again?

$* \quad * \quad * \quad * \quad * \quad * \quad *$

Fair clime! where every season smiles

Benignant o'er those blessed isles,

Which, seen from far Colonna's height,

Make glad the heart that hails the sight,

And lend to loneliness delight. (1-11)55

At the moment when Byron could answer his own question by introducing his

protagonist as a new champion for Greek values in the face of the Ottoman peril, he denies the reader this development. Instead, the text is interrupted, shunted to a

${ }^{55}$ All The Giaour quotes in this section come from archive.org's scan of the University of Toronto's copy of the 11th edition, published by John Murray in 1814. Subsequent to its publication, U. Toronto's copy was bound with contemporary copies of two of Byron's other Turkish Tales, an eighth edition of The Bride of Abydos and a fifth edition of The Corsair, 
consideration of the mild Mediterranean climate. The interruption of the line of asterisks both allows for the deferral of the first mention of the Giaour and establishes early the degree of fragmentation inherent in the structure of the poem, effectively decentering not only the Giaour from the role of protagonist, but it also de-centers the narrative from its own manifestation. Although the intended Reader of The Giaour may find "delight" at the loneliness of the opening, invigorated by the challenge of a poem that enjoys both the Byronic hero and a nonlinear narrative structure, but the Other Reader is left out in the cold, tasked with filling in the intentional gaps.

We can see Byron actively playing with the Reader in a later fragment documenting Emir Hassan's dialogue with an unnamed boatman (Levine 132 n. 4). Here, instead of a single or double line of asterisks, Byron employs the only example in the poem of a line and a half of asterisks, interrupting Hassan mid-sentence:

"Thou speakest sooth: thy skiff unmoor, And waft us from the silent shore; Nay, leave the sail still furled, and ply The nearest oar that's scattered by, And midway to those rocks where sleep The channelled waters dark and deep. Rest from your task-so-bravely done, Our course has been right swiftly run; Yet 'tis the longest voyage, I trow, That one of $-\quad * * * *$

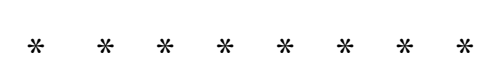


Sullen it plunged, and slowly sank,

The calm wave rippled to the bank;

I watched it as it sank, methought

Some motion from the current caught

Bestirred it more,-'twas but the beam

That checkered o'er the living stream:

I gazed, till vanishing from view,

Like lessening pebble it withdrew; (364-81)

The abrupt transition from Hassan complementing the boatman on a successful voyage to a description of an object sinking suggests a comical juxtaposition. Less immediately obvious is the grotesque truth, that Hassan asked the boatman to take him to the "channelled waters dark and deep," to drown Leila, who has been carried aboard wrapped up in a bundle (361-3). The sinking object is not the boat, but the dying girl.

Rogers originates the use of a line of asterisks as a mechanism for accelerating the development of his narrative, allowing him to constantly "flash forward" to the next highlight of a larger Voyage of Columbus that exists only in potentiality. The result is an "incomplete" work that is complete insofar as it contains everything Rogers wants the Reader to encounter. Byron elaborates on Rogers' technique by exploiting the disjunctions as a literary effect in their own right, playfully denying the reader's expectations and using the putative gaps in the text to connect disparate passages. For the Reader, Byron is inviting them to join him in playing with the conventions of poetic narrative storytelling. The Other Reader, who may not be as familiar with those 
conventions, is left out in the cold.

The redeployment of the asterisk as a null indicator and the erection of the folly ruin both demonstrate the increasing encroachment of hyperreality in British culture. The establishment of the folly is an exercise in hyperreal construction, a conspicuous consumption of intentionally fragmentary and anachronistic architecture. The folly allows us to imagine a better, more romantic world where every estate, even the recently cleared land of the nouveau riche, can have a crumbling castle and an ancestral ghost. Similarly, the Voyage of Columbus and The Giaour implicate a higher order, a hyperreal world where their complete texts are possible. Both the folly and the line of asterisks gesture toward authenticity not available to the reader. Whether a hole in the manuscript or the poet's memory, the effect is to remind the reader that another version of the text exists, a prior, ideal version from which the mere consumer of printed text is barred.

The problem of the Other Reader, the anxiety that someone other than the intended audience might read and misinterpret the work, can become expressed through a variety of pathologies. Chapter I demonstrates the way in which the preface alleviates the fear of the Other Reader, while chapter II examines the marginal note as another strategy for relief from this anxiety. Chapter III's examination of the poioumenon shows the fear of the Other Reader metastasized throughout the body of the text. Here, in The Voyage of Columbus and The Giaour, we have the opposite reaction to the potent threat of the Other Reader, an outright denial of the Other Reader's existence. The line of asterisks parallels the artificial ruination of the folly in that both signify a rejection. Crumbling, weathered Pulhamite rejects the ideal of the 
whole in favor of an aesthetic of ruination,

By supplying deliberately incomplete texts, Rogers and Byron disrupt the relationship between author and reader under the regime of print and hearken back to the earlier, oral mode of presentation. Marshall McLuhan refers to this mode as the “conversational" nature of manuscript culture (Gutenberg Galaxy 96). Walter J. Ong explains the interaction between oral performance and manuscript authorship prior to the rise of print:

In conversation, if you omit reasons backing a statement and you hearer wants them, the normal response is to ask you for them, to challenge you. If the connections between the statements you make are not supplied by the concrete situation--which can supply connections of the most complex, multileveled sort, as students of ethnomethodology well know--your interlocutor can be expected to ask you to specify the connections. Generally speaking, in live oral communication the hearer will not need many "logical" connections, again because the concrete situation supplies a full context that makes articulation, and thus abstraction, at many points, superfluous. (469)

The "concrete situation" described by Ong corresponds to the discourse community in the era of print, while the hypothetical missing text implied by the lines of asterisks correspond to Ong's "'logical' connections." The Voyage of Columbus signals its retreat to the earlier oral/manuscript mode by its declarations in the prefatory poem "Inscribed on the Original Manuscript" in which the manuscript itself directly addresses the reader, as if the reader is physically present and hearing the manuscript speak (65-7). The 
Giaour similarly presents itself as Byron's incomplete transcription of an oral performance. Both texts attempt to solve the problem of the Other Reader by a structure of omission aimed squarely at growing the gap between their intended discourse community and the Other Reader. The line of asterisks becomes a dividing line: one side welcomes those who can read and enjoy the intentionally abbreviated texts as a virtuoso performance by a pair of technical masters, the other side alienates those who cannot follow the abrupt shifts and starts of the fragmented form of that performance.

The end of the age of the folly did not arrive until as late as 1935. Faringdon Tower in Oxfordshire--a chimera of modern and Gothic revival architecture--is generally considered one of the last follies erected in the Britain (Follies: A National Trust Guide 262). Faringdon was built on the order of the fourteenth Lord Berners, "one of the most brilliant stars in the firmament of English eccentrics" (114). Unlike previous generations of folly-builders, the construction of Lord Berners's Folly (as the locals referred to the tower even prior to its being built) necessitated squabbling with the local Council and the Ministry in order to grudgingly receive approval for the building plans (Jones 272). The age of the folly as a symbol of the wealth and whimsy of the aristocracy has waned. 56

Just as folly scholars Gwyn Headley and Peter Ashley argue that a folly is only

${ }^{56}$ There is a connection between Lord Berner's Folly and the history of British poetry. Henry James Pye, Poet Laureate from 1790 to 1813, planted the trees on the hill, some of which would later be cleared for the construction site (Follies, Grottoes \& Garden Buildings 409). 
truly foolish when viewed from an outsider's perspective, The Giaour and The Voyage of Columbus are only incomplete works when viewed from outside the circumstances of their composition. From within the circle of the authors, these artificial ruins possess a beauty not fully attainable in mere reality. To be on the outside, in the position of the Other Reader, is to see incomplete works, foolish half-structures of stone and verse. 


\section{CHAPTER V: THE STUDENT AS AUTHOR: NINETEENTH CENTURY LITERATURE}

\section{AND A PEDAGOGY OF AUTHORSHIP}

Students learn on the basis of what they do... not on the basis of what you know. --Therese Huston, Teaching What You Don't Know

In this chapter, I discuss teaching nineteenth-century literature to undergraduate students via an emphasis on the economic and social dimensions of authorship, the power of the paratext, and the role of the materiality of the book in the creation and transmission of literature. In particular I will look at the student Daybook, a form of journaling in which students are invited to grapple with how they can best document and reflect upon their learning. The intention of this method is to forefront student manuscript practices, asking them to consider themselves as authors of their own educations.

My approach in the specific course examined here relates to questions around canonicity, authorship and authors in the literary studies classroom. Rather than imagine the author as a distant tyrant, the text as an implacable object, and themselves as passive readers subordinate to both, I want them to participate in the classroom as authors and manipulators of texts, interacting with other authors and texts in what object oriented ontologist Levi R. Bryant calls a flat ontology, a rejection of a hierarchy of being that elevates some objects over others (246). Additionally, I see a homologous relationship between the dyadic author/Other Reader structure explored in the previous chapters and the relationship of the learner to their own unconscious learning. The student Daybook enables the bridging of the same communications gap that haunts the author in chapters I through III. 
The teaching of literature focused on the formation of authorship widely lends itself to the teaching of literature using an author-centered approach. This is a major stumbling block of the teaching of literature, as it too easily elides from authorship being the focus of the course to the individual author becoming the focus of the course. The slippery slope ends with a return to the great man theory of history, a model that disserves and erases the vast majority of humanity and enables the ongoing propagation of structures of imperialism and colonialism which in the past literature itself all too regularly served

These risks are particularly dangerous within the structure of a British literature classroom. In the American educational system and American popular culture in general all things British already come with the veneer of respectability and thus the British literature classroom all too readily becomes an extension of the same structures of power that served the British Empire. This problem is especially clear in a country where the teaching of Shakespeare has been used as an indicator as to whether an institution is teaching "traditional values." ${ }^{57}$

\footnotetext{
${ }^{57}$ For one strand of the tendency to use Shakespeare as synecdoche for Western civilization as whole, see Humanities in America: A Report to the President, the Congress, and the American People, issued by the National Endowment for the Humanities in 1988, under the chairmanship of Lynne V. Cheney, and the follow-up reports from ACTA, the Cheney-founded American Council of Trustees and Alumni, The Vanishing Shakespeare (2007) and The Unkindest Cut (2015). These reports treat the
} 
What, then, can we do if we are to teach authorship as a formation, a force acting in the world, in a literature course so that we do not fall back into the grand narrative of the great man acting in history? One solution would be to anonymize literature, presenting it as the individual facets of a single great Intertext, all of which emerge from "culture" and "history." Another method might be to focus on underserved authors. Great strides are being made in this area to focus on more women poets of the Romantic Period such as Letitia Elizabeth Landon and Charlotte Smith, or on the voices of color such as Mary Prince, Mary Seacole, Juan Manzano and others investigated as part of Black Atlantic Romanticism. ${ }^{8}$ Even those authors we consider most problematic still have something to offer the world when put in conversation with these previously overlooked voices. Although we may no longer think of canonical British literature as, in the words of Matthew Arnold, the best that is written and thought, we can find a place for the old canon and the newly rediscovered if we envision the field of literature as the emergent property of an ongoing process of reevaluation.

The solution proposed in this chapter is to confront both authors and authorship in the literature classroom by elevating students to the rank of co-authors in their education. This idea is in line with the model of the constructivist classroom while

teaching of Shakespeare in higher education as a reactionary touchstone, the polar opposite of English programs that engage with cultural theory. ${ }^{58}$ In the latter case I am thinking about the scholarship arising from Paul Gilroy's The Black Atlantic, such as the work of Paul Youngquist and Frances Botkin. See, for example, their collaboration in Circulations: Romanticism and the Black Atlantic. 
stepping away from the banking model which itself provides a social hierarchy of power from teacher to student that itself mimics the author to reader which in turn mimics the despotic ruler to the subject. In other words, if the classroom is to be a liberatory space AND we are to hold on to the Lord Byrons of the world, then students need to in some way to act such that they feel that they are meeting Lord Byron on an even playing field, not as an idol to be worshipped.

In short, I am positing the literature student in a typical course as an analog of the Other Reader, someone whose positionality lies well beyond the ken of the author. My goal is to close the distance between the student and the author, bringing them together by emphasizing the agency of the students in their own writing. Before introducing expanding on the pedagogical thinking behind this approach, I briefly outline the vector of the authorship formation through the history of pedagogy. Following these overviews, I provide the details of implementation in my approach using the student Daybook, followed by a review of the resulting student work.

\section{The Pedagogy of Authorship in British Literary Studies}

Within the context of university curricula, the formalized study of English literature--that is, literature by English authors written in the English vernacular-begins outside of England itself. The first English literature curriculum can be traced back to Adam Smith at the University of Edinburgh (Richter 17). Occurring only a generation after the Acts of Union created the United Kingdom by political merger of the prior kingdoms of Scotland and England and the English education offered by Smith and his successors aided the cultural acclimation of Scottish youths seeking careers in the more prosperous south. Similarly, the study of English literature flourished in the 
first quarter of the nineteenth century in colonial India, where it was part of the curriculum for natives seeking civil service positions. In this venue, it served as a tool for sociopolitical control via the performance of the superiority of British culture (Viswanathan 3). In England itself, the formal study of English literature emanates not from the university system, but rather “Mechanics' Institutes, working men’s colleges, and extension learning circuits." The teaching of British authors and British texts to the lower classes was part of a larger project of instilling a sense of national solidarity (Eagleton 23).

Embedded within the British nationalist/imperialist project, English studies found itself imbricated in a constellation of binary oppositions designed to exercise and maintain power over the colonial subject, including (but not limited to) English/Scottish, British/Indian, ruler/ruled, and teacher/student. The author/reader relationship easily maps onto this system; as, for example, the ruled/Indian/students find themselves on the receiving end of the texts of the ruler/British/teacher, their relationship to the author is similarly subordinated.

Under the mutually reinforcing system, the tendency is for the social position of the British author to expand from mere inscriptor of text to full-blown cultural hero. Literary history tends toward hagiography (or, in the case of Shakespeare, Bardolatry). So successful is this configuration that we can see its fruits seven thousand miles from India and one hundred years later. Writing in 1922, Lane Cooper, Professor of the English Language and Literature at Cornell University, repeatedly describes the field of English letters as a litany of great names: 
The record of the studies of Chaucer, Spenser, Shakespeare, Milton, Pope, Dryden, Gray, Wordsworth, Tennyson, and Browning, and of Bacon, Chatham, Johnson, Burke, Ruskin, and Newman, represents the great experiment in English education--an experiment lasting through the centuries, and a successful one, the results of which no teacher or theorist on teaching in the field of English may set aside. (32)

Cooper goes on to directly contrast the "vital influence" of these authors as compared to the "overburdened, stultified, or disheartened" effect produced by reading "huge piles of uninspiring manuscript" produced by students (95).

Eighteenth century scholar and pedagogue David H. Richter records his early 1960's experience as an undergraduate encountering the cult of the author:

$[T]$ he professor who taught my course on eighteenth-century literature handed out a ten-page ditto called the "Slavish Note-Taker's Handy Home Guide to Dates in English Literature 1660-180o," with starred ratings (as in a Baedeker travel guide) to distinguish highly important poets like ****Pope, Alexander, from figures of minor interest like *Behn, Aphra.

Another measure of a literary figure's importance was the number of courses devoted solely to his or her writings: if Pope, stuck in a survey, rated four stars, then Whitman and Dickinson (who share a course) each rated five, Chaucer and Milton (solo billing) rated six apiece, and Shakespeare (with two courses) deserved seven. (121-2) 
Note how both Cooper and Richter focus on names of individual authors rather than genres, historical era, literary movement, or some other method for sorting the bewildering number of texts encountered in university-level study of literature. The classification of discourses that Foucault identifies as a primary function of the author is not a naturally occurring phenomenon but the result of cultural processes and institutions (123). An educational system that sorts, rates, and teaches texts based upon their relationship to an author forms a component of that system.

Within the realm of literary criticism, there have been significant challenges to regime of the author, starting with the rise of the New Critics including W.K. Wimsatt and Monroe C. Beardsley's development of the concept of the intentional fallacy (3). The resulting decoupling of the interpretation of the text from author's intention was partially undone by the new politics of the 6o's, where the author's relationship to leftist struggle became a classroom concern (Showalter 23). The political project developed in this era continued through the rise of critical pedagogy in the 1980's and 1990's (28). However the author's positionality becomes imbricated in a social milieu, i.e. depending on the interpretive lens being used, the author's race, gender, sexual orientation or other identity markers become nearly as important as the idiosyncrasies of the author's personal history (28).

The originary cult of authorship casts a long shadow, however. Writing in the midst of the critical pedagogy years, Carl Woodring describes the typical classroom practice by literature instructors as an "eclectic" approach, wherein the New Critical method of examining the text on its own merits and the sociopolitical contexts of critical pedagogy sit side-by-side with interpretations based upon authorial intent or personal 
history. Under the eclectic approach, all of these options are tools available to meet the interpretive needs of the moment (182).

Woodring's description of the eclectic method seems to align with my own experiences as an undergraduate in the early nineties, as well as much of my graduate education since returning to the academy in 2011. Although the era of author-worship seems to be over, many courses are still organized and many syllabi similarly use the author as an organizing principle, even in those courses where authorship was being explicitly scrutinized, challenged, or problematized. No matter to what degree the author appeared as a key figure in the course, the relationship between the author and the student was subjected to the same basic power differential: although the author was free to write about nearly any subject, student writing tended to only be validated to the degree it connected to the author's writing.

\section{A Different Approach}

In What the Best College Teachers Do, Ken Bain reports the results of a fifteenyear study of over one hundred academics across a range of disciplines (3). Bain's second chapter, "What do the best teachers know and understand?", provides three key insights into the learning process. The second of the three is metacognition, which manifests as pausing the learning process to actively think about one's own thinking, to consciously review what one has learned and how that new learning can be integrated with what is already known (25). Furthermore, Bain found that the most successful teachers tend to focus more on measuring student learning rather than adherence to an arbitrary standard (155). 
Many pedagogical researchers have shown the value of providing students with self-direction and opportunities for reflection. Susan A. Ambrose, Michael W. Bridges, Marsha C. Lovett, Michele DiPietro, and Marie K. Norman reach conclusions like Bain's in their broad survey of pedagogy research, How Learning Works: Seven ResearchBased Principles for Smart Teaching (89). They also endorse requiring student reflection as a learning activity, including activities such as annotating their own work (209). Peter C. Brown, Henry L. Roediger III, and Mark A. McDaniel's Make It Stick: The Science of Successful Learning makes a similar point about the importance of reflective learning, noting that "reflection is a form of practice" $(26-7,66,88-90)$. In her handbook Tools for Teaching, Barbara Gross Davis also indicates the importance of selfreflection and note-taking to the learning process $(259,263,265-267,280)$.

The student Daybook provides an opportunity to elicit visible evidence of student metacognition, making their learning available for direct assessment. The key document in the development of the Daybook as a learning tool is Thinking Out Loud on Paper: The Student Daybook as a Tool to Foster Learning. A collaboration by six members of the UNC Charlotte Writing Program, Thinking Out Loud proposes the student Daybook as a place "where students write about their lives, to keep track of their thinking, and to notice all the world around them with open eyes and ears and hearts" (3). It is "a place where students put all their thoughts throughout the day." The focus is less on perfect performance and more on creating an archive of student thought:

A Daybook captures students' thinking, making it visible to them. We often tell our students that that the writing in their Daybooks is their “thinking out loud on paper.” We say we aren’t so much concerned with 199 
the quality of their writing but with the quality of their learning. The Daybook is a student's process of learning. (13)

Additionally, the Daybook as used here fulfills two of the three recommendations from Steve Graham and Michael Hebert's 2010 Carnegie-funded report, Writing to Read: Evidence for How Writing Can Improve Reading. A meta-analysis of the best research on the impact of writing instruction on reading skills, Graham and Hebert conclude that reading comprehension can be improved among students by having students write about the texts they read and by increasing the frequency at which students are asked to write (4-5).

Graham and Hebert note that "[c]omprehending a text involves actively creating meaning by building relationships." These relationships form between texts, between the reader and the text, and between the ideas present in the text and the reader's personal identity and history (13). The Daybook provides a venue for the exploration of these relationships via all the specific techniques recommended by Graham and Hebert. These include writing personal reactions, analyses, responses to questions, drafts of/answers to their own questions, summaries, structured notes, and concept mapping (14-17).

Although the studies regarding the impact of frequency of writing on reading skills all involved students younger than college age, Graham and Hebert discovered an 
overall trend pointing to a correlation between daily writing and more effective reading. As little as fifteen minutes of writing a day produces a beneficial effect (20).59

Finally, the practice of the Daybook as a daily discipline, but as an exploratory one, must not be overlooked. As philosopher and educator Karmen MacKendrick observes, "most undergraduate students have had little reason to associate discipline with pleasure" (121). By demanding that students write everyday while giving them the freedom and guidance to explore a variety of writing genres, it is hoped that the chances that they find their own way into pleasurable writing are increased.

The student Daybook is presented here as a means of empowering students as authors of their educations. The Daybook provides a venue for the writing of course notes, homework, first drafts, and literally anything else the student desires. With the Daybook they continually face the freedom and the power (as well as the terror) of the author facing the blank page. And then like an author they are ultimately responsible for what text they will present to the world and what paratext they will use to present those texts.

${ }^{59}$ Recent research suggests that note-taking with paper and pen/pencil, leads to better understanding and longer retention of course material when compared to note-taking with a laptop (Mueller and Oppenheimer 1166). This conclusion aligns with the MRI study at Indiana University showing "enhanced blood oxygen-level-dependent activation" in the brain when a subject reads and writes versus merely reads the same text (James 285-6). 


\section{What is a Daybook?}

At its most elemental, Daybook is simply an alternative term for journal, notebook or workbook, taking the form of a blank composition book in which the student records their daily learning process in whatever form that takes. The use of the term Daybook, as opposed to the better-known terms, is meant to achieve two goals: The first is to alienate the students from any preconceptions they may possess regarding how a student journal or notebook should work. This effect makes it easier to make specific demands about the Daybook activities and the Daybook itself. For example, I insist that a proper Daybook needs to be a sturdily bound composition notebook of at least 80 pages in length and no smaller than 9.75 inches by 7 and a half inches. I also strongly recommend the composition book be quad ruled rather than college ruled, as it aids with charts, drawings and paste-ins. Students seem more willing to comply with these specifications if you somehow disabuse them of the notion that they know what they are going to do with them.

The second reason to use the term Daybook is to emphasize that writing in it should be an everyday activity. By the end of the semester most of my students are tired of the ritual exchange where I ask, "Why is it called a Daybook?” and they respond "Because you write in it every day.” In previous semesters I stipulated that not everything written in Daybook must be relevant to the class, and indeed I encouraged students to collect all their coursework into this one location rather than reproduce the artificial divisions between knowledge that the university course system forces upon them. So, I want students to write in their Daybook every day, but not everything they write needs to be about my course. 
What Gets Written in a Daybook?

Anything. Everything. Even things not normally considered "writing" in an academic context. I tell my students that all sorts of academic things can go in the Daybook: notes from class (my course or others), exercises done in class should be written into the Daybook, notes taken while reading, definitions of words they looked up, favorite lines from readings, outlines for papers, as well as anything they stumble across that might be related to the subject of the course. Nonacademic writing can go into the Daybook as well. My Daybooks have recipes and shopping lists as well as things like the names of movies and TV shows people have recommended to me. I invite my students to use the pages as a diary as well. The authors of Thinking Out Loud: The Student Daybook as a Tool for Learning suggest that "[w]e think of the Daybook like that drawer in the kitchen where we stick everything that does not yet have a place, but we know we might need someday" (11).

I also encourage my students to acquire a glue stick or pot of rubber cement so that other texts can be pasted into the Daybook. Outside texts can be added to the Daybook this way. My current Daybook contains, among other thing, a handout on motivational interviewing from the Temple University Wellness Resource Center, all the notes from the last conference I attended, a selection of family photos my aunt Carolyn was going to throw out, numerous quotes from the last two books I've read (Douglas R. Hofstadter's Gödel, Escher, Bach and R. D. Laing's The Politics of Experience), a gluedin wrapper of a fried cheese snack bar, and a transcription of the entire DNA sequence of the virus $\Phi X 174$, the first genome to ever be analyzed (Sanger 687). I can't correlate these things into an organic conceptual whole, but when my Daybook is full, I will have a 
comprehensive material record of the period it covers: the work I did then, the thoughts I had, the things I did. All other pedagogical concerns aside, I find that simple fact immensely satisfying, as do many of my students.

\section{Why Use Daybooks?}

For me, the Daybook is a way of addressing an anxiety that previously haunted my teaching. In my own career as a student I find learning to be a highly complex process. Learning is not a straightforward business. It is often messy, murky, muddled, nonlinear, synthetic, and unstable. It happens as much in the hidden depths of ourselves as on the visible surfaces.

Meanwhile our assessment methods tend to be the opposite. We so often assess by asking our students to write essays, either as papers or questions on exams. Does tasking our students with writing well-developed paragraphs and sentences with proper grammar and punctuation actually aid us in assessing their learning of the course content? It makes assessments easier for instructors to read, which I do not discount as valuable, but it seems to me that relying solely on essays produced under formal conditions (i.e. exams or papers) results in an unnecessary and inefficient remediation of student learning. To put it more simply, if a student is worried about comma splices or i-before-e rules then they aren't as focused on the actual content of the course as I would like them to be. If learning is messy, then the why not account for a certain messiness in the way the students document that learning?

\section{The History of the Daybook}

According to the Oxford English Dictionary, the term Daybook has been extant in English since the 16th century ("Daybook, n."). It originally referred to a personal, 
daily record of events and later gained currency as the technical term in nautical circles for the daily log of events at sea before being replaced by terms such as logbook or captain's log. The authors of Thinking Out Loud on Paper also find a vector for the practice of Daybooking in the commonplace book (sometimes called the silva rerum, Latin for "forest of things"), a personal collection of useful quotes, tables, charts and other miscellaneous data, served as a sort of private textual scrap-book (2-3). Examples of commonplace books that have been subsequently published include those commonplaces written, collected, and curated by Francis Bacon, John Milton, and E. M. Forster. Although known examples of commonplace books date to antiquity, the earliest surviving example belonging to the sophist Protagoras in the $5^{\text {th }}$ century $\mathrm{BC}$, the modern form can be traced back to the zibaldone (literally, "a heap of things") of 14th century Venetian merchants (D’Intino xvi-xvii; Dotson 10-11; Giaimo).

The twenty-first century form of the Daybook as a pedagogical tool can be attributed to author and educator Jim Burke, who has worked with Daybooks since the 1980 and published his approach for use of Daybooks by instructors (rather than students) in his series of workbooks titled The Teacher's Daybook: Time to Teach, Time to Learn, Time to Live (Bannon, et al. 2). Burke's methodology was subsequently taken up and expanded by members of the Writing Project at the University of North CarolinaCharlotte, who produced Thinking Out Loud on Paper: The Student Daybook as a Tool to Foster Learning. It is this work that informs Daybook usage among instructors in the English Department at Illinois State University, beginning with Dr. Karen Coats and later adapted by her students Elizabeth Bell and Amy Magnifichi, who subsequently mentored me in this body of techniques. 


\section{Challenges of the Daybook}

The single biggest problem I have encountered with the Daybook is dubious penmanship. Every semester I find myself with one or two students whose writing I cannot fathom. As a result, I urge my students to remember that they are writing for potentially more than one person every time they do work in their Daybook, and I suggest that they take extra time, and multiple drafts if necessary, when composing the explanatory sticky-note (explained in more detail below).

The other concern is that, in every semester I have used Daybooks, at least one student did not take the exercise seriously, despite my best efforts to convey how important the Daybook was to their academic success. At least one student doesn't purchase the required composition book, at least one student phones it in on the sticky notes, etc. Since these students generally seem less committed to the course in general, I'm not sure any other technique would reach them more effectively. What are Some of the Ways Daybooks can be Used?

Students in my class are given wide latitude as to what they can include in a Daybook, but they are also provided guidance. Last semester, for the first 8 weeks or so of the course, I updated a Google Docs file weekly with 2 to 4 ideas for Daybook activities. For example, after assigning the students a theoretical piece, one of these prompts might ask them to look back at a primary text from earlier in the semester and analyze it using the new theoretical framework. By the time the first half of the course was over, the students had a collection of 25 or so example activities for their Daybook.

In-class activities can also appear in the Daybook. Since these can be included in the Daybook submission process, I am able to gauge more effectively which activities 
clicked with the students and which did not. Students who do good work in class but don't feel like sharing with the group also benefit this way, as their efforts are not concealed by their timidity.

In-class exercises sometimes take the form of drawing rather than writing, as when I asked the class to draw Grendel on the first day we talked about Beowulf, or when we drew maps of the British Isles as a group on the day we spent learning about the differences between England, Britain and the United Kingdom. Some assignments come at the end of class, as a way of priming the pump for the next period. For example, I asked students to make a list of everything they thought they knew about Frankenstein prior to reading the novel.

The Daybook itself becomes folded back into the primary subject material of the class. One way I start class is by asking who has written something in their Daybook that they really like since last we met. Or when a Daybook submission looms, we might take ten or fifteen minutes out of class for small groups to peer review Daybook entries to help students select their best work.

How are Daybooks Assessed?

Thinking Out Loud on Paper provides several methods for assessing Daybooks. Daybook audits involve simply collecting and reading all the student Daybooks, assessing them in their totality. This method is mentioned in Thinking Out Loud specifically to discourage it; the time investment involved in reading all the material produced by students is immense and students will be discouraged from writing exploratory/experimentally if they know every single thing in their Daybook may be read by the instructor (105-6). Daybook conferencing is also time intensive but more 
interactive. Students attend one-on-one meetings with the instructor, ranging between 10 and 30 minutes each, to which they bring their Daybook. The student directs the instructor's attention specific entries. They talk out what the entries signify and how they document student learning (100-103). I've not attempted this method, but my colleague Evan Nave tried something similar in his African-American Literature class for a student journaling assignment and now employs this method regularly.

My own method is based on Shana Woodward's Daybook defense, as described in Thinking Out Loud (97-99). Woodward asks students to self-select their best work over the course of the semester, photocopying seven pages from their Daybooks. She asks that the students attach a standard 3" by 3" sticky note to each individual page. On the sticky note students are asked to explain the learning that is happening on the page. Since they only have 9 square inches to work with, brevity is rewarded. Woodward's assessment via excerpt requires students to review, reflect, and report on their previous work, which I find to be a powerful metacognitive technique that encourages deeper learning.

Although Woodward only collects seven annotated pages at the end of the course, I find it useful to have one or more Daybook submissions earlier in the semester, with a lower page count appropriate to the point in the semester. A one-page, one-sticky note submission early in the course allows me to check that all the students get what I am asking them to do. A three- or four-page submission near the middle of the course keeps the student on track with the project. Also, multiple submissions over the course of the semester allows me to see themes developing in the work of the students and I can more easily assess what is and isn't working in my teaching. 
Following the model I first encountered in the ISU Writing Program, I do not attempt to assess Daybook entries for mastery of the subject matter. Rather I am looking for evidence of learning in progress. In my mind there is no arbitrary amount of British Literature my students must leave my course possessing knowledge of. Rather, with the Daybook I am concerned with seeing whether they are working on expanding that knowledge, no matter whether they showed up the first day of class already a fellow Brit Lit nerd or if they started the semester not knowing who the heck Bill Shakespeare is. Is the student making serious efforts to build on whatever prior knowledge they possess? That's the question I am asking as I read the Daybook excerpts.

How Does the Daybook Work in Practice?

I put these ideas to the test in the Fall of 2015 in a section of IDS 121.19, the Interdisciplinary Studies course "Texts \& Contexts," which is described in the Illinois State University Undergraduate Catalog as "focusing on significant humanities texts in relationship to their historical and cultural contexts” (112). Designated an LH or "Language in the Humanities" general education course, students in a wide variety of programs take this course. Notably, English majors are exempt from fulfilling the "Language in the Humanities" requirement, so serious students of literature tend to be rare in IDS 121.19 (80).

Since the catalog description of "Texts \& Contexts" does not specify which texts or which contexts must be covered, individual instructors have wide latitude in selecting course content. My particular instantiation of IDS 121.19 was titled "Grand Impostors of the 19th Century" and focused on issues of authorship and authenticity within primarily British texts. 
Furthermore, the archival aspect of the day book should not be overlooked as a benefit of approaching it with daily discipline. At the end of the semester a student with a full Daybook has accomplished something; they have created an object that testifies forever that they were student, that they worked hard, and that they learned something. The Daybook turns the everyday work of the college student into an artifact in the same way that literature as an art form takes letters and words and turns them into art objects. There is an undeniable sense of accomplishment for a student who has completed a Daybook as part of their studies and an almost ontological proof of their existence as thinking, learning beings. In much the same way that graffiti serves as a testimony in a hostile or been environment of the existence and importance of the individual human being, so does the day book offer a venue for the student to assert that they to exist and matter in the educational environment in a way that disposable papers quizzes and exams could never achieve

This focus on the materiality of the Daybook brings the teaching of English literature in line with the shift toward book studies that has occurred in my own scholarship over the past 5 years. Attendance to the material affordances of the students' learning--the actual objects that they use as in the classroom space parallels--the same attention asked of them when examining literature through a book studies lens.

\section{Course Readings and Activities}

In this section I will present my impressions of the results from teaching the five largest texts on the course schedule. Taken in aggregate, these five texts were the focus of 15 of the 31 scheduled class sessions. 
The Rime of the Ancient Mariner by Samuel Taylor Coleridge

The first major in-class Daybook activity was a concerted effort in class to break down the text part by part to understand the who, what, and how of the work, even if the why remained elusive.

The Giaour by Lord Byron

The Giaour was perhaps the hardest text for the students read on their own, but the kinds of difficulties it posed produced good work in the classroom. Much of the time we spent on this poem was devoted to using our Daybooks to map out who spoke in each passage and how the various narrative levels interacted.

\section{Don Juan by Lord Byron}

We only read the first canto of Don Juan. Much of our first class devoted to the poem was spent on small group work interpreting one or two stanzas selected by the instructor, writing summaries of their findings into their Daybook. Students were generally able to make some progress on these small snippets of the work, but for the most part they were not able to get a sense of the canto as a whole. For the second class period on Don Juan students read one of ten different Juan successor texts. Working in trios, they wrote compare-and-contrast pieces of the original and the later work. This proved difficult, though, since the first class period left them with an unformed impression of the original Byron work.

\section{Dracula by Bram Stoker}

One of the most popular texts of the semester, Dracula produced an array of successful activities. In their Daybooks, students made lists of what they knew about the title character from pop culture and drew what they thought he looked like. They did 
this prior to the reading in order to compare with later impressions. Later in the unit, they worked in small groups to document the events of individual chapters and the means by which the narrating characters recorded them. We also watched portions of two different film adaptations and discussed the differences between the three texts.

In addition to the lecture and the open-ended discussion typical of literature courses, nearly every classroom session featured one or more Daybooks prompts, for which students are typically given 5 minutes to write. Often these Daybook prompts are incorporated into the slide show, either when transitioning from one topic to the next or simply to give the students a break from the instructor (see figure 8 for an example). Daybook writing is usually followed by some sort of debrief, often in the form of sharing with a partner or a small group.

\section{Daybook Exercise}

Part 1

- Reviewyour daybook submission (or your daybook if you're not ready to hand in today).

- Identify your best/favorite daybook entry.

- Write a paragraph or so on what learning your fave entry documents and why you like it.
Part 2

- Get with a partner or two.

- Explain what you wrote about.

- (Feel free to share the original entry.)

- Take notes in your daybook on what you learned from your peers.

Figure 8. Slide with two-part Daybook exercise asking students to reflect on prior work 
Other small group activities include the jigsaw, a technique promoted at several Center for Teaching, Learning, and Technology events, in which a large text is broken into small pieces. Small groups read individual pieces, then report back to the whole to assemble a sense of the entire text. Each group is given specific things to look for as they read the text or questions to be answered. Typically, the questions started with basics of the characters and plot involved but also included one or more questions that spoke to core issues of the class. The jigsaw worked very well for both The Rime of the Ancient Mariner, which initially baffled the students, and Dracula, which had more characters and locations than they anticipated.

Another popular small group activity was the Jack the Ripper investigation. Students were given the text of four different letters purportedly written by Jack the Ripper and a brief description of their reception. The small groups were tasked with determining which, if any, they thought were genuine Ripper communications and why they reached their conclusions.

Students were invited to draw on the board for several activities, often after a prompt asking them to first draw in their Daybook. The most popular of these activities, based on comments in Daybook submissions, were from the days we covered "Kubla Khan,” where students were asked to draw the relationship between reality and fiction, and Don Juan's successors, where students drew a schematic showing the relationship between text, context, and paratext.

For September 23rd in lieu of a normal class period I invited Elizabeth Jett Bell, a graduate assistant working at the Center for Teaching, Learning, and Technology to conduct a midterm chat (small group instructional diagnostic) with my students. The 
midterm chat is a meeting in which students are asked to come to a consensus in answering four questions:

1. What aspects of this course help you learn?

2. What aspects hinder your learning?

3. What suggestions can you offer that would enhance your learning in this course?

4. What can you, as students, do to improve your learning in this course? CTLT offers this service because a trained professional with no power to affect the student's final grades can get more honest information than an instructor asking such questions on their own.

I won't discuss all the results of the written report or my post-chat meeting with Ms. Bell here. However, I will summarize two of the results I found to be most important. First, the students reported that they found the weekly quizzes to be obnoxious, especially since they were keeping up with the reading whether a quiz was imminent or not. Ms. Bell noted this was the first time she or any of her colleagues could recall a midterm chat in which students in a literature class said they were doing all the reading. In response to this complaint, I cancelled the rest of the quizzes for the semester, warning that they would be reinstituted if I felt they were needed. Second, the students liked the major assignments, particularly the Daybook work and the papers. They communicated to Ms. Bell that they enjoyed the "freedom to connect personal interests" afforded by these assignments.

In subsequent semesters I have myself conducted over a dozen midterm chats for other instructors, as well as discussing the in-and-outs of this evaluative tool with more 
experienced colleagues. My IDS121.19 students keeping up with the reading remains an anomalous result; literally every other midterm chat I have conducted resulted in students reporting that they were behind in the reading. And my professional development colleagues--with years of experience in this area--report no other instance they can remember where the students said they were adhering to the reading schedule. I know of no way to explain this result outside the effect of the Daybook on student engagement.

My reading schedule for the course was not light. Indeed, I would call it ambitious for a 100-level course full of non-majors. It seems like the key thing that distinguished my classroom from most others: the Daybook. Therefore, it seems reasonable to me to hypothesize that perhaps the Daybook activities had an impact on student engagement, the result of which was better-than-average reading endurance. The Daybook and the Learning Management System

For this course I used the Lessons Builder tool in ReggieNet (a localized version of the Sakai open source learning platform) to construct a series of weekly pages, each of which was divided into two subpages. The two subpages were labeled "For Monday DD/MM" and "For Wednesday DD/MM." Clicking through to the daily subpage, the students encounter a page with a standardized layout. At the top of the page would appear any reminders, such as upcoming due dates with a link to the assignment sheet. Next is either the main assignment for the day or some introductory materials. If the reading for the day is an electronic text, it is embedded directly in the page and available as a download. Otherwise, a picture of the cover of the book plus a page or chapter range 
is given. Introductory materials usually take the form of an embedded YouTube clip or a Daybook prompt to be done before or during the reading.

After the text a Daybook writing prompt usually appears if one is not encountered before the main text. Supplementary materials follow, often brief documentaries, links to additional resources, music (such as various musical adaptations of the Don Juan myth) and, where available, audio versions of the main text. Video clips and other supplementary materials are generally kept brief (a few pages to read, a few minutes to watch) to enhance the main text rather than overwhelm it.

Daybook Submissions

Three times during the semester students were asked to photocopy their best work from their Daybooks and submit it, along with a standard 3" x 3" sticky note. On the sticky note they were asked to explain what was on the page (in case it was idiosyncratic or illegible) and what learning that page documents. Originally the Daybook submissions considered as a whole were listed as $20 \%$ of the students' final grades, this was later amended to $24 \%$ when the quizzes were cancelled after the midterm chat.

The first Daybook submission asked for only one page, mainly as a way of ensuring the students would get the format right for the bigger submissions. (Some struggled with being brief and relevant on the sticky note. A surprising number had no idea how to make a photocopy and tried to submit photos taken with smartphones or bad scans.) The second Daybook submission asked for five pages of student work, while the last submission called for six pages from the Daybook plus a special final page. For 
the final page the students were asked to compose something new that reflected on the course as a whole.

Questionnaires

Three times during the semester (the first week, at the midterm, and the last class before the Thanksgiving break) students were asked to provide answers to the same six questions:

1. What is an author?

2. Name someone you consider to be an author. Explain what makes them an author.

3. What is an authority?

4. Name someone you consider to be an authority. Explain the source of their authority.

5. What is authenticity?

6. Name someone or something you consider to be authentic. Explains how you know they/it possess authenticity.

No credit was offered for answering the questions and the instructor did not read any of the answers until after the last day of class. Due to absences, only 22 students completed all three questionnaires. The results of the five students who only completed two of the questionnaires and the three students who were present for only one of them were discarded for purpose of this analysis. 


\section{Case Studies}

Case Study 1: Bruno 60

\section{Daybook \#1}

Bruno's first Daybook submission is a bit of a mess, but it is a mess that shows him grappling with the course materials. On this page he has a variety of notes from the day we spent on The Rime of the Ancient Mariner, including his efforts to understand the paratextual elements surrounding the main body of the text. This page also shows him working with one of the Daybook tasks included in the ReggieNet lesson for Rime: to listen to the musical adaptation by heavy metal band Iron Maiden and compare the two versions (see fig. 9). The accompanying sticky note emphasizes that paratext "pushes the poem to a certain direction."

${ }^{60}$ All names in the Case Studies section have been changed to preserve the anonymity of the students. 


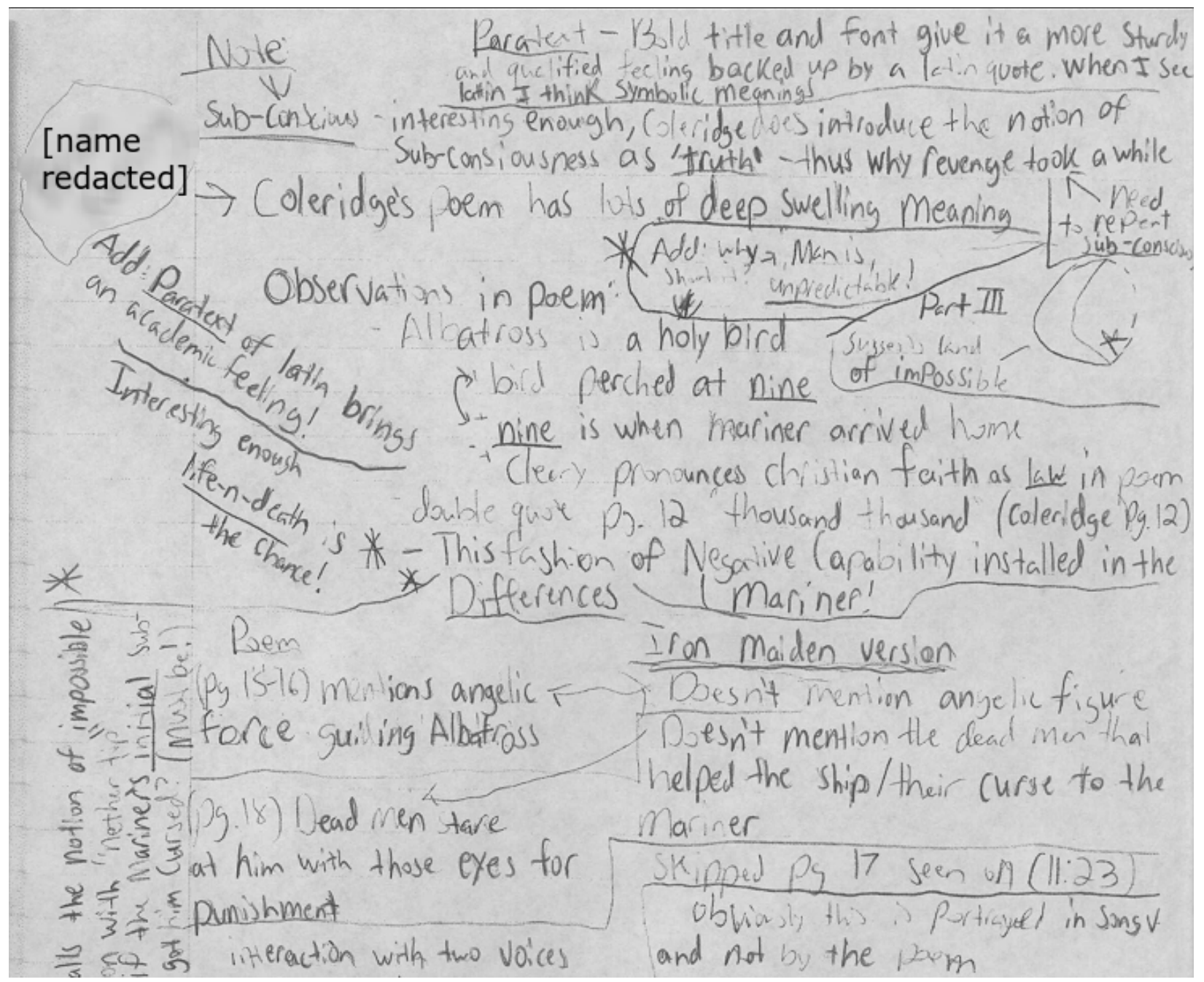

Figure 9. Excerpt from Bruno's Daybook submission \#1

\section{Daybook \# 2}

For the second Daybook submission Bruno submitted a page of notes taken as he read The Giaour, a transcription of the biographical information for Lord Byron given in class, and his notes on a video in the ReggieNet lesson on The Giaour in which the Rashomon Effect is discussed. He gives two examples of texts featuring the Rashomon Effect, the SpongeBob SquarePants episode “Friend or Foe?” and the South Park 
episode “Fishsticks." I can't speak to the South Park episode, but the last act of "Friend or Foe?" is structured as an assemblage of conflicting perspectives much like The Giaour and the film Rashomon. Another great component of this hand-in was the page that recorded Bruno's participation in an in-class Daybook activity in which all the students were asked to diagram the relationship between text, paratext, and context (see fig. 10). Bruno's illustration nicely demonstrates the idea that readings change as texts migrate across contexts.

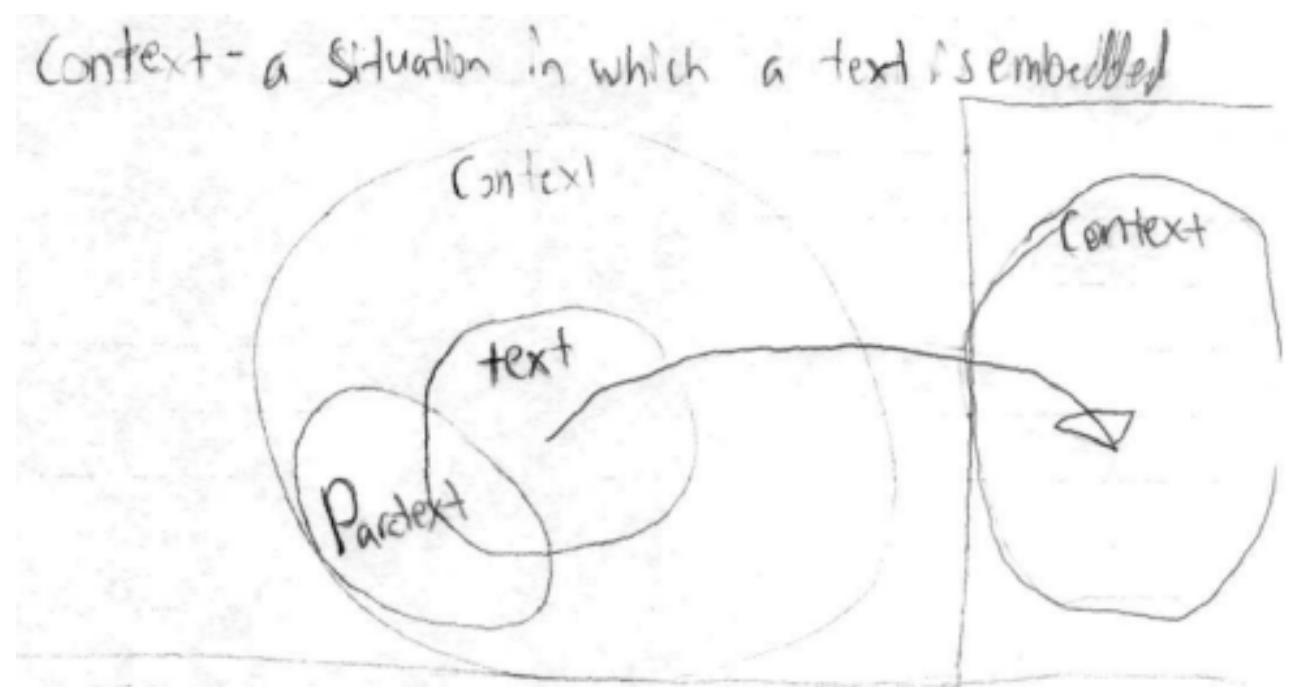

Figure 10. Excerpt from Bruno's Daybook submission \#2

\section{Questionnaire \#2}

Bruno's idea of an author is slightly more sophisticated than at the beginning of the semester, as he now separates imaginative work and actual inscription of the text into two required components for authorship. He cites as an author Lord Byron, which perhaps should come as no surprise given that The Giaour and Don Juan have occupied nearly a third of the course thus far. Bruno's conception of authority is largely 
unchanged. His idea of authenticity continues to rely on a third party for validation without questioning the right or ability of that party.

\section{Final Daybook}

Bruno's final Daybook submission includes his notes from the day spent on "The Chaldee Manuscript," his map and lecture notes from the class spent on the history and geography of Great Britain, notes from Dr. Kathy Yancey's guest lecture to the ISU Writing Program on transfer as a pedagogical concept, notes on the Ems Dispatch and the Franco-Prussian War, a comparison between the title character of Bram Stoker's Dracula and Count Orlok of the film Nosferatu, and notes from the day spent on "The Purloined Letter."

In lieu of a final Daybook page reflecting on the entire course, Bruno submitted a typed one-page essay on the topic. He focuses primarily on the role of paratext and context in complicating our relationship to texts. He ends his essay "I will never again open up a book and not be aware of the Paratext."

Overall, Bruno was one of the most successful students in the class, demonstrating an attention to the issues raised by the course and documenting dogged efforts to understand them. I'd like to pat myself on the back for the ways that the questionnaires and graded work show Bruno's learning, but that credit belongs squarely with him and earlier teachers that inculcated the value of seriously engaging with his schoolwork. His final essay on paratext demonstrated a new understanding of the ways in which the materiality of text mediates the relationship between authors and readers. 
Case Study 2: Bella

\section{Daybook \#1}

For her first Daybook submission, Bella chose the page with her notes from an inclass exercise in which groups were assigned a part of The Rime of the Ancient Mariner and asked to summarize it for the rest of the class. In her notes she suggests that the Mariner's strange compulsion to tell his tale may suggest that authors don't always have conscious control over their textual productions (see fig. 11).

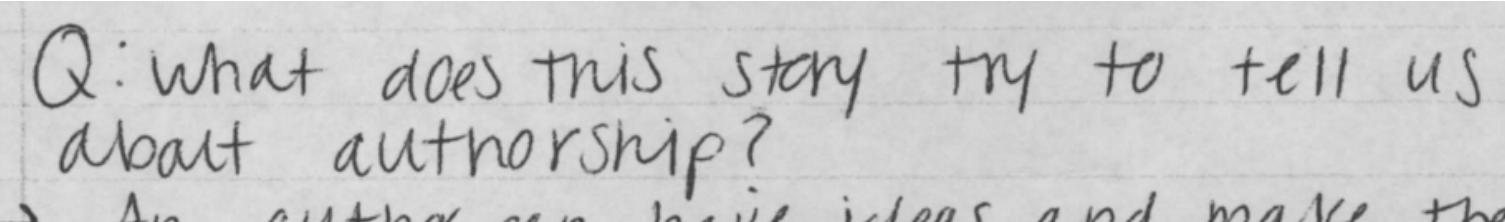
$\rightarrow$ An author can have icleas and make them realities through writing. Reach parts of yaur brain that are unconsciaus. Authors don't have conscious access to What they write abaut.

Figure 11. Excerpt from Bella's Daybook submission \#2

\section{Daybook \#2}

Bella's second Daybook submission included her initial notes for her first paper, a page where she pasted in a copy of "Kubla Khan" and in the margins defined all the terms unknown to her (including sinuous, chasm, athwart, meandering, tumult, and dulcimer), a page where she researched the meaning and origin of the word giaour, a page on the Rashomon Effect and its relationship to the song "Summer Nights" from the musical/film Grease, and notes from an in-class exercise in which small groups were 
tasked with interpreting one or two stanzas from the first canto of Byron's Don Juan. All these tasks were in response of direct instructions in class or suggestions made in the ReggieNet lessons.

\section{Final Daybook}

Bella's final Daybook includes a page in which she tries to understand why Coleridge went to such great lengths to label "Kubla Khan" a fragment rather than a whole poem, notes comparing Stoker's novel Dracula to the film adaptations Bram Stoker's Dracula and Nosferatu, her notes from 2 days of class and the map of Great Britain every student drew as an in-class exercise. Her final page she makes the painful (to the instructor) mistake as identifying the material of the course as situated in the eighteenth century instead of the nineteenth, but the rest of her overview is split between homing in on key issues of the course (authorship as a construct, the importance of paratext, multiple modes of diegesis in a narrative) and meditating on the benefits of the Daybook as a way of expressing learning without the difficulties of navigating a rigid school genre.

Overall, Bella's uptake of the course material was less complete than Bruno's but her written work for the course and her participation in small group activities showed her engagement and learning. Her biggest breakthrough was in her exploration of the Daybook as a venue for the recording of genuine learning (that is, intrinsically motivated learning) versus learning designed solely to attain a good grade. 
Case Study 3: Anna

\section{Daybook \#1}

For her initial Daybook submission Anna selected a page where she has several different things are happening: notes from the initial day in which paratext was defined, notes on Horace Walpole, responses to two Daybook writing prompts ("What have you learned so far?" and "How would you react to the 2nd edition preface of The Castle of Otranto [which reveals the hoax of the 1st edition] had you been a fan of the original version?" She also records her own definitions of negative capability and mystery. She also makes a note to herself regarding an issue she has with an unclear section of the syllabus. The issue was addressed in class, but I don’t recall if she brought it up or another student. Anna also doodles in her Daybook, a practice I encourage. ${ }^{61}$

\section{Daybook \# 2}

Like Daybook submission \#1, most of the pages handed in by Anna are subdivided into many different materials related to the course, all interspersed with various small doodles. Almost all the material shared are notes from class or exercises performed in class. She also submits her notes from her attendance at an extra credit event. Perhaps the two most interesting items from this submission are her diagram of the relationship between text, context, and paratext (see fig. 12) and her note from the day that we discussed the differences between us and nineteenth century readers. She suggests in the latter section that the original readers of our course materials probably

\footnotetext{
${ }^{61}$ See, for example, Milton Glaser's Drawing is Thinking or the last several works by artist/educator Lynda Barry.
} 
had to deal with less paratext mediating between them and the text. She does not elaborate on this point, but I find it intriguing nonetheless as it indicates she has given some thought to the history of the reception and reproduction of our texts.

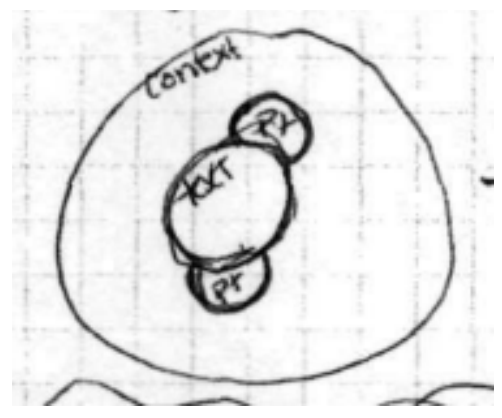

Figure 12. Excerpt from Anna's Daybook submission \#2

\section{Final Daybook}

Anna's final Daybook submission included notes taken for the Dr. Orpana and Dr. Yancey reports and notes taken in class for Dracula, "The Purloined Letter," Private Memoirs and Confessions, and Sartor Resartus. Her final Daybook page is an elaborate illustration of the network of questions raised in the course, which I reproduce in full below (see fig. 13). She attached a sticky note (optional for the final page) in which she explains:

My illustration is a learning web in a way. My image represents what all I have learned in the class. The web helps to show how everything is connected and how it will be locked in my memory. I choose the eyes to be in color because the class helped see things/history more in a colorful way. 


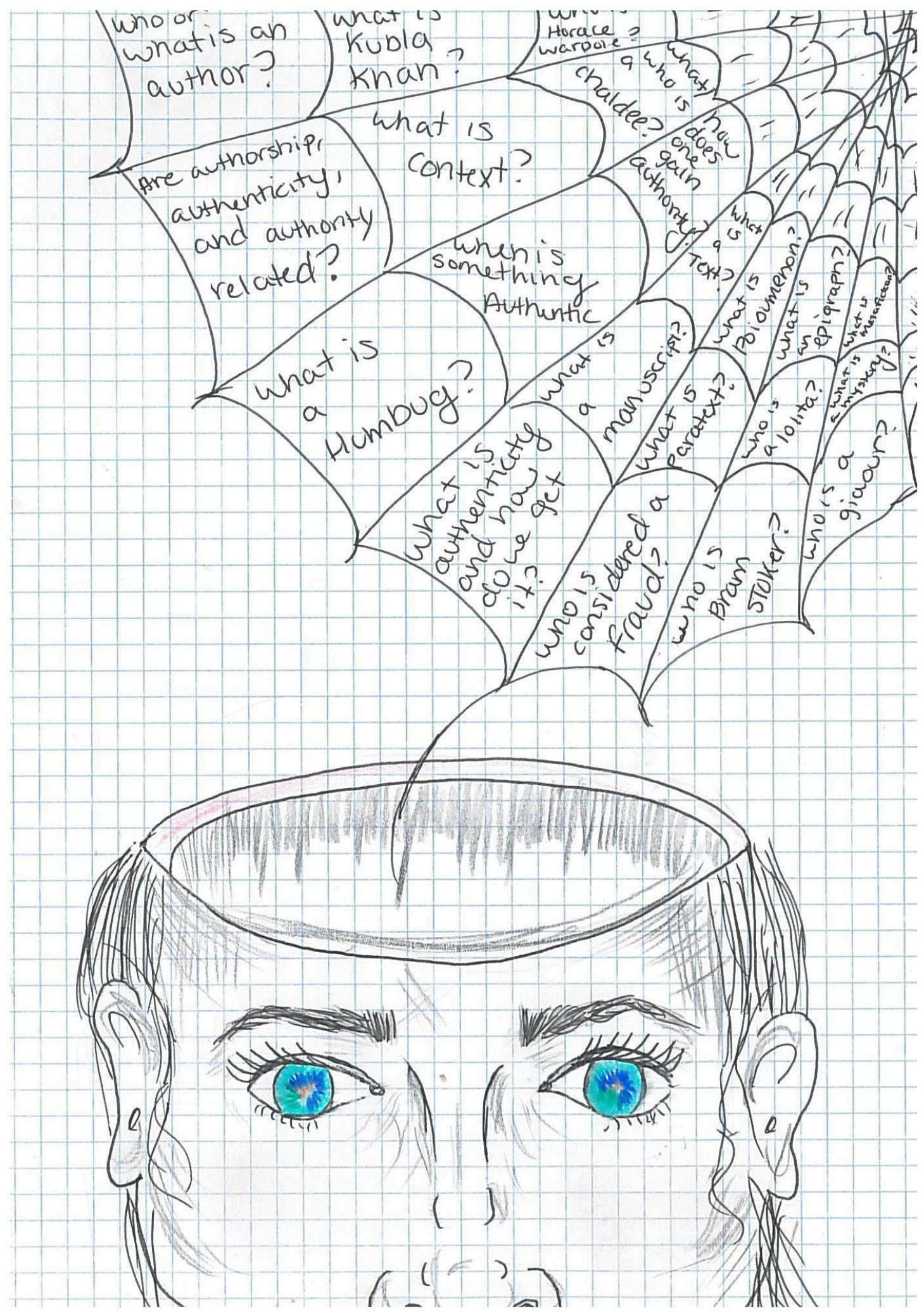

Figure 13. Last page from Anna's final Daybook submission 
Anna's work underlines the advantages of providing students multiple ways of showing their learning. The basic Daybook format, in which students share their notes, demonstrated little more than the fact that Anna is a diligent note-taker. But the final summary page clearly demonstrates an attempt to understand and implement the key lessons of the course. The Daybook served as a venue for her to integrate her learning. Case Study 4: Michelle

\section{Daybook \# 1}

Michelle's first Daybook submission consists of a page overflowing with notes, including definitions supplied in class (paratext, metacognition), definitions developed as part of a homework assignment in a ReggieNet lesson (negative capability, mystery), notes to herself to look up words from course readings, and a section discussion the relationship between the course content and a lesson on Aristotle from another class she is taking.

\section{Daybook \#2}

Michelle's second Daybook submission consists of her notes made in preparation for writing the first paper, notes for The Giaour (including a brief analysis of the paratexts accompanying the poem), a drawing illustration the differences between fantasy and reality (an in-class exercise), notes on the humbugs of P. T. Barnum (a Daybook prompt from a ReggieNet lesson), and notes from the day we discussed Andy Kaufman and Bob Zmuda's invented persona, the lounge singer Tony Clifton. Although she doesn't show the same synthetic reasoning as seen in Daybook submission \#1's work with Aristotle, Michelle clearly demonstrates that the various in-class and ReggieNet Daybook prompts are leading her to engage with the key issues of the course. 


\section{Final Daybook}

For her final submission Michelle included a reflective exercise from earlier in the semester in which students first wrote about their favorite Daybook entry thus far, then wrote about another student's favorite Daybook entry. She also included her hand drawn map of Great Britain; some notes from the Sartor Resartus class period; a diagram on the relationship between authors, people, and important documents like the Declaration of Independence or the Magna Carta; a sketch of Dracula made before reading the novel (it looks like Bela Lugosi); and notes from one of the Dracula class periods. Michelle also included the in-class exercise, inspired by Dr. Yancey's presentation on transfer, in which students were asked to come up with a list of keywords for the course. She wrote the following list:

1. way back in time

2. text, paratext, context [a side annotation marks paratext as "most important"]

3. Daybook

4. readings

5. authorship

6. authenticity

7. perspective

Perhaps her best work is her attempt to diagram Gérard Genette's three levels of diegesis (see fig. 14). She doesn't quite get the metadiegetic level correct, but here we see Michelle attempting to make sense of a new concept without a direct prompt from the instructor. 


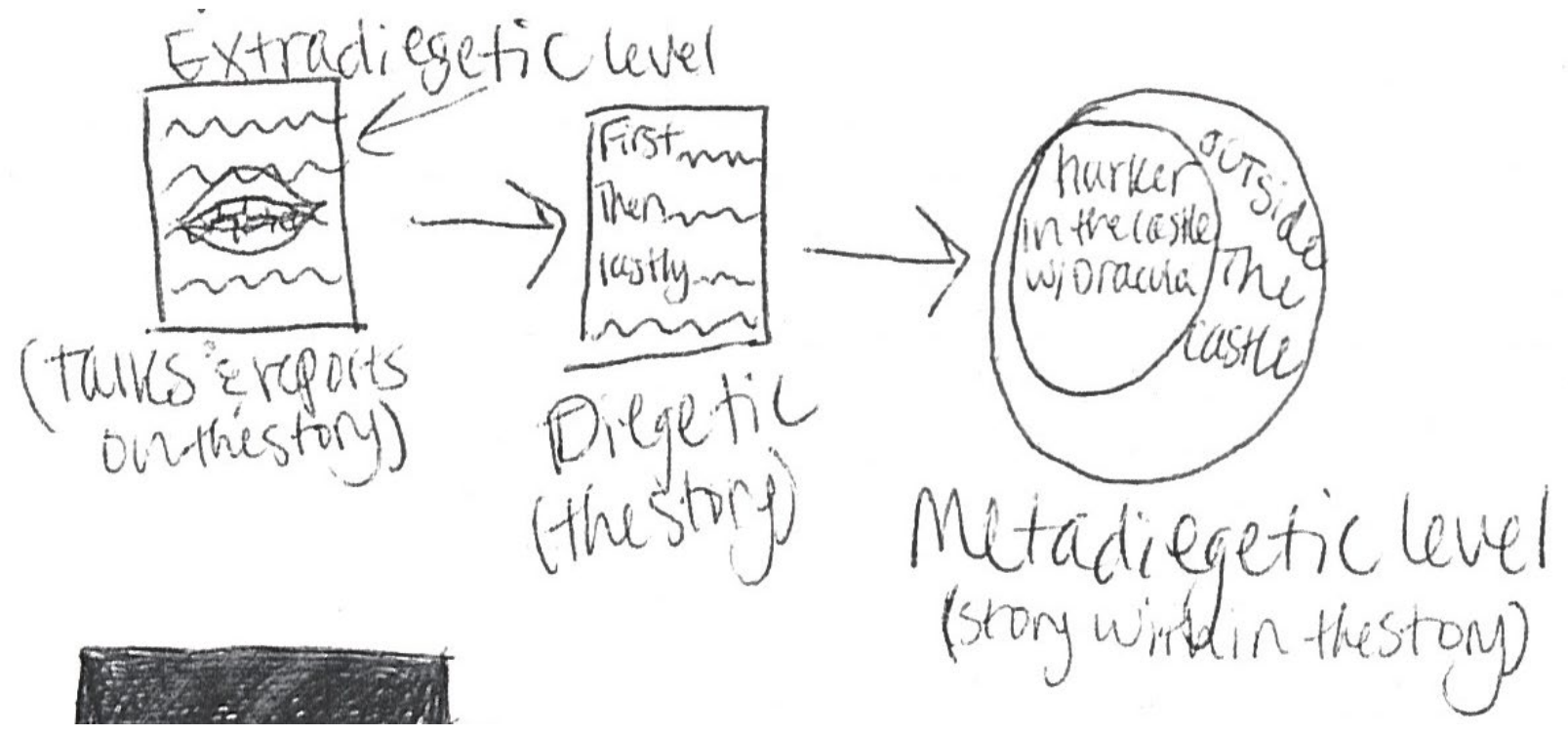

Figure 14. Excerpt from Michelle's final Daybook submission

Her final Daybook page is divided between a stream-of-consciousness description of the course content that hits most of the conceptual highlights of the course and a handwritten crossword/word cloud-like text (see fig. 15).

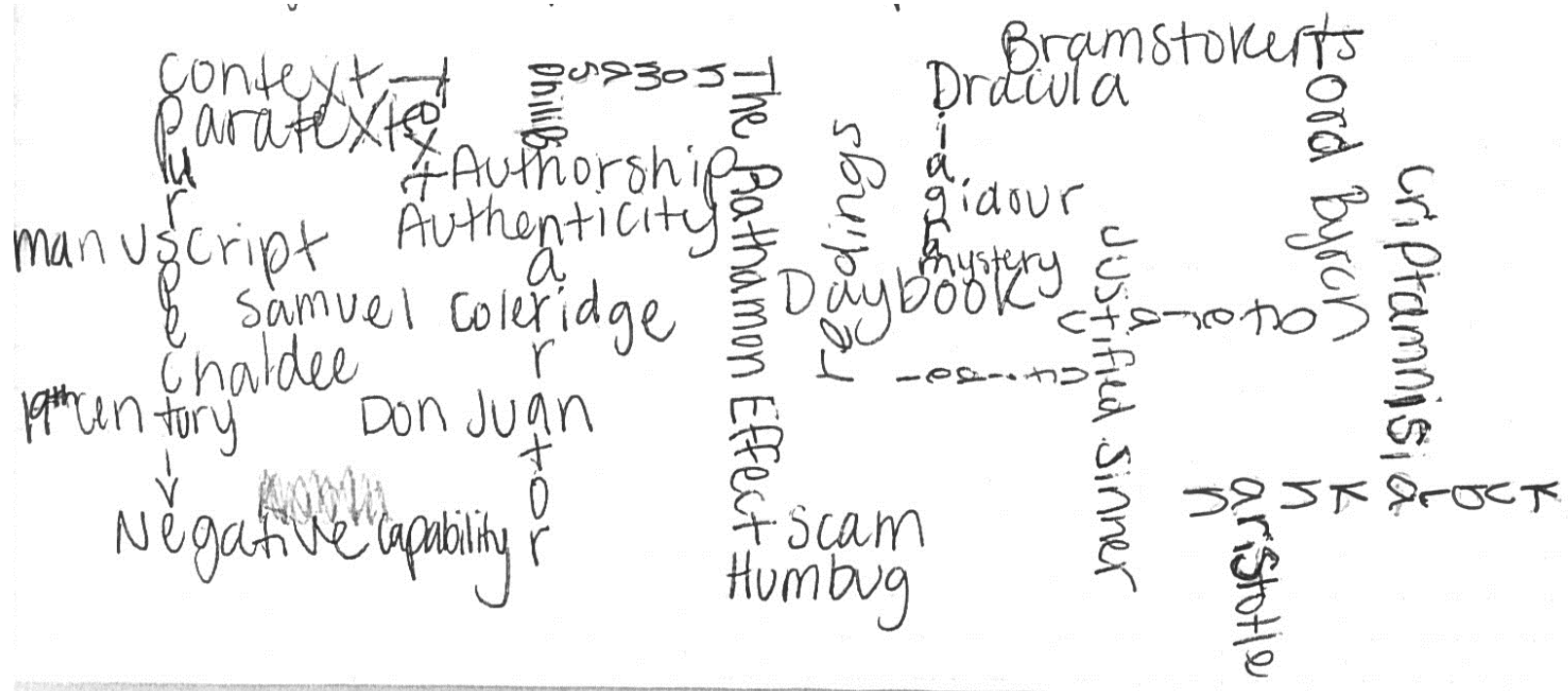

Figure 15. Excerpt from last page of Michelle’s final Daybook submission

Overall my impression of Michelle is that she would have floundered in a literature class that did not make use of the Daybook concept or something similar, as 
her papers did not provide an appropriate venue for her to demonstrate her learning. Grading her on class participation (a practice I've eschewed out of fear of punishing the wallflowers of the world) would have torpedoed her grade as well. But her Daybook submissions clearly document that she was engaged with the materials of the course and attempting to make some sort of sense of them.

Case Study 5: Nina

\section{Daybook \#1}

For her first Daybook submission Nina handed in a page that consisted mostly of biographical facts on Horace Walpole, John Keats, and Samuel Taylor Coleridge as mentioned in class; a definition of the term "gloss" in relation to The Rime of the Ancient Mariner, some notes on the Walpole/Chatterton controversy, and her response to the prompt asking students to imagine their reaction to the original publication of the second edition of The Castle of Otranto.

\section{Daybook \#2}

For her second Daybook submission Nina provided a page with extensive verseby-verse notes attempting to parse the first chapter of "The Chaldee Manuscript," a second page on "The Chaldee Manuscript" with notes on what she learned about the text in class, a one page summary of The Rime of the Ancient Mariner with one to three sentences describing the action of each part of the poem, notes she took preparing her first paper (including pasted-in thumbnail images of the front and back cover of the Sam Smith album), a page on the life and humbugs of P. T. Barnum, and a page of notes on "Kubla Khan" and The Giaour. 


\section{Final Daybook}

For her final Daybook submission Nina includes two pages of notes comparing the popular notion of Dracula to the novel and the two film adaptations we watched; two pages of notes on The Private Memoirs and Confessions of a Justified Sinner, including all the evidence she could find on young Wringhim's paternity; a page on the four Jack the Ripper letters we examined, with her opinion on which one might be actually from the Ripper; her hand drawn map of Great Britain and notes from the installment of the Noctes Ambrosianæ we read. Her final page takes the form of a hierarchically arranged list of knowledge gained from the course, see figure 16 for an example.

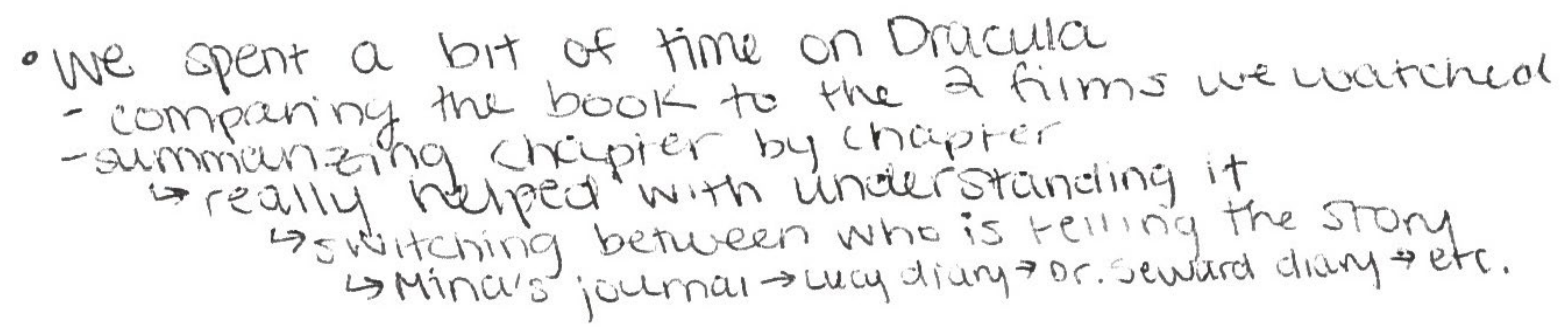

Figure 16. Excerpt from last page of Nina's final Daybook submission

Overall, I think Nina would have been just as successful in a more traditionally designed literature class that relied heavily on papers, quizzes, and tests. Her submitted Daybook entries demonstrated that she was an effective reader and note-taker, but she did not do anything with the venue that wouldn't have served her equally well in a class that did not ask her to submit her notes for assessment.

Case Study 6: Joan

\section{Daybook \# 1}

Joan's first Daybook submission was split between two pieces. The top of the page was a lengthy reflection on how hurt she would have been to have been fooled by 
Horace Walpole's original Otranto preface. The bottom section contains an exercise related to The Rime of the Ancient Mariner. It was not a Daybook exercise, but Joan recorded it anyway.

\section{Daybook \# 2}

Joan's second Daybook submission include notes made for an extra credit report on tattooing, a page of notes on The Giaour in which she asks in large letters "Who is narrating this poem?”, notes on canto 1 of Don Juan and one of the later Juan imitators, and a hand-copied transcription of "Kubla Khan" with marginal notes defining words new to her.

\section{Final Daybook}

Joan's final Daybook entry contains a one page reflection on the game she played on the day we played all the small group games, notes from Simon Orpana's zombie presentation, notes comparing the novel Dracula with Bram Stoker's Dracula and Nosferatu, notes on the first three chapters of Dracula, notes on the first four chapters of Sartor Resartus, and a copy of the family tree I drew on the whiteboard for The Private Memoirs and Confessions of a Justified Sinner. Her final Daybook page discusses the Daybook process: "I also really came to appreciate the prompts to write in our Daybooks, because they forced me to give some thought on the subject and write it down to further reinforce my learning. We were pushed to think about things I would have never thought about on my own, such as authorship + what forces led to our present self."

Joan's work on the paper assignments showed a great deal of creative and nuanced thinking, but her Daybook work also captured some interesting examples of 
original work. She undoubtedly possesses the tools to thrive in a more traditional literature class, but I suspect she would do just as well in a class that was even more strongly focused on Daybook work.

\section{Conclusion and Discussion}

Based upon the results of the Midterm Chat, discussions at the Future Professor's Circle and with fellow instructors, review of all the Daybook assignments and the case studies, I conclude that incorporating Daybooks as a form of reflective practice resulted in mixed but promising results. Overall, I found the Daybook to be a useful tool for the teaching of literature, particularly when combined with a course focusing on the function of authorship. Studying the author-function while challenging the students to act as authors of their own education produced a useful synergy.

A particularly striking effect of the Daybook is the variety of student writing arising from it. Emphasizing the daily discipline of writing, but leaving open the form that it takes, combined with the freedom to excerpt only they work the students considers their best resulted in a dazzling array of experiments in thought and word. Perhaps Bruno would have taken up the relationship between The Giaour and the SpongeBob episode "Friend or Foe?" in a traditional paper assignment, but maybe he would not have risked writing about such an apparently frivolous textual paring with the encouragement provided by the experimental nature of the Daybook. Without the Daybook, I doubt I would have seen Michelle teasing out a single of mention of Aristotle in my course with a lesson about the philosopher from another class. Both Daybook submissions, and many more I received from many other students, only manifested due 
to the pressure to write every day and the freedom to explore both the subject and the shape of that writing.

Since concluding this course, I have continued to refine the use of Daybooks in my classrooms. The biggest area that continues to need work is the development of the Daybook as a daily discipline. Most of my creative writing colleagues ${ }^{62}$ begin their First Year Composition classes with five to fifteen minutes of uninterrupted writing time. It helps establishes a classroom routine and gives the students time to practice the primary skill they are all supposed to be improving. Many instructors provide a prompt for this writing task relevant in some way to the day's lesson or the current major project.

For this study I made extensive use of Daybook writing prompts in my classroom and the students generally reacted well to them. I found it helpful to prime discussions by asking students to write on the topic before asking them to speak about it, if for no other reason than, when confronted by 30 silent students, I could say "I know you've all just finished writing some thoughts on this very topic." Subsequently I found it useful to routinize this practice by starting nearly every class period with a Daybook writing prompt followed by calling on students to share their thoughts. Thus, students who struggled with material for their Daybook could expect to create at least two kinds of material every class meeting: the initial prompt and their notes from the rest of the lesson.

${ }^{62}$ In particular, I would like to thank Cory Hudson for several conversations on this subject. 
Additionally, making this practice part of the everyday classroom activity encourages students to keep up with the reading without resorting to a quizzing regime. Anything that increases the volume of thoughtful material in their Daybooks affords them more opportunities for better Daybook submissions.

The other side of this daily disciplinary approach comes in the form of supplying more and better distributed Daybook prompts for writing between class meetings. In my initial attempt to offer suggestions for Daybook entries, I used a single shared Google doc which I added to as I prepared each lesson. In retrospect, a single multi-page list of prompts appears to many students as an unassailable wall of text. To avoid this problem, I have taken to building weekly homework pages in the course's Learning Management System. Each page gives the assignment for the week and one to three optional Daybook prompts. Many students found this a more manageable arrangement.

It has also proven useful to simply remain mindful of the student's need to write in their Daybook when teaching a lesson. An impromptu comment such as "Further exploration of this topic would make a great Daybook entry" tends to cause at least a few students to write down that idea.

The idea of a list of pre-generated Daybook prompts has not been altogether abandoned. My current practice is to issue the students a handout they can paste into their Daybook. See Figure 17. 


\section{Evergreen Questions for Your Daybook}

What did I learn today? This week? This unit?

$\square \quad$ What are the main points of this lesson or reading?

$\square$ If I had to explain what I learned today to someone back home, what would I say?

How can I connect what I just learned to my previous learning?

How could what I just learned be useful to me in the future?

$\square$ What connections can I make between what I am learning in this course and what I am learning in another course this semester?

$\square$ What questions do I have about what I have learned? Where am I struggling?

What questions do I have that I need to research myself? What am I curious about?

Figure 17. Evergreen Daybook questions handout

Experience teaching subsequent courses has demonstrated that simply distributing this list does not achieve the intended results. Students need to be reminded of its existence on an ongoing basis and occasionally tasked with writing in response to one of these prompts as an in-class activity. 
Additionally, in subsequent semesters I have incorporated Daybooks even more in my classroom practice. Students submit Daybook submissions four or five times over the course of the semester. The Daybook submissions as a whole worth are worth at least one third of the student's final grade, making the Daybook the single biggest determiner of the student grade success. And I have made a consistent effort to ensure that every single class period involves some sort of Daybook activity. Though often this activity is writing, I have also taken to asking the students to sit in small groups and discuss their writing and/or read aloud from their Daybooks. To underscore the emphasis on the Daybook as the keystone of the class, I have even attempted distributing a first day syllabus that is a photocopied page from my own Daybook, with the fully fleshed out syllabus available via the course's learning management system webpage.

\section{Looking to the Future}

Additionally, the work of L. Dee Fink can aid in the analysis of Daybook assignments. Fink's influential work Creating Significant Learning Experiences: An Integrated Approach to Designing College Courses outlines a taxonomy of significant learning. This taxonomy analyzes learning via six categories: foundational knowledge (remembering and understanding information and ideas), application (use of skills, critical thinking, creative work, project management), integration (connecting learning to other ideas, experiences, and learning), the human dimensions (learning about the self and relationships with others), caring (developing new feelings, interests, values), and learning how to learn (becoming a curious, self-directed learner) (34-6). 
Traditional student note-taking, with its focus on whatever information will appear on exams, usually only addresses the foundational knowledge form of learning. Instructors who foster an active learner environment often work within the categories of application and/or integration, and many of the basic Daybook prompts and activities I have used fall into those areas. My initial formulation of the concept of self-authorship focused on what Dee identifies as learning how to learn, though I initially encountered it as "metacognitive knowledge," as identified in David R. Krathwohl's revision of Bloom's taxonomy of cognitive learning, but Fink's caring and human dimension outcomes go more to the heart of what I want to happen in my classroom (Krathwohl 214). The "learning about self" component of Fink's human dimension makes assumptions about the self as a fixed, received thing. I find it more useful to conceptualize the Daybook as a vehicle for the construction of self.

Since completing my initial forays into Daybooking as a form of student metacognitive self-authorship, I have continued my research in this direction. The pedagogical research of Marcia B. Baxter Magolda focuses on self-authorship as the primary goal of postsecondary education. Baxter Magolda defines self-authorship while outlining the need for it:

Many students enter college having learned how to follow formulas for success, lacking exposure to diverse perspectives, and unclear about their own beliefs, identities, and values (Baxter Magolda, 2001b). Moving from these entering characteristics to intended learning outcomes requires transformational learning, or "how we learn to negotiate and act on our own purposes, values, feelings, and meanings rather than those we have 
uncritically assimilated from others" (Mezirow, 2000, p. 8). Extracting themselves from what they have uncritically assimilated from authorities to define their own purposes, values, feelings, and meanings involves far more than information and skill acquisition. It requires a transformation of their views of knowledge, their identity, and their relations with others. Twenty-first century learning outcomes require self-authorship: the internal capacity to define one's own belief system, identity, and relationships... (69)

Under this conception of the purpose of learning in higher education, students do not simply receive, process, manipulate, and evaluate “information" or "content." Rather their whole being, their present and future selves as members of humanity, becomes principle around which the whole class, not just the Daybook, is organized.

Using this framework, the Daybook becomes an instrument for the construction of a self. This self is, of course, an unknown entity lurking in an unrevealed future, the most distant and yet most intimate form of the Other Reader. Building a future self from the position of the present will always be a fraught affair, but writing can help navigate this strange frontier.

Looking back at the work done over the course of the semester, some student writing starts to look like attempts at self-authorship. The most obvious instance is Joan's exploration of "what forces led to our present self." Bruno's declaration that he will never read another book without considering the paratext surrounding it has implications for all his future reading. Michelle's attempt to map the relationship between ordinary people and documents like the Constitution and the Magna Carta 
could impact the way she thinks about citizenship and the law for the rest of her life. Bella's investigation of the difference between learning-for-the-assessment and genuine learning sets her on the path toward becoming a lifelong learner. Both Nina's attempts to arrange her learning from the course hierarchically and Anna's probing questions at the end of the course gesture in this same direction.

Finally, Dannelle D. Stevens, one of the co-authors of Journal Keeping: How to Use Reflective Writing for Learnings, Teaching, Professional Insight, and Positive Change, introduces to her students the Daybook as a book, as an archive, and as an artifact:

This is your first book, a journal about your school work, your life, and how you organize and think about what you do. I encourage you to not only use this journal for this class but use it every day: to note meetings you attend, groups you work with, etc. You do not have to limit your entries to this class. Perhaps you will find ways to include other parts of your life as well. Remember journals can be archival, too. My grandmother was a high school mathematics teacher in the 1890's. I would love to have her journal today. Perhaps your future grandchildren will feel the same way. (Stevens and Cooper 61-2)

Among the first things Stevens asks her students to do with their journals is to set aside two pages for a table of contents to be written later and to number the pages, a practice shared with several of the authors of Thinking Out Loud on Paper (Stevens and Cooper 64; Brannon et al. 30-1, 34-5). Not only do these moves assist in navigating the journal 
later in the semester, they help establish what might be called the "bookness" of the object, as a simulation the materials and protocols of print book production.

To this end, I have organized my own current Daybook to account for the front and back matter typical of printed books. The first and last opening of the composition notebook have been set aside for pasting in end papers, which will probably end up taking the form of wrapping paper pasted in with rubber cement. In the front of the Daybook, this is followed by a blank opening, then an opening with a frontispiece on the verso and a title page on the recto. The frontispiece--also pasted in with rubber cement-takes the form of a whimsical illustration depicting me as a wizard, done by an artist friend. The title is simply Daybook $X$, as this is my tenth composition notebook since adopting Thinking Out Loud on Paper for my own practice.

The reverse of the title page is reserved for a colophon statement, with the next leaf set aside as a table of contents. Then follows a page set aside for a dedication, followed by a forward. The latter I hope will be filled in by someone else when the rest of the Daybook is complete, probably my wife. The first page of text in the Daybook is an introduction, briefly outlining the same project I am explaining here. At the end of the Daybook are pages set aside for an epilogue and afterword as well as two pages each for glossary and bibliography. The latter two sections consist of brief definitions for any word I look up in course of my reading and a complete list of all texts I read in their entirety during the life of the Daybook. Should either overrun the two pages allocated, I plan to end the section with a note "continued on page XX," placing the balance of items in a new section early in the Daybook. 
The effect intended overall in asking the students to parcel out and complete these various subdivisions is threefold. First, it provides an opportunity for students to learn the interior structure of the book. Second, by including paratextual components (such as an introduction, afterword, etc.) in their Daybook, the student can better prepare their Daybook for reception by an Other Reader, including a future self looking back at this period in their education. Finally, by aligning their Daybook more closely in configuration to that of a printed volume, an implicit argument is made for valuing the student's own work on an equal footing with that of any other authorial production, potentially increasing the student's intrinsic motivation to take up the Daybook task.

Furthermore, inspired by the attention-focused, detail-oriented praxis of artist Lynda Barry as outlined in her book Syllabus: Notes from an Accidental Professor, I intend to use the following exercise as a default Daybook activity for the students: in a two page spread, the student will be asked to copy a page of text from the assigned reading on the left hand page, with their annotations of that text to be added to the right. I've begun this practice myself and found hand copying text an excellent learning activity. Furthermore, the simple act of putting pen to paper knowing exactly what you are going to write serves as a nice counterpoint to typical learning activities, relieving the anxiety to abstract one's experience.

Prior to gaining first-hand teaching experience I possessed an unquestioned model of how literature courses should operate. In this fantasy world everyone in the room has read the text, given it some serious thought, and is prepared to discuss it in a nuanced way. I certainly don't doubt that such a classroom experience is possible, as I have seen it happen. However, I think it may be counterproductive to expect this fantasy 
to magically materialize in our classrooms. This is especially true when we are teaching undergraduates who may not have fully developed the skills necessary to engage literature in the same way that their instructors do, and it is doubly true when teaching literature to students taking a general education class.

This gap between the fantasy and the reality is why the Daybook, when used to both require specific student activities (daily writing prompts, formal class participation) and to allow student agency in selecting the specific writing genres through which students can demonstrate their learning, has produced better results than any other pedagogical technique I have attempted thus far. The specified activities give students the opportunity to practice and develop the skills necessary to become active readers, thinkers, and speakers in the class. The freedom of expression provides multiple venues beyond the typical term paper for expressing their learning. Taken together, these two seemingly contradictory approaches acknowledge and respects that students may have vastly different strengths and interests than someone with the instructor's proclivities while at the same time demanding they practice the skills necessary to be successful in a literature class.

Ultimately, the Daybook demonstrates the beneficial aspect of the Other Reader. The traditional writing assignment implicates an audience of one, the instructor. By asking students to write a large variety of exploratory texts but asking that they only share a small slice of that material with the instructor, student writing becomes at least partially decoupled from the tyranny of the assessing instructor. In fact, I challenge my students, if they feel so moved, to write Daybook pages with titles like "Why My English Teacher Sucks" or "Top 10 Reasons I Hate Going to Lit Class." They'll feel better for 
writing out the problem and I'll never see those pages unless they were to share them with me voluntarily. But that raises the question, if the bulk of the Daybook isn't written for assessment by the instructor, who is it for? The Other Reader enters the learning situation by this back door, leading the student to a place where they are writing for their own benefit, for their own learning, for their own future. 


\section{CODA}

In his 1941 short story “The Library of Babel,” Jorge Luis Borges imagines a universe that takes the form of a library containing all possible texts. These texts take the form of books laid out using twenty-five "orthographical symbols," consisting of an alphabet of twenty-two letters, the period, the comma, and the blank space (53). Borges' story is first and foremost a meditation on the nature of infinity; to truly contain all possible texts in its collection, within the gloomy halls of the library one must be able to find

the minutely detailed history of the future, the archangels' autobiographies, the faithful catalogues of the Library, thousands and thousands of false catalogues, the demonstration of the fallacy of those catalogues, the demonstration of the fallacy of the true catalogue, the Gnostic gospel of Basilides, the commentary on that gospel, the commentary on the commentary on that gospel, the true story of your death, the translation of every book in all languages, the interpolations of every book in all books. (56)

But in addition to a thought experiment exploring the consequences of access to all texts, "The Library of Babel" is also a fantasy of a world without remediation. In exchange for the new problem of the near impossibility of finding any particular book in an infinite sea of text, the library disposes of all of the perennial problems of communication that have irked humanity since the dawn of writing. The books contained within the library are not the products of an economic and material communication system; they are ontologically pure entities, they simply exist in the 
eternity of the library. These volumes have neither editors nor distributors. No pressmen or compositors labored over them. They have always sat on their shelves of the library, awaiting readers.

Following this logic to its ultimate limits yields the inevitable conclusion that no one authored these works, despite whatever claims may be made in the texts themselves. Freed from the shackles of authorial intent and the inescapable transformations of the publishing process, the reader is left in an idealized position: alone with the text, free of outside interference. The solitary joy of the reader alone with a book can be fully realized at last, isolated from the vicissitudes of the wide, weird world of book production. The audience for books in this eternal space of infinite extension never changes either; all books are available to all. Travel time from one set of shelves to another is the only limiting factor. Under these phantasmagorical conditions, the Other Reader never manifests. In fact, there is no Reader, only readers. Without an Author to imagine an audience, the Reader is never imagined and the Other Reader can't possibly exist.

Although this dissertation focuses primarily on the emergence of the Other Reader as a result of the expansions of print production over the course of the nineteenth century, a similar formation can rise to prominence during any period of media transition. The moment the inscriber of a text becomes cognizant of the fact that writing can escape the bounds of the discourse community, the Other Reader is born. The Other Reader can be found wherever an author asks who else will encounter their text. Although experienced at the individual scale, such as when a blogger lands a book deal and suddenly must consider who outside their blog readership will encounter the 
print edition, the Other Reader's appearance actually signals an ongoing phase shift in the media landscape. The gap between blog readers and book readers--or between the low-print-run upper class readers of the end of the eighteenth century and the growth of mass media book production during the nineteenth--creates the opportunity for the specter of the Other Reader to influence the writer.

These sorts of transitional periods can be found throughout the history of media. The invention of rhyme and meter as a way of increasing the reproducibility of verbally transmitted to text could be considered the earliest such event; the ability of nonliterate humans to memorize verse allowed for the faithful reproduction of text across continents and across centuries. The Life of King Gesar, a twenty-million word Tibetan epic composed in the twelfth century, continues to be transmitted orally to this day (Samuel 68-9; "World's Longest Epic Sung for a Thousand Years"). What changes might the composer or composers of this work have made to the King Gesar, if they knew that a thousand years later it would still be sung? What responsibility would they feel to an audience they could barely imagine? It is attempting to answer questions like this that leads to the haunting presence of the Other Reader.

The earliest thinker to express concern over the problem of the reader was Plato, who did so in connection with the unknowable audiences opened by the proliferation of the written word. He puts the following words in Socrates' mouth to criticize the practice of transcribing speeches:

You would imagine that they [written speeches] had intelligence, but if you want to know anything and put a question to one of them, the speaker always gives one unvarying answer. And when they have been once written 
down they are tumbled about anywhere among those who may or may not understand them, and know not to whom they should reply, to whom not: and, if they are maltreated or abused, they have no parent to protect them; and they cannot protect or defend themselves. (139 [275])

This reluctance to allow words to circulate freely, subjecting them to imagined "maltreatment or abuse" at the hands of an Other Reader, may explain why neither Socrates, nor his near-contemporaries Zoroaster and Buddha, chose to write down their teachings.

The influence of the Other Reader can also be found in the transition from manuscript to print culture. Elizabeth L. Eisenstein's observation that "within a generation" of the rise of movable type that priorities shifted "away from fidelity to scribal conventions and toward serving the convenience of the reader" demonstrates, at least in part, an awakening to the problem of the Other Reader (52). Manuscript culture's inherent insularity, which tends toward producing texts for the scribal class and their elite sponsors, begins to open up to the new potential audiences afforded by mass reproduction.

The move from scribal fidelity to reader convenience as the new ethos of print prefigures our own era's practice of continuous remixing and remediating of text. Whether the same text is released in cheap paperback, as an electronic book, a rogue pdf scan, a large print edition, an audio recording, or as the script for video adaptation, each of these versions gestures toward a different slice of the public. An author's ability to envision these slices as alien to the core audience of the text creates a conundrum: how does one write for someone other than one's audience? The ultimate insolubility of this 
paradoxical challenge creates the phantom of the Other Reader, an unknowable creature lurking beyond the safe boundaries of every discourse community.

But is the Other Reader an inevitable phantom? Are writers doomed to its nightly visitations until they discover a way to address it in their manuscripts? Conscious efforts toward a universal appeal help but tend toward the inverse problem of cultural myopia, e.g. Silas Flannery, the fictional author in Calvino's If on a winter's night a traveler, and his ilk quite easily imagine themselves as writing universal experiences while giving short shrift to la Lettrice and other non-male, non-white, non-straight readers. L. L. Zamenhof fell victim to the same problem when he developed the international auxiliary language Esperanto. Hoping to create a communication tool for the benefit of all of humanity, he actually re-encoded many of the key structural features of the languages of Europe, leaving much of the world beyond the limits of his consideration (Okrent 258).

Finally, it must be remembered that the Other Reader, the Reader, and the Author are abstracts, psychological constructs that simplify and generalize real actual social relations between those who encounter texts. Any change to those relationships will inevitably--though not necessarily immediately--change the way the abstracts function. The consequence of this fact is that although it may be possible to look for the Other Reader in other times and places (as suggested above), the phenomenon will not manifest in the same way that they did in nineteenth-century British letters. But wherever the gap between the writer and the audience grows, the Other Reader haunts the edges of understanding. 


\section{REFERENCES}

Adler, Mortimer and Charles Van Doren. How to Read a Book: The Classic Guide to Intelligent Reading. 1940, Simon and Schuster, 1986.

Alford, Henry. “Name That Book.” The New York Times, 26 Nov. 2006. https://www.nytimes.com/2006/11/26/books/Alford.t.html. Accessed 18 Aug. 2018.

Ambrose, et al. How Learning Works: Seven Research-Based Principles for Smart Teaching. Wiley, 2010.

“American Book Review.” The University of Houston-Victoria, americanbookreview.org. Accessed 24 Nov. 2018.

Anesko, Michael. "Collected Editions and the Consolidation of Cultural Authority: The Case of Henry James.” Book History. vol. 12. 2009, pp 186-208.

Ashley, Peter. Preposterous Erections: A Book of English Towers. London: Frances Lincoln, 2012.

Austen, Jane. Pride and Prejudice. London: T. Egerton, 1813. Project Gutenberg. 9 May 2013. http://www.gutenberg.org/files/42671/42671-h/42671-h.htm. Accessed 7 Feb. 2018.

Bain, Ken. What the Best College Teachers Do. Harvard UP, 2004.

Bakhtin, M.M. The Dialogic Imagination. Translated by Caryl Emerson and Michael Holquist, U of Texas P, 1981.

Bari, Shahidha K. Keats and Philosophy: The Life of Sensations. New York: Routledge, 2012. 
Barkley, Elizabeth. “Next Steps in Student Engagement.” ISU University-Wide Teaching and Learning Symposium, 7 Jan. 2015, Marriott Conference Center, Normal, IL. Keynote Address.

Barry, Lynda. Syllabus: Notes from an Accidental Professor. Drawn \& Quarterly, 2014.

Bartal, Renana. Gender, Piety, and Production in Fourteenth-Century English Apocalypse Manuscripts. Routledge, 2017.

Barthes, Roland. "The Death of the Author.” Translated by Stephen Heath. Image, Music, Text, Hill and Wang, 1978, pp. 142-8.

Baudrillard, Jean. Simulacra and Simulation. Translated by Sheila Faria Glaser, U of Michigan P, 1997.

Baxter Magolda, Marcia B. "Self-Authorship: The Foundation for Twenty-First Century Education." New Directions for Teaching and Learning, No, 109, Spring 2007, pp. 69-83.

Bayle, Pierre. Dictionnaire historique et critique. Vol. 2, part 2, Chez Renier Leers, 1697. Internet Archive, 12 Sept. 2018, https://archive.org/details/gri_33125008462794. Accessed 14 Oct. 2018.

Beam, Alex. A Great Idea at the Time: The Rise, Fall, and Curious Afterlife of the Great Books, Public Affairs, 2008. 
Behn, Aphra. Poems upon several occasions with, A voyage to the island of love. $\mathrm{R}$. Tonson and J. Tonson, 1684. EEBO: Early English Books Online. http://eebo.chadwyck.com.libproxy.temple.edu/search/full_rec?SOURCE=var_s pell.cfg\&ACTION=ByID\&ID=11719861\&ECCO=param(ECCO)\&FILE=../session $/$ 1539458427_29512\&HIGHLIGHT_KEYWORD=param(HIGHLIGHT_KEYWOR D). Accessed 12 Sep. 2018.

Belloc, Hilaire. “On Footnotes.” On, George H. Doran Co., 1923, pp 43-51.

Bemong, Nele \& Pieter Borghart. Introduction. Bakhtin's Theory of the Literary Chronotope: Reflections, Applications, Perspectives. Ed. Bemong, Nele, et al. 2728 June. 2008, Academia P, 2010. 3-16.

“Benington Castle.” Gatehouse Gazetteer, 26 July 2017, http://www.gatehouse-gazetteer.info/English\%20sites/1531.html . Accessed 27 Mar 2018.

"Benington Castle, TL 297-236 Hertfordshire." CastleUK.net, 2014, http://www.castleuk.net/castle_lists_midlands/166/benington.htm. Accessed 27 Mar 2018.

Bentley, Richard, ed. Milton's Paradise Lost: A New Edition. Jacob Tonson, 1732. Internet Archive, 26 May 2011, https://archive.org/details/ParadiseLostRichardBentley1732. Accessed 12 Sept. 2018.

Bhaskar, Michael. The Content Machine: Towards a Theory of Publishing from the Printing Press to the Digital Network. Anthem P, 2012. 
"Bible." Amazon.com.

https://www.amazon.com/s/gp/search/ref=sr_nr_p_n_feature_eight_br_6?fst =as\%3Aoff\&rh=n\%3A283155\%2Cn\%3A12290\%2Cn\%3A12059\%2Ck\%3Abible\%2 Cp_n_feature_eight_browsebin\%3A6581496011\%7C6581490011\%7C10135930011\%7C6581492011\%7C65814 94011\%7C6581491011\%7C6581495011\&keywords=bible\&ie=UTF8\&qid=1514473 o87\&rnid=6581487011, Assessed 28 December 2017.

Bidwell, John. American Paper Mills, 1690-1832: A Directory of the Paper Trade, with Notes on Products, Watermarks, Distribution Methods, and Manufacturing Techniques. Dartmouth College P, 2013.

Bizzell, Patricia. Academic Discourse and Critical Consciousness. U of Pittsburgh P, 1992.

Blake, William. The Complete Illuminated Books. New York: Thames \& Hudson, 2000.

Bloom, Harold. The Anxiety of Influence: A Theory of Poetry. 2nd ed. Oxford UP, 1997.

Bone, Drummond, ed. The Cambridge Companion to Byron. Cambridge: Cambridge UP, 2004. Print.

Borges, Jorge Luis. “The Library of Babel.” Labyrinths: Selected Stories and Other Writings, edited and translated by Donald A. Yates and James E. Irby, New Directions, 1964, pp. 51-8.

Borst, Arno. The Ordering of Time: From the Ancient Computus to the Modern Computer. Translated by Andrew Winnard, U of Chicago P, 1993.

Brannon, Lil, et al. Thinking Out Loud on Paper: The Student Daybook as a Tool to Foster Learning. Heinemann, 2008. 
Briggs, Gordon. "Rashomon in 9 Minutes." Online video clip. YouTube. YouTube, 14 May 2012. Web. 2 Sep. 2015.

Brown, Deborah, et al., eds. Lofty Dogmas: Poets on Poetics. U of Arkansas P, 2005.

Brown, Peter C., et al. Make It Stick: The Science of Successful Learning. Harvard UP, 2014.

Browning, Robert. "Psellus, Michael.” Who's Who in the Classical World. Oxford UP. Oxford Reference, 2003. Accessed 16 Apr. 2016.

Bryant, Levi R. The Democracy of Objects. Open Humanities P, 2011.

Buchanan, George. Buchanan's History of Scotland in Twenty Books. Vol. 1, D. Midwinter and A. Ward, 1733. Google Books, 9 Oct. 2007. https://books.google.com/books?id=ruQOAAAAYAAJ. Accessed 11 Nov. 2018.

Bulwer-Lytton, Edward. Paul Clifford. Project Gutenberg. 16 March 2009. http://www.gutenberg.org/files/7735/7735-h/7735-h.htm. Accessed 7 February 2018.

Burke, Jim. The Teacher's Daybook, 2007-20o8: Time to Teach, Time to Learn, Time to Live. Heinemann, 2007

Burkle-Young, Francis A. and Sandra Rose Maley. The Art of the Footnote: The Intelligent Student's Guide to the Art and Science of Annotating Texts. UP of America, 1996.

Burton, Robert. The Anatomy of Melancholy, New York Review Books, 2001.

Buxbaum, Tim. Scottish Garden Buildings: From Food to Folly.

Byron, George Gordon. Don Juan. Edited by T.G. Steffan, E. Steffan, and W. W. Pratt, Penguin, 2004. 
---. The Giaour. 1st ed, John Murray, 1813. Internet Archive, 6 Aug. 2012, https://archive.org/details/giaourfragmentofo1byro. Accessed 14 Aug. 2018.

---. The Giaour. 3rd ed, John Murray, 1813. Internet Archive, 23 June 2008, https://archive.org/stream/giaourafragmentoobyrogoog. Accessed 14 Aug. 2018.

---. The Giaour. 5th ed, John Murray, 1813. Internet Archive, 28 Feb. 2008, https://archive.org/stream/giaourfragmentofoobyrorich. Accessed 14 Aug. 2018.

---. The Giaour. 7th ed, John Murray, 1813. Google Books, 6 Dec. 2011, https://books.google.com/books?id=ed5NAAAAcAAJ. Accessed 14 Aug. 2018.

---. The Giaour. 8th ed, John Murray, 1813. Google Books, 6 Dec. 2011, https://books.google.com/books?id=4G5bAAAAQAAJ. Accessed 14 Aug. 2018.

---. The Giaour. 10th ed, John Murray, 1814. Internet Archive, 23 Aug. 2012, https://archive.org/details/giaourfragmentof13byro. Accessed 14 Aug. 2018.

---. The Giaour. 11th ed, John Murray, 1814. Internet Archive, 2 Nov. 2006, https://archive.org/stream/giaourfragmentofoobyrouoft. Accessed 14 Aug. 2018.

Byron, Gerald Noel. The New Don Juan. E. Head, 1880. Google Books, 26 Sep. 2006, books.google.com/books?id=vqoDAAAAQAAJ. Accessed 2 Dec. 2014. 
Calvino, Italo. If on a winter's night a traveler. Translated by William Weaver, Harcourt, 1981.

Campbell, Ian. "Thomas Carlyle (4 December 1795-5 February 1881)." Victorian Prose Writers Before 1867. Edited by William B. Thesing, vol. 55, Gale, 1987, pp. 46-64. Dictionary of Literary Biography, vol. 55. Dictionary of Literary Biography Complete Online. Accessed 2 Feb. 2019.

Carpenter, Rhys. The Esthetic Basis of Greek Art of the Fifth and Fourth Centuries B.C. Indiana UP, 1921. Google Books, 30 May 2007, https://books.google.com/books?id=ANYCAAAAYAAJ. Accessed 2o Feb. 2018.

Carlyle, Thomas. Sartor Resartus. Boston, 1837. Internet Archive, 14 Apr. 2010, https://archive.org/details/sartorresartuso2carl. Accessed 28 Jan 2019.

Carpenter, Rhys. The Esthetic Basis of Greek Art of the Fifth and Fourth Centuries B.C. New York: Longmans, Green, and Co., 1921. Google Books.

“The Celebrated but Hitherto Unpublished Poem of Lord Byron to Mr. Rogers.” Fraser's Magazine for Town and Country, vol. VII, Jan-Jun. 1833, James Fraser, 1833, pp. 81-4, Internet Archive, 19 Jan. 2017, https://archive.org/details/in.ernet.dli.2015.91898. Accessed 20 Sep. 2018. Chapman, James V. “10 Most Read Books in the World." HubPages, 20 March 2015, https://hubpages.com/literature/mostreadbooks, accessed 28 December 2017.

Chatterton, Thomas. “To Horace Walpole.” The Poetical Works of Thomas Chatterton. With a Prefatory Notice, Biographical and Critical, Walter Scott Publishing, 1865, p. 183. 
Cheney, Lynne V. Humanities in America: A Report to the President, the Congress, and the American People. National Endowment of Humanities, 1988.

Christensen, Jerome. Lord Byron's Strength: Romantic Writing And Commercial Society. Baltimore: Johns Hopkins UP, 1993.

Clare, John. I Am: The Selected Poetry of John Clare. Farrar, Straus and Giroux, 2003. Clayden, P. W. The Early Life of Samuel Rogers. Smith, Elder, and Co., 1887. Google Books, https://books.google.com/books?id=YNVyIoZ17noC. Accessed 4 May 2019.

Clason, Isaac Star. Don Juan Cantos XVII-XVIII. 2nd ed., Charles Wiley, 1825. Google Books, 6 Oct. 2006, books.google.com/books?id=rRETAAAAIAAJ. Accessed 2 Dec. 2014 .

Coleman, Joyce C. Public Reading and the Reading Public in Late Medieval England and France. Cambridge UP, 2005.

Coleridge, Ernest Hartley, ed. Letters of Samuel Taylor Coleridge. William Heinemann, 1895. Project Gutenberg, 1 Jan. 2014. http://www.gutenberg.org/files/44553/44553-h/44553-h.htm. Accessed 23 Sep. 2018.

---. The Works of Lord Byron. Vol III, John Murray, 1900. Project Gutenberg, 12 Jun. 2007. https://www.gutenberg.org/files/21811/21811-h/21811-h.htm. Accessed 17 Aug. 2019.

Coleridge, Samuel Taylor. Biographia Literaria; or, Biographical sketches of my literary life and opinions. Kirk and Mercein, 1817. Internet Archive, 13 August 2013. https://archive.org/details/biographialitera1ocole. Accessed 23 Sep. 2018. 
---. Sibylline Leaves: A Collection of Poems. Rest Fenner, 1817. Google Books, 9 Sep. 2010. https://books.google.com/books?id=lidEAAAAcAAJ. Accessed 12 Mar. 2016.

---. Sibylline Leaves: A Collection of Poems. Rest Fenner, 1817. Internet Archive, 27 June 2010. https://archive.org/details/cu31924105501773. Accessed 19 Apr. 2019.

Coleridge, Samuel Taylor and William Wordsworth. Lyrical Ballads 1798 and 1800. Edited by Michael Gamer and Dahlia Porter, Broadview Editions, 2008.

Continuation of Don Juan, Cantos XVII and XVIII. G. B. Whittaker, 1825. Google Books, 10 Dec. 2014, books.google.com/books?id=JwpgAAAAcAAJ. Accessed 22 Mar. 2019

Cook, Daniel. "The Critical and The Curious: Thomas Chatterton's First Reviewers" Romanticism, vol. 15, no, 2, 2009, pp. 109-120.

Cooper, Andrew M. "James Hogg (December 1770-21 November 1835)." British Romantic Novelists, 1789-1832. Edited by Bradford Keyes Mudge, vol. 116, Gale, 1992, pp. 138-150. Dictionary of Literary Biography, vol. 116. Dictionary of Literary Biography Complete Online. Accessed 2 Feb. 2019.

---. "John William Polidori (7 September 1795-27 August 1821)". British Romantic Novelists, 1789-1832. Ed. Bradford Keyes Mudge. Dictionary of Literary Biography Vol. 116. Detroit: Gale Research, 1992. 249-256. Dictionary of Literary Biography Complete Online. Gale. Milner Library, Illinois State University. 14 April 2013. 
Cooper, Lane. Two Views of Education with Other Papers Chiefly on the Study of Literature. Yale UP, 1922.

Corbet, Edward. Gods Providence, A SERMON Preached before the Honourable House of COMMONS, at their late solemne Fast, Decemb. 28. Anno 1642, in S. Margaret's Church at Westminster. Robert Bostock, 1642. EEBO: Early English Books Online.

http://eebo.chadwyck.com.libproxy.temple.edu/search/fulltext?SOURCE=var_s pell.cfg\&ACTION=ByID\&ID=Dooooo121747600ooo. Accessed 1 Sep. 2018.

Cottle, Robert J. The Bible True, Relevant or a Fairy Tale?: Of What Relevance Is a Book, Thousands of Years Old, in Our Modern Times? No city: Bellbird Trust, 2017. Google Books. https://books.google.com/books?id=VNGgDgAAQBAJ. Accessed 28 December 2017.

Cowley, William. Don Juan Reclaimed, or His Peregrination Continued. J. Pickering, 1840. Google Books, 7 Sep. 2015, ooks.google.com/books?id=fBtkAAAAcAAJ. Accessed 22 Mar. 2019

Cronin, Brian. “Comic Book Legends Revealed \#309.” CBR.com, 15 Apr. 2011. https://www.cbr.com/comic-book-legends-revealed-309. Accessed 23 Jan 2018. Darnton, Robert. "What is the History of Books?" The Kiss of Lamourette: Reflections in Cultural History, Norton, 1990, pp. 107-36.

Davis, Barbara Gross. Tools for Teaching. 2nd ed., Jossey-Bass, 2009.

"daybook, n." OED Online, Oxford University Press, December 2018, www.oed.com/view/Entry/47531. Accessed 26 January 2019.

deGategno, Paul J. James Macpherson. Twayne, 1989. 
Derrida, Jacques. Dissemination. Translated by Barbara Johnson, U of Chicago P, 1981. de Wendover, Robert. The Flowers of History [Rogeri de Wendover Liber Qui Dicitur Flores Historiarum Ab Anno Domini MCLIV. Annoque Henrici Anglorum Regis Secundi Primo.] Vol II. Ed. Henry G. Hewlett. London: H.M. Stationary Office, 1887.

Dickens, Charles. The Adventures of Oliver Twist and A Tale of Two Cities. London: Chapman \& Hall, n.d. Internet Archive. 15 August 2007. https://archive.org/details/adventuresofolivoodickiala. Accessed 6 Feb. 2018.

Dickens, Charles (Boz). “Oliver Twists, Or, the Parish Boy's Progress” Bentley’s Miscellany, vol. I, Richard Bentley, 1837, pp. 105-15. Internet Archive, 29 Aug, 2008, https://archive.org/details/bentleysmiscell22smitgoog. Accessed 27 Apr. 2019.

D’Intino, Franco. Introduction. Zibaldone. By Giacomo Leopardi, revised ed., Farrar, Straus and Giroux, 2015, pp. xi-lxviii.

Dotson, John E. Merchant Culture in Fourteenth Century Venice: The Zibaldone da Canal. Medieval \& Renaissance Texts \& Studies, 1994.

Douglass, Paul. "Byron's life and his biographers." Bone, Drummond, ed. The Cambridge Companion to Byron. Edited by Drummond Bone, Cambridge UP, 2004. 7-26. Print.

Drescher, H. W. “Mackenzie, Henry (1745-1831).” Oxford Dictionary of National Biography, 23 Sept. 2004, https://doi-org.libproxy.temple.edu/10.1093/ref:odnb/17586. Accessed 28 Apr. 2019. 
Drucker, Johanna. "Entity to Event: From Literal, Mechanistic Materiality to Probabilistic Materiality." Parallax, vol. 15, no. 4, 2009, pp. 7-17.

Dunbar, Robin. Grooming, Gossip, and the Evolution of Human Language. Harvard UP, 1998.

---. “Neocortex Size as a Constraint on Group Size in Primates." Journal of Human Evolution, vol. 20, 1992, pp. 469-93.

Duncan, Ian. Scott's Shadow: The Novel in Romantic Edinburgh. Princeton UP, 2007. Dworkin, Craig. No Medium. The MIT Press, 2013.

Eagleton, Terry. Literary Theory: An Introduction. 1981, U of Minnesota P, 2008. eBay. eBay Inc., 1995, www.eBay.com. Accessed 29 November 2017.

Eco, Umberto. Travels in Hyperreality: Essays. Houghton Mifflin Harcourt, 1990. Edzard, Dietz Otto. Sumerian Grammar. BRILL, 2003.

Eisenstein, Elizabeth L. The Printing Press as an Agent of Change: Communications and Cultural Transformations in Early-Modern Europe. Cambridge UP, 1979.

Eisner, Eric. Nineteenth-Century Poetry and Literary Celebrity. Palgrave Macmillan, 2009.

Eliot, Charles W., ed. Prefaces and Prologues to Famous Books. 1909, Collier, 1969.

Eliot, George. The Mill on the Floss. William Blackwoods and Sons, 1869. Google Books. https://books.google.com/books?id=l9QNAAAAQAAJ. Accessed 1 Sept. 2018.

Eller, Ruth. "Themes of Time and Art in The Lay of the Last Minstrel." Studies in Scottish Literature, vol. 13, no. 1, 1978, pp. 43-56. 
Eng, Steve. "The Story Behind: Red Letter Bible Editions." International Society of Bible Collectors, 2015, http://www.biblecollectors.org/articles/red_letter_bible.htm. Accessed 2 Feb. 2019.

Engar, Ann W. "Thomas Carlyle (4 December 1795-5 February 1881)." Nineteenth-Century British Literary Biographers. Edited by Steven Serafin, vol. 144, Gale, 1994, pp. 34-45. Dictionary of Literary Biography, vol. 144. Dictionary of Literary Biography Complete Online. Accessed 2 Feb. 2019.

Erickson, Lee. The Economy of Literary Form: English Literature and the Industrialization of Publishing, 180o-1850. John Hopkins UP, 2000.

Evans, Dylan. An Introductory Dictionary of Lacanian Psychoanalysis. Routledge, 1996.

Everest, Kelvin. “Coleridge's Life.” The Cambridge Companion to Coleridge. Ed. Lucy Newlyn, Cambridge UP, 2002, pp. 17-31.

Fattori, Marta. "The 'Nouvelles de la République des Lettres': Origins and Aims.” Intellectual News, vol. 11-12, no. 1, 2003, pp. 111-113.

Fazio, Emily. "How to Distress Furniture: Learn How to Give a Piece of Wood Furniture an Antique Look.” DIY Network. Scripps Networks, 2018. https://www.diynetwork.com/how-to/make-and-decorate/decorating/how-todistress-furniture. Accessed 21 March 2018.

Fielding, Henry. The History of Tom Jones, a Foundling, Encyclopædia Britannica, 1952.

Finegan, Edward. Language: Its Structure and Use. 6th ed., Wadsworth, 2012. 262 
Finnegan, Ruth. Oral Poetry: Its Nature, Significance, and Social Context. Cambridge UP, 1977 .

Fink, L. Dee. Creating Significant Learning Experiences: An Integrated Approach to Designing College Courses. Revised edition, Jossey-Bass, 2013.

Finkelstein, David and Alistair McCleery. An Introduction to Book History. Routledge, 2005 .

Fischer, Sheldon. "Poioumenon and Performative Storytelling in Canadian Fiction." Studies in Canadian Literature/Études en littérature canadienne, vol. 22, no. 2, 1997, pp. 83-104.

“Flight to the West?" Time, vol. 55, no. 10, 6 Mar. 1950, p. 59.

Foley, John Miles. Immanent Art: From Structure to Meaning in Traditional Oral Epic. Indiana UP, 1991.

Foley, John Miles and Peter Ramey. "Oral Theory and Medieval Literature.” Medieval Oral Literature, edited by Karl Reichl, De Gruyter, 2012, pp. 71-102.

"folly, n.1." OED Online, Oxford University Press, June 2017, www.oed.com/view/Entry/72576. Accessed 17 December 2017.

Foucault, Michel. Discipline and Punish: The Birth of the Prison. Translated by Alan Sheridan. 1977. New York: Vintage Books, 1995.

---. The Order Of Things: An Archaeology Of The Human Sciences, Pantheon Books, 1970.

---. “What is an Author?” Language, Counter-Memory, Practice, translated by Donald F. Bouchard and Sherry Simon, Cornell UP, 1977, pp. 113-38. 
Fowler, Alastair. "The Future of Genre Theory: Functions and Constructional Type.” The Future of Literary Theory, edited by Ralph Cohen, Routledge, 1989.

---. “Genre.” Encyclopedia of Literature and Criticism, edited by Martin Coyle, Routledge, 1990, pp. 151-163. EBSCOhost, search.ebscohost.com/login.aspx?direct=true $\& \mathrm{db}=$ nlebk\&AN=77059\&site=ehost -live\&scope $=$ site\&authtype $=$ uid\&user $=$ ebony\&password=lewis. Accessed $30 \mathrm{Jan}$. 2019.

---. A History of English Literature: Forms and Kinds from the Middle Ages to the Present. Basil Blackwell, 1987.

---. Kinds of Literature: An Introduction to the Theory of Genres and Modes. Harvard UP, 1982.

Freire, Paolo. Pedagogy of the Oppressed. Translated by Myra Bergman Ramos, Penguin, 1996.

Freud, Sigmund. "The 'Uncanny'.” Translated by Alix Strachey, Psychological Writings and Letters, edited by Sander L. Gilman, Continuum, 1995, pp. 120-153.

Frye, Northrop. Anatomy of Criticism: Four Essays. 1971. Princeton UP, 1957.

Furner, Jennifer. "Sir Walter Scott (15 August 1771-21 September 1832)". Orientalist Writers. Ed. Coeli Fitzpatrick and Dwayne A. Tunstall. Dictionary of Literary Biography Vol. 366. Detroit: Gale, 2012. 268-277. Dictionary of Literary Biography Complete Online. Gale. Milner Library, Illinois State University. 16 April 2013.

Galloway, Alexander R. and Eugene Thacker. The Exploit: A Theory of Networks. U of Minnesota P, 2007. 
Gamer, Michael and Dahlia Porter, eds. with Samuel Taylor Coleridge and William Wordsworth Lyrical Ballads 1798 and 180o. Broadview, 2008.

Gardiner, Judith Kegan. “Liberty, Equality, Fraternity: Utopian Longings in Behn’s Lyric Poetry." Rereading Aphra Behn: History, Theory, and Criticism, edited by Heidi Hunter, U of Virginia P, 1993, pp 273-300.

Gardner, Martin, editor with Samuel Taylor Coleridge. The Annotated Ancient Mariner. Bramhall House, 1965.

Gaskill, Howard. The Reception of Ossian in Europe. Thoemmes Continuum, 2004. Gatton, John Spalding. "Lord George Gordon Byron (22 January 1788-19 April 1824)". British Romantic Prose Writers, 1789-1832, Second Series. Ed. John R. Greenfield. Dictionary of Literary Biography Vol. 110. Detroit: Gale Research, 1991. 18-38. Dictionary of Literary Biography Complete Online. Gale. Milner Library, Illinois State University. 20 March 2013.

Genette, Gérard. Paratexts: Thresholds of Interpretation. Translated by Jane E. Lewin, Cambridge UP, 1997.

Giaimo, Cara. "How to Keep a Zibaldone, the 14th Century's Answer to Tumblr." Atlas Obscura, 29 Aug. 2016, www.atlasobscura.com/articles/how-to-keep-azibaldone-a-13thcentury-answer-to-tumblr, 29 Jan. 2018.

Gilroy, Paul. The Black Atlantic. Harvard UP, 1993.

Ginzburg, Carlo. “Clues: Morelli, Freud, and Sherlock Holmes.” The Sign of Three:

Dupin, Holmes, Peirce, edited by Umberto Eco and Thomas A. Sebeok, Indiana UP, 1988, pp. 81-118. 
Giuliano, Edward and Philip Collins, eds. The Annotated Dickens. vol. I, Clarkson N. Potter, 1986.

Glaser, Milton. Drawing is Thinking. Overlook P, 2008.

Goodson, A. C. "Samuel Taylor Coleridge (21 October 1772-25 July 1834)." British Romantic Poets, 1789-1832: First Series. Ed. John R. Greenfield. Vol. 93. Gale, 1990. Pp. 95-133.

Grabianowski, Ed. “The 21 Best-selling Books of All Time.” 19 December 2011. HowStuffWorks.com. https://entertainment.howstuffworks.com/arts/literature/21-best-sellers.htm, Accessed 28 December 2017.

Grafton, Anthony. The Footnote: A Curious History. Harvard UP, 1997.

---. Forgers and Critics: Creativity and Cuplicity in Western Scholarship. Princeton UP, 1990.

Grafton, Anthony, et al. The Classical Tradition. Harvard UP, 2010.

Graham, Steve and Michael Hebert. Writing to Read: Evidence for How Writing Can Improve Reading. Alliance for Excellent Education, 2010.

Gramley, Stephan. The History of English: An Introduction, Routledge, 2012.

Gray, Alasdair, et al. The Book of Prefaces: A Short History of Literate Thought in Words by great Writers of Four Nations from the 7 th to the 2oth Century. London: Bloomsbury, 2000.

Gregory, G. Introduction. “The Life of Chatterton”. The Works of Thomas Chatterton, vol. 1, AMS, 1969, pp. i-clx. 
Gribbon, John. In Search of Schrödinger's Cat: Quantum Physics and Reality. Bantam Books, 1984 .

Groom, Nick. Introduction. Thomas Chatterton and the Romantic Culture, MacMillan, 1999, pp. 3-11.

Grubrich-Simitis, Ilse. Early Freud and Late Freud: Reading Anew Studies on Hysteria and Moses and Monotheism, Routledge, 2003.

Halmi, Nicholas, et al., eds. Coleridge's Poetry and Prose: A Norton Critical Edition. Norton, 2004.

Hardy, Thomas. Far from the Madding Crowd, Signet Classics, 2002.

Harmon, William and Hugh Holman. A Handbook to Literature. 11th ed., Pearson, 2009.

Harrison, Peter. The Bible, Protestantism, and the Rise of Natural Science. Cambridge UP, 2001.

Harvey Wood, Harriet. Sir Walter Scott. Horndon, Northcote, 2006.

Haywood, Ian. The Making of History: A Study of the Literary Forgeries of James Macpherson and Thomas Chatterton in Relation to Eighteenth Century Ideas of History and Fiction. Associated UP, 1986.

Headley, Gwen. Follies: Fabulous, Fanciful and Frivolous Buildings. London: National Trust Books, 2010.

Headley, Gwen and Wim Meulenkamp. Follies, Grottoes \& Garden Buildings. London: Aurum P, 1999.

---. Follies: A National Trust Guide. London: Jonathan Cape, 1986.

Hegel, G. W. F. Phenomenology of Spirit. Translated by A. V. Miller, Oxford UP, 1977. 267 
Heraclitus of Ephesus. Heraclitus: The Cosmic Fragments: Edited with an Introduction and Commentary. Translated by Geoffrey Stephen Kirk, Cambridge UP, 1954.

Hermann, Bruce P. "Unsuccessful Self-Treatment of a Case of 'Writer's Block': A Partial Failure to Replicate." Perceptual \& Motor Skills, vol. 58, Apr. 1984, p. 350.

Hernando, A., et al. "Unravelling the Size Distribution of Social Groups with Information Theory in Complex Networks.” The European Physical Journal B, vol. 76, 2010, pp. 87-97.

Heyward, Michael. The Ern Malley Affair. Faber, 1993.

Hiller, Shari. "How to Distress Furniture." HGTV. Scripps Networks, 2018. https://www.hgtv.com/design/decorating/design-101/decorative-painttechnique-furniture-and-wall-marbling-instructions. Accessed 22 March 2018.

Himmelfarb, Gertrude. "The Haunted House of Jeremy Bentham." Victorian Minds. New York: Knopf, 1968.

Hitching, Claude. Rock Landscapes: The Pulham Legacy: Rock Gardens, Grottoes, Ferneries, Follies, Fountains, and Garden Ornaments. Woodbridge, Suffolk, UK: Garden Arts P, 2012.

Hodgson, James T. Memoir of the Rev. Francis Hodgson: B. D., Scholar, Poet, and Divine. Vol. I, MacMillan, 1878. Google Books, 11 Jul. 2007, https://books.google.com/books?id=k6EEAAAAYAAJ. Assessed 22 Dec. 2018.

Hofstadter, Douglas R. Gödel, Escher, Bach: An Eternal Golden Braid. Vintage Books, 1980.

Hogg, James. The Private Memoirs and Confessions of a Justified Sinner. Edited by Ian Duncan, Oxford UP, 2010. 
The Holie Bible : conteynyng the Olde Testament and the Newe. R. Iugge, 1568. Internet Archive. 16 Oct. 2011. https://archive.org/details/holiebibleconteyoolond. Accessed 8 Aug. 2018. "Homer saves people in the Monorail- The Simpson." Youtube, uploaded by Marine Admiral Jeronimo, 17 August 2015, https://www.youtube.com/watch?v=5GcJsgqfxU8.

Hone, William. Don Juan, Canto the Third. William Hone, 1819. Google Books, 23 June 2008, books.google.com/books?id=_SoUAAAAQAAJ. Accessed 2 Dec. 2014 .

Houston, Keith. Shady Characters: The Secret Life of Punctuation, Symbols, \& Other Typographical Marks. Norton, 2013.

Howard, Nicole. The Book: The Life Story of a Technology, John Hopkins UP, 2009. Hughes, Gillian H. "James Hogg (November? 1770-21 November 1835)." British Short-Fiction Writers, 180o-188o. Edited by John R. Greenfield, vol. 159, Gale, 1996, pp. 152-166. Dictionary of Literary Biography, vol. 159. Dictionary of Literary Biography Complete Online. Accessed 2 Feb. 2019.

Humez, Alexander and Nicholas Humez. On the Dot: The Speck that Changed the World. Oxford: Oxford UP, 2008.

Hutchins, Robert M. The Great Conversation: The Substance of a Liberal Education, Encyclopædia Britannica, 1952.

Illinois State University Undergraduate Catalog, 2014-2015. Illinois State University, 2014 . 
“I'm Spartacus - Spartacus (8/10) Movie CLIP (1960) HD.” Youtube, uploaded by Movieclips, 16 June 2011, https://www.youtube.com/watch?v=FKCmyiljKoo. “Inflation Calculator." Bank of England, 22 Jan. 2019, https://www.bankofengland.co.uk/monetary-policy/inflation/inflationcalculator. Accessed 20 Mar. 2019.

Ingram, John H. Chatterton \& His Poetry. Harrap, 1916.

Iron Maiden. "Rime of the Ancient Mariner." Online video clip. YouTube. YouTube, 18 Jan. 2012. Web. 24 Aug. 2015.

Iser, Wolfgang. The Act of Reading: A Theory of Aesthetic Response, Johns Hopkins $\mathrm{UP}, 1978$.

James, Karin Harman. "Sensori-Motor Experience Leads to Changes in Visual Processing in the Developing Brain." Developmental Science, vol. 13, no. 2, 2010, pp. 279-288.

Jackson, H. L. Romantic Readers: The Evidence of Marginalia. Yale UP, 2005.

Jacobs, Joseph and M. Seligsohn. “Tosafot ('additions').” Jewish Encyclopedia. 12 vols. 1901-1906. JewishEncyclopedia.com. 2002-2011. Accessed 7 Nov. 2018.

Jerome, Joseph. "Reflections Upon Pierre Bayle.” The Journal of the Core Curriculum, vol. XIV, 2005, pp. 42-50.

Johns, Adrian. Piracy: The Intellectual Property Wars from Gutenberg to Gates. U of Chicago P, 2009.

Jones, Barbara. Follies \& Grottoes. 2nd ed. London: Constable, 1974. Johnson, Edgar. Sir Walter Scott: The Great Unknown. Macmillan, 1970. 
"Josephus." Oxford Dictionary of the Classical World. Edited by John Roberts, Oxford UP. Oxford Reference, 2007. Accessed 16 Apr. 2016.

Kaplan, Fred, ed. Oliver Twist: A Norton Critical Edition. By Charles Dickens, Norton, 1993.

Keats, John. The Complete Poems. 3rd ed. Ed. John Barnard. New York: Penguin, 1988.

---. Keats's Poetry and Prose. Ed. Jeffrey N. Cox. New York: Norton, 2009.

Keats, Jonathon. Forged: Why Fakes Are The Great Art of Our Age. Oxford UP, 2013.

Kedwards, Dale. Cartography and Culture in Medieval Iceland. Dissertation, U of York, 2014.

Kellman, Steven G. The Self-Begetting Novel. Columbia UP, 1980.

Kershaw, Nora. Anglo-Saxon and Norse Poems. Cambridge UP, 1922. Internet Archive, 17 June 2008, https://archive.org/details/anglosaxonnorsepoochadrich. Accessed 13 Mar. 2019.

"The Kings and Queens of Scotland." Dictionary of British History, Market House Books Ltd, 1st edition, 2002. Credo Reference, http://libproxy.temple.edu/login?url=https://search.credoreference.com/conten t/entry/mhbh/the_kings_and_queens_of_scotland/o?institutionId=1644. Accessed 13 Nov. 2018.

King, Steve. “Literary Daybook, Feb. 1.” Salon, 2 Feb. 2002., www.salon.com/2002/02/01/febo1/. Accessed 25 Feb. 2018. 
Kirsch, Adam. "The 'Five Foot Shelf' Reconsidered: Revising a Monument from a More Humane and Confident Time.” Harvard Magazine, November-December 2001, https://harvardmagazine.com/2001/11/the-five-foot-shelf-reco.html, Accessed 20 December 2017.

Klinck, Anne L. The Old English Elegies: A Critical Edition and Genre Study. London: McGill-Queen’s UP, 1992.

Knox, Tim. Introduction. Follies of Europe: Architectural Extravaganzas. By Caroline Holmes. Woodbridge, Suffolk, UK: Garden Art P, 2008.

Kort, Carol. A to $Z$ of American Women Writers. Facts on File, 2007.

Krathwohl, David R. “A Revision of Bloom's Taxonomy: An Overview.” Theory Into Practice, vol. 41, no. 4, Autumn 2002, pp. 212-8.

Kuhn, Thomas S. The Copernican Revolution: Planetary Astronomy in the Development of Western Thought. Harvard UP, 1985.

Kunitz, Stanley J., ed. British Authors of the Nineteenth Century: Complete in One Volume with 1000 Biographies and 350 Portraits. New York: H.W. Wilson, 1936.

Lacan, Jacques. Écrits: A Selection. Translated by Alan Sheridan, Norton, 1977.

---. The Seminar of Jacques Lacan. Vol. II, translated by Sylvana Tomaselli, Cambridge UP, 1988.

Laing, R. D. The Politics of Experience. Pantheon Books, 1967.

Langan, Celeste. "Understanding Media in 1805: Audiovisual Hallucination in The Lay of the Last Minstrel." Studies in Romanticism, vol. 40, no. 1, 2001, pp. 49-70. 
Langan, Celeste and Maureen N. McLane. "The Medium of Romantic Poetry.” The Cambridge Companion to British Romantic Poetry, edited by James Chandler and Maureen McClane, Cambridge UP, pp. 239-62.

Lennon, Thomas M., Reading Bayle. U of Toronto P, 1999.

Levinson, Marjorie. The Romantic Fragment Poem: A Critique of a Form. U of North Carlina P, 1986.

Lewis, Wilmarth Sheldon. Horace Walpole. Pantheon, 1960.

Löchle, Stefan. "The Impostor as Trickster as Innovator: A Re-Reading of Carlos Castaneda's Don Juan-Cycle." Fake Identity?: The Impostor Narrative in North American Culture, edited by Caroline Rosenthal and Stefanie Schäfer, Campus Verlag, 2014, pp. 81-96.

Lockhart, John Gibson. Memoirs in the Life of Sir Walter Scott, vol. I, Houghton Mifflin, 1910.

Lolla, Maria Grazia. “Truth Sacrifising to the Muses': The Rowley Controversy and the Genesis of the Romantic Chatterton." Thomas Chatterton and the Romantic Culture, edited by Nick Groom, MacMillan, 1999, pp. 151-71.

Luckombe, Philip. The History and Art of Printing in Two Parts. W. Adlard and J. Browne, 1771. Google Books. https://books.google.com/books?id=kkI5AAAAMAAJ. Accessed 30 Aug. 2018.

Lundmark, Torbjörn. Quirky Qwerty: The Story of the Keyboard at Your Fingertips. U of New South Wales P, 2003

Lyotard, Jean-François. The Postmodern Condition: A Report on Knowledge. Translated by Geoff Bennington and Brian Massumi, U of Manchester P, 1984. 273 
Maas, David F. “Consciousness of Projection in Composition and Literature." Etc.: A Review of General Semantics, vol. 59, no. 4, 2002-3, pp. 429-35.

MacKendrick, Karmen. "Slow Reading: Learning in the Time of the Body." Journal for Cultural \& Religious Theory, vol. 12, no. 2, 2012, pp. 106-121.

Macpherson, James. Fragments of Ancient Poetry, collected in the Highlands of Scotland, and translated from the Galic or Erse language. G. Hamilton and J. Balfour, MDCCLX [1760]. Internet Archive, 30 Apr. 2009. https://archive.org/details/fragmentsofancieo1macp. Accessed 4 Nov. 2011. Marchand, Leslie A. Introduction. Byron's Letters and Journals. Vol 3. John Murray, 1975.

“Marge vs. the Monorail.” The Simpsons. Fox, WYZZ, Bloomington, IL, 14 Jan. 1993. Marotti, Arthur F. Manuscript, Print, and the English Renaissance Lyric. Cornell UP, 1995 .

Martin, Phillip W. "Authorial Identity and the Critical Act: John Clare and Lord Byron.” Questioning Romanticism. Ed. John Beer, John Hopkins UP, 1995, pp. 71-91.

---. Byron: A Poet Before His Public. Cambridge UP, 1982.

Mason, Fran. Historical Dictionary of Postmodernist Literature and Theater. 2nd ed., Rowman and Littlefield, 2016.

Mays, J. C. C. The Collected Works of Samuel Taylor Coleridge: Poetical Works II:: Poems (Variorum Text). General Ed. Kathleen Coburn, 2 vols, Princeton UP, 2001.

---. "The Later Poetry." The Cambridge Companion to Coleridge. Cambridge UP, 2002, pp. 89-99. 
McCarty, Christopher, et al. "Comparing Two Methods for Estimating Network Size." Human Organization, vol. 60, no. 1, 2001, pp. 28-39.

McCrum, Robert. “The Masterpiece that Killed George Orwell.” The Guardian, 9 May 2009. https://www.theguardian.com/books/2009/may/10/1984-george-orwell. Accessed 18 Aug. 2018.

McDowell, Paula. "Mediating Media Past and Present: Toward a Genealogy of 'Print Culture' and 'Oral Tradition.” This is Enlightenment, edited by Clifford Siskin and William Warner, U of Chicago P, 2010, pp. 229-46.

McGhee, Richard D. "Sir Walter Scott (15 August 1771-21 September 1832)." British Romantic Prose Writers, 1789-1832: First Series. Edited by John R. Greenfield, vol. 107, Gale, 1991, pp. 247-6. Dictionary of Literary Biography, vol. 107. Dictionary of Literary Biography Complete Online. Accessed 1 Feb. 2019.

McGill, Meredith L. "Reprints." The Encyclopedia of the Novel, edited by Peter Melville Logan, Wiley, 2014, pp. 676-84.

McHaney, Pearl. “Kathryn Stockett’s Postmodern First Novel.” Southern Cultures, vol. 20, no. 1, 2014, pp. 77-92

McLean, Derrick C. and Benjamin R. Thomas. "Unsuccessful Treatments of 'Writer's Block’: A Meta-Analysis." Psychological Reports, vol. 115, no. 1, Aug. 2014, pp. 276-278.

McLuhan, Marshall. The Gutenberg Galaxy: The Making of Typographic Man. U of Toronto P, 1962.

---. Understanding Media: The Extensions of Man. 2nd ed., MIT P, 1994.

Meggs, Philip B. A History of Graphic Design. Van Nostrand Reinhold, 1992. 
Merrell, Douglass. Umberto Eco, The Da Vinci Code, and the Intellectual in the Age of Popular Culture. Palgrave Macmillan, 2017.

Meyerstein, E. H. W. A Life of Thomas Chatterton. Ingpen and Grant, 1930.

Millgate, Michael. Testamentary Acts: Browning, Tennyson, James, Hardy. Clarendon $\mathrm{P}, 1992$.

Mole, Tom. Byron's Romantic Celebrity: Industrial Culture and the Hermeneutic of Intimacy. Palgrave Macmillan, 2007. Print.

Molloy, Geoffrey N. "The Unsuccessful Self-Treatment of a Case of 'Writer's Block': A Replication." Perceptual \& Motor Skills, vol. 57, 1983, p. 566.

Moore, Thomas, ed. Letters and Journals of Lord Byron: with Notices of His Life. vol. 1, Harper, 1830. Print.

Morelli, Giovanni. Italian Painter; Critical Studies of Their Works. Revised edition, translated by Constance Jocelyn Ffoulkes, John Murray, 1900.

Morford, Henry. The Rest of Don Juan Inscribed to the Shade of Byron. Burgess, Stringer \& Co., 1846. Google Books, 6 Sep. 2007, books.google.com/books?id=PKc-AAAAIAAJ. Accessed 2 Dec. 2014.

Morson, Gary Saul and Caryl Emerson. Mikhail Bakhtin: Creation of a Prosaics. Stanford UP, 1990.

Morton, Timothy. The Poetics of Spice: Romantic Consumerism and the Exotic. Cambridge UP, 2006. 
Moss, Stephanie. "Bram Stoker (8 November 1847-20 april 1912)." British Fantasy and Science-Fiction Writers Before World War I. Edited by Darren Harris-Fain, vol. 178, Gale, 1997, pp. 229-237. Dictionary of Literary Biography, vol. 178. Dictionary of Literary Biography Complete Online. Accessed 2 Feb. 2019. Moxon, Joseph. Moxon's Mechanick Exercises; Or The Doctrine of Handy-works Applied to the Art of Printing: A Literal Reprint in Two Volumes of the First Edition Published in the Year 1683, Volume 1. Typothetæ of the City of New York, 1896. Google Books. https://books.google.com/books?id=gERFAAAAYAAJ. Accessed 15 Jun. 2017.

Mueller, Pam A. and Oppenheimer, Daniel M. "The Pen Is Mightier Than the Keyboard: Advantages of Longhand Over Laptop Note Taking." Psychological Science, vol. 25, no. 6, 2014, pp. 1159-1168.

Murphy, Patrick J. Unriddling the Exeter Riddles. Penn State University Press, 2011. EBSCOhost, search.ebscohost.com/login.aspx?direct=true $\& \mathrm{db}=$ nlebk\&AN=1250335\&site $=\mathrm{eh}$ ost-live\&scope=site\&authtype=uid\&user=ebony\&password=lewis. Accessed 14 Feb. 2019.

Musil, Robert. Posthumous Papers of a Living Author. Translated by Peter Wortsman. Eridanos, 1987.

Neil, Anne V. The Vanishing Shakespeare. American Council of Trustees and Alumni, 2007. 
Neudorf, Benjamin and Yin Liu. "Signes-de-renvoi." ArchBook: Architectures of the Book. University of Saskatchewan Humanities and Fine Arts Digital Research Centre, 21 Dec. 2016.

http://drc.usask.ca/projects/archbook/signes_de_renvoi.php. Accessed 14 Feb, 2017.

Nelwyn, Lucy. Introduction. The Cambridge Companion to Coleridge. Cambridge UP, 2002, pp. 1-14.

Okrent, Arika. In the Land of Invented Languages: A Celebration of Linguistic Creativity, Madness, and Genius. Spiegel \& Grau, 2010.

The Oldest English Epic: Beowulf, Waldere, Deor, Widsith, and the German Hildebrand. Translated by Francis Barton Gummere, MacMillan, 1909. Wikisource, 22 Aug, 2014, https://en.wikisource.org/wiki/The_Oldest_English_Epic. Accessed 11 Feb. 2019.

Ong, Walter J. "Literacy and Orality in Our Times." An Ong Reader: Challenges for Further Inquiry, edited by Thomas J, Farrell and Paul A. Soukup, Hampton P, 2002.

Padgett, Ron. Creative Reading: What It Is, How to Do It, and Why. National Council of Teachers of English, 1997.

Page, Norman. A Byron Chronology. Boston: G. K. Hall, 1988. Print.

Page, Raymond Ian. An Introduction to English Runes. Methuen, 1973.

Parkes, M. B. Pause and Effect: An Introduction to the History of Punctuation in the West. U of California P, 1993. 
Pattison, Thomas Harwood. The History of the English Bible. American Baptist Publication Society, 1894.

Peacock, John A. Cosmological Physics. Cambridge UP, 1998.

Pennac, Daniel. The Rights of the Reader. Translated by Sarah Ardizzone. Candlewick P, 2007.

Plato. "Phaedrus." The Dialogues of Plato, translated by Benjamin Jowett, Encyclopedia Britannica, 1952, pp. 115-41.

"Poioumenon." Radiotonic, ABC [Australian Broadcasting Commision], 8 May 2015, www.abc.net.au/radionational/programs/archived/radiotonic/poioumenon/642 5606. Accessed 20 Jan. 2019.

Poliakoff, Michael. The Unkindest Cut. American Council of Trustees and Alumni, 2015.

Pool, Daniel. What Jane Austen Ate and Charles Dickens Knew: From Fox Hunting to Whist - the Facts of Daily Life in 19th Century England. Touchstone, 1993.

Pope, Alexander. The Dunciad in Four Books. eBooks@Adelaide, 17 Dec. 2014, https://ebooks.adelaide.edu.au/p/pope/alexander/dunciad/complete.html. Accessed 7 July 2018.

Praz, Mario. Introduction. Three Gothic Novels. Penguin, 1968, pp. 7-42.

Preminger, Alex and T. V. F. Brogan, eds. The New Princeton Encyclopedia of Poetry and Poetics. MJF Books, 1993.

Price, Leah. How to Do Things with Books in Victorian Britain. Princeton UP, 2012.

Prothero, Rowland E., ed. The Works of Lord Byron: Letters and Journals. Vol. 5. London: John Murray, 1904. Google Books. Web. 4 May 2013. 
Rabinowitz, Tova. Exploring Typography. 2nd edition. Cengage Learning, 2016

Reynolds, George William MacArthur. A Sequel to Don Juan. 2nd ed, Paget \& Co., 1843. Google Books, 16 Jul. 2008, books.google.com/books?id=dW4UAAAAQAAJ. Accessed 2 Dec. 2014.

Richardson, Alan. "Sir Walter Scott (15 August 1771-21 September 1832)." British Romantic Poets, 1789-1832: First Series. Edited by John R. Greenfield, vol. 93, Gale, 1990, pp. 236-259. Dictionary of Literary Biography, vol. 93. Dictionary of Literary Biography Complete Online. Accessed 1 Feb. 2019.

Richter, David H. Falling into Theory: Conflicting Views on Reading Literature. 2nd ed., Bedford/St. Martin’s, 2000.

Riedler, Nina A. "Thomas Carlyle (4 December 1795-5 February 1881)." Orientalist Writers. Edited by Coeli Fitzpatrick and Dwayne A. Tunstall, vol. 366, Gale, 2012, pp. 37-44. Dictionary of Literary Biography, vol. 366. Dictionary of Literary Biography Complete Online. Accessed 2 Feb. 2019.

Riekki, Ron. “Steel Drivin’ Man.” American Book Review, vol. 36, no. 1, 2014, p. 26. Robinson, Eric and Geoffrey Summerfield. Introduction. The Later Poems of John Clare. Barnes \& Noble, 1964, pp. 1-31.

Robinson, Solveig. The Book in Society: An Introduction to Print Culture. Broadview, 2013.

Rogers, Pat. “Addison, Joseph (1672-1719).” Oxford Dictionary of National Biography, 28 May 2015, https://doi-org.libproxy.temple.edu/10.1093/ref:odnb/156. Accessed 28 Apr. 2019. 
Rogers, Samuel. Poems by Samuel Rogers: A New Edition. T. Cadell, 1827. Google Books. 3 Aug. 2007, https://books.google.com/books?id=TFUJAAAAQAAJ. Accessed 14 Feb. 2019.

---. The Poetical Works of Samuel Rogers. Edward Moxon, 1856.

Rowe, Anna Beth. A Poetic Poioumenon: Coterie and Ekphrasis in David Lehman 's "The Breeders' Cup. “2015. University of Southern Mississippi, Master's thesis. Aquila, https://aquila.usm.edu/masters_theses/136/. Accessed 11 Jan. 2019.

Rudman, Joseph. "The State of Non-Traditional Authorship Attribution Studies--2012: Some Problems and Solutions.” English Studies, vol. 93, no. 3, 2012, pp. 259-74.

"The Ruin.” Translated by Megan Via, Uncovering English Texts, 2004, http://homepages.bw.edu/ uncover/megan\%20via\%2oruin\%2otrans.htm. Accessed 17 Jul. 2018.

Russett, Margaret. Fictions and Fakes: Forging Romantic Authenticity, 1760-1845. Cambridge UP, 2006.

---. De Quincey's Romanticism: Canonical Minority And The Forms Of Transmission. Cambridge UP, 1997.

Ruthven, K. K. Faking Literature. Cambridge UP, 2001.

Ryan, Judith and Alfred Thomas, editors. Cultures of Forgery: Making Nations, Making Selves. Routledge, 2003.

Sabor, Peter. Horace Walpole: The Critical Heritage. Routledge, 1987.

Samuel, Geoffrey. Civilized Shamans: Buddhism in Tibetan Societies. Smithsonian, 1993. 
Sanger, F., et al. "Nucleotide Sequence of Bacteriophage $\Phi$ X174 DNA." Nature, vol. 265, 24 Feb. 1977, pp. 687-95.

Saunders, Bailey. The Life and Letters of James Macpherson. 1894. Haskell House, 1968.

Schaeffer, Ursula. "Alterities: On Methodology in Medieval Literary Studies.” Oral Tradition, vol. 8, no. 1, 1993, pp. 187-214.

Schironi, Francesca. The Best of the Grammarians: Aristarchus of Samothrace on the Iliad. U of Michigan P, 2018.

Showalter, Elaine. Teaching Literature. Blackwell, 2003.

Scott, Sir Walter. The Abbot. 3 vols. London: Hurst, Rees, Orme, and Brown, 1820 Edinburgh: Archibald Constable and Co.; John Ballantyne, 1820. Internet Archive. 26 July 2010. https://archive.org/details/abboto1scot. Accessed 16 Jan. 2018.

---. Anne of Geierstein; Or, The Maiden of the Mist. 3 vols. Edinburgh: Cadell and Co., 1828. London: Simpkin and Marshall, 1828. Internet Archive. 8 July 2008. https://archive.org/details/annegeiersteinoo3scotgoog. Accessed 17 Jan. 2018.

---. The Antiquary. 3 vols. Edinburgh: Archibald Constable and Co., 1816. London: Longman, Hurst, Rees, Orme, and Brown, 1816. Internet Archive. 25 Oct. 2007. https://archive.org/details/antiquary21unkngoog. Accessed 15 Jan. 2018.

---. Chronicles of the Canongate. 2 vols. Edinburgh: Cadell and Co., 1827. London:

Simpkin and Marshall, 1827. Internet Archive. 24 Feb. 2007. https://archive.org/details/chroniclescanono6unkngoog. Accessed 17 Jan. 2018. 
---. Chronicles of the Canongate, Second Series. 3 vols. Edinburgh: Cadell and Co., 1828. London: Simpkin and Marshall, 1828. Internet Archive. 20 Jan. 2010. https://archive.org/details/chroniclesofcanoo1scot. Accessed 17 Jan. 2018.

---. The Fortunes of Nigel. 3 vols. Edinburgh: Archibald Constable and Co., 1822.

London: Hurst, Robinson, and Co., 1822. Internet Archive. 17 Oct. 2007. https://archive.org/details/fortunesnigelo6scotgoog.Accessed 16 Jan. 2018.

---. Guy Mannering; Or, The Astrologer. 3 vols. London: Longman, Hurst, Rees, Orme, and Brown, 1815. Edinburgh: Archibald Constable and Co., 1815. Internet Archive. 13 July 2007. https://archive.org/details/guymanneringora14scotgoog. Accessed 15 Jan. 2018.

---. Ivanhoe; a Romance. 3 vols. Edinburgh: Archibald Constable and Co., 1820. London: Hurst, Robinson, and Co., 1820. Internet Archive. 16 Oct. 2007. https://archive.org/details/ivanhoearomanceo8scotgoog. Accessed 15 Jan. 2018.

---. Kenilworth, a Romance. 3 vols. Edinburgh: Archibald Constable and Co.; John Ballantyne, 1821. London: Hurst, Robinson, and Co., 1821. Internet Archive. 16 Oct. 2007. https://archive.org/details/kenilwortharomaooconggoog. Accessed 16 Jan. 2018.

---. The Lay of the Last Minstrel. Longman, Hurst, Rees, and Horme, 1805. Internet Archive, 11 Feb. 2009, https://archive.org/details/laylastminstrel13scotgoog/. Accessed 2 Feb. 2019. 
---. The Monastery, a Romance. 3 vols. London: Hurst, Rees, Orme, and Brown, 1820 Edinburgh: Archibald Constable and Co.; John Ballantyne, 1820. Internet Archive. 16 Oct. 2007. https://archive.org/details/monasteryaromanooballgoog. Accessed 16 Jan. 2018.

---. Peveril of the Peak. 4 vols. Edinburgh: Archibald Constable and Co.; John Ballantyne, 1822. London: Hurst, Robinson, and Co., 1822. Internet Archive. 16 Oct. 2007. https://archive.org/details/peverilpeako1unkngoog. Accessed 16 Jan. 2018.

---. The Pirate. 3 vols. Edinburgh: Archibald Constable and Co., 1822. London: Hurst, Robinson, and Co., 1822. Internet Archive. 16 Oct. 2007. https://archive.org/details/pirate12scotgoog. Accessed 16 Jan. 2018.

---. The Prefaces to the Waverly Novels. Ed. Mark A. Weinstein. Lincoln: U of Nebraska $\mathrm{P}, 1978$.

---. Quentin Durward. Vol. 1. Paris: P. Didot, 1823. Google Books. 30 Sep. 2010. https://books.google.com/books?id=6nV4pICnAuEC. Accessed 5 March 2017.

---. Quentin Durward. 3 vols. Edinburgh: Archibald Constable and Co., 1823. London: Hurst, Robinson, and Co., 1823. Internet Archive. 16 Oct. 2007. https://archive.org/details/quentindurward14scotgoog. Accessed 16 Jan. 2018.

---. Redgauntlet. 3 vols. Edinburgh: Archibald Constable and Co., 1824. London: Hurst, Robinson, and Co., 1824. Internet Archive. 17 Jan. 2007. https://archive.org/details/redgauntletbyauo2scotgoog. Accessed 17 Jan. 2018. 
---. Rob Roy. 3 vols. Edinburgh: Archibald Constable and Co., 1818. London: Longman, Hurst, Rees, Orme, and Brown, 1818. Internet Archive. 7 July 2006. https://archive.org/details/robroyo1scotgoog. Accessed 16 Jan. 2018.

---. St. Ronan's Well. 3 vols. Edinburgh: Archibald Constable and Co., 1824. London: Hurst, Robinson, and Co., 1824. Internet Archive. 28 Jan. 2010. https://archive.org/details/stronanswello1scott. Accessed 17 Jan. 2018.

---. Tales of the Crusaders. 4 vols. Edinburgh: Archibald Constable and Co., 1825. London: Hurst, Robinson, and Co., 1825. Internet Archive. 18 May 2009. https://archive.org/details/talescrusadersoounkngoog. Accessed 17 Jan. 2018.

---. Tales of My Landlord, Collected and Arranged by Jedediah Cleishbotham, Schoolmaster and Parish-Clerk of Gandercleugh. 4 vols. London: William Blackwood and John Murray, 1816. Internet Archive. 23 Oct. 2007. https://archive.org/details/talesmylandlord27scotgoog. Accessed 15 Jan. 2018.

---. Tales of My Landlord, Second Series, Collected and Arranged by Jedediah Cleishbotham, Schoolmaster and Parish-Clerk of Gandercleugh. 4 vols. Edinburgh: Archibald Constable and Co., 1818. Internet Archive. 7 July 2006. https://archive.org/details/talesmylandlordo2scotgoog. Accessed 16 Jan. 2018. ---. Tales of My Landlord, Third Series, Collected and Arranged by Jedediah Cleishbotham, Schoolmaster and Parish-Clerk of Gandercleugh. 4 vols. Edinburgh: Archibald Constable and Co., 1819. London: Hurst, Rees, Orme, and Brown; Hurst, Robinson, and Co., 1819. Internet Archive. 23 Oct. 2007. https://archive.org/details/talesmylandlord19cogoog. Accessed 16 Jan. 2018. 
---. Tales of My Landlord, Fourth and Last Series, Collected and Arranged by Jedediah Cleishbotham, Schoolmaster and Parish-Clerk of Gandercleugh. 4 vols.

Edinburgh: Robert Cadell, 1832. London: Whittaker and Co., 1832. Internet Archive. 23 Aug. 2008. https://archive.org/details/talesmylandlordo5cleigoog. Accessed 17 Jan. 2018.

---. Waverly, or Tis Sixty Years Since. 3rd ed. Vol I. Edinburgh: Constable \& Co., 1814. Google Books, https://books.google.com/books?id=7A4UAAAAQAAJ. Accessed 11 November 2017.

---. Waverly, or Tis Sixty Years Since. 3rd ed. Vol III. Edinburgh: Constable \& Co., 1814. Google Books, https://books.google.com/books?id=7R8GAAAAQAAJ. Accessed 11 November 2017.

---. Woodstock; Or, The Cavalier. 3 vols. Edinburgh: Archibald Constable and Co., 1826. London: Hurst, Rees, Orme, Brown, and Green, 1836. Internet Archive. 21 Dec. 2007. https://archive.org/details/woodstockorcavalo1scotrich. Accessed 17 Jan. 2018.

Seccombe, Thomas and W. Robertson Nicoll. Bookman Illustrated History of English Literature. 2 vols Hodder and Stoughton, 1906.

Shakespeare, William. Hamlet (Folio I, 1623). Edited by David Bevington, Internet Shakespeare Editions, University of Victoria, 17 Feb. 2019, http://internetshakespeare.uvic.ca/doc/Ham_GenIntro/complete//. Accessed 17 Feb. 2019. 
---. King Lear. The Complete Works of William Shakespeare, Massachusetts Institute of Technology, n. d., http://shakespeare.mit.edu/lear/full.html. Access 24 June. 2018.

"shall, v." OED Online, Oxford University Press, June 2017, www.oed.com/view/Entry/177350. Accessed 29 December 2017.

Sharma, Ramen and Preety Chaudhary. "Common Themes and Techniques of Postmodern Literature of Shakespeare." International Journal of Educational Planning \& Administration, vol. 1, no. 2, 2011, pp. 189-198.

Shelley, Percy Bysshe. The Complete Poetical Works of Percy Bysshe Shelley. Ed. Thomas Hutchinson. Project Gutenberg. 13 April 2002. http://www.gutenberg.org/cache/epub/480o/pg480o-images.html. Accessed 20 January 2018.

---. The Major Works. Eds. Zachary Leader and Michael O'Neill. Oxford: Oxford UP, 2003.

Shelley, Mary. Frankenstein. Edited by J. Paul Hunter, 2nd ed., Norton, 2012.

Sher, Richard B. "Scotland Transformed: The Eighteenth Century." Scotland: A History, edited by Jenny Wormald, Oxford UP, 2005, pp. 150-175.

Sherman, William H. Used Books: Marking Readers in Renaissance England. U of Pennsylvania P, 2008.

Slights, William W. E. Managing Readers: Printed Marginalia in English Renaissance Books. U of Michigan P, 2001.

Smart, J. S. James Macpherson: An Episode in Literature. 1905. AMS, 1973. 
Smith, Margaret M. "The Design Relationship Between the Manuscript and the Incunable". A Millennium of the Book: Production, Design and Illustration in Manuscript and Print, 900-1900, edited by Robin Myers and Michael Harris, Oak Knoll P, 1994, pp. 23-45.

Smith, N. C. "James Hogg (November 1770-21 November 1835)." British Romantic Poets, 1789-1832: First Series. Edited by John R. Greenfield, vol. 93, Gale, 1990, pp. 175-184. Dictionary of Literary Biography, vol. 93. Dictionary of Literary Biography Complete Online. Accessed 2 Feb. 2019.

Southward, Daniel. "Dealing with the Creative/Critical Divide: These men as readers simply cannot know what it is to write." New Writing, vol. 13, no. 2, 2012, pp 273-80.

Stafford, Fiona. Reading Romantic Poetry. Wiley, 2012.

St. Clair, William. The Reading Nation in the Romantic Period. Cambridge UP, 2004. Steel, Danielle. Mixed Blessings. Delacorte P, 1992.

Steiner, Jon. "Poioumenon.” Escape: An Anthology of Short Stories, edited by Bronwyn Mehan, Spineless Wonders, 2011, pp. 45-52. Google Books, 1 Sep. 2018, books.google.com/books?id=ss9tDwAAQBAJ. Accessed 11 Nov. 2018.

Steinhoff, Stephen T., ed. with John Keats. Keats's Endymion: A Critical Edition. Troy, NY: Whitsun, 1987.

Sterne, Laurence. Tristram Shandy. Encyclopedia Britannica, 1952.

Stevens, Dannelle D. and Joanne E. Cooper. Journal Keeping: How to Use Reflective Writing for Learnings, Teaching, Professional Insight, and Positive Change. Stylus, 2009. 
Stewart, Susan. Crimes of Writing: Problems in the Containment of Representation. Duke UP, 1994.

Stillinger, Jack. Coleridge and Textual Instability. Oxford UP, 1994.

Stirner, Max. The Ego and His Own. Trans. Steven T. Byington. New York: Ben J. R. Tucker, 1907. Project Gutenberg. 5 Dec. 2010. http://www.gutenberg.org/files/34580/34580-h/34580-h.htm. Accessed 7 Dec. 2017.

Stoker, Bram. Dracula. Archibald Constable and Co., 1897. Project Gutenberg, 30 May 2014, http://www.gutenberg.org/files/45839/45839-h/45839-h.htm. Access 9 Feb. 2019.

---. The Last Wilkie's and Other Stories. Spineless Wonders, 2018. Google Books, 1 Sep. 2018, books.google.com/books?id=20FvDwAAQBAJ. Accessed 11 Nov. 2018.

Swales, John M. Genre Analysis: English in Academic and Research Settings. Cambridge UP, 1990.

Tarr, Rodger L., editor. Sartor Resartus: The Life and Opinions of Herr Teufelsdröckh in Three Books. By Thomas Carlyle, U of California P, 2000.

Thomson, Derick S. The Gaelic Sources of Macpherson's 'Ossian'. 1952, Oliver \& Boyd, 1969.

Thorndike, Lynn. Introduction. The Sphere of Sacrobosco and Its Commentators. U of Chicago P, 1949. HathiTrust. catalog.hathitrust.org/Record/oo1475759. Accessed 24 Aug. 2018.

Tolkien, J. R. R. The Lord of the Rings Collector's Edition. Houghton Mifflin, 1974. 
Toremans, Tom. "Sartor Resartus and the Rhetoric of Translation." Translation and Literature, vol. 20, no. 1, 2011, pp. 61-78.

Tulathimutte, Tony. “Title Fights.” The Paris Review, 25 May 2016.

https://www.theparisreview.org/blog/2016/05/25/title-fights/. Accessed 18 Aug. 2018.

Tyrwhitt, Thomas. Preface. Poems, supposed to have been written at Bristol, by Thomas Rowley, and others, in the fifteenth century; the greatest part now first published from the most authentic copies, with an engraved specimen of one of the mss. To which are added, a preface, an introductory account of the several pieces, and a glossary, by Thomas Chatterton, Thomas Tyrwhitt, MDCCLXXVII. [1777]. Eighteenth Century Collections Online, Gale. Accessed 20 Nov. 2011.

Upper, Dennis. "The Unsuccessful Self-Treatment of a Case of 'Writer's Block.” Journal of Applied Behavior Analysis , vol. 7 , Sep. 1974, p. 497.

van Gelderen, Elly. An Introduction to the Grammar of English: Revised Edition. John Benjamins, 2010.

Veblen, Thorstein. Theory of the Leisure Class: An Economic Study of Institutions. 2nd ed. New York: Macmillan, 1912. Google Books. 13 June 2008. https://books.google.com/books?id=2kAoAAAAYAAJ. Accessed 21 June 2017.

Viswanathan, Gauri. Masks of Conquest: Literary Study and British Rule in India. Columbia UP, 2015 .

von Petzinger, Genevieve. The First Signs: Unlocking the Mysteries of the World's Oldest Symbols. Atria Paperback, 2016. 
Warner, Ferdinando. Remarks on the history of Fingal, and other poems of Ossian: translated by Mr. Macpherson. In a letter to the Right Honourable the Lord L-. By Ferdo. Warner, L.L.D. London, MDCCLXII. [1762]. Eighteenth Century Collections Online. Gale. Illinois State ECCO. 14 Nov. 2011

Walpole, Horace. The Castle of Otranto, a story. Translated by William Marshal, Gent. from the original Italian of Onuphrio Muralto, Canon of the Church of St. Nicholas of Otranto, London, 1765 [i.e. 1764]. Eighteenth Century Collections Online. Gale. Illinois State ECCO. 2 Dec. 2011

---. The Castle of Otranto, a Gothic Story. William Bathoe, 1766. Internet Archive, 8 Feb. 2009, https://archive.org/details/castleotrantooowalpgoog. Accessed 6 May 2019.

Westwood, Martin. “Juno Moneta Atlas: Warburgian Production or Performing Context-Change." Philosophy of Photography, vol. 8, nos. 1-2, 2017, pp. 119-30.

Whalley, George, ed. The Collected Works of Samuel Taylor Coleridge: Marginalia I. Princeton UP, 1980.

Whitehead, John. This Solemn Mockery: The Art of Literary Forgery. Arlington Books, 1973.

Williams, Carolyn D. “'On Tiber's Banks': Chatterton and Post-Colonialism.” Thomas Chatterton and the Romantic Culture, edited by Nick Groom, MacMillan, 1999, pp. 48-63.

Wilson, Robert Anton. Quantum Psychology: How Brain Software Programs You \& Your World. New Falcon, 1990.

Wilt, Judith. Secret Leaves: The Novels of Sir Walter Scott. U of Chicago P, 1985. 
Wimsatt, W.K. and Monroe C. Beardsley. "The Intentional Fallacy.” The Verbal Icon: Studies in the Meaning of Poetry, 1954, UP of Kentucky, 1982, pp. 3-19.

Wolfson, Susan. "Keats's 'Isabella' and the 'Digressions' of 'Romance.” Criticism: a Quarterly for Literature and the Arts, vol. 27, no. 3, 1985, pp. 247-61.

Wolfson, Susan J. and Peter J. Manning. Introduction. Don Juan. By Lord Byron, Penguin, 2004. vii-lv. Print.

Woodring, Carl. Literature: An Embattled Profession. Columbia UP, 1990.

“World's Largest Print Run Now Carries FSC Label.” WWF - World Wide Fund for Nature, 3 Oct. 2014, http://wwf.panda.org/wwf_news/?230291/worlds-largestprint-run-now-carries-fsc-label. Accessed 28 Dec. 2017.

"World's Longest Epic Sung for a Thousand Years." China Through a Lens, 9 Jul. 2002, http://www.china.org.cn/english/2002/Jul/36579.htm. Accessed 6 Jun. 2013.

Worthen, John. The Cambridge Introduction to Samuel Taylor Coleridge. Cambridge UP, 2010.

Yamashita, Karen Tei. Tropic of Orange. Coffee House P, 1997.

Youngquist, Paul and Frances Botkin. "Introduction: Black Romanticism: Romantic Circulations." Circulations: Romanticism and the Black Atlantic, 2011, https://romanticcircles.org/praxis/circulations/HTML/praxis.2011.youngquist.html. Accessed 29 Aug. 2019.

Zerby, Chuck. The Devil's Details: A History of the Footnote. Invisible Cities P, 2002. 